UNIVERSIDADE DE SÃO PAULO

ESCOLA DE EDUCAÇÃO FÍSICA E ESPORTE

\title{
VALIDADE DAS ESTIMATIVAS DE INGESTÃO ENERGÉTICA DE TRÊS MÉTODOS DE AVALIAÇÃO DO CONSUMO ALIMENTAR, EM RELAÇÃO À ÁGUA DUPLAMENTE MARCADA
}

Fernanda Baeza Scagliusi 


\section{VALIDADE DAS ESTIMATIVAS DE INGESTÃO ENERGÉTICA DE TRÊS MÉTODOS DE AVALIAÇÃO DO CONSUMO ALIMENTAR, EM RELAÇÃO À ÁGUA DUPLAMENTE MARCADA.}

FERNANDA BAEZA SCAGLIUSI

Tese apresentada à Escola de Educação Física e Esporte da Universidade de São Paulo, como requisito parcial para obtenção do grau de Doutor em Educação Física.

ORIENTADOR: PROF. DR. ANTONIO HEBERT LANCHA JUNIOR 


\section{AGRADECIMENTOS}

Dedicatória - “There are places I'll remember all my life, though some have changed, some forever, not for better, some have gone and some remain. All these places had their moments, with lovers and friends I still can recall, some are dead and some are living, in my life I've loved them all" (McCartney \& Lennon).

Ao meu vô, que não viveu para ver isso.

Às minhas queridas guerreiras Marisa Cambraia, Maria Thereza Moura e Rosa Godoy, por terem me dado a luz que me permitiu fazer essa tese ("E a você, Frodo Bolseiro, eu lhe dou a luz de Eãrendil, nossa estrela mais amada. Que seja uma luz para você, em lugares sombrios, quando todas as luzes se apagarem”).

Ao "Seu" Daniel, uma das pessoas mais sábias e generosas que conheci na USP ("He never listens to them, he knows that they're the fools. They don't like him, but the fool on the hill sees the sun going down and the eyes in his head see the world spinning round" McCartney).

\section{Agradecimentos}

Ao meu querido orientador Antonio Herbert Lancha Junior. Não conheço palavras que possam demonstrar minha imensa gratidão. Mas também não conheço nenhum outro orientador que dê tanto apoio e confiança quanto você me deu, que seja tão otimista e generoso quanto você. Agradeço enormemente o fato de que um dia, em 1998, assisti a uma palestra sua na faculdade e fiquei encantada com a sua erudição e com a paixão que você tinha pela Nutrição. Sem dúvida aquela palestra mudou minha vida, pois foi com a sua ajuda, orientação e amizade que consegui chegar até aqui.

Ao Wolvie, meu querido marido. Você não me ajudou a trilhar esse caminho, e sim trilhou comigo. Não me ajudou a fazer essa tese, e sim a fez comigo. Você está presente em todas 
as linhas dessa tese, em todos os cantos da minha alma, em todos os sorrisos, abraços, projetos e sonhos da minha vida.

Ao Professor Eduardo Ferriolli, que considero meu co-orientador. Esse trabalho jamais seria possível se você não tivesse tido toda a paciência do mundo para me ensinar sobre a água duplamente marcada e toda a disposição do mundo para conduzir as dosagens. Agradeço também por você sempre ter me estimulado e "levantado" minha moral nos momentos difíceis, além de sempre comemorar comigo nossas conquistas.

À querida amiga Karina Pfrimer, que, da forma mais altruísta e competente possível, realizou as dosagens.

À Fapesp, que, por meio do auxílio à pesquisa 03/12337-8, financiou esse projeto.

Aos colegas do Laboratório de Nutrição, que sempre contribuíram para minha formação, com suas críticas e discussões de nível extremamente elevado. Agradeço especialmente às colegas Cibele Laureano, Caroline Sanita, Desire Coelho, Fabiana Benatti, Patrícia Rogeri, Viviane Polacow, Bruna São Pedro, Aline Kazurayama e Geisa Gastal pela ajuda na coleta de dados. Também agradeço imensamente ao colega Bruno Gualano, que me ajudou na coleta de dados e na elaboração dos artigos e que me estimula a produzir cada vez mais e melhor, com seu exemplo de dedicação e excelência acadêmica. Novamente agradeço às colegas Desire Coelho, Fabiana Benatti e Patrícia Rogeri, pela amizade que fazia com que os procedimentos mais tediosos virassem uma grande diversão, e à minha grande amiga Viviane Polacow, que esteve comigo em todos os momentos importantes da minha vida e sempre me apoiou em tudo.

À Bárbara Lourenço, minha querida "filhinha" Babi, que me ajudou com a formatação da tese e dos artigos, além de ter corrigido a tese e de me dar muita alegria e carinho.

À minha mãe, que se dedica a me ajudar o tempo inteiro, e que me estimulou mais do que ninguém a seguir a carreira acadêmica.

Ao meu pai, que, pelo exemplo, me ensinou a nunca desistir.

À Sandra Ribeiro e Camila Maria de Melo, que me ajudaram a terminar a coleta de dados, quando eu já não estava mais conseguindo sujeitos. 
À amiga Marle Alvarenga, por ter aberto um mundo de possibilidades para mim e por ser quem me socorre quando tudo dá errado. Depois do Lancha, você foi outro divisor de águas na minha vida.

Ao Professor Táki Cordas, por ter permitido que eu realizasse a etapa preliminar dessa tese no Ambulim e pelas inúmeras possibilidades que me propiciou.

À Professora Sonia Tucunduva, que, com seu carinho maternal, cuida de mim desde a graduação.

À Professora Marly Cardoso, pela prontidão com que me ajuda com todas as minhas dúvidas.

Aos pesquisadores Barry Popkin e Lenore Arab, que auxiliaram na obtenção de recursos.

Aos funcionários da Comissão de Pós-Graduação, que nunca pouparam esforços para me ajudar.

Aos meus queridos amigos e acima de tudo, companheiros: Andrea Scagliusi, Tiago Marinho, Nyara Didone, Gisele Queiroz, Fernanda Timerman, Alessandra Fabbri, Priscila Sato, Erlei Sassi, Fernanda Celeste e Anderson Sarmento.

Aos meus alunos que, ao longo dessa tese, me fizeram professora. 


\section{SUMÁRIO}

Página

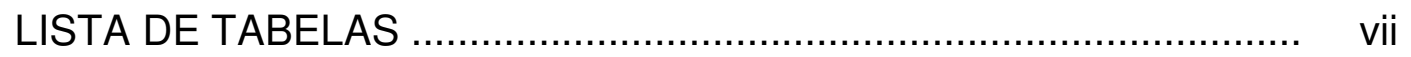

LISTA DE FIGURAS …..................................................... ix

LISTA DE QUADROS .......................................................... xi

LISTA DE SIGLAS, ABREVIAÇÕES E SÍMBOLOS ........................... xii

LISTA DE ANEXOS .............................................................. XV

RESUMO .................................................................... xvi

ABSTRACT ........................................................................... xvii

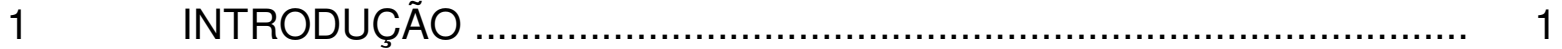

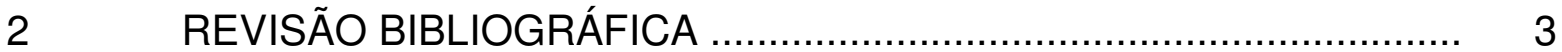

2.1 Validação dos métodos de avaliação do consumo alimentar 3

2.2 Outras formas de validação das estimativas de ingestão energética ... 8

2.3 Características do sub-relato da ingestão energética ........................ 11

2.3.1 Ocorrência e magnitude do sub-relato da ingestão energética em países desenvolvidos ............................................................ 11

2.3.1.1 Fatores associados ao sub-relato em nações desenvolvidas .............. 15

2.3.1.2 Presença do sub-relato na análise de padrões alimentares ................ 20

2.3.2 Ocorrência e magnitude do sub-relato da ingestão energética em nações em desenvolvimento ................................................... 23

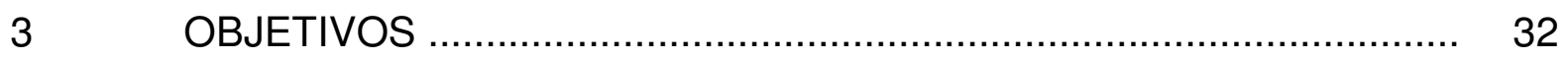

$4 \quad$ CASUÍSTICA E MÉTODOS ................................................... 33

$4.1 \quad$ Local de estudo .................................................................. 33

4.2 População de estudo .................................................................... 33

$4.3 \quad$ Desenho do estudo ................................................................ 34

4.4 Avaliação antropométrica e da composição corporal .......................... 35

4.5 Avaliação da prática de atividade física .......................................... 36 
4.6 Avaliação das características psicossociais ................................. 36

4.7 Mensuração do gasto energético total ........................................ 39

4.8 Avaliação do consumo alimentar ............................................. 45

4.9 Detecção do sub-relato da ingestão energética ............................. 47

4.10 Cálculo do $n$ amostral ......................................................... 49

4.11 Obtenção de padrões alimentares ............................................. 50

4.12 Análises estatísticas ........................................................... 52

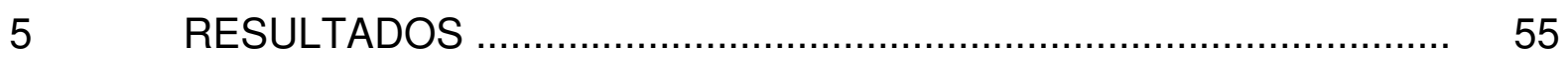

5.1 Caracterização da amostra ................................................... 55

5.2 Avaliação antropométrica e da composição corporal ........................ 56

5.3 Avaliação da validade das estimativas de ingestão energética ............ 57

5.4 Avaliação do sub-relato da ingestão energética entre as categorias de Índice de Massa Corporal (IMC) ........................................... 67

5.5 Avaliação das características dos sub-relatores ................................ 74

5.6 Avaliação da presença do sub-relato na análise de padrões alimentares ................................................................................ 81

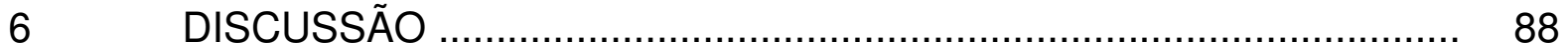

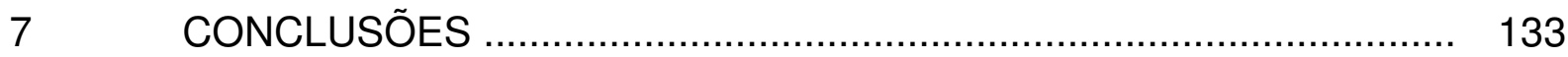

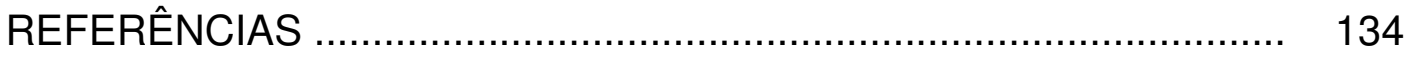

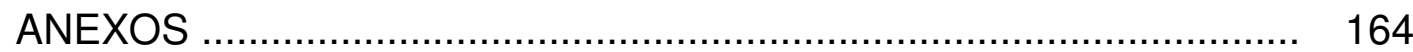




\section{LISTA DE TABELAS}

Página

TABELA 1 - Dados psicossociais da amostra, apresentados como média, desvio-padrão, mediana, valor mínimo e valor máximo

TABELA 2 - Dados antropométricos e de composição corporal obtidos pela amostra, apresentados como média, desvio-padrão, mediana, valor mínimo e valor máximo

TABELA 3 - Parâmetros metabólicos obtidos pela água duplamente marcada: gasto energético total (GET); taxa de produção de $\mathrm{CO}_{2}$; espaço de diluição do deutério $(\mathrm{Nd})$; espaço de diluição do oxigênio-18 (No); razão entre os espaços de diluição (Nd/No); taxa de eliminação do deutério (Kd) e; taxa de eliminação do oxigênio (Ko)

TABELA 4 - Estimativas de ingestão energética e indicadores de sub-relato obtidos por cada método de avaliação do consumo alimentar (dados apresentados como: média \pm desvio-padrão [mediana; mínimo - máximo])

TABELA 5 - Estimativas de ingestão energética, gasto energético total e indicadores de sub-relato obtidos pelas voluntárias com eutrofia, sobrepeso e obesidade em cada método de avaliação do consumo alimentar (dados apresentados como: média \pm desvio-padrão [mediana; mínimo - máximo])

TABELA 6 - Correlações entre a razão IE/GET (transformada em log de base 10), obtida pelo recordatório alimentar e as variáveis independentes 
TABELA 7 - Correlações entre a razão IE/GET (transformada em log de base 10), obtida pelo diário alimentar e as variáveis independentes

TABELA 8 - Correlações entre a razão IE/GET (transformada em log de base 10), obtida pelo questionário de freqüência alimentar e as variáveis independentes

TABELA 9 - Comparação das características entre os sujeitos "nunca subrelatores", "sub-relatores ocasionais" e "sub-relatores freqüentes" (dados apresentados como: média \pm desvio-padrão [mediana; mínimo - máximo])

TABELA 10 - Distribuição percentual dos sujeitos "nunca sub-relatores", "sub-relatores ocasionais" e "sub-relatores freqüentes" entre as categorias de IMC

TABELA 11 - Freqüências diárias de consumo/1.000 kcal de cada grupo alimentar, obtidas por cada cluster de padrão alimentar - dados apresentados como: média (limite inferior - limite superior do intervalo de $95 \%$ de confiança)

TABELA 12 - Valores de IE, IE/GET e IG obtidos por cada cluster de padrão alimentar (dados apresentados como: média \pm desvio-padrão [mediana; mínimo - máximo])

TABELA 13 - Valores de idade, índice de massa corporal (IMC) e ingestão de macronutrientes obtidos por cada cluster de padrão alimentar dados apresentados como: média \pm desvio-padrão (mediana; mínimo - máximo) 


\section{LISTA DE FIGURAS}

Página

FIGURA 1 - Discrepância entre o consumo de energia (em kcal) (obtido por recordatório alimentar de 24 horas) e o gasto energético total (em kcal) (determinado pela água duplamente marcada), conforme o Índice de Massa Corporal - IMC (em kg/m²) (adaptado de BALLARD-BARBASH et al., 1996 e PRENTICE et al., 1996)

FIGURA 2 - Diagrama de dispersão entre o gasto energético total (GET) e a ingestão energética obtida pelo recordatório alimentar (IE recordatório)

FIGURA 3 - Diagrama de dispersão entre o gasto energético total (GET) e a ingestão energética obtida pelo diário alimentar (IE diário)

FIGURA 4 - Diagrama de dispersão entre o gasto energético total (GET) e a ingestão energética obtida pelo questionário de freqüência alimentar (IE questionário)

FIGURA 5 - Distribuição percentual de sujeitos sub-relatores e não subrelatores em cada método de avaliação do consumo alimentar .

FIGURA 6 - Gráfico de Bland e Altman: diferença entre a IE obtida pelo recordatório alimentar e o GET versus a média entre os mesmos

FIGURA 7 - Gráfico de Bland e Altman: diferença entre a IE obtida pelo diário alimentar e o GET versus a média entre os mesmos .......

FIGURA 8 - Gráfico de Bland e Altman: diferença entre a IE obtida pelo questionário de freqüência alimentar e o GET versus a média entre os mesmos 
FIGURA 9 - Gráfico de Bland e Altman: diferença entre a IE obtida pelo recordatório alimentar e o GET versus a média entre os mesmos, de acordo com as categorias de IMC

FIGURA 10 - Gráfico de Bland e Altman: diferença entre a IE obtida pelo diário alimentar e o GET versus a média entre os mesmos, de acordo com as categorias de IMC

FIGURA 11 - Gráfico de Bland e Altman: diferença entre a IE obtida pelo questionário de freqüência alimentar e o GET versus a média entre os mesmos, de acordo com as categorias de IMC

FIGURA 12 - Distribuição percentual de indivíduos sub-relatores em cada categoria de IMC, de acordo com os dados do recordatório alimentar

FIGURA 13 - Distribuição percentual de indivíduos sub-relatores em cada categoria de IMC, de acordo com os dados do diário alimentar .

FIGURA 14 - Distribuição percentual de indivíduos sub-relatores em cada categoria de IMC, de acordo com os dados do questionário de freqüência alimentar

FIGURA 15- Proporção de sub-relatores em cada cluster de padrão alimentar 


\section{LISTA DE QUADROS}

Página

QUADRO 1 - Confrontação de estimativas de ingestão energética obtidas por inquéritos alimentares com medidas do gasto energético determinadas pela água duplamente marcada (adaptadas das referências citadas abaixo)

QUADRO 2 - Descrição das avaliações conduzidas durante o módulo de estudo

QUADRO 3 - Dias e horários das coletas de amostras de urina, para mensuração do gasto energético total

QUADRO 4 - Distribuição percentual da amostra segundo características demográficas 


\section{LISTA DE SIGLAS, ABREVIAÇÕES E SÍMBOLOS}

A

a

ADM

AIDS

$\mathrm{CV}_{\mathrm{GET}}$

$\mathrm{CV}_{\mathrm{IE}}$

E1

E4

E9

$\mathrm{Ea}$

EEFE

El

Ep

Es

Ew

FAO

GET

IBGE

IE

IE diário

IE questionário

IE recordatório

IE/TMB

IE/GET

IE-GET massa de dose administrada ao sujeito (em gramas)

massa de dose usada para a amostra de dose diluída (em gramas)

água duplamente marcada

síndrome da imunodeficiência adquirida

coeficiente de variação intra-individual do gasto energético total

coeficiente de variação intra-individual da ingestão energética

enriquecimento da amostra 1

enriquecimento da amostra 4 ou 5

enriquecimento da amostra 9 ou 10

enriquecimento isotópico da amostra de dose diluída

Escola de Educação Física e Esporte

energy intake

enriquecimento isotópico da amostra pré-dose (amostra 1)

enriquecimento isotópico da amostra de urina, pós-dose, equilibrada (amostras 4 ou 5)

enriquecimento isotópico da amostra tap (de água potável)

Food and Agriculture Organization

gasto energético total

Instituto Brasileiro de Geografia e Estatística

ingestão energética

ingestão energética obtida pelo diário alimentar

ingestão energética obtida pelo questionário de freqüência alimentar

ingestão energética obtida pelo recordatório alimentar

razão entre ingestão energética e taxa de metabolismo basal

razão entre ingestão energética e gasto energético total

diferença entre ingestão energética e gasto energético total; acurácia 
do relato

IG

IMC

IRMS

Kd ou Kh

Ko

$\log$

$\mathrm{N}$

$\mathrm{Nd}$

$\mathrm{Nd} / \mathrm{No}$

No

OPEN

Q

Quar

Quin

$\mathrm{R}$

$\mathrm{rCO}_{2}$

RDA

$r_{G F}$

$\mathrm{RQ}$

RS

Sáb

Seg

Sex

$\mathrm{t}$

TACO

TBCA

TBW diferença entre ingestão energética e gasto energético total índice de massa corporal espectrometria de massa por determinação da razão isotópica taxa de eliminação do deutério taxa de eliminação do oxigênio-18 logaritmo de base 10 conjunto (pool) de água corporal espaço de diluição do deutério razão entre espaço de diluição do deutério e espaço de diluição do oxigênio-18 espaço de diluição do oxigênio-18 Estudo de Observação da Nutrição Protéica e Energética (Observing Protein and Energy Nutrition)

ácido paraminobenzóico

questionário de freqüência alimentar

quarta-feira

quinta-feira

instrumento de referência

taxa do fluxo ou produção de $\mathrm{CO}_{2}$

Ingestão Dietética Recomendada (Recommended Dietary Allowances) taxa de perda de gás fracionado

quociente respiratório

Escala de Restrição (Restraint Scale)

sábado

segunda-feira

sexta-feira

tempo (dias)

Tabela Brasileira de Composição de Alimentos (NEPA, 2004)

Tabela Brasileira de Composição de Alimentos (LAJOLO \& MENEZES, 1997)

total de água corporal 
TEE

Ter

TMB

W

$\varepsilon q$

$\varepsilon r$ total energy expenditure

terça-feira

taxa de metabolismo basal

quantidade de água usada para diluir a dose e fazer a amostra de dose diluída (em gramas)

erro aleatório total $=$ viés específico do sujeito + porção randômica deste viés

erro aleatório do instrumento de referência 
LISTA DE ANEXOS

Página

ANEXO I - Termo de Consentimento Livre e Esclarecido

164 


\title{
RESUMO
}

\section{VALIDADE DAS ESTIMATIVAS DE INGESTÃO ENERGÉTICA DE TRÊS MÉTODOS DE AVALIAÇÃO DO CONSUMO ALIMENTAR, EM RELAÇÃO À ÁGUA DUPLAMENTE MARCADA.}

\author{
Autora: FERNANDA BAEZA SCAGLIUSI \\ Orientador: PROF. DR. ANTONIO HEBERT LANCHA JUNIOR
}

Introdução: O gasto energético total (GET) pode ser usado como medida da ingestão energética (IE). Existe um constante sub-relato da IE obtida por métodos de avaliação do consumo alimentar, mas poucos estudos o investigaram em nações em desenvolvimento. Objetivos: a) comparar a validade das estimativas de IE de um questionário de freqüência alimentar, três recordatórios alimentares e um diário alimentar de três dias, segundo a água duplamente marcada; b) determinar a influência da prática de atividade física, do índice de massa corporal e de fatores psicossociais no sub-relato e; c) comparar as taxas de sub-relato entre agrupamentos de padrões alimentares. Métodos: Sessenta e cinco mulheres responderam aos métodos de inquérito supracitados, a partir dos quais foi estimada a IE. O GET foi medido pela água duplamente marcada. A prática de atividade física, índice de massa corporal, escolaridade, renda, idade, conhecimento nutricional, insatisfação corporal, restrição dietética, compulsão alimentar e o desejo de aceitação social foram correlacionados ao sub-relato. Os padrões alimentares foram obtidos pela análise de cluster. Resultados: O GET foi de $2.622 \pm 490 \mathrm{kcal}$, enquanto que a IE, mensurada respectivamente pelo recordatório, diário e questionário, foi de $2.078 \pm 430 \mathrm{kcal} ; 2.044 \pm 479 \mathrm{kcal}$ e $1.984 \pm 832 \mathrm{kcal}$. A 
proporção de sub-relatores foi de 24,6\% para o recordatório, 29,2\% para o diário e $53,8 \%$ para o questionário $(p<0,005$ ). Os sub-relatores apresentaram menores médias de renda e escolaridade e maiores valores de idade, insatisfação corporal e desejo de aceitação social. O sub-relato foi mais comum no padrão alimentar mais frugal. Conclusão: Os três métodos de avaliação do consumo alimentar apresentaram erros sistemáticos, embora o questionário de freqüência alimentar tenha tido o pior desempenho. O sub-relato foi influenciado por diversos fatores psicossociais e variou conforme o padrão alimentar relatado, o que pode comprometer a avaliação do consumo.

Palavras-chave: avaliação do consumo alimentar, gasto energético total, ingestão energética, validade, água duplamente marcada, sub-relato. 


\begin{abstract}
VALIDITY OF THE ENERGY INTAKE ESTIMATES OBTAINED BY THREE DIETARY ASSESSMENT METHODS, IN RELATION TO DOUBLY LABELED WATER.
\end{abstract}

\author{
Author: FERNANDA BAEZA SCAGLIUSI \\ Adviser: PROF. DR. ANTONIO HEBERT LANCHA JUNIOR
}

Introduction: Total energy expenditure (TEE) may be used as a measure of energy intake (EI). There is a constant underreporting of El obtained by dietary assessment methods, but few studies have investigated it in developing nations. Objectives: a) to compare the validity of El estimates obtained by a food-frequency questionnaire, three diet recalls and a three-day food record; $b$ ) to determine the influence of physical activity, body mass index and psychosocial factors on underreporting and; c) to compare underreporting rates between dietary pattern's clusters. Methods: Sixty-five women completed the dietary assessment methods, which were used to estimate EI. TEE was measured by doubly labeled water. Physical activity practice, body mass index, education, income, age, nutritional knowledge, body dissatisfaction, dietary restraint, binge eating and social desirability were correlated to underreporting. Dietary patterns were obtained by cluster analysis. Results: TEE was $2,622 \pm 490 \mathrm{kcal}$, while El, measured respectively by the diet recall, food record and food-frequency questionnaire, was 2,078 $\pm 430 \mathrm{kcal} ; 2,044 \pm$ $479 \mathrm{kcal}$ and 1,984 $\pm 832 \mathrm{kcal}$. Proportion of underreporters was $24.6 \%$ (recall), $29.2 \%$ (record) and $53.8 \%$ (questionnaire) $(p<0.005)$. Underreporters had smaller income and education and greater age, body dissatisfaction and social desirability. 
Underreporting was more common in the 'frugal foods' pattern. Conclusions: The three dietary assessment methods presented systematic errors, although the foodfrequency questionnaire had the worst performance. Underreporting was influenced by psychosocial factors and varied according the reported dietary pattern, which may compromise dietary assessment.

Keywords: dietary assessment, total energy expenditure, energy intake, validity, doubly labeled water, underreporting. 
A avaliação do consumo alimentar pode ser definida como um conjunto de métodos que medem e/ou estimam a ingestão de alimentos (THOMPSON \& BYERS, 1994). Ela é de suma importância na prática e ciência da nutrição (HILL \& DAVIES, 2001) e uma variedade de instrumentos de avaliação do consumo alimentar foi desenvolvida, bem como diversas técnicas de como aplicá-los (LINDQUIST, CUMMINGS \& GORAN, 2000; SLIMANI, FERRARI, OCKÉ, WELCH, BOEING, VAN LIERE, PALA, AMIANO, LAGIOU, MATTISON, STRIPP, ENGESET, CHARRONDIĖRE, BUZZARD, VAN STAVEREN \& RIBOLI, 2000; TRAN, JOHNSON, SOULTANAKIS \& MATTHEWS, 2000). Os levantamentos populacionais de consumo alimentar fornecem informações que são usadas para detectar deficiências ou excessos alimentares, e para a elaboração de recomendações nutricionais (HIRVONEN, MÄNNISTÖ, ROOS \& PIETINEN, 1997). Tais instrumentos também são particularmente importantes no campo da Epidemiologia Nutricional, que visa estabelecer relações entre dieta e saúde (LANGSETH, 1996; WILLETT, 1998).

Entretanto, para tais estudos, nos quais se deseja estabelecer determinantes dietéticos das doenças (na forma de fatores de risco ou proteção), avaliações individuais do consumo alimentar são necessárias (LANGSETH, 1996). A avaliação do consumo alimentar individual pode ser feita por métodos indiretos, como recordatório alimentar, o diário alimentar, a história alimentar e o questionário de freqüência alimentar. Os dois primeiros avaliam a dieta atual, enquanto que a história alimentar e o questionário de freqüência alimentar analisam a dieta pregressa (THOMPSON \& BYERS, 1994).

Os recordatórios fazem com que o avaliado relembre e relate todos os alimentos consumidos em um determinado período, que geralmente compreende 24 horas, mas que pode se estender por vários dias (MAJEM \& BARBA, 1995; THOMPSON \& BYERS, 1994).

O diário alimentar consiste em um registro de todos os alimentos consumidos ao longo de determinado período, que usualmente varia entre três e sete dias (BARTRINA \& RODRIGO, 1995; THOMPSON \& BYERS, 1994). Este registro prospectivo pode ser por escrito ou gravado em fitas de áudio (LINDQUIST et al., 2000). A quantificação das porções alimentares pode ser feita por medidas caseiras 
e dimensões, por pesagem das mesmas ou por fotos e desenhos (THOMPSON \& BYERS, 1994).

A história alimentar consiste em uma detalhada entrevista, na qual o sujeito deve descrever a rotina da sua alimentação durante um período de tempo. $O$ objetivo é a obtenção de um padrão da alimentação típica daquele indivíduo (BARTRINA \& MAJEM, 1995; THOMPSON \& BYERS, 1994).

O questionário de freqüência, por sua vez, estima a freqüência com a qual um alimento (ou grupo de alimento) é consumido em um período de referência, que geralmente varia de uma semana a um ano. Algumas vezes, o sujeito deve relatar também o tamanho da porção alimentar ingerida e por isso o instrumento é então denominado questionário semiquantitativo de freqüência alimentar. Normalmente, o avaliado assinala qual dos tamanhos padrões, fornecidos pelo questionário e descritos como porção pequena, média ou grande, corresponde à sua porção alimentar habitual (PEREIRA \& KOIFMAN, 1999; THOMPSON \& BYERS, 1994). Por avaliar a ingestão habitual, de forma prática e rápida, e ainda ser capaz de classificar os sujeitos segundo grau de exposição, o questionário de freqüência alimentar é o método de primeira escolha nos estudos epidemiológicos (PEREIRA \& KOIFMAN, 1999). 


\subsection{Validação dos métodos de avaliação do consumo alimentar}

Desde que estes métodos foram desenvolvidos, os pesquisadores preocuparam-se em analisar a validade dos mesmos, para que eles pudessem de fato ser usados nos tipos de pesquisas citadas anteriormente (LÓPEZ, 1995).

$O$ termo validade refere-se à capacidade de um instrumento de medir o aspecto dietético que ele foi desenvolvido para medir (WILLETT, 1998). A acurácia é a medida quantitativa da validade de um método ou, em termos matemáticos; acurácia $=$ valor mensurado - valor real (LENNERNAS, 1998). O relato válido ou acurado é aquele que mede a ingestão real durante o período de estudo, sem que, inclusive, o consumo tenha sido alterado em função da mensuração (LIVINGSTONE \& BLACK, 2003).

Segundo KAAKS, FERRARI, CIAMPI, PLUMMER e RIBOLI (2002), quando se possui um instrumento "padrão-ouro", a validação é a comparação entre o padrão-ouro e a nova forma de medida que está sendo testada. Se os erros dessa nova medida forem pequenos, ela será considerada válida e poderá ser usada no lugar do padrão-ouro em estudos futuros. Infelizmente, esta simples definição de validação não pode ser aplicada aos métodos de avaliação do consumo alimentar, porque, como já vem sendo apontado há bastante tempo (KARKECK, 1987; MERTZ, 1992), não existe um método de avaliação da ingestão alimentar que possa ser considerado padrão-ouro. Desta forma, esta definição de validação foi expandida para a "avaliação dos erros de mensuração de um instrumento", o que contextualiza tal validação em um modelo de erro de mensuração.

Durante muito tempo, as validações foram então conduzidas da seguinte forma: o método de teste era comparado com outro método considerado superior, porém mais trabalhoso e com maior custo (geralmente o diário alimentar, sendo que aquele cujas porções eram pesadas era considerado mais superior ainda) (BARTRINA \& RODRIGO, 1995; GIBSON, 1990; LISSNER, HEITMANN \& LINDROOS, 1998). Quando se observava boa correlação entre os dois métodos, o instrumento de teste era considerado válido e os estudos sobre a relação saúde e dieta eram baseados, freqüentemente, nesta "validade presumida" (BLACK, 
GOLDBERG, JEBB, LIVINGSTONE, COLE \& PRENTICE, 1991; BLACK, PRENTICE, GOLDBERG, JEBB, BINGHAM, LIVINGSTONE \& COWARD, 1993; LIVINGSTONE \& BLACK, 2003). Ao se comparar dois métodos como estratégia de validação, foi assumido que ambos pudessem possuir erros, mas que tais erros eram aleatórios (BLACK et al., 1991).

As avaliações de consumo alimentar freqüentemente obtêm intervalos de ingestão bastante grandes, cujos extremos se devem à escolha aleatória de dias nos quais a ingestão foi analisada (BLACK \& COLE, 2001). Em outras palavras, em qualquer levantamento do consumo alimentar algumas pessoas estarão ingerindo mais alimentos e outras menos. Isto faz parte da variação normal do consumo alimentar, de forma que, neste caso, a ingestão média deve refletir a ingestão habitual deste grupo. Se o fato de ter seu consumo avaliado faz com que alguns indivíduos relatem ou consumam menor quantidade de alimentos e outros maior quantidade, isto produz erro, chamado de aleatório. Entretanto, se o total de subestimação anular o total de superestimação, os valores médios de ingestão permanecerão válidos, ou seja, os resultados não estarão enviesados. Deve-se lembrar, contudo, que o erro de mensuração é aumentado, assim como a variação dos valores relatados torna-se mais ampla.

Quando a análise do consumo alimentar ocasiona alterações nos hábitos alimentares ou distorce o relato da ingestão em apenas, ou predominantemente, uma direção, tem-se o erro sistemático ou viés. Mais importante ainda é quando tal distorção é identificada em um grupo especifico de sujeitos e não na amostra como um todo. Este tipo de erro não pode ser eliminado ou minimizado com o aumento da amostra e invalida os valores médios de ingestão obtidos pelos inquéritos alimentares. Este padrão de viés constitui a mais séria forma de erro sistemático nos métodos de avaliação do consumo alimentar (BLACK et al., 1991).

KAAKS et al. (2002) e KAAKS e FERRARI (2006) analisaram os modelos vigentes de erro de mensuração, de tal forma que suas limitações ficaram bastante evidentes, e propuseram novos modelos. Tais análises e proposições serão apresentadas a seguir.

Os autores partiram de um cenário muito comum na epidemiologia nutricional: grandes estudos populacionais, nos quais se deseja investigar 
associações entre dieta e doenças, e a avaliação do consumo alimentar é feita por meio de um questionário de freqüência alimentar.

A mensuração obtida por este questionário (denominada $Q$ ), supostamente, está relacionada à ingestão real habitual e ao erro de mensuração. $\mathrm{O}$ modelo clássico de erro de mensuração expressa $Q$ como a soma de duas variáveis independentes e aleatórias (a ingestão real habitual e o erro de mensuração). Para ser considerada válida, a mensuração $Q$ deve concordar com uma mensuração obtida pelo instrumento de referência $(R)$. Este modelo postula que a mensuração obtida pelo instrumento de referência $(R)$ é igual à soma da ingestão real e o erro aleatório de $R(\varepsilon r)$.

As premissas deste modelo são as seguintes:

a) A média de er é igual a zero (isto é, a média grupal não está enviesada).

b) Não há covariância entre ingestão real e $\varepsilon r$ (o erro do método de referência não se correlaciona com a ingestão real).

c) Não há covariância entre $\varepsilon r$ e $\varepsilon q$ (o erro do método de referência não se correlaciona com o erro do método teste - por exemplo, Q, o questionário de freqüência alimentar).

d) Não há correlação entre os erros obtidos em repetidas aplicações do método de referência.

A comparação das ingestões de energia e proteína obtidas pelos métodos de avaliação do consumo alimentar com o gasto energético (obtido pela água duplamente marcada) e o consumo de proteínas derivado da excreção urinária de nitrogênio mostrou que, independentemente do método de avaliação do consumo alimentar aplicado, obesos subestimavam sua ingestão mais do que eutróficos. Isto faz com que عq e عr sejam correlacionados, o que leva à superestimação dos fatores de atenuação. Por outro lado, se $\mathrm{R}$ é aplicado mais de uma vez e há correlação entre o erro de cada aplicação, ocorre subestimativa dos fatores de atenuação. Este efeito também é bem freqüente, posto que alguns estudos verificaram que os mesmos indivíduos tendem a ter o mesmo padrão de erro de relato ao longo do tempo (BLACK \& COLE, 2001; PRICE, PAUL, COLE \& WADSWORTH, 1997). Isto significa que ignorar o fato de que as medidas $Q$ e $R$ têm erros correlacionados pode produzir um viés imprevisível nas estimativas de risco relativo, aumentando ou diminuindo tais estimativas. Por fim, descobriu-se também que os indivíduos que, provavelmente, 
têm maior consumo de alguns alimentos e/ou nutrientes são os que mais subestimam a ingestão desses componentes (HEITMANN, 1993; HEITMANN, LISSNER \& OSLER, 2000), fazendo com que haja correlação entre o erro do método de referência e a ingestão real. Com isso, ajustar um método teste (como o questionário de freqüência) por um outro método de avaliação do consumo alimentar (como os diários) não pode ser considerado uma validação externa e independente e sim uma validação relativa, pois, na melhor das hipóteses, apenas uma parte do viés nas estimativas de risco relativo será corrigida.

Para resolver este problema, um terceiro tipo de mensuração precisa ser encontrado, cujo erro não esteja correlacionado com $Q$ e $R$, e, quando for aplicado várias vezes, não produza erros com correlação entre si.

Muito do erro encontrado nos métodos de avaliação do consumo alimentar vem da dificuldade dos sujeitos em relatarem sua ingestão. Marcadores biológicos, por sua vez, são mais objetivos, porque não dependem do auto-relato. Além disso, os erros destes não se correlacionam com os erros dos métodos de avaliação do consumo alimentar. Os marcadores biológicos podem ser divididos em duas categorias: marcadores de concentração e marcadores de recuperação.

Os marcadores de concentração são baseados na medida de concentração de um composto específico, como, por exemplo, concentração de vitamina $\mathrm{C}$ no plasma e composição de ácidos graxos no tecido adiposo. Uma de suas características é que eles não expressam dimensão de tempo; seus valores são medidos e expressos sem unidade de tempo. Eles não apresentam a mesma relação quantitativa com a ingestão para todos os indivíduos da população, posto que fatores relacionados à digestão, absorção, metabolismo, troca com outros conjuntos (pools) do organismo e excreção podem ser importantes fontes de variação aleatória nestes marcadores. Assim, eles não podem ser traduzidos para uma ingestão absoluta por dia, e sim, no máximo, fornecer uma correlação com a ingestão dietética.

Os marcadores de recuperação, por sua vez, são baseados no conhecimento preciso e quantitativo do balanço fisiológico entre a ingestão e a excreção de compostos ou elementos químicos. São eles: o nitrogênio urinário, o gasto energético total medido pela água duplamente marcada e o potássio urinário.

A água duplamente marcada consiste em $\mathrm{H}_{2} \mathrm{O}$, porém composta pelos isótopos estáveis ${ }^{2} \mathrm{H}$ - deutério - em vez de ${ }^{1} \mathrm{H}$, e ${ }^{18} \mathrm{O}$, em vez de ${ }^{16} \mathrm{O}$ (WALCZYK, 
COWARD, SCHOELLER, PRESTON, DAINTY, TURNLUND \& IYENGAR, 2002). Ela é considerada o método padrão-ouro para determinação do gasto energético total (GET).

Em humanos, a precisão do método em calcular a produção de $\mathrm{CO}_{2}$ varia entre 93-97\%, dependendo das condições do experimento e do estado fisiológico dos sujeitos (ROBERTS, 1989). A acurácia do método é de cerca de 97 a $99 \%$, em relação à calorimetria indireta (NAGY, 1990). Além de ser muito preciso e acurado, este método praticamente não interfere com as atividades cotidianas dos sujeitos de pesquisa, posto que só são necessárias algumas amostras de urina. Por isso ele é bastante apropriado para ser usado em indivíduos fora de confinamento. Esta é uma grande vantagem deste método sobre a calorimetria indireta, que exige 0 confinamento em câmaras, para coleta dos gases. Sabe-se que, por mais sofisticadas que tais câmaras sejam, elas nunca serão capazes de reproduzir 0 número e a complexidade das tarefas que os indivíduos desempenham rotineiramente em suas vidas (SPEAKMAN, 1998).

As pesquisas que compararam o GET, medido pela água duplamente marcada, à ingestão de energia (IE) indicaram que havia uma subestimação constante e sistemática da ingestão energética obtida por auto-relato nos métodos de avaliação do consumo alimentar. Esta subestimação ficou conhecida como sub-relato ou subnotificação da ingestão energética (ou em inglês, underreporting of energy intake) (SCHOELLER, BANDINI \& DIETZ, 1990). KANT (2002) definiu o sub-relato como uma condição na qual indivíduos saudáveis e em balanço energético relatam consumo energético muito baixo, implausível e inconsistente com a viabilidade biológica. Em outras palavras, relatar uma ingestão energética menor do que o gasto de energia, sem apresentar perda de peso, corresponderia ao sub-relato. Deste modo, em indivíduos com peso e estado fisiológico estáveis, que não estejam em estado ativo de crescimento (como a infância e a gravidez), o gasto energético é igual à ingestão habitual de energia, de tal forma que, nestas condições supracitadas, o gasto energético total pode ser usado como medida da ingestão de energia (TRABULSI \& SCHOELLER, 2001).

A FIGURA 1 mostra um exemplo da magnitude do sub-relato, quando a IE é comparada com o GET determinado pela água duplamente marcada. Nesta figura, percebe-se claramente a grande diferença entre a IE e o GET. O fato da discrepância 
entre as duas variáveis ter aumentado proporcionalmente ao Índice de Massa Corporal será discutido mais adiante.

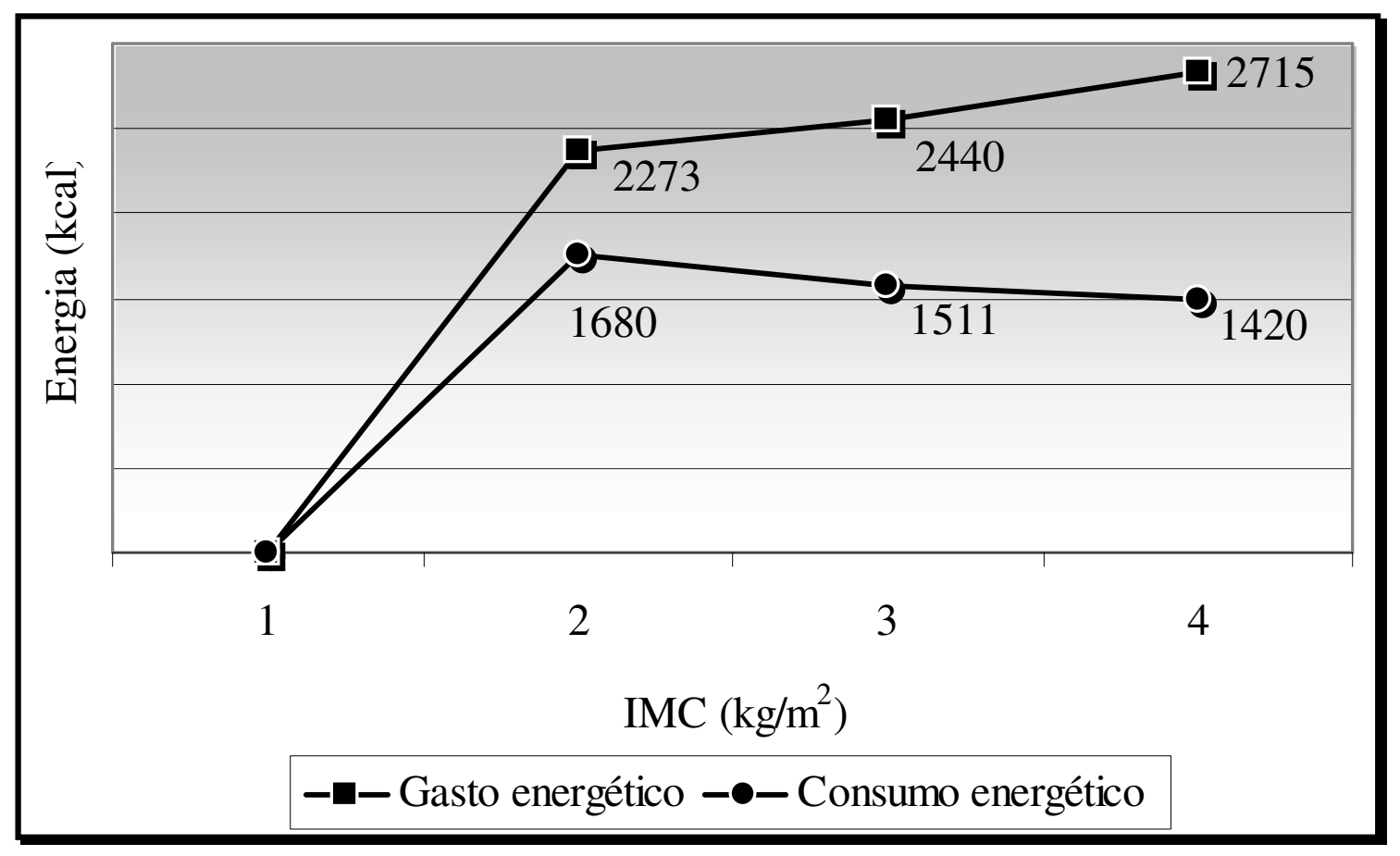

Ponto 1 no eixo das categorias $=\mathrm{IMC}$ de $0 \mathrm{~kg} / \mathrm{m}^{2}$; Ponto 2 no eixo das categorias = IMC de $21 \mathrm{~kg} / \mathrm{m}^{2}$; Ponto 3 no eixo das categorias = IMC de $28 \mathrm{~kg} / \mathrm{m}^{2}$; Ponto 4 no eixo das categorias $=I M C$ de $32 \mathrm{~kg} / \mathrm{m}^{2}$.

IMC = índice de massa corporal.

FIGURA 1 - Discrepância entre o consumo de energia (em kcal) (obtido por recordatório alimentar de 24 horas) e o gasto energético total (em kcal) (determinado pela água duplamente marcada), conforme o Índice de Massa Corporal - IMC (em kg/m²) (adaptado de BALLARD-BARBASH et al., 1996 e PRENTICE et al., 1996).

\subsection{Outras formas de validação das estimativas de ingestão energética}

Como a água duplamente marcada é extremamente cara e demanda treinamento, outros métodos foram empregados para detectar a subnotificação. Os estudos observacionais continuaram a ser conduzidos e outras fórmulas de determinação do GET foram empregadas. Embora, nesta revisão, os resultados de 
estudos que usaram a água duplamente marcada e os métodos descritos abaixo sejam apresentados em conjunto, deve-se ressaltar que as evidências provenientes dos estudos com água duplamente marcada são mais consistentes, porque os outros métodos possuem grandes limitações.

GOLDBERG, BLACK, JEBB, COLE, MURGATROYD, COWARD e PRENTICE (1991) compararam os valores de GET mensurados pela água duplamente marcada com aqueles obtidos por equações, a fim de obter um valor mínimo de ingestão de energia abaixo do qual a manutenção do peso corporal seria estatisticamente implausível. Os autores determinaram que ingestões inferiores a $1,35^{\star}$ taxa de metabolismo basal (TMB) apresentadas por indivíduos com peso estável significavam sub-relato, pois é estatisticamente improvável que tal ingestão relatada represente o consumo habitual. BLACK e COLE (2001), entretanto, afirmam que este valor deve ser alterado em função do nível de atividade física de cada amostra. De forma geral, muitos estudos empregam a razão IE/TMB como medida de detecção do sub-relato, sendo que o valor do ponto de corte varia conforme o estudo, não só de acordo com a atividade física, mas também com o número de sujeitos da amostra e número de dias de avaliação do consumo alimentar (BLACK et al., 1991; GOLDBERG et al., 1991). É importante lembrar que, embora o erro inerente ao cálculo da TMB esteja inserido na fórmula que calcula o ponto de corte da IE/TMB para cada amostra, o coeficiente de variação da TMB não é considerado, o que diminui a acurácia, precisão e sensibilidade do ponto de corte.

Observar e pesar o consumo de indivíduos em situações artificiais, como em unidades metabólicas e nas lanchonetes que são usadas especificamente nas pesquisas, diminui a validade ecológica do estudo. Ter um pesquisador observando e pesando seu consumo é algo extremamente constrangedor, o que pode contribuir para que o sujeito consuma menos alimentos do que o habitual. Por outro lado, poder ingerir o que desejar em um buffet, sem qualquer custo, pode fazer com que o sujeito consuma mais alimentos do que o habitual, ou ainda, consuma alimentos mais caros, que podem ser bem diferentes dos alimentos que ele usualmente consome. Confinar um indivíduo em unidade metabólica pode reduzir seu GET, e isso pode fazer com que o sujeito diminua o consumo (HISE, SULLIVAN, JACOBSEN, JOHNSON \& DONNELLY, 2002; PENNINGTON, 1991). Além disso, o número de dias de observação também parece ser importante. Nos estudos de CONWAY, 
INGWERSEN, VINYARD e MOSHFEGH (2003) e CONWAY, INGWERSEN e MOSHFEGH (2004), os sujeitos só foram observados por um dia. De certa forma, isto foi adequado ao objetivo do estudo, que era verificar se o relato pelo recordatório era fidedigno ao que foi consumido. Entretanto, os autores não puderam generalizar seus achados, porque o número de dias de observação e relato foi muito pequeno.

Muitas vezes, as estimativas de GET por outros métodos que não a água duplamente marcada (monitoramento da freqüência cardíaca, acelerômetros e equações) possuem uma média grupal válida, porém a estimativa individual apresenta muito erro, como descrito nos estudos de JOHNSON, RUSS e GORAN (1998) e LOVELADY, MEREDITH, MCCRORY, NOMMSEN, JOSEPH e DEWEY (1993). Devido a este fato, é possível estimar o sub-relato de um grupo por meio destes métodos, porém identificar quais indivíduos sub-relataram torna-se mais complicado, por causa do grande erro embutido. Entretanto, para se investigar quais são as características pessoais associadas à subnotificação, é necessário saber quem sub-relatou. Assim, investigar as características dos sub-relatores, com base no GET estimado por outros métodos que não a água duplamente marcada, como foi feito em muitos estudos, não é metodologicamente apropriado. Mesmo quando se usa a água duplamente marcada para determinar o GET, não se deve usar a razão IE/GET diretamente, isto é, não se devem identificar como sub-relatores aqueles indivíduos que não perderam peso e apresentaram razão IE/GET inferior a 1. A IE e - GET estão sujeitos à variações intra-individuais normais que tornam a concordância individual exata entre elas pouco provável. Desta forma, é necessário obter a variação intra-individual da IE e do GET para se calcular os limites do intervalo de $95 \%$ de confiança, dentro dos quais as duas mensurações individuais devem concordar (BLACK \& COLE, 2000). Poucos estudos, entretanto, utilizaram esta abordagem. Assim, embora alguns estudos tenham tentado identificar os fatores associados ao sub-relato, tais achados são algumas vezes controversos e devem ser vistos com cautela em função das limitações metodológicas descritas acima. Uma outra limitação freqüentemente encontrada, especialmente nos estudos com água duplamente marcada (devido ao seu alto custo), é o tamanho reduzido das amostras. 


\subsection{Características do sub-relato da ingestão energética}

2.3.1 Ocorrência e magnitude do sub-relato da ingestão energética em países desenvolvidos

O sub-relato do consumo de energia parece ser um fenômeno bastante freqüente em levantamentos da ingestão alimentar, pelo menos nos países desenvolvidos. Na maioria dos estudos, encontra-se tanto uma alta proporção de indivíduos sub-relatores quanto uma grande quantidade de energia subnotificada. Dessa forma, os pesquisadores da área são unânimes em afirmar que ele se trata do maior erro presente na avaliação do consumo alimentar (BELLISLE, 2001; HILL \& DAVIES, 2001; LIVINGSTONE \& BLACK, 2003). Em sua análise de 37 levantamentos do consumo alimentar, BLACK et al. (1991) encontraram que $88 \%$ dos estudos que utilizaram o recordatório de 24 horas, $64 \%$ dos que se basearam em diários alimentares e $25 \%$ dos que usaram a história alimentar apresentaram estimativas médias de ingestão energética inferiores às necessidades mínimas de cada população. O QUADRO 1 mostra alguns exemplos de estudos acerca do subrelato, que usaram a água duplamente marcada como método de referência para a ingestão energética. 
QUADRO 1 - Confrontação de estimativas de ingestão energética obtidas por inquéritos alimentares com medidas do gasto energético determinadas pela água duplamente marcada (adaptadas das referências citadas abaixo).

\begin{tabular}{|c|c|c|c|c|}
\hline Estudo & Amostra & $\mathrm{IE}^{1}$ (kcal) & $\mathrm{GET}^{2}$ (kcal) & Protocolo \\
\hline $\begin{array}{l}\text { CHAMPAGNE } \\
\text { et al., } 1998\end{array}$ & $\begin{array}{l}\text { Crianças de } \\
\text { ambos os sexos } \\
\quad(n=118)\end{array}$ & $\begin{array}{l}F: 1.033 \pm 54 \\
M: 1.953 \pm 53\end{array}$ & $\begin{array}{l}F: 2.232 \pm 52 \\
M: 2.555 \pm 51\end{array}$ & $\begin{array}{c}\text { Diário } \\
\text { alimentar de } \\
\text { oito dias }\end{array}$ \\
\hline $\begin{array}{l}\text { LIVINGSTONE } \\
\text { et al., } 1990\end{array}$ & $\begin{array}{l}\text { Adultos de ambos } \\
\text { os sexos }(n=31)\end{array}$ & $\begin{array}{l}F: 1.912 \pm 449 \\
M: 2.679 \pm 592\end{array}$ & $\begin{array}{l}F: 2.373 \pm 365 \\
M: 3.404 \pm 705\end{array}$ & $\begin{array}{c}\text { Diário } \\
\text { alimentar de } \\
\text { sete dias }\end{array}$ \\
\hline $\begin{array}{l}\text { PRENTICE et } \\
\text { al., } 1986\end{array}$ & $\begin{array}{l}\text { Mulheres obesas } \\
\qquad(\mathrm{n}=9)\end{array}$ & $1.567 \pm 430$ & $2.466 \pm 313$ & $\begin{array}{c}\text { Dois diários } \\
\text { alimentares de } \\
\text { sete dias }\end{array}$ \\
\hline $\begin{array}{c}\text { TOMOYASU et } \\
\text { al., } 1999\end{array}$ & $\begin{array}{l}\text { Idosos de ambos } \\
\text { os sexos }(n=82)\end{array}$ & $\begin{array}{l}F: 1.641 \pm 60 \\
M: 2.086 \pm 76\end{array}$ & $\begin{array}{l}F: 1.996 \pm 60 \\
M: 2.701 \pm 84\end{array}$ & $\begin{array}{c}\text { Diário } \\
\text { alimentar de } \\
\text { três dias }\end{array}$ \\
\hline
\end{tabular}

IE: ingestão energética, ${ }^{2}$ GET: gasto energético total, F: sexo feminino, M: sexo masculino

Poucas pesquisas compararam, simultaneamente, a validade de diversos métodos de avaliação do consumo alimentar. Esta avaliação simultânea seria de bastante interesse, posto que, muitas vezes, as diferenças metodológicas entre os estudos limitam a comparabilidade entre os mesmos.

No Estudo de Observação da Nutrição Protéica e Energética (Observing Protein and Energy Nutrition - OPEN), SUBAR, KIPNIS, TROIANO, MIDTHUNE, SCHOELLER, BINGHAM, SHARBAUGH, TRABULSI, RUNSWICK, BALLARDBARBASH, SUNSHINE e SCHATZKIN (2003) encontraram, entre as mulheres, em relação à energia, 49,0\% de sub-relatores (quando a ingestão era avaliada pelo questionário de freqüência alimentar) ou 22,3\% (quando se utilizava o recordatório de 24 horas). Para homens, estas taxas foram de $49,6 \%$ e $20,8 \%$, respectivamente. $O$ 
sub-relato da IE ocorreu simultaneamente nos dois métodos em 14\% dos homens e $13 \%$ das mulheres, o que mostra que o método de avaliação do consumo alimentar interfere diretamente no sub-relato.

KROKE, KLIPSTEIN-GROBUSCH, VOSS, MÖSENEDER, THIELECKE, NOACK e BOEING (1999) aplicaram um questionário de freqüência alimentar e 12 recordatórios alimentares de 24 horas em uma amostra de 134 adultos alemães, sendo que em 28 deles a água duplamente marcada também foi administrada. A IE obtida pelo questionário correspondeu a $2.163 \pm 509 \mathrm{kcal}$, enquanto que a obtida pelos recordatórios foi igual a $1.996 \pm 454 \mathrm{kcal}$. O GET correspondeu a $2.684 \pm 569$ kcal. Os autores informaram que, em média, o questionário de freqüência subestimou a IE em $20 \%$. Este valor não foi dado para o recordatório, porém, como a IE obtida por este método foi menor, espera-se que a sua taxa de sub-relato seja maior, ao contrário do que foi observado no estudo de SUBAR et al. (2003). Em ambos os métodos, quando a IE média foi confrontada graficamente com a IE-GET, os limites de concordância foram extremamente amplos, variando de 478 a $-1.673 \mathrm{kcal}$, o que indica que os métodos produzem resultados individuais muito discrepantes em relação ao GET. SAWAYA, TUCKER, TSAY, WILLETT, SALTZMAN, DALLAL e ROBERTS (1996) aplicaram um diário alimentar de sete dias (com pesagem das porções), um recordatório alimentar de 24 horas e dois questionários de freqüência alimentar em 10 mulheres jovens e 10 mulheres idosas. Respectivamente, as diferenças entre IE e o GET foram iguais a $-445 \pm 598 \mathrm{kcal} ;-79 \pm 884 \mathrm{kcal} ;-382 \pm$ $335 \mathrm{kcal} ;-679 \pm 311 \mathrm{kcal}$, entre as jovens. Entre as idosas, estes valores corresponderam a $-399 \pm 359 \mathrm{kcal} ;-284 \pm 359 \mathrm{kcal} ; 124 \pm 693 \mathrm{kcal} ;-282 \pm 717 \mathrm{kcal}$, respectivamente. Embora, entre as jovens, a diferença média entre a IE e o GET tenha sido menor para o recordatório de 24 horas, apenas a IE obtida pelos dois questionários de freqüência alimentar esteve correlacionada com o GET, o que indica que estes métodos tiveram melhor desempenho individualmente (percebe-se também que o desvio-padrão da IE-GET do recordatório é bem maior do que todos os outros métodos). Entre as idosas, um dos questionários de freqüência alimentar subestimou menos a IE, contudo nenhum dos métodos apresentou correlação significante com o GET. Os autores concluíram que, de fato, o diário alimentar de sete dias com pesagem das porções, antes considerado padrão-ouro, não era superior aos demais métodos. Considerando que ele é um método custoso e que 
demanda muito trabalho, tanto por parte do sujeito (para preenchê-lo) quanto por parte do pesquisador (para analisá-lo), sua utilidade torna-se questionável. Estes dados, contudo, devem ser interpretados com cautela, posto que o número de sujeitos deste estudo foi muito pequeno.

MCKEOWN, DAY, WELCH, RUNSWICK, LUBEN, MULLIGAN, MCTAGGART e BINGHAM (2001) compararam a excreção urinária de nitrogênio, calculada por seis coletas de urina obtidas em nove meses, com a ingestão relatada de nitrogênio em dois diários alimentares de sete dias e dois questionários de freqüência alimentar, aplicados no mesmo período. Foram encontrados coeficientes de correlação entre o nitrogênio excretado e relatado iguais a 0,51 (para os homens) e 0,48 (para as mulheres), quando o diário foi usado. Para os questionários de freqüência, os coeficientes variaram entre 0,13-0,12 (para os homens) e 0,10-0,20 (para as mulheres). Estes resultados indicam que o diário foi superior aos questionários, porém seu próprio desempenho também não foi satisfatório. BINGHAM, CASSIDY, COLE, WELCH, RUNSWICK, BLACK, THURNHAM, BATES, KHAW, KEY e DAY (1995) conduziram um longo estudo, no qual, durante um ano, 160 mulheres forneceram oito coletas de urina, 16 dias de diário alimentar com pesagem das porções, dois questionários de freqüência alimentar, recordatórios alimentares de 24 horas (os autores não especificam o número destes) e diários alimentares de sete dias sem pesagem das porções. Os coeficientes de correlação entre o nitrogênio urinário e o relatado foram maiores para o diário de 16 dias com pesagem das porções e menores para os recordatórios de 24 horas. Contudo, é importante ressaltar que os 16 dias de diários alimentares com pesagem de porções não foram obtidos continuamente, e sim em quatro ocasiões distintas, o que pode ter reduzido o cansaço dos participantes em registrar sua ingestão.

Com base nos estudos apresentados, não é possível estabelecer qual método de avaliação do consumo alimentar é mais válido. Pesquisadores como KAAKS et al. (2002) e KIPNIS, SUBAR, MIDTHUNE, FREEDMAN, BALLARDBARBASH, TROIANO, BINGHAM, SCHOELLER, SCHATZKIN e CARROLL (2003) constantemente criticam a validade dos questionários de freqüência alimentar, mas alguns estudos mostraram que eles obtêm estimativas mais válidas do que os recordatórios alimentares de 24 horas. Por sua vez, o estudo de SAWAYA et al. (1996), com água duplamente marcada, indicou que a validade do diário alimentar 
com pesagem de porções é baixa, ao passo que os estudos com excreção urinária de nitrogênio indicaram o oposto. Mais estudos comparativos são necessários, sendo que estes devem tentar: a) usar a água duplamente marcada; b) empregar amostras com tamanho adequado e; c) testar outros métodos de avaliação do consumo alimentar, como o diário alimentar de três dias.

\subsubsection{Fatores correlacionados ao sub-relato em nações desenvolvidas}

Em todos os estudos que investigam o sub-relato, a obesidade é apontada como o fator mais correlacionado a este fenômeno. Embora se admita que a subnotificação não ocorra exclusivamente em obesos, a maioria dos estudos coloca que os obesos sub-relatam mais (BELLISLE, 2001; PRENTICE, BLACK, COWARD, DAVIES, GOLDBERG, MURGATROYD, ASHFORD, SAWYER \& WHITEHEAD, 1986; PRENTICE, BLACK, COWARD \& COLE, 1996). Todavia, este achado não é consistentemente encontrado em todas as pesquisas (HORNER, PATTERSON, NEUHOUSER, LAMPE, BERESFORD \& PRENTICE, 2002; LISSNER, HABICHT, STRUPP, LEVITSKY, HAAS \& ROE, 1989).

Diversas explicações foram postuladas para explicar esta controvérsia. Muitos estudos não excluem sujeitos com doenças, que estejam praticando dietas restritivas ou que estejam perdendo peso. Por definição, o sub-relato é considerado o relato de IE inferior ao GET (feitos os devidos ajustes estatísticos) por indivíduos que estejam em balanço energético. O que ocorre é que, em uma dada amostra, vários indivíduos podem estar em balanço energético negativo, de tal forma que sua IE é de fato inferior ao GET, sem que isso constitua subnotificação. Parece muito intuitivo supor que pessoas obesas freqüentemente fazem dieta para controlar ou diminuir seu peso. Neste caso, a IE menor que o GET não implica sub-relato (BALLARDBARBASH, GRAUBARD, KREBS-SMITH, SCHATZKIN \& THOMPSON, 1996; BRAAM, OCKÉ, BUENO-DE-MESQUITA \& SEIDELL, 1998). Por isso, tais condições devem ser critérios de exclusão nesses estudos.

LISSNER et al. (1989) colocaram que, na maioria dos estudos nos quais se constatou que obesos sub-relatavam mais, o GET não foi de fato medido e sim estimado como um múltiplo da TMB, que também é estimada por meio de equações, que, geralmente, consideram gênero, idade, peso e altura, apenas. Entretanto, 
BLACK (2000) e FERRARI, SLIMANI, CIAMPI, TRICHOPOULOU, NASKA, LAURIA, VEGLIA, BUENO-DE-MESQUITA, OCKÉ, BRUSTAD, BRAATEN, TORMO, AMIANO, MATTISON, JOHANSSON, WELCH, DAVEY, OVERVAD, TJONNELAND, CLAVEL-CHAPELON, THIEBAUT, LINSEISEN, BOEING, HEMON e RIBOLI (2002) apontaram que as fórmulas que estimam a TMB superestimam tal variável em obesos. Este efeito aumenta artificialmente as taxas de sub-relato entre obesos. Segundo FERRARI et al. (2002), fazer correlações entre IMC e a razão IE/TMB, quando a TMB é estimada por equações, também é problemático porque ambos os termos, IMC e TMB, são uma função do peso e altura e, portanto, dividem uma fonte comum de variação. Parte da correlação estatística observada pode ser gerada simplesmente pela fonte comum de variabilidade entre os termos, e não por uma relação causal entre IMC e sub-relato. Todos estes fatores de confusão são evitados quando o GET é objetiva, precisa e acuradamente medido, o que só é possível por meio da água duplamente marcada, o que justifica seu uso neste tipo de estudo.

Alguns estudos tentaram verificar se havia correlação entre a prática de atividade física e a subnotificação. AMBLER, ELIAKIM, BRASEL, LEE, BURKE e COOPER (1998) objetivaram verificar se o aumento do GET induzido por uma intervenção controlada de atividade física seria compensado por aumento na IE, entre meninos e meninas de 15 a 17 anos. Para tanto, foram divididos em dois grupos; o grupo intervenção, que foi submetido a duas horas de atividades físicas de resistência aeróbia por dia, em cinco dias da semana; e o grupo controle, que recebia aulas de computação com a mesma duração. Foi encontrado que o grupo submetido à intervenção tinha maior GET, em relação aos controles. Não houve perda de peso em nenhum dos grupos, sugerindo, portanto, que se o grupo intervenção possuía maior GET, sua IE deve ter aumentado para compensar o maior dispêndio. Entretanto, a IE relatada não se alterou em função do treinamento. Segundo os autores, os dados sugeriram que a possibilidade de sub-relato é mais pronunciada em sujeitos em fase de transição de um estado fisiológico estável (steady state) de GET para outro. Os pesquisadores especularam que os sujeitos não estavam ainda suficientemente acostumados com seu novo consumo alimentar para poder relatá-lo acuradamente.

Entretanto, este estudo possui uma série de falhas metodológicas, como o fato de que o GET não foi medido antes da intervenção e de que os parâmetros da 
água duplamente marcada apresentaram alterações que indicavam erros de análise. Além disso, medidas que poderiam ter sido feitas em toda a amostra, como o monitoramento da freqüência cardíaca, foram só aplicadas às meninas. Sem estes dados, não é possível rejeitar a possibilidade de que o treinamento não tenha sido efetivo nos meninos. Por fim, em todas as mensurações houve muitos dados faltosos, especialmente nas informações de consumo alimentar dos meninos.

A relação entre prática de atividade física e o sub-relato também foi objeto de estudo de algumas pesquisas populacionais. KANT (2002) analisou os dados do maior levantamento de consumo alimentar norte-americano, conduzido em adultos. Ele classificou os indivíduos em tercis de acordo com a razão IE/TMB, sendo que a IE foi estimada por um recordatório alimentar de 24 horas e a TMB por equações. Os indivíduos forneceram informações sobre a freqüência com a qual eles faziam atividade física. No primeiro tercil, de menor valor de IE/TMB (isto é, de maior subrelato), foi encontrada maior proporção de indivíduos que relataram não fazer atividade física. KREBS-SMITH, GRAUBARD, KAHLE, SUBAR, CLEVELAND e BALLARD-BARBASH (2000) utilizaram os dados de outro grande levantamento norte-americano. Indivíduos com razão $\mathrm{IE} / \mathrm{TMB}$ inferior a 0,8 foram considerados sub-relatores, sendo que a TMB também foi estimada por equações, e a IE foi estimada por dois recordatórios de 24 horas. Novamente, a prática de atividade física foi quantificada em termos de freqüência. Os autores encontraram que os subrelatores praticavam atividade física menos freqüentemente do que aqueles que relatavam sua IE acuradamente.

Muito poucos estudos foram feitos nessa área, e há grande variação de desenho experimental e amostragem entre os estudos aqui apresentados, mas, de certa forma, as pesquisas de KANT (2002), KREBS-SMITH et al. (2000) contradizem os resultados encontrados por AMBLER et al. (1998).

Algumas considerações a respeito da validade dos métodos de avaliação da prática de atividade física empregados nos estudos supracitados devem ser feitas. A forma pela qual KANT (2002) e KREBS-SMITH et al. (2000) avaliaram a prática de atividade física considera apenas a freqüência com a qual a atividade física é feita, enquanto se sabe que este aspecto é somente uma das dimensões da atividade física (HASKELL \& KIERNAN, 2000). Além disso, em vez de simplesmente formularem algumas questões sobre prática de atividade física, as quais não tiveram 
sua validade e sua precisão investigadas, os autores deveriam ter usado algum destes métodos baseados no auto-relato que já foram validados e testados e que são apropriados, em termos de custo e aplicabilidade, para estudos epidemiológicos. Tendo em vista o escasso número de estudos que investigou a relação entre subrelato e atividade física e as limitações metodológicas que permeiam os trabalhos existentes, não é possível estabelecer como se comporta tal relação. Entretanto, tal pergunta é extremamente pertinente.

O comportamento envolvido no sub-relato é um processo complexo que inclui componentes perceptivos, emotivos e cognitivos ainda pouco explorados (KRETSCH, FONG \& GREEN, 1999; SMITH, 1993; SUBAR, THOMPSON, SMITH, JOBE, ZIEGLER, POTISCHMAN, SCHATZKIN, HARTMAN, SWANSON, KRUSE, HAYES, LEWIS \& HARLAN, 1995). O processo de relembrar e registrar a ingestão de alimentos requer atenção e percepção, pois depende de alguns fenômenos como o registro mental, o armazenamento e a recuperação de eventos diários (sendo que alguns destes são bastante detalhados e complexos) e o cálculo da freqüência de ocorrência de tais eventos. Outros fatores influentes incluem julgamentos morais e emocionais, que alteram a percepção do registro, e variáveis motivacionais que modificam a capacidade de colaborar com instruções (BLUNDELL, 2000). Assim, alguns estudos procuraram verificar se os indivíduos sub-relatores possuíam características psicológicas e sociais específicas.

Tradicionalmente, foi suposto que o menor nível sócio-econômico implicaria em maior dificuldade na resposta e, por isso, em maior erro, mas tal resultado foi verificado por apenas alguns estudos (KREBS-SMITH et al., 2000; POMERLEAU, OStBYE \& BRIGHT-SEE, 1999; PRICE et al. 1997). Ao mesmo tempo, é possível que aspectos psicológicos também influenciem o relato alimentar. De maneira geral, as pesquisas que se debruçaram sobre essa questão apontam que pessoas mais preocupadas com alimentação e forma física sub-relatem mais.

No estudo de JOHANSSON, SOLVOLL, BJORNEBOE e DREVON (1998), ingestões energéticas inferiores a $1,34^{\star} \mathrm{TMB}$ (taxa de metabolismo basal, calculada a partir de equações) foram consideradas fruto de sub-relato. $O$ desejo de reduzir 0 peso corporal esteve presente em $54 \%$ das mulheres com ingestão inferior a $1,14^{*} \mathrm{TMB}$, em $43 \%$ daquelas com ingestão entre $1,14-1,34^{*} \mathrm{TMB}$ e em $29 \%$ daquelas com ingestão entre $1,35-2,39^{\star}$ TMB $(p<0,001)$. NOVOTNY, RUMPLER, RIDDICK, 
HEBERT, RHODES, JUDD, BAER, MCDOWELL e BRIEFEL (2003) encontraram que se achar com peso excessivo acarretava em sub-relato de $-304 \mathrm{kcal} / \mathrm{dia}$; desejar perder ou manter o peso causava subnotificação de $-334 \mathrm{kcal} / \mathrm{dia}$ e que cada quilograma de peso considerado acima do ideal levava ao sub-relato de $-15,6$ $\mathrm{kcal} / \mathrm{dia}$. Desta forma, os dois trabalhos concluíram que questões de imagem corporal estavam correlacionadas ao sub-relato. A grande limitação destas pesquisas é que elas alegam medir problemas de imagem corporal, porém, utilizam questões que nunca foram testadas psicometricamente. Assim, como em todas as áreas de pesquisa científica, se é desejado mensurar uma característica psicológica, é preciso mensurá-la com fidedignidade e validade.

Um aspecto do comportamento alimentar que se tentou correlacionar ao sub-relato é a restrição dietética, definida por BATHALON, TUCKER, HAYS, VINKEN, GREENBERG, MCCRORY e ROBERTS (2000) como uma diminuição auto-imposta do consumo alimentar, feita de forma consciente, para manter ou perder peso. Estes mesmos autores estudaram a subnotificação em uma amostra de 60 mulheres, divididas em dois grupos; um de menor e outro de maior restrição. A IE (estimada por recordatórios alimentares, questionário de freqüência e diário de sete dias) foi comparada com o GET medido pela água duplamente marcada. Assim, a razão IE/GET média foi igual a $99 \pm 6,8 \%$ nas mulheres com baixa restrição e 89,1 \pm $5,3 \%$ naquelas com maior. Apenas nestas últimas este valor foi diferente de $100 \%$. Mesmo assim, quando se examinou esta razão em cada método de avaliação do consumo alimentar, esta diferença só permaneceu para os recordatórios alimentares. Por sua vez, ASBECK, MAST, BIERWAG, WESTENHÖFER, ACHESON e MÜLLER (2002) obtiveram correlação de $-0,32$ entre a restrição e a diferença percentual entre a IE e o GET. Neste estudo, a IE foi novamente medida pelo diário alimentar de sete dias. Para calcular o GET, foi determinado o gasto energético no repouso por calorimetria indireta e este foi multiplicado por 1,55, o qual corresponde ao fator de atividade física proposto pela FAO (Food and Agriculture Organization) para indivíduos sedentários. Em aproximadamente $8 \%$ da amostra foi também aplicada água duplamente marcada e constatou-se que a forma de cálculo do GET adotada pelo estudo o subestimava, o que, conseqüentemente, leva a subestimação da taxa de sub-relato. 
Alguns autores tentaram verificar a influência do desejo de aceitação social (social desirability) na subnotificação. Este construto foi definido como a tendência de um indivíduo fornecer a resposta mais desejada e aceita pela sociedade, independentemente dela ser verdadeira (BALLARD, CRINO \& RUBENFELD, 1988). HEBERT, CLEMOW, PBERT, OCKENE e OCKENE (1995) foram os primeiros a sugerir que pessoas com alto desejo de aceitação social provavelmente não relatam sua ingestão real, e sim a ingestão considerada ideal, que, devido à pressão social pela magreza, seria um consumo mais frugal.

De forma geral, constata-se que poucos estudos investigaram as características associadas à subnotificação. Além disso, os estudos existentes apresentam diversas falhas metodológicas que limitam seus achados. Para conseguir identificar tais características, é necessário empregar um método de avaliação do GET que obtenha estimativas individuais válidas, o que, atualmente, apenas a água duplamente marcada é capaz. Mesmo quando se emprega a água duplamente marcada, é necessário determinar sua variação intra-individual, o que foi feito por pouquíssimos estudos. Por sua vez, também é fundamental avaliar criteriosamente como as características de interesse serão mensuradas. Devem ser usados instrumentos de mensuração pertinentes, válidos e precisos.

\subsubsection{Presença do sub-relato na análise de padrões alimentares}

Uma nova forma de se avaliar a dieta, para que a mesma possa ser associada aos efeitos de saúde, é a análise de padrões alimentares. Tradicionalmente, procuram-se associações entre o risco de desenvolvimento de doenças e a ingestão de alimentos e/ou nutrientes, sendo que cada alimento ou nutriente é analisado isoladamente (LANGSETH, 1996). Porém, a dieta é algo muito complexo, que acaba sendo artificialmente reduzido e simplificado quando se analisa a ingestão isolada de cada nutriente ou alimento. Desta forma, HU (2002) e MILLEN, QUATROMONI, COPENHAFER, DEMISSIE, O'HORO e D'AGOSTINO (2001) apontaram as limitações metodológicas e conceituais desta análise reducionista.

A avaliação de padrões alimentares, por sua vez, aproveita, de forma vantajosa, a interação e a colinearidade existentes entre os alimentos ou nutrientes. Contudo, os padrões alimentares não podem ser medidos diretamente, de tal forma 
que o emprego de técnicas estatísticas se faz necessário. Atualmente, são utilizadas três formas de avaliação de padrões alimentares: análise fatorial, índices de qualidade da dieta e análise de agrupamento (cluster), sendo que esta última é a mais utilizada. $\mathrm{Na}$ análise de agrupamento, os indivíduos são aglomerados em grupos, de acordo com o seu consumo alimentar. Em cada aglomerado, alguns alimentos terão maior contribuição e, geralmente, os grupos são denominados conforme este alimento (NEWBY \& TUCKER, 2004). WIRFÄLT e JEFFERY (1997), em uma pesquisa extremamente cuidadosa, encontraram os seguintes padrões, ao analisar a dieta de adultos americanos: a) refrigerantes; b) produtos de pastelaria, c) leite desnatado; d) carne; e) carne e queijo e; f) pão branco.

Assim como nas outras formas de avaliação do consumo alimentar, há preocupação sobre a validade destes métodos. A avaliação da validade destes métodos tem sido feita de três formas: a) comparando os padrões obtidos por um método de avaliação do consumo alimentar com a ingestão nutricional obtida por outro método de avaliação do consumo alimentar; b) analisando o estado nutricional dos indivíduos de cada padrão em relação a marcadores biológicos e; c) determinando o risco de desenvolvimento de doenças em relação aos padrões obtidos (QUATROMONI, COPENHAFER, DEMISSIE, D'AGOSTINO, O'HORO, NAM \& MILLEN, 2002; MILLEN et al., 2001).

Percebe-se que há certa inconsistência em tais resultados de validações das formas de obtenção de padrões alimentares. Primeiramente, não se sabe ao certo qual é a melhor forma de conduzir tal validação. Aparentemente, na possível ânsia de se obter uma nova forma de análise da dieta, os pesquisadores têm desconsiderado as lições aprendidas com a aplicação de marcadores biológicos para validação do relato de componentes dietéticos isolados. Há um grande corpo de literatura, apresentado exaustivamente nos tópicos anteriores, que indica que os métodos de avaliação do consumo alimentar subestimam o consumo energético, e em menor escala também a ingestão protéica, e que, de acordo com os resultados dos marcadores de recuperação, eles não podem ser tidos como válidos. A análise de padrão alimentar deriva destes mesmos métodos de baixa validade, o que parece não ser considerado nos estudos que a utilizam.

Pode-se citar como exemplo o fato de que no estudo de AKIN, GUILKEY, POPKIN e FANELLI (1986), em nenhum dos agrupamentos encontrados, a IE atingiu 
o consumo energético preconizado pela RDA (Recommended Dietary Allowances), sendo que, entre os homens a IE atingiu aproximadamente $85 \%$ e, entre as mulheres, a IE preencheu apenas $65 \%$ da RDA. Estes dados indicavam que poderia haver sub-relato da IE, mas os autores não consideraram esta hipótese. O mesmo foi verificado nos estudos de QUATROMONI et al. (2002) e MILLEN et al. (2001), nos quais os sujeitos dos agrupamentos ditos "mais saudáveis" apresentaram IE extremamente baixa, porém em nenhum momento se levantou a hipótese de que havia sub-relato e que este poderia afetar os resultados.

A especificidade de alimentos e nutrientes no sub-relato também deve ser considerada uma possível fonte de erro na análise de padrões alimentares. Os estudos disponíveis parecem apontar para a existência de especificidade de alimentos e nutrientes dentro do sub-relato. Especula-se que há uma tendência de maior subnotificação de alimentos vistos como "não saudáveis" e "engordativos" (HEITMANN et al., 2000; HEITMANN \& LISSNER, 1995). O fato de que o sub-relato provavelmente não é homogêneo para todos os alimentos, de tal forma que o ajuste pela IE não consegue corrigi-lo, afeta todas as inferências que se baseiam no consumo alimentar (BELLACH \& KOHLMEIER, 1998), inclusive a obtenção de padrões alimentares.

Além disso, também é clarividente que a comparação de um método de avaliação do consumo alimentar teste com um outro método de referência não é capaz de detectar tal erro sistemático, pois ele está presente em todos os métodos, de forma não aleatória. Sabendo isso, questiona-se porque tal abordagem tem sido utilizada para validar a análise de padrões alimentares. Estudos como o de QUATROMONI et al. (2002) e MILLEN et al. (2001) têm comparado os padrões obtidos por métodos distintos ou também correlacionando o padrão obtido por um método com a ingestão nutricional estimada por outro. Entretanto, já foi demonstrado, matematica e empiricamente, que todos os métodos de avaliação do consumo alimentar possuem erros correlacionados e dependentes da ingestão real e que, portanto, tal comparação não atende os pressupostos necessários para ser considerada uma validação. Assim, torna-se necessário integrar esta nova abordagem com a questão do sub-relato da IE e dos marcadores de recuperação. Determinar a proporção de sub-relatores, detectada de forma confiável, entre os padrões alimentares obtidos por qualquer uma das formas de análise parece ser de 
grande valia. O presente estudo também tem como objetivo realizar tal avaliação. Como as pessoas tendem a sub-relatar mais intensamente o consumo de alimentos vistos como "não-saudáveis" ou mais "engordativos", nossa hipótese é de que o subrelato seja mais intenso nos agrupamentos de padrão alimentar mais saudável.

2.3.2 Ocorrência e magnitude do sub-relato da ingestão energética em nações em desenvolvimento

Pode-se perceber que existe um recente corpo de literatura sobre a subnotificação do consumo energético, embora muitos aspectos deste fenômeno permaneçam inexplorados ou contraditórios, em função das limitações metodológicas dos estudos. Em contraste com este conjunto de evidências estabelecidas em nações desenvolvidas, raras foram as pesquisas que analisaram o sub-relato em países em desenvolvimento, sendo que nenhuma empregou a água duplamente marcada.

Estes isótopos foram aplicados, algumas vezes, nestes países, porém nunca foram usados para o estudo do sub-relato. Em 1998, COWARD revisou os estudos com água duplamente marcada e encontrou que, de mais de 250 estudos com esta técnica conduzidos no mundo, apenas doze haviam sido em países em desenvolvimento. Certamente, este número já deve ter aumentado, porém as críticas que COWARD fez aos estudos existentes permanecem válidas. Primeiramente, o autor apontou que os estudos utilizaram amostras muito pequenas, que não eram compostas por pessoas "típicas" de cada país e sim por grupos muito específicos, o que dificulta a comparação com dados de países desenvolvidos. A maioria destes trabalhos visava avaliar o balanço energético nestes indivíduos menos favorecidos. Entretanto, poucos estudos também mensuraram a TMB e/ou o consumo alimentar, componentes fundamentais do balanço energético. COWARD (1998) afirmou que, nestas pesquisas, a água duplamente marcada tornava-se mais um fim do que um meio, o que é extremamente frustrante, pois ela é uma ferramenta promissora que poderia ajudar a responder questões nutricionais importantes nestes países. Finalmente, o autor colocou que a prioridade dos estudos nutricionais das nações em desenvolvimento deveria ser a determinação da validade dos métodos de avaliação 
do consumo alimentar, por meio da água duplamente marcada, já que, nos países desenvolvidos, foi demonstrado sério erro sistemático nos mesmos.

HARRISON, GALAL, IBRAHIM, KHORSHID, STORMER, LESLIE e SALEH (2000) compararam o sub-relato entre mulheres americanas e egípcias, com idades entre 18 e 60 anos. Os dados de consumo alimentar, obtidos por recordatórios alimentares de 24 horas em um estudo populacional em cada país, foram convertidos em valores de IE, com base nos mesmos bancos de dados de composição dos alimentos. A TMB foi estimada por equações e o ponto de corte para o sub-relato foi estabelecido como IE/TMB <0,92. Os valores médios de IE/TMB foram iguais a 1,56 $\pm 0,55$, entre as egípcias, e 1,13 $\pm 0,50$, entre as americanas. Apenas $10 \%$ das egípcias foram consideradas sub-relatoras, sendo que o mesmo ocorreu para $35 \%$ das americanas. A obesidade esteve correlacionada negativamente à razão IE/TMB nas duas amostras, porém esta correlação foi muito mais forte entre as americanas. Algumas diferenças metodológicas podem ajudar a explicar este fato. Embora o método de avaliação do consumo alimentar tenha sido o mesmo nos dois países, as técnicas de aplicação foram diferentes. Nos Estados Unidos, foi utilizada a técnica de três passos, que não obteve resultados válidos em estudos anteriores (CONWAY et al., 2003; 2004). No Egito, por sua vez, antes de fornecer os dados sobre o seu próprio consumo no dia anterior, a mulher entrevistada tinha de recordar o consumo doméstico no dia anterior. Segundo os autores, no Egito os papéis de cada gênero são muito bem delimitados, e um dos papéis femininos mais importantes é a compra, armazenamento, gerenciamento e preparo dos alimentos que serão consumidos pela sua família. Assim, recordar o que foi preparado para a sua família no dia anterior ajudaria recuperar as informações do seu próprio consumo, o que foi verificado empiricamente que realmente funciona. Portanto, embora os dois levantamentos tenham usado o mesmo método de avaliação do consumo alimentar, o estudo egípcio empregou uma técnica de aplicação comprovadamente eficiente, o que não pôde ser feito no estudo americano. O ponto de corte para o sub-relato também é controverso, posto que é muito menor do que o geralmente usado nos outros estudos, embora os autores justifiquem seu uso com base nos cálculos propostos por GOLDBERG et al. (1991). Mesmo tendo em vista estas limitações metodológicas, deve-se indagar porque o sub-relato foi tão inferior entre as egípcias. A maior familiaridade das egípcias com os alimentos, bem 
como o reduzido número de lanches e refeições fora de casa realizadas por esta população podem ter contribuído para o menor sub-relato. Os autores também colocaram que, embora a prevalência de excesso de peso tenha sido maior na amostra egípcia, a pressão social pela magreza está apenas começando a despontar em tal sociedade. Na sociedade americana, provavelmente, uma mulher que ingere grandes quantidades de alimentos em público é mal-vista, ao contrário da sociedade egípcia, na qual a fartura ainda é valorizada.

Em concordância com os achados citados acima, MENNEN, JACKSON, CADE, MBANYA, LAFAY, SHARMA, WALKER, CHUNGONG, WILKS, BLAKAU, FORRESTER e CRUICKSSHANK (2000) propuseram que fatores culturais devem afetar o sub-relato. O objetivo do seu estudo, portanto, foi verificar como a subnotificação variava em quatro populações de adultos com origem africana, que viviam em uma destas regiões: meio rural na República dos Camarões, meio urbano na República dos Camarões, Jamaica (regiões urbanas e rurais foram analisadas em conjunto) e Reino Unido. Em cada região, foi aplicado um questionário de freqüência alimentar específico para a população de estudo. A TMB foi estimada por equações e o sub-relato foi definido como IE/TMB $<1,15$. A maior razão IE/TMB média (ajustada pela idade, IMC e educação) foi encontrada entre as mulheres do meio rural de Camarões $(2,93)$ e a menor entre os homens do Reino Unido $(1,58)$. Entre as mulheres, as porcentagens de indivíduos sub-relatores foram: 6\% (meio rural de Camarões); 4\% (meio urbano de Camarões); 24\% (Jamaica) e 28\% (Reino Unido). Os autores afirmaram que, no meio rural de Camarões, a diversidade da alimentação é menor, o que pode ter facilitado o relato. Além disso, muitos sujeitos desta região eram fazendeiros, que plantavam e preparavam seus próprios alimentos e, por isso, tinham grande familiaridade com os mesmos. Entretanto, estas condições não existiam no meio urbano de Camarões, onde o sub-relato foi também muito baixo, 0 que sugere outras razões para a subnotificação. Foi sugerido que a influência cultural ocidental deveria seguir uma linha crescente coincidente com a linha crescente do sub-relato: menor nos meios rural e urbano da República dos Camarões, maior na Jamaica e muito maior no Reino Unido. Esta influência cultural se traduziria pelo conjunto das seguintes concepções: padrão magro de beleza, abundância de alimentos, maior restrição alimentar, maior conhecimento sobre as relações entre 
dieta e saúde. Entretanto, estas são apenas especulações, posto que nenhuma dessas variáveis foi, de fato, mensurada.

MENDEZ, WYNTER, WILKS e FORRESTER (2004) conduziram um estudo para avaliar os preditores do sub-relato em adultos jamaicanos e, também, para avaliar se a subnotificação era específica para alguns alimentos. Foi aplicado um questionário de freqüência alimentar a 351 homens e 539 mulheres, que viviam em um subúrbio próximo à capital da Jamaica. A TMB foi estimada por fórmulas e estabeleceu-se como ponto de corte para o sub-relato razões IE/TMB inferiores a 1,35. Cerca de $22 \%$ dos homens e $39 \%$ das mulheres foram considerados subrelatores. Entre as mulheres, os fatores associados ao sub-relato foram: ter obesidade, ter mais de 45 anos e fazer dieta restritiva. Entre os homens, o único preditor significante foi possuir sobrepeso ou obesidade. Estes dados mostram que este país possui um padrão de sub-relato semelhante àquele encontrado nas nações desenvolvidas, isto é, de alta magnitude e correlacionado ao excesso de peso. Os autores sugeriram que o sub-relato deve ter aumentado ao longo dos últimos anos em países em desenvolvimento, conforme a prevalência de obesidade aumentou e as mensagens sobre nutrição e excesso de peso se disseminaram. Infelizmente, nenhum estudo analisou as tendências seculares de sub-relato nestas populações, de tal forma que esta hipótese nunca foi testada. É curioso observar que, embora muitos estudos especulem que maiores informações sobre nutrição sejam responsáveis pelo sub-relato, nenhum deles, inclusive entre aqueles conduzidos em nações desenvolvidas, testou esta hipótese de forma quantitativa.

No Brasil, poucos estudos avaliaram a validade dos métodos de avaliação do consumo alimentar. LEAL e BITTENCOURT (1997) afirmaram que este é um grande empecilho para a utilização de dados de consumo alimentar em políticas públicas de saúde e nutrição. Foram levantados sete estudos de validação, sendo que quatro deles compararam os métodos que estavam sendo testados (questionários de freqüência alimentar nos estudos de CARDOSO, KIDA, TOMITA \& STOCCO, 2001; SALVO \& GIMENO, 2002 e; SLATER, PHILIPPI, FISBERG \& LATORRE, 2003 e recordatórios alimentares de 24 horas no trabalho de TRIGO, 1993) com métodos considerados de referência (diários alimentares, pesagem direta dos alimentos e recordatórios alimentares de 24 horas). Esta revisão, entretanto, enfatiza a necessidade de avanço nas metodologias de validação de métodos de 
avaliação do consumo alimentar, isto é, de se passar a validar tais métodos com base em critérios mais objetivos, da mesma forma como é feito nas nações desenvolvidas. Assim, serão discutidos aqui os trabalhos que se inserem nesta perspectiva.

SICHIERI e EVERHART (1998) conduziram estudo pioneiro no Brasil, no qual validaram um questionário de freqüência alimentar desenvolvido especificamente para a população brasileira contra o gasto energético (estimado pelas equações que calculavam a TMB e fatores de atividade da Organização Mundial de Saúde), em uma amostra de 91 sujeitos. A razão IE/TMB média variou entre 1,77 \pm 0,77 e 1,99 \pm 0,89, para as mulheres, e entre 1,67 $\pm 0,67$ e 1,79 0,64, para os homens, conforme a faixa etária. Aparentemente, estes dados parecem indicar que os dados de consumo energético eram válidos. Contudo, como foi apontado por LIVINGSTONE e BLACK (2003), além desta estimativa de uma média grupal, é preciso investigar a concordância entre as medidas de consumo e dispêndio energéticos em nível individual, por meio de correlações ou pelo gráfico de Bland e Altman, o que não foi feito neste estudo. Este questionário foi então utilizado por SICHIERI (1998) em um estudo epidemiológico conduzido no Rio de Janeiro, que contava com uma amostra de 3.539 sujeitos. Neste, a autora comparou o consumo de energia ao GET, estimado por fórmulas. Novamente, quando se observam as médias grupais, a IE excede o GET, principalmente entre as mulheres. Quando estes dados foram tratados de forma individual, constatou-se que entre, aproximadamente, 37 e $16 \%$ das mulheres e entre 36 e $24 \%$ dos homens consumiam menos energia do que o recomendado. A maior parte dos indivíduos com consumo abaixo do recomendado se encontrava em classes sociais mais pobres, mas este déficit foi observado em todas as classes. Maior proporção de sujeitos com consumo inferior ao GET também foi encontrada nos indivíduos com IMC acima de $25 \mathrm{~kg} / \mathrm{m}^{2}$. SICHIERI (1998) afirmou que GET de pessoas com excesso de peso pode ser superestimado quando se usam equações para calculá-lo, porém não afastou a possibilidade de haver uma discrepância, provavelmente causada pelo sub-relato. Este impasse só pode ser resolvido com o uso de métodos que de fato meçam o GET de forma precisa e válida (inclusive no nível individual). O único método disponível atualmente que possui estas características é a água duplamente 
marcada, que nunca foi aplicada em países em desenvolvimento com essa finalidade.

Em 2001, nosso grupo de pesquisa também conduziu um trabalho, no qual usamos equações para estimar a TMB de 52 mulheres brasileiras que participavam de um curso de atividade física ministrado na Escola de Educação Física e Esporte, da Universidade de São Paulo (SCAGLIUSI, FRANCISCHI, PEREIRA, POLACOW, OLIVEIRA, FREITAS, BUENO, VIEIRA, KLOPFER, PEREIRA \& LANCHA JR, 2001). A IE foi estimada por meio de diários alimentares de sete dias e, de acordo com os cálculos propostos por GOLDBERG et al. (1991), estabeleceu-se como ponto de corte para o sub-relato IE/TMB inferior a 1,48. A razão IE/TMB média foi igual a 1,22 $\pm 0,38$, sendo que entre as eutróficas ela foi igual a $1,27 \pm 0,35$, entre as mulheres com sobrepeso verificou-se o valor de 1,22 \pm 0,33 e entre as obesas valor de 1,17 \pm 0,46 . Esta diferença entre os grupos não foi estatisticamente significante. Especulamos que o pequeno número da amostra e a grande variabilidade encontrada entre as obesas poderiam ter contribuído para esta ausência de significância. Setenta e cinco por cento da amostra apresentou IE/TMB inferior a 1,48 . Sabe-se que este ponto de corte foi calculado para detectar a subnotificação de um grupo, e que sua capacidade para detectar indivíduos sub-relatores é pequena. Assim, também observamos quantos sujeitos possuíam IE inferior à TMB: esta proporção foi de $32,7 \%$. A chance de estes dezessete indivíduos serem sub-relatores é alta, até porque houve monitoramento do peso corporal até quatro semanas após o diário e não houve perda de peso. Este estudo, portanto, gerou resultados diferentes dos trabalhos de SICHIERI e EVERHART (1998), que, ao menos em nível de grupo, obtiveram médias de IE/TMB válidas. Sugerimos, portanto, que a subnotificação da ingestão energética poderia ser um viés importante nos estudos brasileiros e que ela deveria ser investigada mais profundamente. Para que isto pudesse se feito, era necessário empregar um método que de fato mensurasse o GET, em vez de estimálo, como fazem as fórmulas. Também era preciso investigar como outros fatores, além do excesso de peso, podiam influenciar o sub-relato.

Assim, conduzimos um estudo com uma outra amostra de 35 mulheres ingressantes neste curso de atividade física, na qual o monitoramento da freqüência cardíaca foi utilizado para determinar o GET e a calorimetria indireta foi usada para determinar a TMB (SCAGLIUSI, POLACOW, ARTIOLI, BENATTI \& LANCHA JR, 
2003). Quarenta e nove por cento dos sujeitos relataram IE inferior ao GET e $14 \%$ relataram IE menor do que a TMB. A razão IE/GET da amostra foi igual a 0,96 \pm 0,30 , enquanto que entre as eutróficas este valor foi igual a $0,93 \pm 0,20$, entre as mulheres com sobrepeso obteve-se 1,04 $\pm 0,40$ e entre as obesas obteve-se 0,89 \pm 0,20 (sem diferença estatisticamente significante). Entre os sub-relatores (sujeitos com IE/GET < 1), a IE foi subnotificada, em média, por $21 \%$. Observamos que as eutróficas que sub-relatavam possuíam menor grau de escolaridade do que as eutróficas que não sub-relatavam. Quando diversas variáveis psicossociais foram correlacionadas com a razão IE/GET, encontramos correlação negativa entre 0 desejo de aceitação social e a razão $(r=-0,33, p=0,04)$.

Estes resultados confirmaram a hipótese de que o sub-relato pode ser um erro importante em estudos nacionais, assim como foi constatado nos trabalhos internacionais. Dado o impacto que o sub-relato pode causar nas avaliações de consumo alimentar, os resultados e conclusões dos estudos que se baseiam nelas podem estar seriamente comprometidos. Assim, parece extremamente pertinente a observação feita por COWARD em 1998, de que se deve avaliar, de forma externa e independente, a validade dos métodos de avaliação do consumo alimentar, em nações em desenvolvimento, antes que eles sejam usados em pesquisas de nutrição humana. Sabendo o erro inerente a tais métodos, poder-se-á interpretar os resultados destas pesquisas de forma muito mais cautelosa.

Entretanto, algumas considerações sobre o nosso estudo de 2003 devem ser feitas, já que ele apresenta algumas limitações. A amostra empregada foi pequena, especialmente quando se tem em vista o grande número de variáveis que foram analisadas. Certamente, o $\mathrm{n}$ amostral limitou o poder estatístico do estudo. Além disso, para algumas variáveis (como a escolaridade), a amplitude do intervalo de variação foi pequena, o que pode ter contribuído para a ausência de significância. Também pode se considerar que esta amostra não era aleatória, pelo contrário, ela era composta por mulheres que desejavam perder peso, que já haviam feito inúmeras dietas e, em função disso, se inscreveram para um curso de atividade física. A principal limitação deste estudo, entretanto, se refere ao método pelo o qual - GET foi determinado. O uso do monitoramento da freqüência cardíaca é um avanço em relação ao uso de fórmulas e fatores de atividade física, porém ele não é o método mais adequado para o objetivo que foi utilizado. Como já foi discutido, este 
método não obtém estimativas individuais de GET válidas. Ele seria apropriado para detectar o sub-relato de uma média grupal, porém ele não tem um bom desempenho ao identificar indivíduos sub-relatores. Grande parte dos nossos resultados se baseou em comparações entre sub-relatores e não sub-relatores, mas o método utilizado para identificar estes indivíduos pode não ter sido adequado. Além disso, neste trabalho o sub-relato foi definido como IE/GET $<1$, quando, atualmente, se sabe que a concordância absoluta entre a IE e o GET é improvável, e que este ponto de corte deve ser definido considerando-se os coeficientes de variação intraindividual destas medidas (BLACK \& COLE, 2000).

Em conjunto, os estudos apresentados neste sub-item da revisão mostram que não se pode afirmar que há um padrão de sub-relato nas nações em desenvolvimento. Pode-se dizer que há um mosaico de situações, tanto pelo número escasso de estudos conduzidos, quanto pelas grandes diferenças que existem entre os países estudados, e até mesmo dentro de cada país. Analisar as taxas de subrelato em diversos países pode não ser tão frutífero se não são analisadas as condições de cada um desses países. Em muitos dos trabalhos discutidos, supõe-se que baixas taxas de subnotificação em países menos desenvolvidos devem-se à pequena presença de condições "ocidentalizadas", como preocupação com corpo, saúde, nutrição e principalmente, padrões estéticos que associam beleza à magreza. Entretanto, apenas um estudo mediu indicativos destas condições (SCAGLIUSI et al., 2003).

Mesmo em nações desenvolvidas, nas quais diversos estudos acerca da subnotificação da IE foram conduzidos, várias questões permanecem inexploradas. A influência do conhecimento nutricional sobre o sub-relato, por exemplo, nunca foi investigada, embora muitos autores tenham levantado esta hipótese. A própria influência da atividade física permanece incerta devido às limitações metodológicas dos estudos que tentaram investigar esta relação. Percebe-se claramente que há maior necessidade de quantificar e entender 0 sub-relato nas nações em desenvolvimento, em função da escassez destes dados, mas estes estudos não devem tentar apenas replicar o que foi pesquisado nos países desenvolvidos, e sim fornecer evidências que contribuam para o avanço do conhecimento na área.

Além disso, ao revisar estudos conduzidos em nações desenvolvidas, constatou-se que, geralmente, quando se tenta analisar as características 
associadas ao sub-relato, apenas um método de avaliação do consumo alimentar é estudado. Porém, estudos como o de SUBAR et al. (2003) mostraram que apenas uma pequena parcela de pessoas sub-relata simultaneamente quando são aplicados diversos métodos de inquérito alimentar. Assim, é relevante estudar quais são as características associadas ao sub-relato em cada método de avaliação do consumo alimentar. Da mesma forma, também é importante pesquisar quais são as características das pessoas que subnotificam em qualquer método de inquérito alimentar. Assim, nossa hipótese é de que o sub-relato é extremamente presente em diferentes métodos de avaliação do consumo alimentar, quando aplicados à população brasileira, que o mesmo se correlaciona com diversas características físicas e psicossociais (como a obesidade) e que ele é mais presente entre aqueles sujeitos que relatam um padrão alimentar mais frugal ou "saudável". 
- Comparar a validade das estimativas de ingestão energética de um questionário de freqüência alimentar, três recordatórios alimentares e um diário alimentar de três dias, em relação ao gasto energético total, medido pela água duplamente marcada.

- Determinar a influência da prática de atividade física, do índice de massa corporal e de fatores psicossociais na acurácia do relato da ingestão energética.

- Comparar as taxas de sub-relato entre agrupamentos de padrões alimentares. 


\section{CASUÍSTICA E MÉTODOS}

\subsection{Local de estudo}

Esta pesquisa foi desenvolvida nas dependências do Laboratório de Nutrição e Metabolismo Aplicados à Atividade Motora (Escola de Educação Física e Esporte - EEFE, Universidade de São Paulo) e do Laboratório de Metabolismo do Exercício e Nutrição (Centro de Práticas Esportivas, Universidade de São Paulo).

A análise isotópica da água duplamente marcada, por espectrometria de massa, foi conduzida no Laboratório de Espectrometria de Massa (Faculdade de Medicina de Ribeirão Preto, Universidade de São Paulo). Esse laboratório é certificado pela International Agency of Atomic Energy, o que garante a fidedignidade dos seus resultados (SCHOELLER, 2007). Os procedimentos foram supervisionados pelo Prof. Dr. Eduardo Ferrioli, que conta com ampla experiência nesta técnica.

$O$ protocolo foi aprovado pelo comitê de ética da EEFE. O termo de consentimento livre e esclarecido encontra-se no ANEXO I.

\subsection{População de estudo}

A amostra foi composta por sessenta e cinco mulheres pertencentes à comunidade da Universidade de São Paulo e da Universidade São Judas Tadeu, ambas situadas na cidade de São Paulo. Nenhum sujeito desistiu de participar do estudo. Os sujeitos eram estudantes, funcionárias ou freqüentadoras dos cursos livres oferecidos pelas universidades. Foi distribuído, pessoalmente ou por e-mail, um convite para participação no estudo, no qual eram apresentados os objetivos, procedimentos, riscos e benefícios da pesquisa. Além disso, foram afixados cartazes nesses locais e os pesquisadores compareceram às salas de aula para convidar os alunos. Aqueles indivíduos que desejaram participar responderam a um questionário, cujas respostas serviram para verificar se eles preenchiam os critérios de inclusão.

Os critérios de inclusão na amostra estão listados abaixo:

- Ser do gênero feminino.

- Possuir entre 18 e 59 anos. 
- Possuir IMC entre 18,5 e $39,9 \mathrm{~kg} / \mathrm{m}^{2}$.

- Ser alfabetizada.

Os critérios de exclusão estão listados abaixo:

- Estar realizando dietas restritivas.

- Estar perdendo peso.

- Ter flutuações de peso corporal maiores do que $5 \mathrm{~kg}$ no último ano.

- Relatar possuir doenças que causem alterações no metabolismo energético, como diabetes mellitus, AIDS, doença pulmonar obstrutiva crônica, cardiopatias, nefropatias, anorexia nervosa, bulimia nervosa etc.

- Consumir cigarros diariamente.

- Consumir remédios que possam causar alterações metabólicas e absortivas, como diuréticos, anfetaminas, hormônios tireoidianos, topiramato, orlistat etc.

Todos os sujeitos receberam esclarecimentos orais e escritos acerca da natureza do estudo e eram livres para abandoná-lo a qualquer momento, sem que isso thes acarretasse ônus de qualquer espécie. As voluntárias assinaram o Termo de Consentimento Livre e Esclarecido (ANEXO I) antes de ingressarem no estudo. Os sujeitos também se beneficiaram em participar deste estudo, pois receberam os resultados de todas as avaliações que foram submetidos, juntamente com orientações sobre como se alimentar de forma saudável, adaptadas às suas necessidades.

\subsection{Desenho do estudo}

Cada sujeito participou do estudo por um mês, período denominado "módulo", no qual todas as avaliações eram realizadas. O QUADRO 2 descreve as avaliações realizadas em cada semana do módulo. Os módulos não foram conduzidos nos meses de dezembro, janeiro e fevereiro, pois, devido às altas temperaturas, poderia ocorrer maior fracionamento dos isótopos usados na técnica da água duplamente marcada, ocasionando discrepância nos resultados. Cinco sujeitos $(7,7 \%$ da amostra) participaram do estudo de reteste, no qual a água duplamente marcada foi repetida (um mês após a aplicação inicial), para que se 
pudesse calcular seu coeficiente de variação intra-individual. Esta segunda aplicação foi feita nos mesmos dias da primeira, porém no mês subseqüente.

QUADRO 2 - Descrição das avaliações conduzidas durante o módulo de estudo.

\begin{tabular}{|l|c|c|c|c|c|c|c|c|}
\hline \multirow{3}{*}{ Avaliações } & \multicolumn{7}{|c|}{ SEMANAS } \\
\cline { 2 - 9 } & \multicolumn{1}{|c|}{$\mathbf{1}$} & \multicolumn{5}{|c|}{$\mathbf{2}$} & $\mathbf{3}$ \\
\hline & Quar. & Seg. & Ter. & Quin. & Sex. & Sáb. & Quar. \\
\hline \hline Antropometria & $\mathrm{X}$ & & & & & & $\mathrm{X}$ \\
\hline Dobras cutâneas & $\mathrm{X}$ & & & & & & \\
\hline Questionário de atividade física & $\mathrm{X}$ & & & & & & \\
\hline Questionários psicossociais & $\mathrm{X}$ & & & & & & \\
\hline Recordatório alimentar de 24 horas & $\mathrm{X}$ & $\mathrm{X}$ & & & & & $\mathrm{X}$ \\
\hline Administração de ADM & & $\mathrm{X}$ & & & & & \\
\hline Coleta de urina no laboratório & & $\mathrm{X}$ & & & & & $\mathrm{X}$ \\
\hline Coleta de sangue & & $\mathrm{X}$ & & & & & \\
\hline Treinamento para preencher o diário alimentar & & $\mathrm{X}$ & & & & & \\
\hline Coleta de urina no domić́lio & & & $\mathrm{X}$ & & $\mathrm{X}$ & & \\
\hline Preenchimento do diário alimentar & & & & $\mathrm{X}$ & $\mathrm{X}$ & $\mathrm{X}$ & \\
\hline Questionário de freqüência alimentar & & & & & & & $\mathrm{X}$ \\
\hline
\end{tabular}

$\mathrm{ADM}$ = água duplamente marcada; Quar. = quarta-feira; Seg. = segunda-feira; Ter. = terçafeira; Quin. = quinta-feira; Sex. = sexta-feira; Sáb. = sábado

\subsection{Avaliação antropométrica e da composição corporal}

Conforme descrito no QUADRO 2, os sujeitos foram submetidos à avaliação antropométrica na primeira e na terceira semana do módulo, e à avaliação da composição corporal na primeira. Para realizar essas avaliações, os sujeitos estavam em jejum de dez horas. A avaliação da composição corporal foi realizada por meio do protocolo de dobras cutâneas, estabelecido por GUEDES (1994) para mulheres brasileiras. Esse protocolo utiliza as dobras supra-íliaca, subescapular e da coxa. As mensurações foram feitas por bacharéis em Educação Física ou Esporte, devidamente treinados, e eram realizadas em triplicata, no lado direito do corpo. A densidade corporal foi calculada segundo GUEDES (1994) e a porcentagem de gordura corporal segundo SIRI (1961).

Os sujeitos foram pesados em balança digital (trajando peças íntimas) e tiveram suas estaturas medidas em um estadiômetro de prancha, com suas cabeças 
alinhadas segundo o plano de Frankfort, conforme descrito por FRISANCHO (1999). Os dados de peso corporal e altura, obtidos na primeira semana, foram utilizados para calcular o Índice de Massa Corporal - IMC (QUÉTELET, 1870, apud ANJOS, 1992). Sujeitos com IMC entre 18,5 e $24,9 \mathrm{~kg} / \mathrm{m}^{2}$ foram considerados eutróficos, aqueles com IMC entre 25,0 e $29,9 \mathrm{~kg} / \mathrm{m}^{2}$ foram considerados com sobrepeso e os sujeitos com IMC maior ou igual a $30,0 \mathrm{~kg} / \mathrm{m}^{2}$ foram considerados obesos (WHO, 1997).

Os dados finais de peso corporal foram comparados aos iniciais, para constatar se houve variação de peso ao longo do estudo.

\subsection{Avaliação da prática de atividade física}

A prática habitual de atividade física foi analisada pelo Questionário de Baecke, desenvolvido para uso em estudos epidemiológicos (BAECKE, BUREMA \& FRIJTERS, 1982) e traduzido para a língua portuguesa por FLORINDO e LATORRE (2003). Este instrumento compreende 16 questões sobre atividade física ocupacional, prática de esportes no período de descanso e prática de outras atividades físicas (com exclusão das esportivas) durante este mesmo período. A maior parte das perguntas indaga sobre a freqüência e duração de cada atividade, com exceção daquelas relacionadas à prática esportiva que, além disso, também questionam qual atividade foi realizada e a intensidade. A validade desse questionário foi comprovada por BAECKE et al. (1982) e PHILIPPAERTS, WESTERTERP e LEFEVRE (1999). FLORINDO e LATORRE (2003) traduziram este questionário à língua portuguesa e encontraram que a versão traduzida era válida $\mathrm{e}$ precisa.

\subsection{Avaliação das características psicossociais}

As seguintes variáveis foram mensuradas, a fim de determinar se elas influenciam o sub-relato: escolaridade, renda, compulsão alimentar, insatisfação corporal, restrição dietética, conhecimento nutricional e desejo de aceitação social.

Para avaliação da escolaridade, os sujeitos escolheram entre as opções apresentadas, que variavam de ensino fundamental incompleto a pós-graduação 
completa. Posteriormente, essas faixas foram transformadas pelos pesquisadores em anos de estudo. Foram indagados o número de pessoas residentes no domicílio do sujeito e a renda total de todos os moradores do mesmo. Para determinar a renda per capita, a renda total foi dividida pelo número de moradores. Para caracterizar melhor o nível sócio-econômico dos sujeitos, os seguintes parâmetros foram questionados: a) o tipo de residência (albergue/rua; barraco; cortiço; casa; apartamento, outros); b) número de dormitórios da residência; c) tipo de escoadouro dos banheiros do domicílio (rede geral; fossa séptica; fossa rudimentar; vala; rio/lago/mar; outros) e; d) destino do lixo da residência (coleta pelo serviço de limpeza; caçambas do serviço de limpeza; queimado/enterrado; jogado em terreno baldio ou logradouro ou rio/lago/mar; outros). Essas informações não foram correlacionadas à acurácia do relato; as mesmas foram coletadas apenas para uma melhor caracterização da amostra.

A compulsão alimentar é definida como um episódio no qual ocorre consumo de uma quantidade de alimentos que uma outra pessoa, semelhante ao sujeito, não conseguiria ingerir, em pouco espaço de tempo e sensação de total falta de controle (APA, 1994). A Escala de Compulsão Alimentar (Binge Eating Scale) foi elaborada por GORMALLY, BLACK, DASTON e RARDIN (1982), para medir a gravidade de tais episódios. Esta escala é composta por 16 grupos de quatro afirmações, dentro das quais o sujeito deve escolher a que mais se aproxima de seu comportamento. Ela foi comparada a outros instrumentos semelhantes e obteve desempenho satisfatório, apresentando sensibilidade de 84,8\% (GLADIS, WADDEN, FOSTER, VOGT \& WINGATE, 1998; GREENO, MARCUS \& WING, 1995; RICCA, MANNUCCI, MORETTI, DI BERNARDO, ZUCCHI, CABRAS \& ROTELLA, 2000). Esta escala foi traduzida para a língua portuguesa por FREITAS, LOPES, COUTINHO e APPOLINARIO (2001) e validada por FREITAS, LOPES, APPOLINÁRIO e COUTINHO (2006).

A insatisfação corporal foi analisada a partir da Escala de Figuras de Stunkard (Stunkard's Figure Rating Scale - STUNKARD, SORENSEN \& SCHLUSINGER, 1983), que consta de figuras de silhuetas que variam de magras a obesas. A avaliada escolhe duas figuras que representem melhor como ela se vê e como é o tamanho corporal ideal. Para proceder à análise, cada figura recebe uma pontuação que varia de zero para a mais magra e nove para a mais obesa. Quanto 
maior é a pontuação da figura que representa como a pessoa se vê, mais a pessoa se vê como obesa. É calculado o escore da discrepância entre o tamanho atual e o ideal - que corresponde à pontuação da imagem do indivíduo menos a pontuação da imagem ideal. Maiores pontuações em tais escores refletem maior insatisfação. Essa escala apresenta bons índices de validade e precisão, tanto na versão original quanto na versão adaptada para mulheres brasileiras (STUNKARD et al., 1983; SCAGLIUSI, ALVARENGA, POLACOW, CORDÁS, DE OLIVEIRA QUEIROZ, COELHO, PHILIPPI \& LANCHA JR, 2006a).

A escala escolhida para mensuração do conhecimento nutricional foi aquela desenvolvida por HARNACK, BLOCK, SUBAR, LANE e BRAND (1997), para uso em estudo epidemiológico sobre o câncer (National Health Interview Survey Cancer Epidemiology). Este instrumento foi desenvolvido para testar se o conhecimento nutricional sobre prevenção de câncer correlacionava-se com práticas alimentares que realmente prevenissem a doença. $O$ instrumento compreende três partes: a primeira contém quatro questões sobre relação dieta e doenças, sendo que duas delas se referem ao câncer; a segunda parte tem sete questões que indagam sobre o conteúdo de fibras e lipídeos nos alimentos; e a terceira consiste em uma questão sobre a quantidade de porções de frutas e hortaliças que uma pessoa deve consumir. Pontuações totais entre zero e seis indicam baixo conhecimento nutricional; entre sete e dez indicam moderado conhecimento nutricional e; acima de dez indicam alto conhecimento nutricional. A escala apresenta índices adequados de validade e confiabilidade. Além da tradução para a língua portuguesa, a escala teve de ser adaptada para o Brasil, posto que alguns dos alimentos questionados não são consumidos aqui. Essa versão traduzida e adaptada obteve indicativos satisfatórios de validade e precisão (SCAGLIUSI, POLACOW, CORDÁS, COELHO, ALVARENGA, PHILIPPI \& LANCHA JUNIOR, 2006c).

Para avaliação da restrição dietética, foi utilizada a Escala de Restrição (Restraint Scale - RS), desenvolvida por HERMAN e MACK (1975). Esta escala mede a restrição alimentar crônica, de tal forma que ela deixa de ser um estado e passa a ser um traço (RICCIARDELLI \& WILLIAMS, 1997). Esta escala é composta por dez itens, sendo que seis indagam sobre preocupação com dieta e quatro indagam sobre flutuações de peso. A validade e precisão das versões original e traduzida para a língua portuguesa foram consideradas adequadas (ALLISON, 
KALINSKY \& GORMAN, 1992; HEATHERTON, HERMAN, POLIVY, KING \& MCGREE, 1988; LAESSLE, TUSCCHL, KOTTHAUS \& PIRKE, 1989; SCAGLIUSI, POLACOW, CORDÁS, COELHO, ALVARENGA, PHILIPPI \& LANCHA JUNIOR, 2005).

O desejo de aceitação social foi medido pela escala de Marlowe \& Crowne, constituída por 33 itens (Marlowe-Crowne Social Desirability Scale CROWNE \& MARLOWE, 1960). O desejo de aceitação social é definido como a propensão de um indivíduo fornecer a resposta que ele considera mais desejada e aceita pela sociedade, independentemente dela ser verdadeira (BALLARD et al., 1988). Esse instrumento apresenta elevados índices de consistência interna (CROWNE \& MARLOWE, 1960; BALLARD, 1992; FISHER \& FICK, 1993; LOO \& THORPE, 2000; REYNOLDS, 1982) e precisão (CROWNE \& MARLOWE, 1960). A versão traduzida pela língua portuguesa também obteve bons indicativos de precisão (SCAGLIUSI, CORDÁS, POLACOW, COELHO, ALVARENGA, PHILIPPI \& LANCHA $J R$, 2004).

\subsection{Mensuração do gasto energético total}

O método da água duplamente marcada (ADM) consiste na administração dos isótopos deutério $\left({ }^{2} \mathrm{H}\right)$ e ${ }^{18} \mathrm{O}$. O primeiro é eliminado como água e o segundo como água e $\mathrm{CO}_{2}$. Desta forma, a taxa de produção de $\mathrm{CO}_{2}$ é igual à diferença entre as taxas de eliminação dos isótopos, corrigidas pelo conjunto (pool) de água corporal (SCHOELLER, 1988; SPEAKMAN; 1998). Esta relação está representada na equação abaixo:

$\mathrm{rCO}_{2}=\mathrm{N} / 2 *(\mathrm{Ko}-\mathrm{Kh})$

$\mathrm{Na}$ qual:

$\mathrm{rCO}_{2}$ : taxa do fluxo de $\mathrm{CO}_{2}$

$\mathrm{N}$ : conjunto (pool) de água corporal

Ko: taxa de eliminação do ${ }^{18} \mathrm{O}$

Kh: taxa de eliminação do deutério

Os procedimentos adotados neste estudo quanto à administração dos isótopos, análise e cálculo estão descritos abaixo. 
No dia anterior à aplicação, os isótopos foram pesados e misturados. A mistura era colocada em uma seringa de $50 \mathrm{~mL}$, que infundia a água por um filtro de 0,22 mícron (Milipore). Após a filtragem, a dose era armazenada em um frasco de $200 \mathrm{~mL}$. Tais frascos eram bem tampados, etiquetados, embalados em parafilm e colocados dentro de envelopes plásticos do tipo zip lock. Uma alíquota de $2 \mathrm{~mL}$ desta dose era coletada em um tubo criogênico embalado em parafilm e mantida sob refrigeração.

O QUADRO 3 mostra o esquema de coleta de amostras de urina e de sangue, com seus respectivos dias e horários, a partir da segunda semana do módulo. Abaixo, também se encontram as descrições detalhadas das coletas.

QUADRO 3 - Dias e horários das coletas de amostras de urina, para mensuração do gasto energético total.

\begin{tabular}{|c|c|c|c|}
\hline $\begin{array}{l}\text { Número da } \\
\text { amostra }\end{array}$ & $\begin{array}{c}\text { Material } \\
\text { biológico }\end{array}$ & Data & Horário \\
\hline Amostra 1 & Urina & $\begin{array}{l}\text { Seg. da } 2^{\text {a }} \text {. semana do } \\
\text { módulo }\end{array}$ & $\begin{array}{c}\text { Pré-dose de ADM, jejum } \\
\text { de } 10 \text { horas }\end{array}$ \\
\hline Amostra 2 & Urina & $\begin{array}{l}\text { Seg. da } 2^{a} \text {. semana do } \\
\text { módulo }\end{array}$ & 2 horas após a dose \\
\hline Amostra 3 & Urina & $\begin{array}{l}\text { Seg. da } 2^{\text {a }} \text {. semana do } \\
\text { módulo }\end{array}$ & 3 horas após a dose \\
\hline Amostra 4 & Urina & $\begin{array}{c}\text { Seg. da } 2^{\text {a }} \text {. semana do } \\
\text { módulo }\end{array}$ & 4 horas após a dose \\
\hline Amostra 5 & Urina & $\begin{array}{c}\text { Seg. da } 2^{\text {a }} \text {. semana do } \\
\text { módulo }\end{array}$ & 5 horas após a dose \\
\hline Amostra 6 & Sangue & $\begin{array}{c}\text { Seg. da } 2^{\text {a }} \text {. semana do } \\
\text { módulo }\end{array}$ & 5 horas após a dose \\
\hline Amostra 7 & Urina & $\begin{array}{c}\text { Ter. da } 2^{a} \text {. semana do } \\
\text { módulo }\end{array}$ & $\begin{array}{c}\text { Horário da } 2^{a} \text {. urina do } \\
\text { dia }\end{array}$ \\
\hline Amostra 8 & Urina & $\begin{array}{c}\text { Sex. da } 2^{\text {a }} \text {. semana do } \\
\text { módulo }\end{array}$ & $\begin{array}{c}\text { Horário da } 2^{2} \text {. urina do } \\
\text { dia }\end{array}$ \\
\hline Amostra 9 & Urina & $\begin{array}{l}\text { Quar. da 3‥ semana do } \\
\text { módulo }\end{array}$ & $\begin{array}{c}\text { Mesmo horário da } \\
\text { amostra } 3\end{array}$ \\
\hline Amostra 10 & Urina & $\begin{array}{l}\text { Quar. da 3‥ semana do } \\
\text { módulo }\end{array}$ & 1 hora após a amostra 9 \\
\hline
\end{tabular}

ADM = água duplamente marcada; Seg. = segunda-feira; Ter. = terça-feira; Quar. = quarta-feira; Sex. = sexta-feira 
No dia 1 da $2^{\underline{a}}$ semana do módulo, os sujeitos se dirigiram ao laboratório após dez horas de jejum. Uma primeira amostra de urina foi coletada, em um recipiente de coleta médica seco, com cerca de $80 \mathrm{~mL}$. Esta foi chamada de amostra 1. O recipiente foi imediatamente enrolado em filme plástico.

Para receber a ADM, os sujeitos não poderiam estar febris, ter praticado exercícios intensos no dia anterior ou ter recebido fluidos intravenosos na última semana. Além disso, eles não poderiam viajar para fora do Estado de São Paulo nos dez dias subseqüentes à administração, já que isso provocaria uma mudança da água consumida.

A ADM foi então administrada por via oral. Foram utilizados $0,12 \mathrm{~g}$ de ${ }^{2} \mathrm{H}_{2} \mathrm{O}\left(99,8 \%\right.$ de excesso de átomos)/kg de água corporal e $2 \mathrm{~g} \mathrm{de} \mathrm{H}_{2}{ }^{18} \mathrm{O}$ normalizada (10\% de excesso de átomos)/kg de água corporal. Para calcular a quantidade de água corporal, a massa gorda (determinada pela dobras cutâneas) foi subtraída do peso corporal, resultando na massa magra. Esta foi então multiplicada por 0,732, assumindo-se que $73,2 \%$ da massa magra é formada por água (SCHOELLER, 1996). Estas quantidades de isótopos provocam alterações na abundância natural de deutério e ${ }^{18} \mathrm{O}$ de, respectivamente, 0,03 e 0,06\% de átomos. Os níveis de toxicidade de cada isótopo no organismo são de, respectivamente, 60 e 10\% de átomos, o que confirma a ampla segurança do protocolo (WONG \& SCHOELLER, 1990).

O sujeito devia consumir a dose inteira, sem derramar, com o auxílio de um "canudinho". Cinqüenta mililitros de água potável eram duas vezes adicionados ao recipiente da dose e consumidos. A hora em que a dose foi consumida foi anotada. Após a administração os sujeitos permaneceram por mais cinco horas no laboratório, no chamado período de estabilização. Durante esse período, todos os sujeitos consumiram $300 \mathrm{~mL}$ de água normal e um lanche padronizado (um pacote pequeno de biscoitos salgados, uma porção pequena de bolo simples com recheio e uma caixinha de suco industrializado de frutas). Neste mesmo período novas amostras de urina foram coletadas cerca de duas, três, quatro e cinco horas após a ingestão da água duplamente marcada, produzindo, portanto, as amostras 2, 3, 4 e 5. Os horários de coletas destas amostras foram registrados. Logo após a coleta da amostra 5, foi coletado $10 \mathrm{~mL}$ de sangue venoso, gerando a amostra 6 (o horário dessa coleta também foi anotado). 
Foi selecionada para este protocolo a metodologia de dois pontos, na qual a taxa de eliminação do isótopo é calculada pela diferença de enriquecimento em dois pontos. O período metabólico foi de 10 dias, conforme recomendado por PRENTICE, COWARD, COLE, SCHOELLER e HAGGARTY (1990) para adultos vivendo em clima tropical. Os voluntários foram instruídos a coletar uma amostra (chamada de amostra 7) da segunda urina do dia seguinte à administração (dia 2 da segunda semana do módulo). Na metade do período metabólico, isto é, no dia 5 da segunda semana do módulo, os sujeitos coletaram mais uma amostra (denominada amostra 8). Os sujeitos anotaram os horários das coletas e conservaram as amostras, enroladas em filme plástico, em seus congeladores. No décimo dia do período metabólico os sujeitos retornaram ao laboratório e, além de devolverem as amostras coletadas anteriormente, forneceram as duas últimas amostras (amostras 9 e 10), que foram coletadas aproximadamente nos mesmos horários das amostras 3 e 4.

Cada amostra foi armazenada em dois tubos criogênicos de $5 \mathrm{~mL}$, enrolados em parafilm. Cada tubo possuía uma etiqueta identificatória, coberta com fita adesiva. Os tubos de um mesmo sujeito eram armazenados em um mesmo saco plástico do tipo zip lock e armazenados em refrigerador, até o momento da análise. Tais amostras não eram armazenadas no mesmo refrigerador que os isótopos, conforme recomendado por SCHOELLER, TAYLOR e SHAY (1995). Antes da análise, as amostras eram centrifugadas (RACETTE, SCHOELLER, LUKE, SHAY, HNILICKA \& KUSHNER, 1994; SCHOELLER et al., 1995).

O enriquecimento isotópico das amostras foi analisado pela espectrometria de massa por determinação da razão isotópica (IRMS), método analítico que determina as massas com extrema rapidez, precisão, especificidade e sensibilidade (JUNQUEIRA-FRANCO, VANNUCCHI, FERRIOLI, PADOVAN \& MARCHINI, 1999). Antes de serem analisadas, ocorria a extração dos gases dos fluidos biológicos.

A água pode ser reduzida ao hidrogênio através da platina, de acordo com a técnica de SCRIMGEOUR, ROLLO, MUDAMBO, HANDLEY e PROSSER (1993). Três amostras de $0,5 \mathrm{~mL}$ de urina eram colocadas em vacutainers com pequenos bastões de catalisadores de platina. Os vacutainers, então, eram deixados em repouso por seis horas. 
Para a mensuração do ${ }^{18} \mathrm{O}$, duas amostras de $0,5 \mathrm{~mL}$ de urina eram preenchidas com $\mathrm{CO}_{2}$ e deixadas em repouso por 24 horas. Este gás era então isolado e purificado (WONG \& SCHOELLER, 1990; WONG, LEE \& KLEIN, 1987). Foi analisado o enriquecimento da amostra tap (água potável, não marcada), da amostra de dose diluída (ADM, em diluição proporcional à dose administrada aos sujeitos, recalculada para um conjunto de água corporal de $250 \mathrm{~mL}$ ) e das amostras de urina.

Para se chegar ao resultado do GET, vários cálculos são necessários. $O$ primeiro é o cálculo do espaço de diluição dos isótopos $(\mathrm{N})$, que se dá pela fórmula abaixo (SCHOELLER, 1996).

$\mathrm{N}$ (moles) $=(\mathrm{WA} / 18,02 \mathrm{a}){ }^{*}[(\mathrm{Ea}-\mathrm{Ew}) /(\mathrm{Es}-\mathrm{Ep})]$

Na qual:

W: quantidade de água usada para diluir a dose e fazer a amostra de dose diluída (em gramas);

A: massa de dose administrada ao sujeito (em gramas);

a: massa de dose usada para a amostra de dose diluída (em gramas);

Ea: enriquecimento isotópico da amostra de dose diluída;

Ew: enriquecimento isotópico da amostra tap (de água potável);

Es: enriquecimento isotópico da amostra de urina, pós-dose, equilibrada (amostras 4 ou 5);

Ep: enriquecimento isotópico da amostra pré-dose (amostra 1).

Esta fórmula foi aplicada a ambos os isótopos, gerando, portanto, dois valores de $\mathrm{N}$ : No (para o ${ }^{18} \mathrm{O}$ ) e $\mathrm{Nd}$ (para o deutério). O cálculo da taxa de eliminação (K) também foi feito para cada um dos isótopos, originando os valores Ko e Kd, de acordo com a fórmula abaixo (SPEAKMAN, 1998):

$\mathrm{K}(\mathrm{em} \mathrm{mol} / \mathrm{dia})=[\ln (\mathrm{E} 9-\mathrm{E} 1)-\ln (\mathrm{E} 4-\mathrm{E} 1)] / \mathrm{t}$

Na qual:

E1: enriquecimento da amostra 1;

E4: enriquecimento da amostra 4 ou 5;

E9: enriquecimento da amostra 9 ou 10;

t: tempo (dias).

Com os valores de $\mathrm{N}$ e $\mathrm{K}$ é possível calcular a produção de $\mathrm{CO}_{2}$. Entretanto, a equação original foi modificada, incluindo fatores de correção (NAGY, 1990). As correções mais importantes são quanto ao fracionamento dos isótopos e 
ao tamanho do N. O material fracionado não carrega consigo a mesma quantidade de marcador, o que complica o modelo original (SPEAKMAN, 1998). Atualmente também se sabe que o hidrogênio e o oxigênio se renovam em outros conjuntos (pools) do organismo, que não o de água corporal e que diferem de tamanho entre si. Efetuando-se as correções para o fracionamento dos isótopos e os diferentes tamanhos de $\mathrm{N}$ obtidos por cada um deles, a equação torna-se (SCHOELLER, 2002): $\mathrm{rCO}_{2}(\mathrm{em} \mathrm{mol} / \mathrm{dia})=[(\mathrm{TBW} / 2,078) *(1,007 \mathrm{Ko}-1,04 \mathrm{Kd})]-\left(0,0246^{*} \mathrm{r}_{\mathrm{GF}}\right)$

Na qual:

TBW (total de água corporal, em mol) $=[(\mathrm{No} / 1,007)+(\mathrm{Nd} / 1,041)] / 2$;

Ko: taxa de eliminação do oxigênio-18 (em mol/dia);

Kd: taxa de eliminação do deutério (em mol/dia);

$r_{\text {GF }}($ taxa de perda de gás fracionado $)=\left(1,05^{\star} \mathrm{TBW}\right) *(1,007 \mathrm{Ko}-$ $1,041 \mathrm{Kd})$.

O GET pode então ser calculado através da fórmula modificada de WEIR (1949), apud SCHOELLER (2002):

$\operatorname{GET}(\mathrm{kcal} / \mathrm{dia})=\left(22,4^{\star} \mathrm{rCO}_{2}\right)^{\star}[1,1+(3,94 / \mathrm{RQ})]$

Na qual:

$\mathrm{rCO}_{2}$ : taxa de produção de $\mathrm{CO}_{2}$ (em mol/dia);

$\mathrm{RQ}$ : quociente respiratório $=0,85$.

O quociente alimentar poderia ser usado para calcular o quociente respiratório, pela fórmula de BLACK, PRENTICE e COWARD (1986). Entretanto, quando se considera o erro embutido em tais dados de inquéritos, constata-se que é melhor usar o valor médio populacional, fornecido pelos mesmos autores, obtidos em unidades metabólicas $(\mathrm{FQ}=0,85)$.

Alguns controles foram calculados para se assegurar que os procedimentos foram feitos de forma adequada e todas as dosagens preencheram os seguintes critérios:

- A razão entre o espaço de diluição do deutério/espaço de diluição do oxigênio-18 deveria estar entre 1,00 e 1,07.

- O total de água corporal (TBW) deveria ser calculado separadamente com base nas amostras 4 e 5 . Caso a diferença entre os dois valores fosse maior que $5 \%$, seria improvável que a urina estivesse equilibrada com a água corporal e, 
portanto, dever-se-ia utilizar a amostra de sangue (amostra 6). Caso a diferença variasse entre 2 e $5 \%$, dever-se-ia determinar o pool de água corporal por análise de regressão, com base na amostra 7 .

- A produção de $\mathrm{CO}_{2}$ deveria ser calculada a partir da taxa de eliminação obtida com as amostras 9 e 10, sendo que a diferença entre elas não poderia ser maior do que $8 \%$ (SCHOELLER, 2002).

\subsection{Avaliação do consumo alimentar}

A ingestão alimentar foi avaliada por três métodos: diário alimentar de três dias (na semana 2); três recordatórios alimentares de 24 horas (nas semanas 1, 2 e 3) e questionário semi-quantitativo de freqüência alimentar (na semana 3).

O diário alimentar foi preenchido em três dias consecutivos, sendo um do fim de semana para que a variação da ingestão que normalmente ocorre neste período constasse na avaliação (MAISEY, LOUGHRIDGE, SOUTHON \& FULCHER, 1995). Os diários eram conferidos no momento de sua devolução e, caso alguma inconsistência fosse notada, o sujeito era indagado. Este registro foi feito após os sujeitos terem sido treinados para tal, segundo protocolo já testado pelo nosso grupo de pesquisa (SCAGLIUSI et al., 2003). Os voluntários receberam uma cartilha com instruções e exemplos sobre como preencher o diário e 38 ilustrações bidimensionais em preto e branco, em tamanho real, de medidas caseiras e porções de alimentos. Este instrumento também já foi validado pelo nosso grupo (POLACOW, CUNHA, SCAGLIUSI, ARTIOLI, BENATTI \& LANCHA JR, 2007).

Os recordatórios de 24 horas foram conduzidos em duas quartas-feiras e em uma segunda-feira. Assim, foram coletadas informações sobre o consumo alimentar em um domingo e em duas terças-feiras. Para auxílio na quantificação das porções alimentares durante o recordatório, foram utilizados os desenhos da cartilha supracitada e um livro contendo fotos de 100 porções alimentares (HESS, 1997). Neste estudo, desenvolveu-se uma versão adaptada da técnica de aplicação do recordatório em cinco passos (CONWAY et al., 2003; 2004) e um manual descritivo da mesma. Essa versão também foi baseada nos manuais de estudos epidemiológicos americanos (NUTRITION COORDINATING CENTER, 1992; USDA, 
1997), nas instruções da cartilha supracitada (POLACOW et al., 2007), nos dados da tabela de medidas caseiras de PINHEIRO, LACERDA, BENZECRY, GOMES e COSTA (2004) e em três manuais provenientes da Faculdade de Saúde Pública, da Universidade de São Paulo (FISBERG \& VILLAR, 2002; PHILIPPI, 2004; TOMITA \& CARDOSO, 2002). Além disso, foram incorporados os últimos avanços na área de avaliação do consumo alimentar, oriundos das pesquisas cognitivas e lingüísticas (CONWAY et al., 2003; JONNALAGADDA, MITCHELL, SMICIKLAS-WRIGHT, MEAKER, VAN HEEL, KARMALLY, ERSHOW \& KRIS-ETHERTON, 2000b; JOHNSON, DRISCOLI \& GORAN, 1996; SUBAR et al., 1995; TAPSELL, BRENNINGER \& BARNARD, 2000). Os recordatórios foram aplicados por dois nutricionistas treinados. Antes da realização dos recordatórios com os sujeitos desse estudo, foi conduzido um estudo piloto para checar a concordância entre os dois avaliadores. Obteve-se um coeficiente kappa de 0,97; que indica alta concordância (LANDIS \& KOCH, 1977).

O questionário semiquantitativo de freqüência alimentar utilizado foi aquele desenvolvido por SICHIERI (1998) para a população brasileira (apresentado na revisão bibliográfica). Este questionário possui 73 itens alimentares, para os quais os participantes devem estabelecer sua freqüência de consumo, dentro de categorias diárias, semanais ou mensais. Para cada alimento, são dadas três opções de quantidades, em medidas caseiras. Algumas questões indagam se o sujeito consome com maior freqüência manteiga ou margarina (pois a freqüência de consumo delas é perguntada em conjunto), margarina light ou tradicional, leite desnatado, semidesnatado ou integral, queijo, requeijão e iogurte light ou tradicional e refrigerante tradicional ou diet/light. Com estas perguntas, é possível fazer correções e obter os dados dos alimentos com teores reduzidos de gordura separadamente. Com o auxílio do programa Microsoft Excel, as freqüências mensais foram transformadas em freqüências diárias; estas foram multiplicadas pelas quantidades das porções, para que, finalmente fosse obtido um consumo alimentar médio diário, que pudesse ser transformado em energia e nutrientes.

Os dados das três avaliações foram tabulados por um único avaliador, que conta com experiência e treinamento, com o auxílio do software Virtual Nutri, desenvolvido por PHILIPPI, SZARFARC e LATTERZA (1996), na Faculdade de Saúde Pública da Universidade de São Paulo. Foram analisadas as ingestões de 
energia (em kcal) e macronutrientes (em gramas absolutas e em densidade, isto é, gramas $/ 1.000 \mathrm{kcal})$. Este programa de computador é baseado na Tabela de Composição de Alimentos do IBGE e em diversas tabelas estrangeiras. Todas as preparações foram desenvolvidas em laboratórios de técnica dietética e as porções alimentares foram baseadas em estudos epidemiológicos. O software em si já foi utilizado em diversos estudos de desenvolvimento de métodos de avaliação do consumo alimentar (SLATER et al., 2003; COLUCCI, 2002) e em estudos epidemiológicos (AQUINO, 1999). Mesmo assim, para todos os alimentos possíveis, a composição centesimal apresentada pelo software foi substituída por àquela apresentada pela Tabela Brasileira de Composição de Alimentos - TBCA (LAJOLO \& MENEZES, 1997) e pela Tabela Brasileira de Composição de Alimentos - TACO (NEPA, 2004), posto que estas tabelas apresentam a maior qualidade em análise bromatológica, seguindo as regras internacionais. Nos casos em que foi necessário (como, por exemplo, para o alimento "sorvete", que não consta nas tabelas nacionais), foram utilizados os dados do USDA National Nutrient Database for Standard Reference, Release 17 (USDA, 2004). Apenas para algumas preparações brasileiras (como, por exemplo, o alimento "brigadeiro"), que não constam nestas três tabelas, foram usados os dados originais do software Virtual Nutri.

O manual desenvolvido para aplicação do recordatório alimentar de 24 horas contém uma seção sobre como fazer a tabulação, que também foi usada para o diário e o questionário de freqüência alimentar. Esta seção descreve, por exemplo, como proceder quando o banco de dados não contém um alimento consumido pelo sujeito e apresenta alguns valores oriundos de estudos populacionais, para serem utilizados quando o sujeito não é capaz de quantificar seu consumo (por exemplo, quando ele consome uma bebida previamente adoçada).

\subsection{Detecção do sub-relato da ingestão energética}

Como indicadores do sub-relato, foram utilizados os índices IE/GET e IG (ingestão - gasto, em kcal). Normalmente, a subnotificação é identificada por meio da comparação direta entre a ingestão de energia (IE) e o gasto energético total (GET). Esta abordagem mostra o viés em um grupo, porém não é indicada para detectar quais foram os indivíduos que sub-relataram (o que é importante para se 
estudar as fontes e causas de tal erro). A IE e o GET estão sujeitos a variações intraindividuais normais que tornam a concordância individual exata entre elas pouco provável. Desta forma, é necessário obter a variação intra-individual da IE e do GET.

Para medir o coeficiente de variação intra-individual do GET, a água duplamente marcada foi reaplicada a $7,7 \%$ da amostra, após um mês. Este intervalo de tempo foi escolhido seguindo as recomendações de WILLETT (2003), que afirmou que o tempo de intervalo deve coincidir com o número de dias de avaliação do consumo alimentar (no caso deste estudo, o número máximo é de 30 dias, pois o questionário de freqüência alimentar indaga sobre a freqüência de consumo no último mês). Para o diário alimentar, foi calculado o coeficiente de variação da IE entre os três dias de registro, enquanto que para o recordatório alimentar, foi calculado o coeficiente entre os três dias de recordatório. Para cada método, o coeficiente de variação intra-individual é calculado como o desvio-padrão da IE obtida nos três dias de avaliação, dividido pela média da IE dos mesmos. Para o questionário de freqüência, seria assumido o coeficiente de $23 \%$ proposto por BLACK, WELCH e BINGHAM (2000), porém como se vê na equação a seguir, o coeficiente de variação da IE é dividido pelo número de dias do relato que, no caso deste questionário, é tido como infinito, de tal forma que este termo se torna igual à zero (ANDERSEN, TOMTEN, HAGGARTY, LOVO \& HUSTVEDT, 2003; BLACK \& COLE, 2000; SUBAR et al., 2003).

Assim, foram obtidos os seguintes coeficientes de variação intra-individual: 23,4\% (para o diário alimentar), 22,2\% (para o recordatório alimentar) e 8,8\% (para a água duplamente marcada).

A partir dos coeficientes de variação intra-individual da IE e do GET, puderam-se calcular os limites do intervalo de 95\% de confiança, dentro dos quais as duas mensurações deveriam concordar (BLACK \& COLE, 2000). Este intervalo foi, portanto, calculado para cada um dos três métodos de avaliação do consumo. Tal cálculo se dá pela seguinte fórmula (BLACK \& COLE, 2000):

Limites do intervalo de $95 \%$ de confiança $= \pm 2^{*} \sqrt{ }\left[\left(\mathrm{CV}_{\mathrm{IE}}{ }^{2} / \mathrm{d}\right)+\left(\mathrm{CV}_{\mathrm{GET}}{ }^{2}\right)\right]$

No qual:

$\mathrm{CV}_{\mathrm{IE}}$ : coeficiente de variação intra-individual da IE.

$\mathrm{CV}_{\mathrm{GET}}$ : coeficiente de variação intra-individual do GET. 
Esta fórmula dá um número percentual, que pode ser interpretado como uma diferença esperada entre a IE e o GET, abaixo da qual o indivíduo pode ser considerado sub-relator. Assim, para o questionário de freqüência alimentar, se chegou a uma diferença esperada de $18 \%$, significando, portanto, que indivíduos relatores de IE/GET inferiores a 0,82 , nesse método, podem ser denominados subrelatores, caso eles não tenham perdido peso durante o estudo. Para o recordatório alimentar, obteve-se uma diferença esperada de $31 \%$, indicando que os indivíduos que relataram, por meio desse método, IE/GET inferiores a 0,69 e não perderam peso são sub-relatores. Finalmente, para o diário alimentar, a diferença esperada foi de $32 \%$, indicando que indivíduos que relataram IE/GET inferiores a 0,68, nesse método, e não perderam peso, são sub-relatores.

Como se pode constatar acima, um indivíduo que relata IE/GET abaixo do esperado, mas que também perde peso, não pode ser considerado sub-relator. Porém, como existe uma flutuação normal do peso corporal, foi necessário estabelecer qual seria o critério para "perda de peso". Considerando que houve um mês entre as pesagens, determinou-se que seria considerado como "perda de peso" a redução de pelo menos $1 \mathrm{~kg}$ de peso corporal.

\subsection{Cálculo do $n$ amostral}

$O$ cálculo do $\mathrm{n}$ amostral foi feito de duas formas diferentes. Como ponto de partida, consideramos a recomendação de CADE, THOMPSON, BURLEY e WARM (2002), que postula que estudos envolvidos com a validação de métodos de avaliação do consumo alimentar devem recrutar pelo menos entre 50 e 100 indivíduos de um grupo demográfico, além da adição de 20\%, para compensar possíveis abandonos ou desistências de sujeitos. Como o método da água duplamente marcada é muito caro, tivemos de escolher um número nesse intervalo que fosse compatível com as possibilidades financeiras do estudo. Assim, determinamos a priori recrutar 54 indivíduos o que, somado com mais $20 \%$ para cobrir eventuais desistências (que não houve), formaria uma amostra de aproximadamente 65 sujeitos. Após termos coletados os dados de 65 sujeitos, calculamos as médias e desvios-padrão do GET e das ingestões energéticas obtidas por cada método de avaliação do consumo alimentar. Então, por meio do software 
OpenEpi (DEAN, SULLIVAN \& SOE, 2007), pode-se calcular o número necessário de sujeitos para se comparar a média do GET com a média de cada IE, com $80 \%$ de poder e $5 \%$ de significância. Foi encontrado que eram necessários 24 sujeitos para se comparar o GET médio com a IE média obtida tanto pelo diário quanto pelo recordatório alimentar. Para se comparar o GET médio com a IE média obtida pelo questionário de freqüência alimentar, eram necessários 36 voluntários. Percebe-se, portanto, que nossa amostra é suficiente para se realizar tais comparações.

\subsection{Obtenção de padrões alimentares}

Para a avaliação dos padrões alimentares, apenas os dados do questionário de freqüência alimentar foram considerados. Os alimentos foram agrupados de acordo com as suas características nutricionais em vinte e dois grupos alimentares, e, para cada grupo, foi contabilizada a freqüência com que aqueles alimentos eram consumidos em um dia, segundo o relato no questionário de freqüência alimentar. Não foram feitas correções pelas quantidades consumidas, já que WILLETT (1995) constatou que a freqüência alimentar determina mais o consumo alimentar do que as porções alimentares. Além disso, o questionário não indaga sobre a quantidade consumida de alguns alimentos (como manteiga, margarina, requeijão e bacon). Tais freqüências de consumo foram ajustadas pela ingestão energética relatada, sendo então expressas como freqüência diária de consumo/1.000 kcal.

Os alimentos foram agrupados da seguinte forma:

- Grupo pães: composto por pão (francês ou de forma).

- Grupo grãos e feculentos: composto por arroz, macarrão, polenta/angu, milho verde, pipoca, farinha de mandioca, batata cozida, mandioca/aipim e inhame/cará.

- Grupo leguminosas: feijão e lentilha/ervilha/grão de bico.

- Grupo frutas: composto por laranja/tangerina, banana, mamão/papaia, maçã, melancia/melão, abacaxi, abacate, manga, limão, maracujá, uva, goiaba, pêra e sucos. 
- Grupo hortaliças: composto por vagem, quiabo, cenoura, beterraba, couve-flor, alface, couve, repolho, chicória, tomate, pimentão, chuchu, abóbora, abobrinha e pepino.

- Grupo ovos: composto por ovos.

- Grupo laticínios sem redução do teor de gordura: composto por leite integral, iogurte "normal", queijo e requeijão "normais".

- Grupo laticínios com redução do teor de gordura: composto por leite desnatado, leite semidesnatado, iogurte light, queijo e requeijão lights.

- Grupo carne bovina: composto por carne de boi com osso, carne de boi sem osso e vísceras.

- Grupo carne suína: composto por salsicha/lingüiça, carne de porco e bacon/toucinho.

- Grupo frango: composto por frango.

- Grupo peixes: composto por peixe fresco, sardinha ou atum e camarão.

- Grupo biscoitos: composto por biscoito doce e biscoito salgado.

- Grupo doces: composto por bolos, sorvete, caramelos/balas, chocolate em pó, chocolate em barra/bombom e pudim.

- Grupo açúcares: composto por açúcar.

- Grupo refrigerantes contendo açúcar: composto por refrigerantes sem redução do teor do açúcar.

- Grupo refrigerantes contendo adoçantes artificiais: composto por refrigerantes lights/diets.

- Grupo manteiga/margarina/maionese: composto por manteiga, margarina e maionese sem redução do teor de gordura.

- Grupo margarina com redução do teor de gordura: composto por margarina light.

- Grupo frituras: composto por batata frita/chips e salgadinhos.

- Grupo pizza: composto por pizza.

- Grupo hambúrguer: composto por hambúrguer.

A obtenção de padrões alimentares se deu pela análise de agrupamento (cluster), por meio do software SPSS (Statistical Package for Social Sciences), versão 13. O método não hierárquico k-means, que agrega os indivíduos de acordo 
com as distâncias euclidianas entre eles, foi utilizado. Foi feita a interação, sendo que o número máximo desta foi 10. Foram observados os centros nos quais os agrupamentos se situaram e a qual agrupamento cada sujeito pertencia.

Como não é possível saber, a priori, qual é o número de padrões alimentares, quatro soluções, cujos números de padrões variaram de dois a cinco, foram testadas. Uma análise de variância foi conduzida para constatar quais grupos de alimentos separavam mais os agrupamentos. Para escolher a solução mais adequada, os seguintes aspectos foram observados:

- Distribuição mais homogênea de sujeitos por agrupamento.

- Facilidade de interpretação.

- Maiores valores de F nas análises de variância que determinavam quais grupos de alimentos separavam mais os agrupamentos.

Após a comparação dos padrões supracitados entre as quatro tentativas, foi escolhida a solução com três padrões alimentares.

\subsection{Análises estatísticas}

As análises foram conduzidas com o auxílio dos softwares SPSS (Statistical Package for Social Sciences), versão 13 e MedCalc, versão 9.3.1. O nível de significância adotado foi de 0,05. Os dados foram apresentados como média, desvio-padrão, mediana e valores mínimos e máximos.

Para verificar se as variáveis possuíam distribuição normal, foi conduzido o teste de Kolmogorov-Smirmov e foram observados os histogramas de cada variável, assim como os valores de assimetria e curtose. Quando as variáveis não apresentavam distribuição normal, as mesmas sofreram transformações, de acordo com as suas características. Após a transformação, estes exames eram repetidos.

O teste de Wilcoxon foi usado para verificar se o peso corporal variou entre a primeira e a última semana do estudo.

Para comparar a validade das estimativas de ingestão energética dos três métodos de avaliação do consumo alimentar, as seguintes abordagens foram utilizadas: 
- Comparação entre a IE obtida por cada método e o GET (ambos transformados em logaritmos de base 10), por meio da análise de variância para medidas repetidas. Também foram feitas comparações pareadas, utilizando-se o ajuste de Bonferroni para múltiplas comparações.

- Comparação entre a razão IE/GET e o índice IG, obtidos por cada um dos métodos de avaliação do consumo alimentar, por meio da análise de variância para medidas repetidas.

- Realização de diagramas de dispersão entre o GET e a IE obtida por cada um dos métodos de avaliação do consumo alimentar.

- Comparação entre a proporção de sub-relatores obtida por cada método de avaliação do consumo alimentar, por meio do teste do qui-quadrado.

- Verificação da proporção de sujeitos pertencentes a cada uma das seguintes categorias: a) não sub-relataram em nenhum método; b) sub-relataram em apenas um método; c) sub-relataram simultaneamente em dois métodos e; d) sub-relataram em todos os métodos. Dentre aqueles que sub-relataram simultaneamente em dois métodos, foi observada a proporção de cada combinação: a) sub-relato no recordatório e no diário; b) sub-relato no recordatório e no questionário de freqüência alimentar e; c) sub-relato no diário e no questionário de freqüência alimentar.

- Verificação da concordância individual entre o GET e a IE obtida por cada um dos métodos, por meio do gráfico de BLAND e ALTMAN (1986). Este gráfico é um método estatístico que compara duas mensurações. Nele, as diferenças entre as duas mensurações são "plotadas" contra a média entre as duas mensurações. Esse contraste é feito por meio de um diagrama de dispersão. Uma linha horizontal completa é traçada na diferença média entre as mensurações e duas linhas horizontais tracejadas são mostradas nos pontos que correspondem à diferença média mais e menos 1,96 desvio-padrão.

Para analisar se o sub-relato diferia entre as categorias de IMC, uma análise de variância comparou entre elas as variáveis IE (transformada em log 10 quando necessário), IE/GET (transformada em log 10) e IG (obtidas pelos três métodos de avaliação do consumo alimentar). Além disso, os gráficos de BLAND e ALTMAN (1986) foram repetidos, diferenciando os sujeitos por categoria de IMC. 
Finalmente, para cada método de inquérito alimentar, o teste do qui-quadrado comparou as proporções de indivíduos sub-relatores entre as categorias de IMC.

Para cada método de avaliação do consumo alimentar, foi feita uma matriz de correlação entre a variável IE/GET (transformada em logaritmo de base 10) e as seguintes variáveis: escore total do Questionário de Baecke, peso corporal, índice de massa corporal, idade, escores de conhecimento nutricional, escore de insatisfação corporal, escore de restrição dietética, escore de compulsão alimentar, renda per capita, escolaridade (em anos de estudo) e escore de desejo de aceitação social. Quando a variável independente possuía distribuição normal, foi utilizado o coeficiente de correlação de Pearson. Quando a variável independente não possuía distribuição normal, foi utilizado o coeficiente de correlação de Spearman.

Após esse procedimento, as características supracitadas foram comparadas entre: a) os sujeitos que nunca sub-relataram (denominados nunca subrelatores); b) os sujeitos que sub-relataram apenas em um método de avaliação do consumo alimentar (denominados sub-relatores ocasionais) e; c) àqueles que subrelataram em dois ou três métodos de avaliação do consumo alimentar (denominados sub-relatores freqüentes). Tais comparações foram feitas por meio da análise de variância (quando a variável independente possuía distribuição normal) ou por meio do teste de Kruskall-Wallis (quando a variável independente não possuía distribuição normal). Além disso, o teste do qui-quadrado comparou a proporção de indivíduos com eutrofia, sobrepeso e obesidade em cada uma das categorias supracitadas.

A análise de padrões alimentares foi feita conforme descrito no item 4.11. O consumo de cada grupo alimentar (em freqüência diária/1.000 kcal), entre cada cluster, foi apresentado como média e intervalo de $95 \%$ de confiança. O teste do quiquadrado comparou a proporção dos sub-relatores em cada agrupamento de padrão alimentar. Para cada proporção, também foi calculado seu respectivo intervalo de $95 \%$ de confiança. Além disso, análises de variância compararam entre os agrupamentos as seguintes variáveis: IE (transformada em logaritmo de base 10), IE/GET (transformada em logaritmo de base 10) e IG. 


\subsection{Caracterização da amostra}

A amostra foi composta por 65 mulheres, com idades mínimas e máximas de, respectivamente, 18 e 57 anos (idade média: $34 \pm 11$ anos; idade mediana: 31 anos). O QUADRO 4 mostra as características demográficas da amostra.

QUADRO 4 - Distribuição percentual da amostra segundo características demográficas.

\begin{tabular}{|c|}
\hline Estado civil \\
\hline $50,8 \%$ solteiras $\quad 38,5 \%$ casadas $\quad 9,2 \%$ separadas $\quad 1,5 \%$ viúvas \\
\hline Cor de pele \\
\hline $66,1 \%$ brancas $26,2 \%$ negras/pardas $\quad 7,7 \%$ amarelas (orientais) \\
\hline Tipo de residência \\
\hline $61,8 \%$ casas $36,4 \%$ apartamentos $\quad 1,8 \%$ pensões \\
\hline Tipo de escoadouro dos banheiros da residência \\
\hline $92,7 \%$ rede geral de esgoto ou pluvial $\quad 7,3 \%$ fossas sépticas \\
\hline Destino do lixo da residência \\
\hline 100,0\% coletado pelo serviço de limpeza \\
\hline Número de dormitórios no domicílio \\
\hline $\begin{array}{l}\text { 9,1\% } 1 \text { dormitório } 30,9 \% 2 \text { dormitórios } 43,6 \% 3 \text { dormitórios } \\
16,4 \% 4 \text { dormitórios }\end{array}$ \\
\hline
\end{tabular}

Em relação à prática de atividade física, a pontuação média, obtida pelo Questionário de Baecke, foi de 8,0 \pm 1,3. A mediana foi de 8,1 e os valores mínimos e máximos foram, respectivamente, 6,0 e 10,6. A TABELA 1 mostra, por sua vez, as características psicossociais da amostra. 
TABELA 1 - Dados psicossociais da amostra, apresentados como média, desviopadrão, mediana, valor mínimo e valor máximo.

\begin{tabular}{lccccc}
\hline \multicolumn{1}{c}{ Variáveis } & Média & $\begin{array}{c}\text { Desvio- } \\
\text { padrão }\end{array}$ & Mediana & $\begin{array}{c}\text { Valor } \\
\text { mínimo }\end{array}$ & $\begin{array}{c}\text { Valor } \\
\text { máximo }\end{array}$ \\
\hline $\begin{array}{l}\text { Escolaridade (em } \\
\text { anos de estudo) }\end{array}$ & 12,9 & 2,3 & 13,0 & 4,0 & 15,0 \\
$\begin{array}{l}\text { Renda mensal } \\
\text { per capita (em } \\
\text { reais) }\end{array}$ & 1.285 & 1.223 & 875 & 75 & 6.000 \\
$\begin{array}{l}\text { Escore de } \\
\text { insatisfação }\end{array}$ & 1,9 & 1,4 & 2,0 & $-1,0$ & 5,0 \\
$\begin{array}{l}\text { corporal } \\
\begin{array}{l}\text { Escore de desejo } \\
\text { de aceitação }\end{array}\end{array}$ & 15,9 & 5,0 & 16,0 & 2,0 & 25,0 \\
social & & & & & \\
$\begin{array}{l}\text { Escore de } \\
\text { conhecimento }\end{array}$ & 9,1 & 2,3 & 10,0 & 4,0 & 14,0 \\
nutricional & & & & & \\
$\begin{array}{l}\text { Escore de } \\
\text { compulsão } \\
\text { alimentar }\end{array}$ & 11,3 & 8,3 & 9,0 & 0,0 & 34,0 \\
$\begin{array}{l}\text { Escore de } \\
\text { restrição dietética }\end{array}$ & 16,3 & 7,8 & 15,0 & 2,0 & 33,0 \\
\hline & & & & & \\
\hline
\end{tabular}

\subsection{Avaliação antropométrica e da composição corporal}

A TABELA 2 apresenta os dados antropométricos e de composição corporal da amostra. Cerca de $43,1 \%$ da amostra estavam em estado de eutrofia, enquanto que $15,4 \%$ e $41,5 \%$ estavam, respectivamente, em estado de sobrepeso e obesidade. 
TABELA 2 - Dados antropométricos e de composição corporal obtidos pela amostra, apresentados como média, desvio-padrão, mediana, valor mínimo e valor máximo.

\begin{tabular}{lccccc}
\hline Variáveis & Média & $\begin{array}{l}\text { Desvio- } \\
\text { padrão }\end{array}$ & Mediana & $\begin{array}{c}\text { Valor } \\
\text { mínimo }\end{array}$ & $\begin{array}{c}\text { Valor } \\
\text { máximo }\end{array}$ \\
\hline $\begin{array}{l}\text { Peso inicial } \\
\text { (kg) }\end{array}$ & 73,7 & 17,4 & 68,7 & 47,9 & 113,0 \\
$\begin{array}{l}\text { Altura (m) } \\
\text { Índice de }\end{array}$ & 1,63 & 0,07 & 1,63 & 1,42 & 1,81 \\
$\begin{array}{l}\text { massa } \\
\text { corporal }\end{array}$ & 27,9 & 6,7 & 25,6 & 18,5 & 39,9 \\
$\begin{array}{l}\left.\text { (kg/m }{ }^{2}\right) \\
\text { Peso final }\end{array}$ & & & & & \\
$(\mathbf{k g})$ & 74,2 & 17,6 & 68,0 & 48,2 & 110,6 \\
\hline
\end{tabular}

De acordo com o teste de Wilcoxon, houve diferença significante entre 0 peso final e o peso inicial $(z=-2,69 ; p=0,007)$, sendo que a tendência foi de ganho de peso.

\subsection{Avaliação da validade das estimativas de ingestão energética}

Os parâmetros obtidos pela técnica da água duplamente marcada, incluindo o gasto energético total, encontram-se na TABELA 3. 
TABELA 3 - Parâmetros metabólicos obtidos pela água duplamente marcada: gasto energético total (GET); taxa de produção de $\mathrm{CO}_{2}$; espaço de diluição do deutério (Nd); espaço de diluição do oxigênio-18 (No); razão entre os espaços de diluição ( $\mathrm{Nd} / \mathrm{No}$ ); taxa de eliminação do deutério (Kd) e; taxa de eliminação do oxigênio (Ko).

\begin{tabular}{lccccc}
\hline \multicolumn{1}{c}{ Variáveis } & Média & $\begin{array}{c}\text { Desvio- } \\
\text { padrão }\end{array}$ & Mediana & $\begin{array}{c}\text { Valor } \\
\text { mínimo }\end{array}$ & $\begin{array}{c}\text { Valor } \\
\text { máximo }\end{array}$ \\
\hline $\begin{array}{l}\text { GET } \\
\text { (kcal/dia) }\end{array}$ & 2.622 & 490 & 2.638 & 1.538 & 3.870 \\
$\begin{array}{l}\text { Taxa de } \\
\text { produção do }\end{array}$ & 20,4 & 3,8 & 20,5 & 12,0 & 30,1 \\
$\mathbf{C O}_{2}$ (mol/dia) & & & & & \\
$\mathbf{N d}(\mathbf{m o l})$ & $1.896,7$ & 267,3 & $1.842,1$ & $1.384,9$ & $2.629,6$ \\
No (mol) & $1.828,8$ & 258,6 & $1.776,4$ & $1.363,3$ & $2.496,6$ \\
$\mathbf{N d} / \mathbf{N o}$ & 1,04 & 0,02 & 1,03 & 1,00 & 1,07 \\
$\mathbf{K d}(\mathbf{m o l} / \mathbf{d i a})$ & 0,0809 & 0,0187 & 0,0768 & 0,0538 & 0,1502 \\
$\mathbf{K o}(\mathbf{m o l} / \mathbf{d i a})$ & 0,1324 & 0,1361 & 0,1041 & 0,0784 & 0,9490 \\
\hline
\end{tabular}

A TABELA 4 apresenta as estimativas de ingestão energética obtidas por cada método de avaliação do consumo alimentar, bem como os indicadores de subrelato IE/GET E IG. Uma análise de variância para medidas repetidas encontrou diferença significante entre as estimativas de IE e o GET, transformados em log ( $F=$ $22,9 ; p<0,0001)$. As comparações pareadas mostraram que os valores de IE obtidos pelos três métodos de inquérito alimentar diferiam significativamente do GET ( $p<$ 0,0001 ), porém não diferiam entre si (o valor de $p$ variou entre 1,00 e 0,59). 
TABELA 4 - Estimativas de ingestão energética e indicadores de sub-relato obtidos por cada método de avaliação do consumo alimentar (dados apresentados como: média \pm desvio-padrão [mediana; mínimo máximo]).

\begin{tabular}{|c|c|c|c|}
\hline Variáveis & $\begin{array}{c}\text { Recordatório } \\
\text { alimentar de } 24 \\
\text { horas (média de } \\
\text { três dias) }\end{array}$ & $\begin{array}{l}\text { Diário alimentar } \\
\text { (média de três } \\
\text { dias) }\end{array}$ & $\begin{array}{l}\text { Questionário de } \\
\text { freqüência } \\
\text { alimentar }\end{array}$ \\
\hline $\begin{array}{l}\text { Ingestão de } \\
\text { energia (kcal/dia) }\end{array}$ & $\begin{array}{c}2.078 \pm 430[2.095 \\
1.109-3.363]^{*}\end{array}$ & $\begin{array}{c}2.044 \pm 479[2.009 \\
1.131-3.182]^{*}\end{array}$ & $\begin{array}{c}1.984 \pm 832[1.775 \\
796-4.505]^{\star}\end{array}$ \\
\hline $\begin{array}{l}\text { IE/GET (ingestão } \\
\text { energética/gasto } \\
\text { energético total) }\end{array}$ & $\begin{array}{c}0,83 \pm 0,26[0,78 \\
0,34-1,53]^{\star \star}\end{array}$ & $\begin{array}{c}0,80 \pm 0,23[0,83 \\
0,42-1,34]^{\star \star}\end{array}$ & $\begin{array}{c}0,76 \pm 0,30[0,71 \\
0,30-1,50]^{\star \star}\end{array}$ \\
\hline IG (ingestão & & & \\
\hline $\begin{array}{l}\text { energética - gasto } \\
\text { energético total) } \\
\text { (kcal) }\end{array}$ & $\begin{array}{l}-545 \pm 701[-546 \\
-2.128-1.163]^{\star \star *}\end{array}$ & $\begin{array}{l}-578 \pm 646[-456 \\
-1.885-720]^{\star * *}\end{array}$ & $\begin{array}{l}-638 \pm 814[-691 \\
-2.043-1.508]^{\star \star *}\end{array}$ \\
\hline
\end{tabular}

As FIGURAS 2 a 4 mostram os diagramas de dispersão construídos a partir do GET e da IE obtida por cada método de inquérito alimentar. 


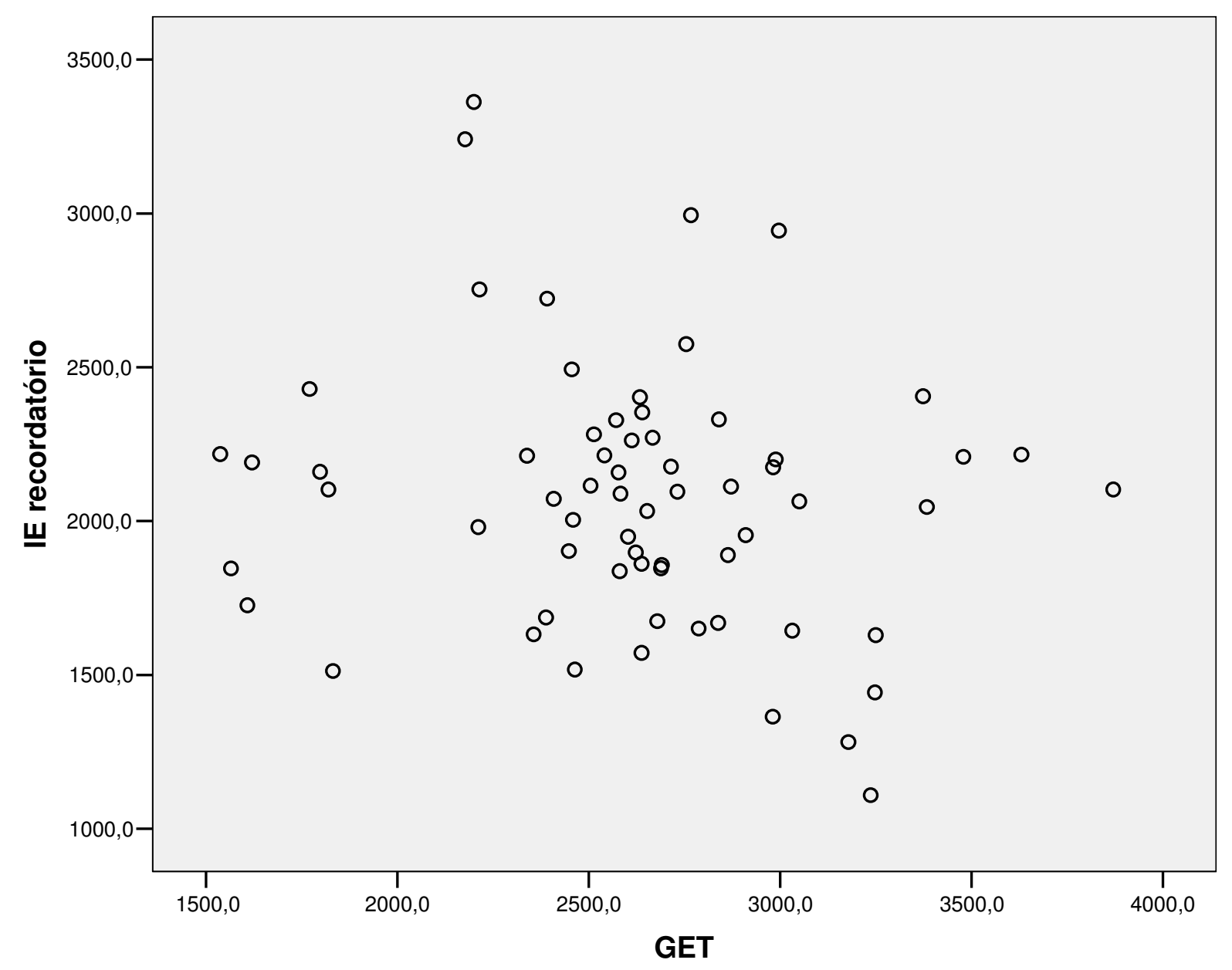

FIGURA 2 - Diagrama de dispersão entre o gasto energético total (GET) e a ingestão energética obtida pelo recordatório alimentar (IE recordatório). 


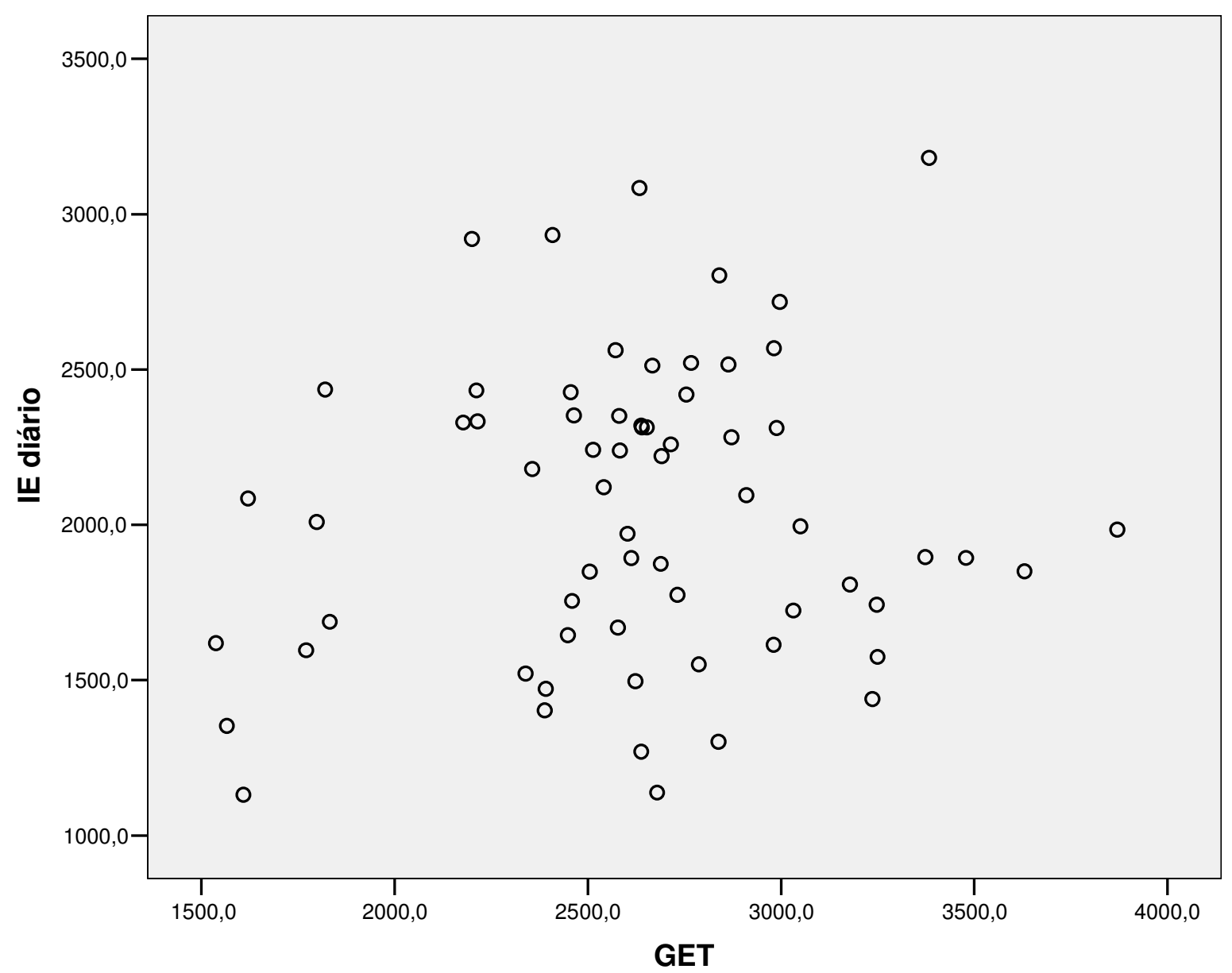

FIGURA 3 - Diagrama de dispersão entre o gasto energético total (GET) e a ingestão energética obtida pelo diário alimentar (IE diário). 


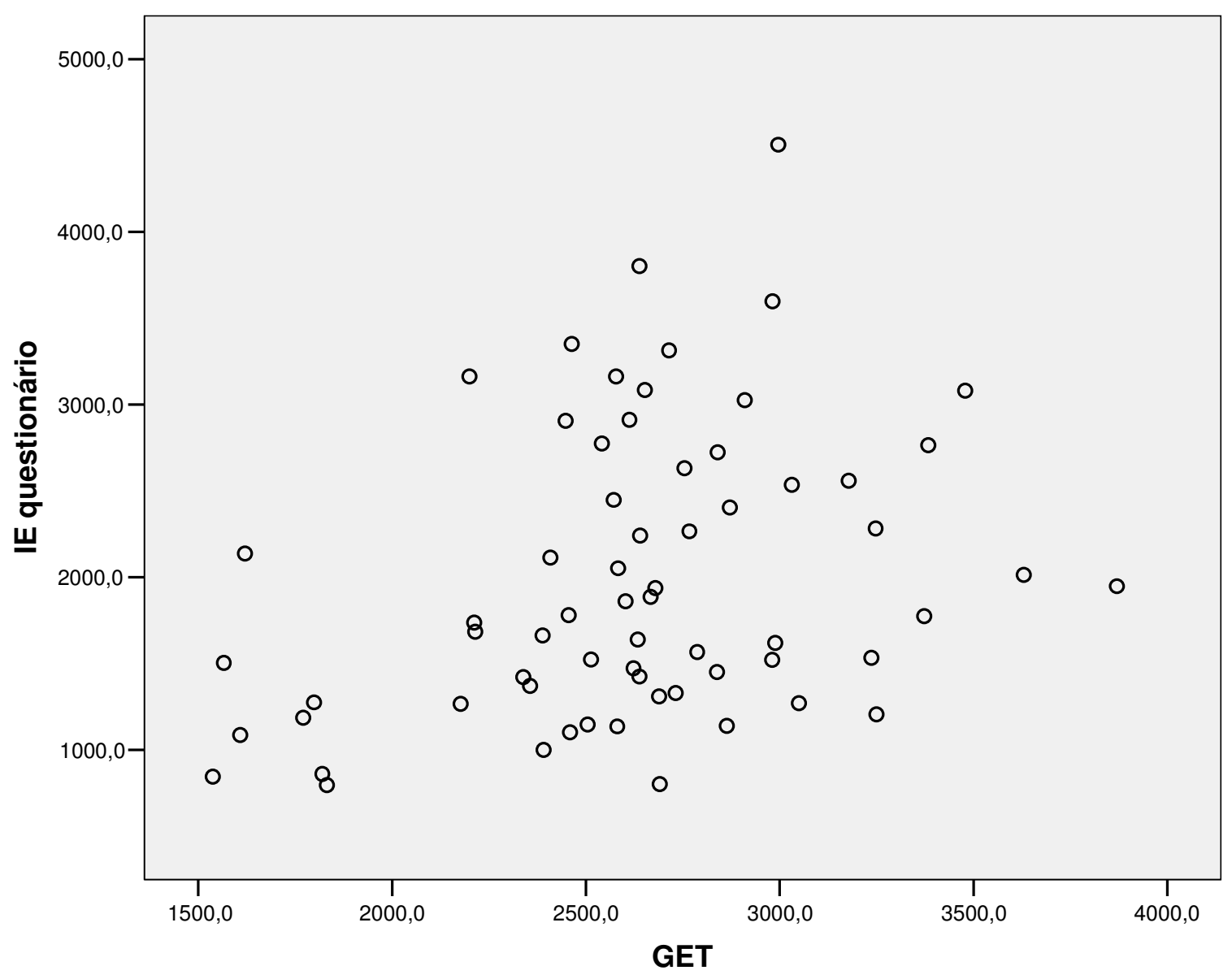

FIGURA 4 - Diagrama de dispersão entre o gasto energético total (GET) e a ingestão energética obtida pelo questionário de freqüência alimentar (IE questionário). 
A FIGURA 5 compara a proporção de sub-relatores em cada método de avaliação do consumo alimentar, ilustrando a grande diferença encontrada pelo teste do qui-quadrado.

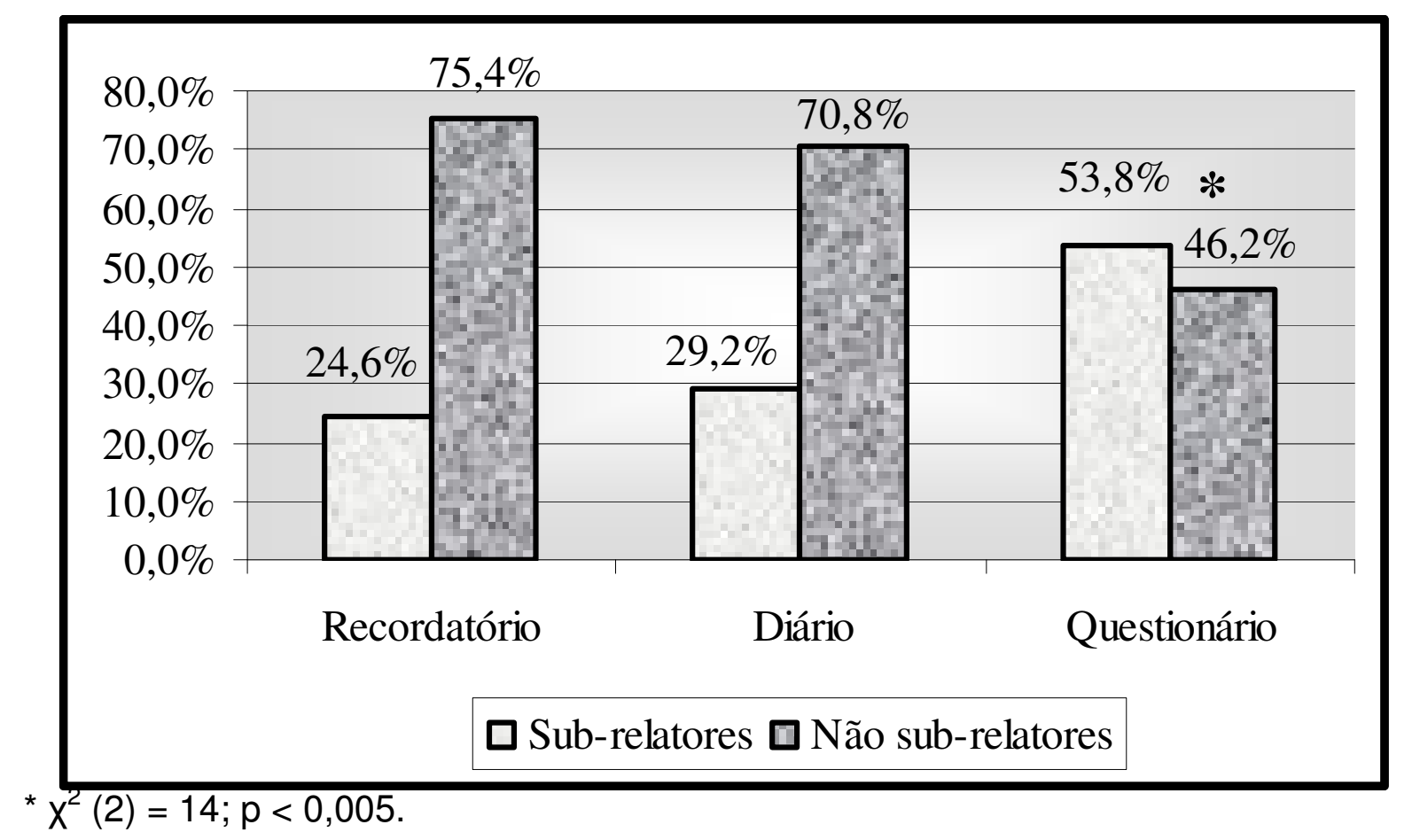

FIGURA 5 - Distribuição percentual de sujeitos sub-relatores e não sub-relatores em cada método de avaliação do consumo alimentar.

Cerca de $35,4 \%$ da amostra não sub-relatou em nenhum dos métodos de avaliação do consumo alimentar. Uma proporção semelhante (36,9\%) sub-relatou em apenas um dos métodos, enquanto que $12,3 \%$ sub-relataram em dois métodos. Aproximadamente $15,4 \%$ da amostra sub-relataram simultaneamente em todos os métodos de avaliação do consumo alimentar.

Entre aqueles sujeitos que sub-relataram em apenas um dos métodos, $79,2 \%$ sub-relataram no questionário de freqüência alimentar, enquanto que $12,5 \% \mathrm{e}$ 8,3\% sub-relataram, respectivamente, só no recordatório e só no diário alimentar.

Entre aqueles indivíduos que sub-relataram simultaneamente em dois métodos, a maioria $(62,5 \%)$ sub-relatou ao mesmo tempo no diário e no questionário de freqüência alimentar. Cerca de $25 \%$ sub-relataram simultaneamente no 
recordatório e no diário, enquanto que apenas 12,5\% sub-relataram ao mesmo tempo no recordatório e no questionário de freqüência alimentar.

Nas FIGURAS 6 a 8, podem ser visualizados os gráficos de Bland e Altman. Esses gráficos mostram a concordância individual entre as medidas de GET e de IE obtidas por cada método de inquérito alimentar.

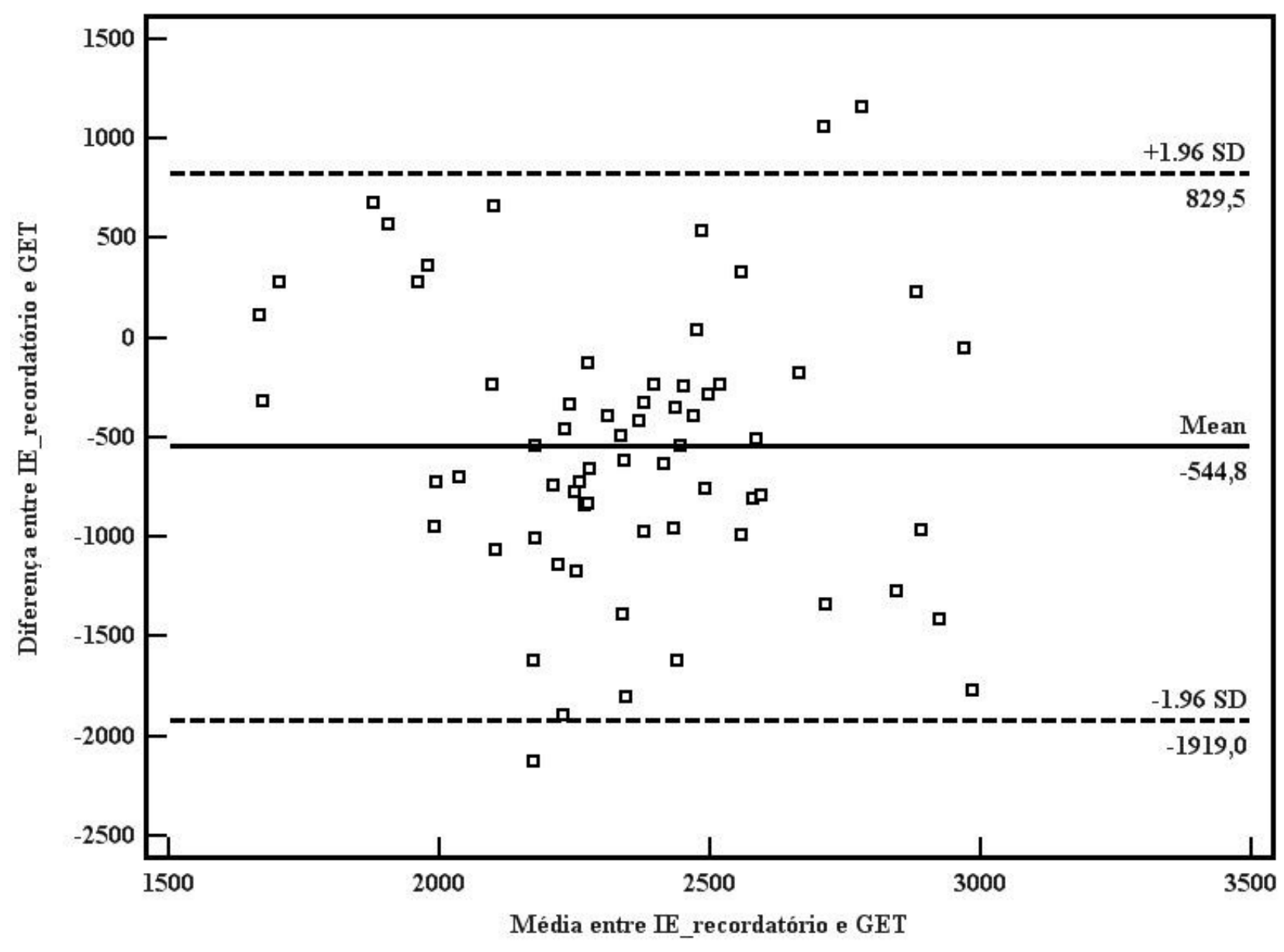

Mean $=$ média. $\mathrm{SD}=$ desvio-padrão.

IE_recordatório: IE obtida pelo recordatório alimentar.

Linha sólida = diferença média entre as mensurações.

Linha tracejada $=$ diferença média mais e menos 1,96 desvio-padrão.

FIGURA 6 - Gráfico de Bland e Altman: diferença entre a IE obtida pelo recordatório alimentar e o GET versus a média entre os mesmos. 


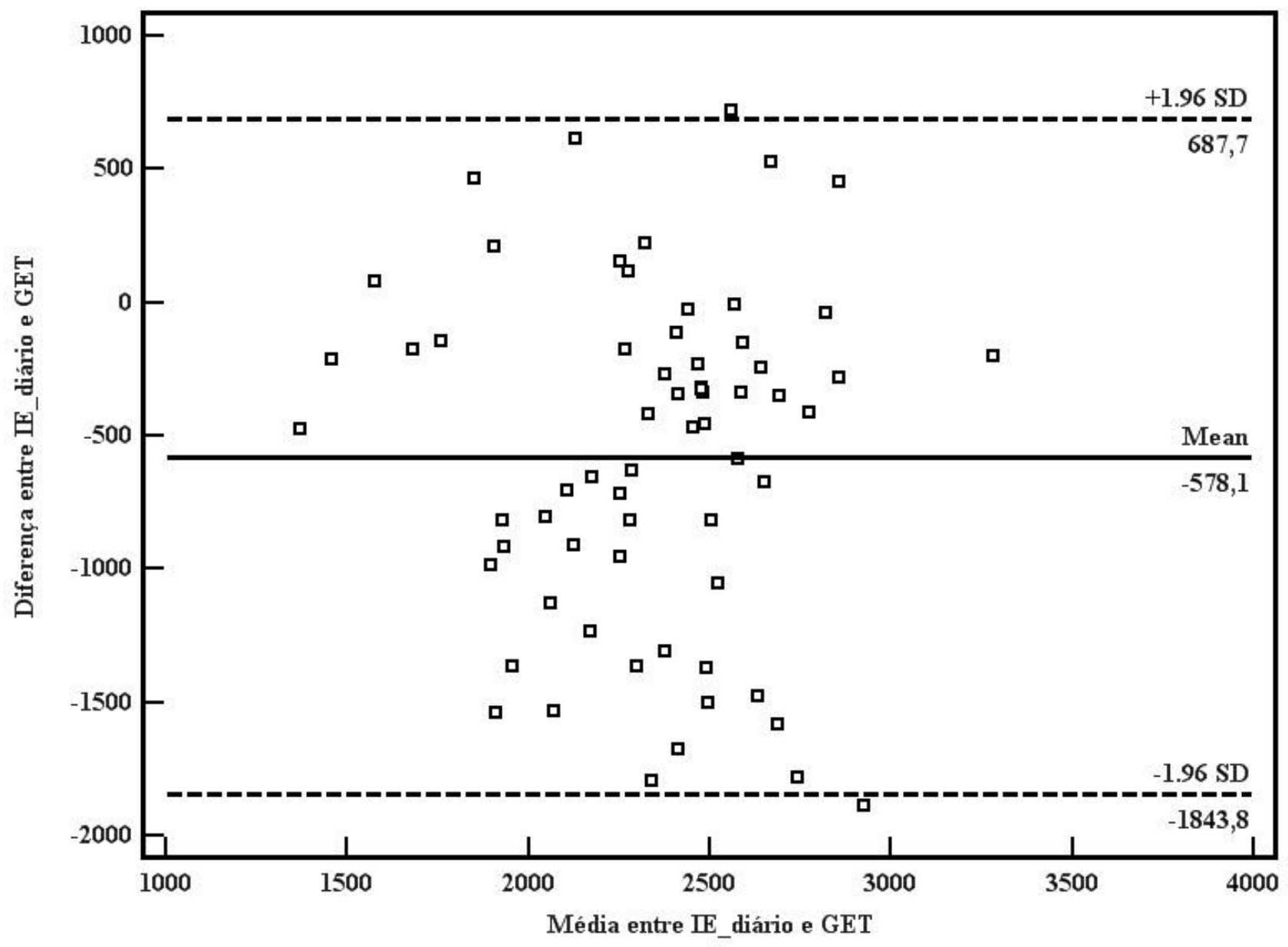

Mean $=$ média. $\mathrm{SD}=$ desvio-padrão.

IE_diário: IE obtida pelo diário alimentar.

Linha sólida = diferença média entre as mensurações.

Linha tracejada $=$ diferença média mais e menos 1,96 desvio-padrão.

FIGURA 7 - Gráfico de Bland e Altman: diferença entre a IE obtida pelo diário alimentar e o GET versus a média entre os mesmos. 


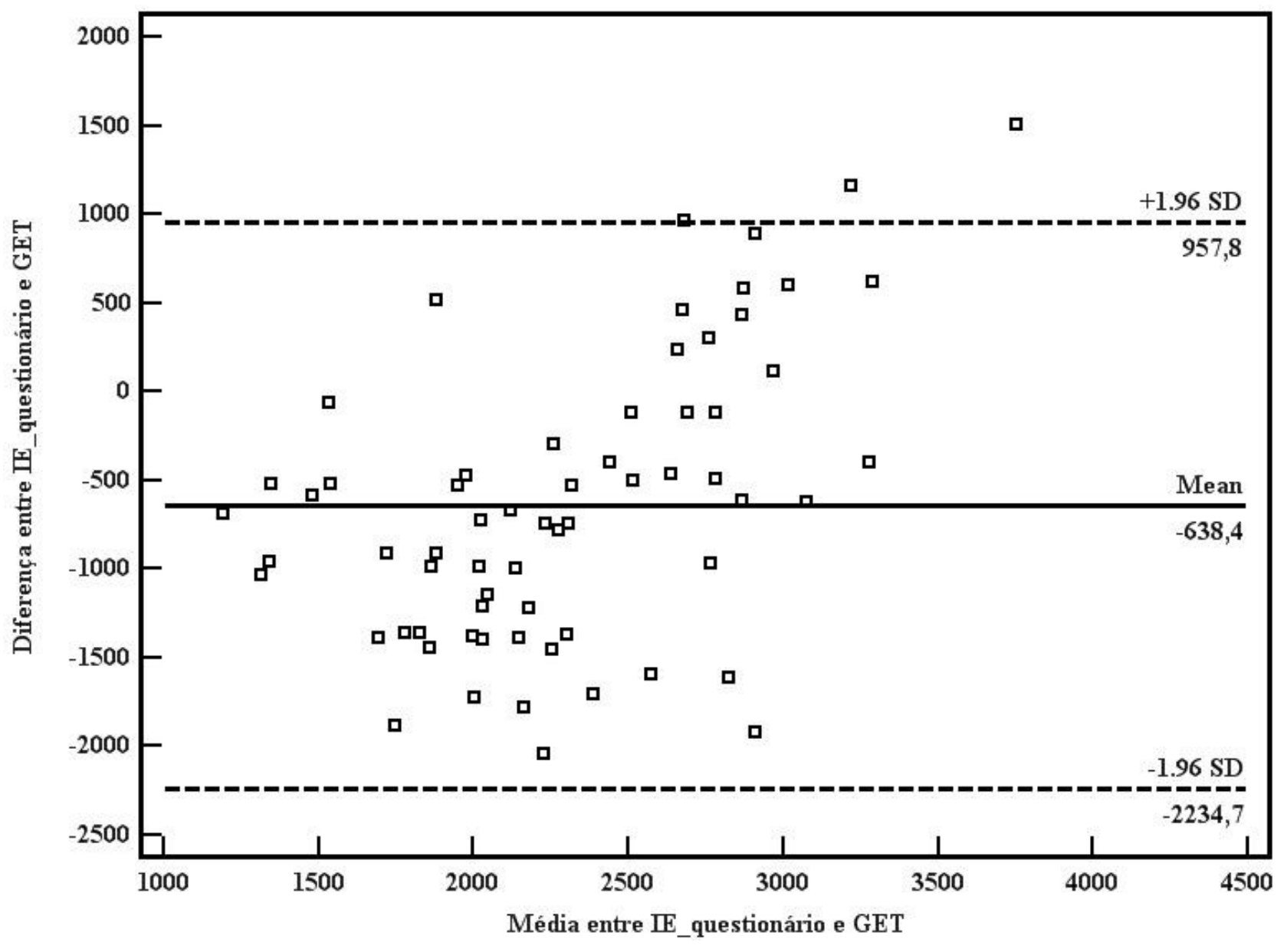

Mean $=$ média. $\mathrm{SD}=$ desvio-padrão.

IE_questionário: IE obtida pelo questionário de freqüência alimentar.

Linha sólida = diferença média entre as mensurações.

Linha tracejada $=$ diferença média mais e menos 1,96 desvio-padrão.

FIGURA 8 - Gráfico de Bland e Altman: diferença entre a IE obtida pelo questionário de freqüência alimentar e o GET versus a média entre os mesmos. 
5.4 Avaliação do sub-relato da ingestão energética entre as categorias de Índice de Massa Corporal (IMC)

A TABELA 5 mostra os valores de IE, IE/GET e IG obtidos pelos sujeitos com eutrofia, sobrepeso e obesidade nos três métodos de inquérito alimentar.

Nas FIGURAS 9 a 11 são apresentados novamente os gráficos de Bland e Altman, porém, dessa vez, os sujeitos estão representados separadamente, de acordo com a sua categoria de IMC. 
TABELA 5 - Estimativas de ingestão energética, gasto energético total e indicadores de sub-relato obtidos pelas voluntárias com eutrofia, sobrepeso e obesidade em cada método de avaliação do consumo alimentar (dados apresentados como: média \pm desvio-padrão [mediana; mínimo máximo]).

\begin{tabular}{|c|c|c|c|}
\hline Variáveis & $\begin{array}{l}\text { Sujeitos com } \\
\text { eutrofia } \\
\qquad(\mathrm{n}=\mathbf{2 8})\end{array}$ & $\begin{array}{c}\text { Sujeitos com } \\
\text { sobrepeso } \\
(n=10)\end{array}$ & $\begin{array}{l}\text { Sujeitos com } \\
\text { obesidade } \\
(n=27)\end{array}$ \\
\hline $\begin{array}{l}\text { IE_recordatório } \\
\text { (em kcal/dia) }\end{array}$ & $\begin{array}{c}2.187 \pm 347[2.183 \\
1.364-2.995]\end{array}$ & $\begin{array}{c}2.053 \pm 508[1.875 \\
1.632-3.363]\end{array}$ & $\begin{array}{c}1.973 \pm 466[2.046 \\
1.109-3.241]\end{array}$ \\
\hline $\begin{array}{l}\text { IE_diário (em } \\
\text { kcal/dia) }\end{array}$ & $\begin{array}{c}2.129 \pm 459[2.171 \\
1.353-3.084]\end{array}$ & $\begin{array}{c}2.144 \pm 550[2.301 ; \\
\quad 1.131-2.920]\end{array}$ & $\begin{array}{c}1.920 \pm 461[1.874 \\
1.138-3.182]\end{array}$ \\
\hline $\begin{array}{l}\text { IE_questionário } \\
\text { (em kcal/dia) }\end{array}$ & $\begin{array}{c}1.898 \pm 772[1.761 \\
796-3.598]\end{array}$ & $\begin{array}{c}1.717 \pm 709[1.398 \\
1.088-2.076]\end{array}$ & $\begin{array}{c}2.172 \pm 916[1.948 \\
\quad 861-4.505]\end{array}$ \\
\hline $\begin{array}{l}\text { GET (em } \\
\text { kcal/dia)* }\end{array}$ & $\begin{array}{c}2.404 \pm 431[2.527 \\
\quad 1.538-2.982]\end{array}$ & $\begin{array}{c}2.481 \pm 376[2.576 \\
1.608-2.872]\end{array}$ & $\begin{array}{c}2.902 \pm 457[2.838 \\
1.820-3.870]\end{array}$ \\
\hline $\begin{array}{l}\text { IE/GET } \\
\text { recordatório* }\end{array}$ & $\begin{array}{c}0,94 \pm 0,23[0,88 \\
0,46-1,44]\end{array}$ & $\begin{array}{c}0,85 \pm 0,27[0,72 \\
0,66-1,53]\end{array}$ & $\begin{array}{c}0,70 \pm 0,24[0,64 \\
0,34-1,49]\end{array}$ \\
\hline IE/GET diário* & $\begin{array}{c}0,90 \pm 0,18[0,89 \\
0,54-1,29]\end{array}$ & $\begin{array}{c}0,87 \pm 0,21[0,88 \\
0,59-1,33]\end{array}$ & $\begin{array}{c}0,68 \pm 0,22[0,57 \\
0,42-1,34]\end{array}$ \\
\hline $\begin{array}{l}\text { IE/GET } \\
\text { questionário }\end{array}$ & $\begin{array}{c}0,79 \pm 0,27[0,74 \\
0,30-1,32]\end{array}$ & $\begin{array}{c}0,71 \pm 0,31[0,63 \\
0,40-1,44]\end{array}$ & $\begin{array}{c}0,76 \pm 0,34[0,58 \\
0,37-1,50]\end{array}$ \\
\hline $\begin{array}{l}\text { IG recordatório } \\
(\text { em kcal)* }\end{array}$ & $\begin{array}{c}-216 \pm 539[-276 \\
-1.617-680]\end{array}$ & $\begin{array}{c}-428 \pm 641[-713 \\
-974-1.163]\end{array}$ & $\begin{array}{c}-929 \pm 702[-987 \\
-2.128-1.064]\end{array}$ \\
\hline $\begin{array}{l}\text { IG diário (em } \\
\text { kcal)* }\end{array}$ & $\begin{array}{c}-274 \pm 457[-260 \\
-1.367-525]\end{array}$ & $\begin{array}{c}-337 \pm 489[-333 \\
-986-720]\end{array}$ & $\begin{array}{c}-982 \pm 660[-1.127 \\
-1.885-616]\end{array}$ \\
\hline $\begin{array}{l}\text { IG questionário } \\
\text { (em kcal) }\end{array}$ & $\begin{array}{c}-506 \pm 647[-530 \\
-1.888-617]\end{array}$ & $\begin{array}{c}-764 \pm 788[-855 \\
-1.724-963]\end{array}$ & $\begin{array}{c}-730 \pm 975[-959 \\
-2.043-1.508]\end{array}$ \\
\hline
\end{tabular}

IE: ingestão energética (obtida pelo método indicado após a sigla). GET: gasto energético total. IE/GET: ingestão energética/gasto energético total (ingestão obtida pelo método indicado após a sigla). IG: ingestão energética - gasto energético total (ingestão obtida pelo método indicado após a sigla).

*: $p \leq 0,05$ nas análises de variância que compararam cada variável entre as categorias de IMC. 


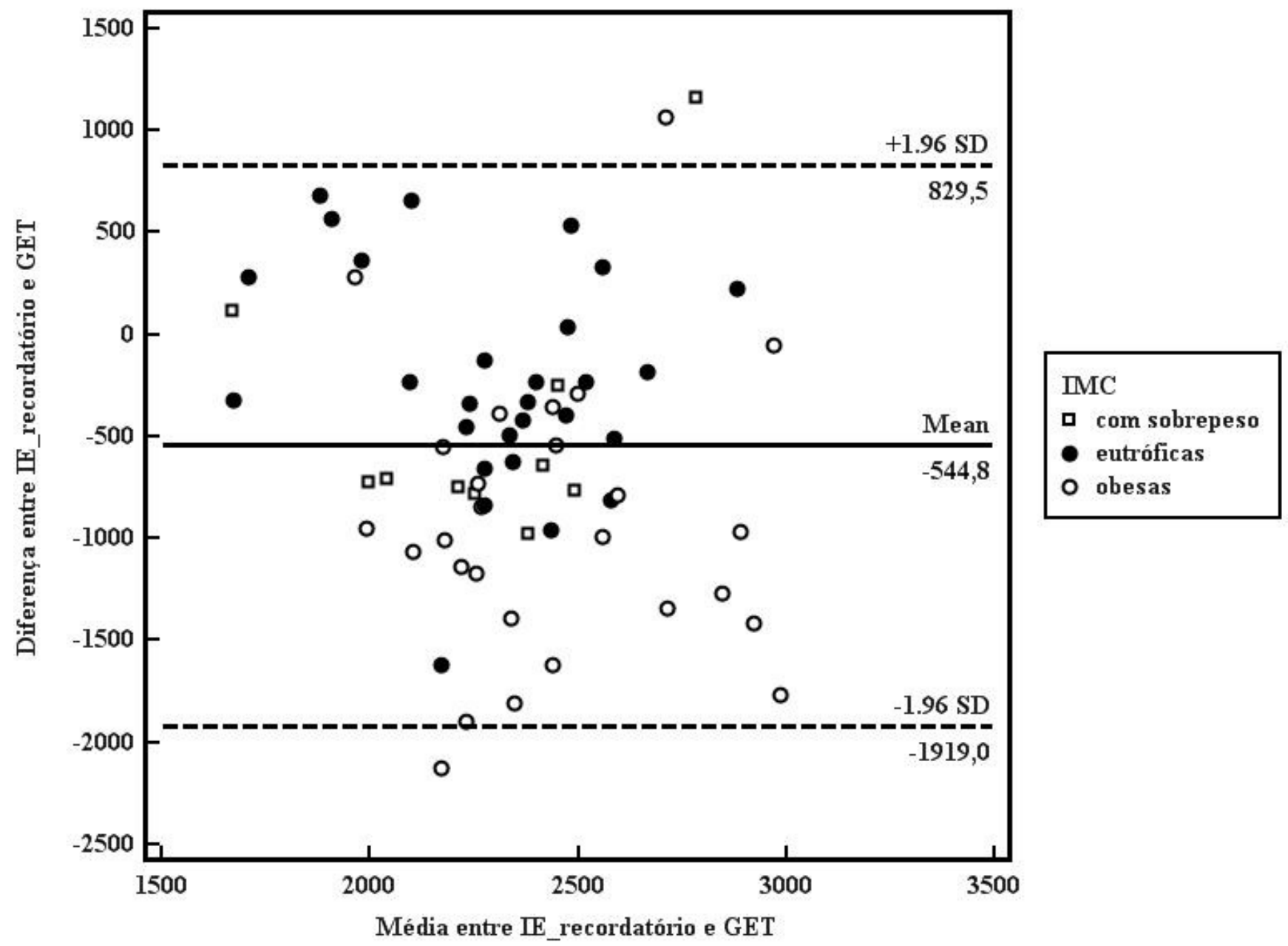

Mean = média. SD = desvio-padrão.

IE_recordatório: IE obtida pelo recordatório alimentar.

Linha sólida = diferença média entre as mensurações.

Linha tracejada = diferença média mais e menos 1,96 desvio-padrão.

FIGURA 9 - Gráfico de Bland e Altman: diferença entre a IE obtida pelo recordatório alimentar e o GET versus a média entre os mesmos, de acordo com as categorias de IMC. 


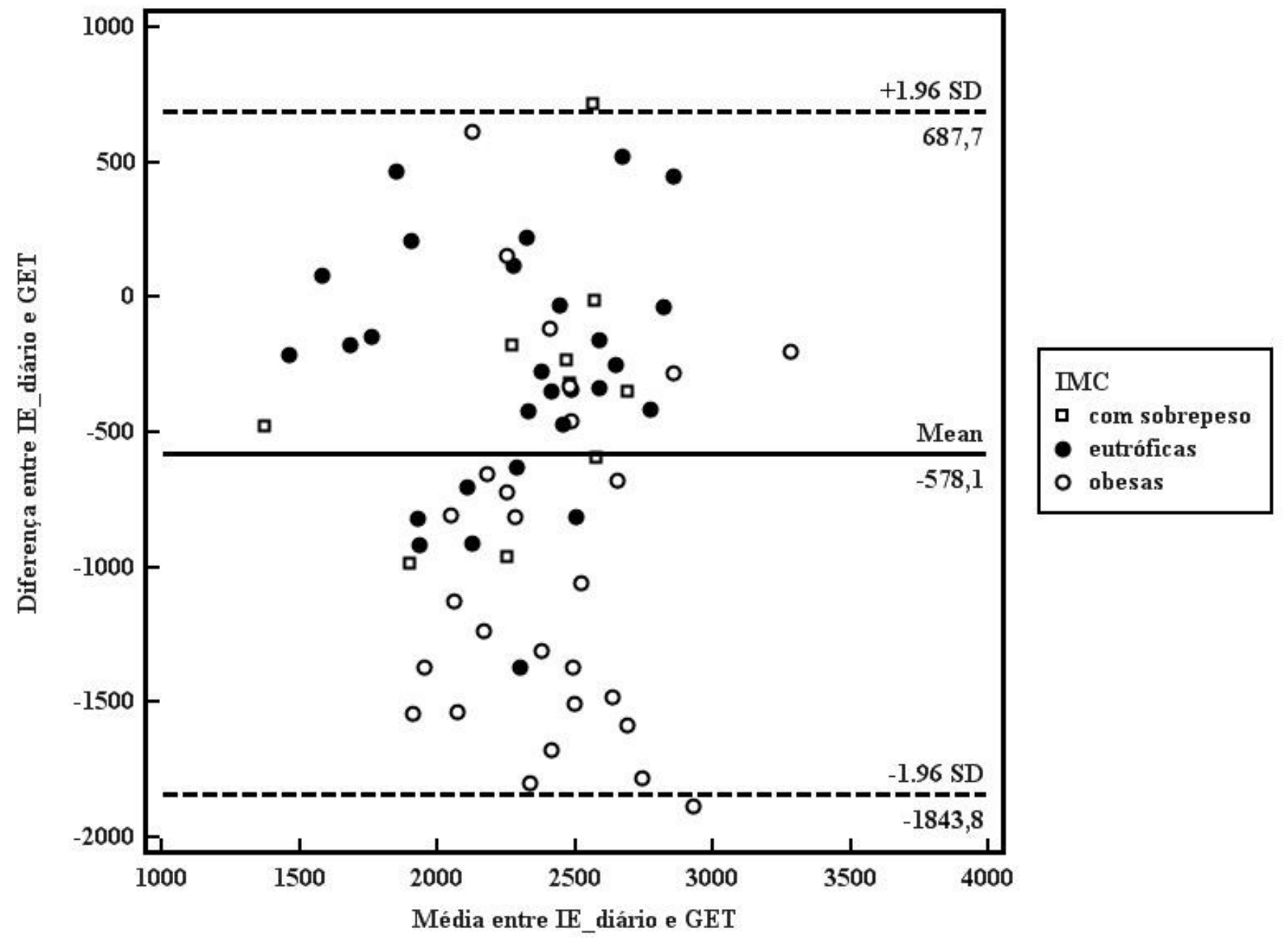

Mean $=$ média. $\mathrm{SD}=$ desvio-padrão.

IE_diário: IE obtida pelo diário alimentar.

Linha sólida = diferença média entre as mensurações.

Linha tracejada $=$ diferença média mais e menos 1,96 desvio-padrão.

FIGURA 10 - Gráfico de Bland e Altman: diferença entre a IE obtida pelo diário alimentar e o GET versus a média entre os mesmos, de acordo com as categorias de IMC. 


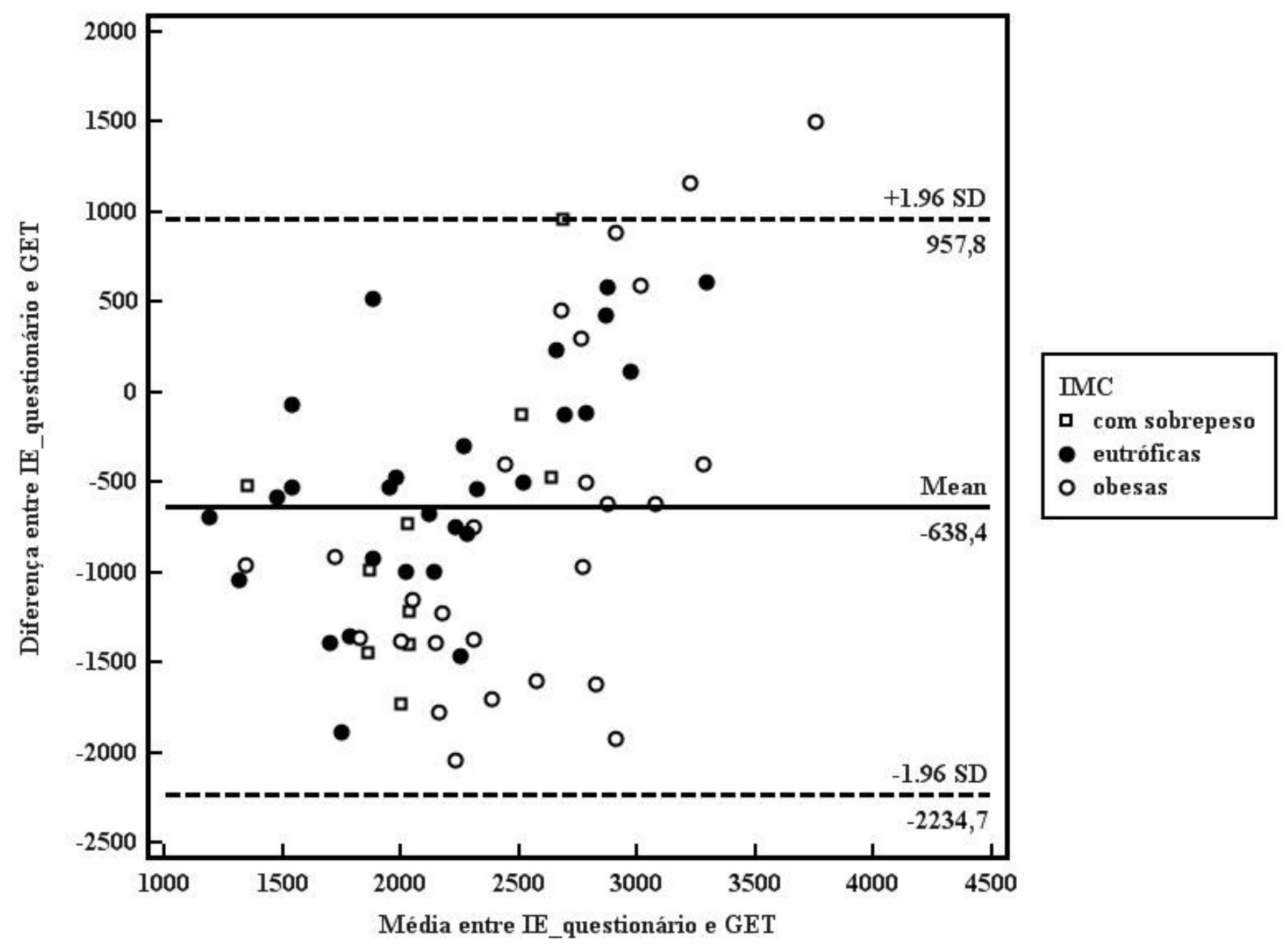

Mean = média. SD = desvio-padrão.

IE_questionário: IE obtida pelo questionário de freqüência alimentar. Linha sólida = diferença média entre as mensurações.

Linha tracejada = diferença média mais e menos 1,96 desvio-padrão.

FIGURA 11 - Gráfico de Bland e Altman: diferença entre a IE obtida pelo questionário de freqüência alimentar e o GET versus a média entre os mesmos, de acordo com as categorias de IMC. 
A FIGURA 12 mostra as proporções de indivíduos sub-relatores (obtidas pelo recordatório alimentar) dentro de cada categoria IMC, bem como o resultado do teste de qui-quadrado que comparou tais proporções.

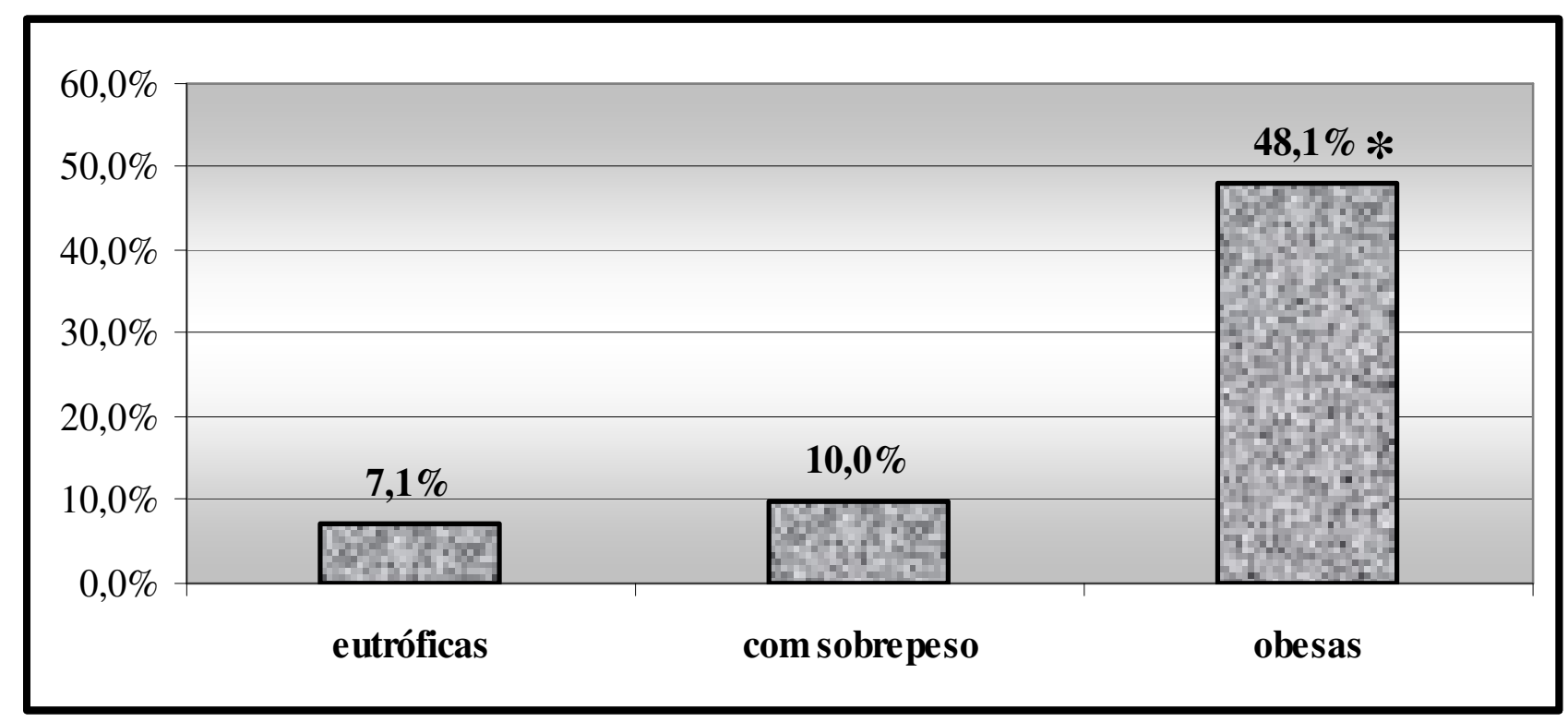

${ }^{*} X^{2}(2)=13,82 ; p=0,001$

FIGURA 12 - Distribuição percentual de indivíduos sub-relatores em cada categoria de IMC, de acordo com os dados do recordatório alimentar.

A FIGURA 13, por sua vez, apresenta as proporções de indivíduos subrelatores (obtidas pelo diário alimentar) dentro de cada categoria IMC, assim como o resultado do teste de qui-quadrado que comparou tais proporções. 


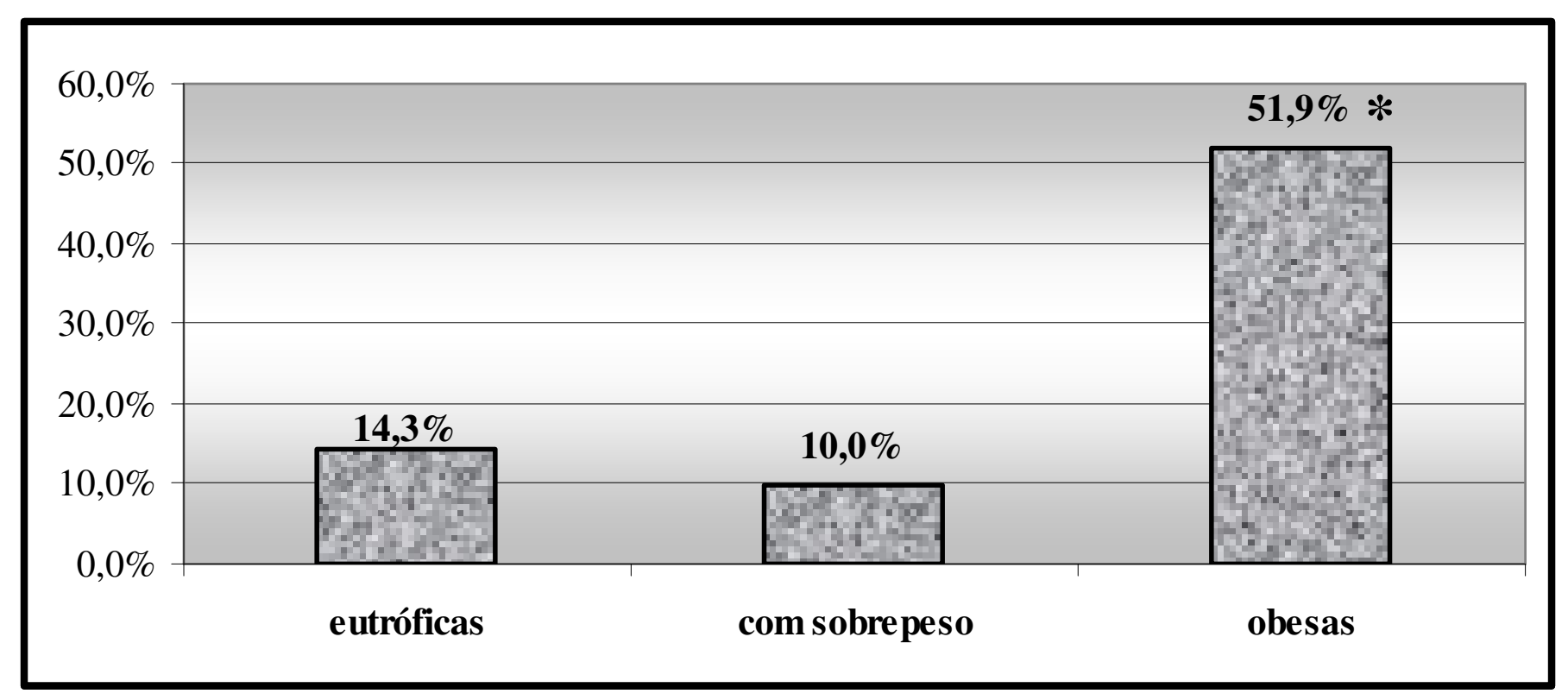

${ }^{*} X^{2}(2)=11,5 ; p=0,003$

FIGURA 13 - Distribuição percentual de indivíduos sub-relatores em cada categoria de IMC, de acordo com os dados do diário alimentar.

Já a FIGURA 14 ilustra as proporções de indivíduos sub-relatores (obtidas pelo questionário de freqüência alimentar) dentro de cada categoria IMC e também o resultado do teste de qui-quadrado que comparou tais proporções. 


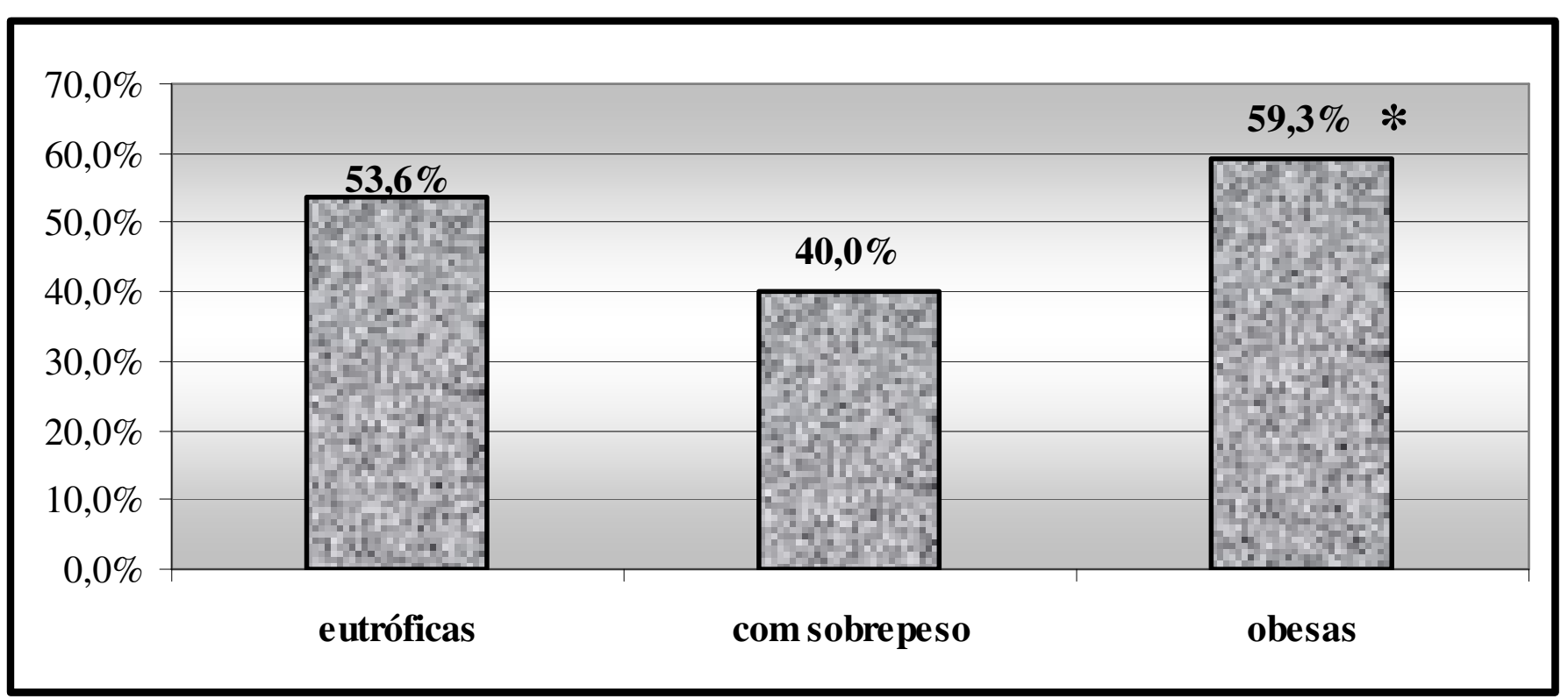

${ }^{*} X^{2}(2)=1,1 ; p=0,58$.

FIGURA 14 - Distribuição percentual de indivíduos sub-relatores em cada categoria de IMC, de acordo com os dados do questionário de freqüência alimentar.

\subsection{Avaliação das características dos sub-relatores}

Para os três métodos de avaliação do consumo alimentar, foram feitas correlações entre a sua respectiva razão IE/GET (transformada em log de base 10) e diversas variáveis independentes. A TABELA 6 mostra as correlações obtidas para o recordatório alimentar, enquanto que as TABELAS 7 e 8 apresentam, respectivamente, as correlações para o diário e para o questionário de freqüência alimentar. 
TABELA 6 - Correlações entre a razão IE/GET (transformada em log de base 10), obtida pelo recordatório alimentar e as variáveis independentes.

\begin{tabular}{|c|c|c|}
\hline Variáveis independentes & $\begin{array}{l}\text { Coeficiente de } \\
\text { correlação }(r)\end{array}$ & Nível de significância $(p)$ \\
\hline \multicolumn{3}{|c|}{ Variáveis com distribuição normal - coeficiente de correlação de Pearson } \\
\hline $\begin{array}{l}\text { Escore de restrição } \\
\text { dietética }\end{array}$ & $-0,40$ & 0,001 \\
\hline $\begin{array}{l}\text { Renda per capita } \\
\text { (transformada em log de } \\
\text { base 10) }\end{array}$ & 0,38 & 0,002 \\
\hline $\begin{array}{l}\text { Escore de compulsão } \\
\text { alimentar (transformado } \\
\text { em raiz quadrada) }\end{array}$ & $-0,27$ & 0,03 \\
\hline \multicolumn{3}{|c|}{ Variáveis sem distribuição normal - coeficiente de correlação de Spearman } \\
\hline Idade & $-0,43$ & 0,0001 \\
\hline IMC & $-0,47$ & 0,0001 \\
\hline $\begin{array}{l}\text { Insatisfação corporal } \\
\text { (escore de discrepância } \\
\text { entre o tamanho corporal } \\
\text { atual e o ideal) }\end{array}$ & $-0,43$ & 0,0001 \\
\hline $\begin{array}{l}\text { Escore de desejo de } \\
\text { aceitação social }\end{array}$ & $-0,22$ & 0,085 \\
\hline $\begin{array}{l}\text { Escore de conhecimento } \\
\text { nutricional }\end{array}$ & $-0,08$ & 0,54 \\
\hline $\begin{array}{l}\text { Escore total do } \\
\text { questionário de Baecke } \\
\text { (prática de atividade } \\
\text { física) }\end{array}$ & $-0,01$ & 0,91 \\
\hline Escolaridade & 0,25 & 0,04 \\
\hline
\end{tabular}


TABELA 7 - Correlações entre a razão IE/GET (transformada em log de base 10), obtida pelo diário alimentar e as variáveis independentes.

\begin{tabular}{lll}
\hline Variáveis independentes & $\begin{array}{l}\text { Coeficiente de } \\
\text { correlação }(r)\end{array}$
\end{tabular}$\quad$ Nível de significância (p)

Variáveis com distribuição normal - coeficiente de correlação de Pearson

Escore de restrição

dietética

$-0,35 \quad 0,004$

Renda per capita

(transformada em log de

0,40

0,001

base 10)

Escore de compulsão

alimentar (transformado $\quad-0,23 \quad 0,068$

em raiz quadrada)

\begin{tabular}{lcc}
\hline \multicolumn{2}{c}{ Variáveis sem distribuição normal - coeficiente de correlação de Spearman } \\
\hline $\begin{array}{l}\text { Idade } \\
\text { IMC }\end{array}$ & $-0,33$ & 0,007 \\
$\begin{array}{l}\text { Insatisfação corporal } \\
\text { (escore de discrepância } \\
\text { entre o tamanho corporal }\end{array}$ & $-0,39$ & 0,001 \\
$\begin{array}{l}\text { atual e o ideal) } \\
\text { Escore de desejo de }\end{array}$ & $-0,37$ & 0,003 \\
$\begin{array}{l}\text { aceitação social } \\
\text { Escore de conhecimento }\end{array}$ & \\
$\begin{array}{l}\text { nutricional } \\
\text { Escore total do } \\
\text { questionário de Baecke } \\
\text { (prática de atividade }\end{array}$ & $-0,26$ & 0,04 \\
física) & 0,15 & 0,24 \\
Escolaridade & & \\
\hline
\end{tabular}


TABELA 8 - Correlações entre a razão IE/GET (transformada em log de base 10), obtida pelo questionário de freqüência alimentar e as variáveis independentes.

\begin{tabular}{|c|c|c|}
\hline Variáveis independentes & $\begin{array}{l}\text { Coeficiente de } \\
\text { correlação (r) }\end{array}$ & Nível de significância $(p)$ \\
\hline \multicolumn{3}{|c|}{ Variáveis com distribuição normal - coeficiente de correlação de Pearson } \\
\hline $\begin{array}{l}\text { Escore de restrição } \\
\text { dietética }\end{array}$ & $-0,12$ & 0,34 \\
\hline $\begin{array}{l}\text { Renda per capita } \\
\text { (transformada em log de } \\
\text { base 10) }\end{array}$ & 0,10 & 0,44 \\
\hline $\begin{array}{l}\text { Escore de compulsão } \\
\text { alimentar (transformado } \\
\text { em raiz quadrada) }\end{array}$ & 0,07 & 0,57 \\
\hline \multicolumn{3}{|c|}{ Variáveis sem distribuição normal - coeficiente de correlação de Spearman } \\
\hline Idade & $-0,09$ & 0,47 \\
\hline IMC & $-0,10$ & 0,42 \\
\hline $\begin{array}{l}\text { Insatisfação corporal } \\
\text { (escore de discrepância } \\
\text { entre o tamanho corporal } \\
\text { atual e o ideal) }\end{array}$ & $-0,001$ & 0,99 \\
\hline $\begin{array}{l}\text { Escore de desejo de } \\
\text { aceitação social }\end{array}$ & $-0,34$ & 0,005 \\
\hline $\begin{array}{l}\text { Escore de conhecimento } \\
\text { nutricional }\end{array}$ & 0,01 & 0,94 \\
\hline $\begin{array}{l}\text { Escore total do } \\
\text { questionário de Baecke } \\
\text { (prática de atividade } \\
\text { física) }\end{array}$ & $-0,03$ & 0,82 \\
\hline Escolaridade & 0,04 & 0,74 \\
\hline
\end{tabular}


Após ter sido confirmado que muitas das variáveis independentes correlacionavam-se com a acurácia do relato e, mais ainda, que tais correlações variavam conforme o método de inquérito alimentar foram feitas análises para detectar se tais variáveis diferiam conforme a freqüência de sub-relato.

Vinte e três sujeitos (35,4\%) foram classificados como "nunca subrelatores". Já vinte e quatro indivíduos (36,9\%) foram considerados "sub-relatores ocasionais", pois sub-relataram em apenas um método de avaliação do consumo alimentar. Finalmente, dezoito sujeitos (27.7\%) foram classificados como "subrelatores freqüentes", já que subnotificaram sua ingestão em dois ou três métodos de avaliação do consumo alimentar. A comparação das variáveis independentes entre esses três grupos encontra-se na TABELA 9. A TABELA 10, por sua vez, mostra a distribuição percentual dos sujeitos "nunca sub-relatores", "sub-relatores ocasionais" e "sub-relatores freqüentes" entre as categorias de IMC. 
TABELA 9 - Comparação das características entre os sujeitos "nunca sub-relatores", "sub-relatores ocasionais" e "sub-relatores freqüentes" (dados apresentados como: média \pm desvio-padrão [mediana; mínimo máximo]).

\begin{tabular}{|c|c|c|c|c|}
\hline Características & $\begin{array}{l}\text { Nunca sub- } \\
\text { relatores } \\
(n=23)\end{array}$ & $\begin{array}{c}\text { Sub-relatores } \\
\text { ocasionais } \\
(n=24)\end{array}$ & $\begin{array}{l}\text { Sub-relatores } \\
\text { freqüentes } \\
(n=18)\end{array}$ & $\begin{array}{l}\text { Estatística do } \\
\text { teste }{ }^{\star} \text { e nível de } \\
\text { significância } \\
\text { (p) }\end{array}$ \\
\hline $\begin{array}{l}\text { Escore de } \\
\text { restrição } \\
\text { dietética }\end{array}$ & $\begin{array}{c}15,7 \pm 7,3 \\
{[15,0} \\
6,0-31,0]\end{array}$ & $\begin{array}{c}14,8 \pm 7,6 \\
{[14,0 ;} \\
2,0-31,0]\end{array}$ & $\begin{array}{c}19,2 \pm 8,5 \\
{[20,5} \\
5,0-33,0]\end{array}$ & $\begin{array}{l}F=1,80 \\
p=0,17\end{array}$ \\
\hline $\begin{array}{l}\text { Renda per capita } \\
\text { (em reais) }\end{array}$ & $\begin{array}{c}1.591 \pm 1.519 \\
{[1.000} \\
175-6.000]\end{array}$ & $\begin{array}{c}1.502 \pm 1.168 \\
{[1.250} \\
117-4.000]\end{array}$ & $\begin{array}{c}619 \pm 359 \\
{[613} \\
75-1.400]\end{array}$ & $\begin{array}{l}F=3,98 \\
p=0,02\end{array}$ \\
\hline $\begin{array}{l}\text { Escore de } \\
\text { compulsão } \\
\text { alimentar }^{\text {b }}\end{array}$ & $\begin{array}{c}12,0 \pm 9,5 \\
{[10,0 ;} \\
1,0-33,0]\end{array}$ & $\begin{array}{c}10,4 \pm 8,0[9,5 \\
0,0-34,0]\end{array}$ & $\begin{array}{c}11,5 \pm 7,2[9,0 \\
4,0-31,0]\end{array}$ & $\begin{array}{l}F=0,23 \\
p=0,79\end{array}$ \\
\hline Idade (em anos) & $\begin{array}{c}30,2 \pm 9,4 \\
{[26,0 ;} \\
18,0-55,0]\end{array}$ & $\begin{array}{c}33,0 \pm 11,2 \\
{[30,0 ;} \\
18,0-57,0]\end{array}$ & $\begin{array}{c}39,1 \pm 10,2 \\
{[41,0 ;} \\
19,0-53,0]\end{array}$ & $\begin{array}{c}x^{2}(2)=6,1 \\
p=0,05\end{array}$ \\
\hline IMC (em kg/m²) & $\begin{array}{c}26,7 \pm 6,8 \\
{[25,4} \\
18,5-39,9]\end{array}$ & $\begin{array}{c}26,9 \pm 6,5 \\
{[24,5} \\
18,5-39,2]\end{array}$ & $\begin{array}{c}30,9 \pm 6,2 \\
{[31,9 ;} \\
18,9-37,9]\end{array}$ & $\begin{array}{c}x^{2}(2)=4,2 \\
p=0,13\end{array}$ \\
\hline $\begin{array}{l}\text { Insatisfação } \\
\text { corporal (escore }\end{array}$ & & & & \\
\hline $\begin{array}{l}\text { de discrepância } \\
\text { entre o tamanho } \\
\text { corporal atual e o } \\
\text { ideal) }\end{array}$ & $\begin{array}{c}2,0 \pm 1,3[2,0 \\
0,0-5,0]\end{array}$ & $\begin{array}{c}1,4 \pm 1,3[1,0 \\
-1,0-5,0]\end{array}$ & $\begin{array}{c}2,3 \pm 1,5[2,0 \\
-1,0-5,0]\end{array}$ & $\begin{array}{c}x^{2}(2)=5,4 \\
p=0,07\end{array}$ \\
\hline $\begin{array}{l}\text { Escore de desejo } \\
\text { de aceitação } \\
\text { social }\end{array}$ & $\begin{array}{c}13,9 \pm 5,5 \\
{[15,0} \\
2,0-25,0]\end{array}$ & $\begin{array}{c}16,8 \pm 4,6 \\
{[17,0} \\
6,0-24,0]\end{array}$ & $\begin{array}{c}17,2 \pm 4,0 \\
{[17,0} \\
9,0-25,0]\end{array}$ & $\begin{array}{c}x^{2}(2)=6,3 \\
p=0,04\end{array}$ \\
\hline
\end{tabular}


Nunca sub- Sub-relatores Sub-relatores

Características relatores ocasionais freqüentes

$(n=23) \quad(n=24) \quad(n=18)$

Estatística do teste ${ }^{\star}$ e nível de significância

(p)

\begin{tabular}{lcccc}
\hline $\begin{array}{l}\text { Escore de } \\
\text { conhecimento }\end{array}$ & $9,2 \pm 2,5$ & $9,2 \pm 2,1[9,5 ;$ & $8,8 \pm 2,5[9,5 ;$ & $x^{2}(2)=0,18 ;$ \\
nutricional & $4,0-14,0]$ & $5,0-13,0]$ & $5,0-12,0]$ & $p=0,31$ \\
$\begin{array}{l}\text { Escore total do } \\
\text { questionário de }\end{array}$ & $8,0 \pm 1,3[8,3 ;$ & $8,0 \pm 1,2[8,3 ;$ & $8,1 \pm 1,4[7,9 ;$ & $x^{2}(2)=0,04 ;$ \\
$\begin{array}{l}\text { Baecke (prática } \\
\text { de atividade }\end{array}$ & $6,0-10,4]$ & $6,4-10,1]$ & $6,0-10,6]$ & $\mathrm{p}=0,98$ \\
física) & & & & \\
Escolaridade (em & $13,4 \pm 2,7$ & $13,2 \pm 2,0$ & $11,9 \pm 2,0$ & $\mathrm{x}^{2}(2)=7,2 ;$ \\
anos de estudo) & {$[15,0 ;$} & {$[13,0 ;$} & {$[11,0 ;$} & $\mathrm{p}=0,03$ \\
\hline
\end{tabular}

*: quando a variável independente possuía distribuição normal, foi utilizada a ANOVA e apresentado o valor de F. Quando a variável independente não possuía distribuição normal, foi utilizado o teste de Kruskal-Wallis e apresentado o valor de $x^{2}$.

a: para realização da ANOVA, a variável foi transformada em log de base 10.

b: para realização da ANOVA, a variável foi transformada em raiz quadrada.

TABELA 10 - Distribuição percentual dos sujeitos "nunca sub-relatores", "subrelatores ocasionais" e "sub-relatores freqüentes" entre as categorias de IMC.

\begin{tabular}{lccc}
\hline Categorias de IMC & $\begin{array}{c}\text { Nunca sub- } \\
\text { relatores } \\
(\mathbf{n}=\mathbf{2 3})\end{array}$ & $\begin{array}{c}\text { Sub-relatores } \\
\text { ocasionais } \\
(\mathbf{n}=\mathbf{2 4})\end{array}$ & $\begin{array}{c}\text { Sub-relatores } \\
\text { freqüentes } \\
(\mathbf{n}=\mathbf{1 8})\end{array}$ \\
\hline $\begin{array}{l}\text { Sujeitos com } \\
\text { eutrofia }(\mathbf{n}=\mathbf{2 8})\end{array}$ & $39,3 \%$ & $50,0 \%$ & $10,7 \%$ \\
$\begin{array}{l}\text { Sujeitos com } \\
\text { sobrepeso }(\mathbf{n}=\mathbf{1 0})\end{array}$ & $60,0 \%$ & $20,0 \%$ & $20,0 \%$ \\
$\begin{array}{l}\text { Sujeitos com } \\
\text { obesidade }(\mathbf{n}=\mathbf{2 8})\end{array}$ & $22,2 \%$ & $29,6 \%$ & $48,1 \%$ \\
${ }^{*} \mathrm{X}^{2}(4)=12,82 ; p=0,01$. & & &
\end{tabular}




\subsection{Avaliação da presença do sub-relato na análise de padrões alimentares}

Após diversas tentativas, foi escolhida uma solução de análise de cluster que obteve três agrupamentos (ou clusters) de padrão alimentar. Para cada cluster de padrão alimentar, foram determinados os centros de todas as variáveis, isto é, de todos os grupos alimentares. Em seguida, análises de variância foram realizadas para determinar quais grupos de alimentos separavam mais os clusters de padrão alimentar. Observando esses resultados, os clusters foram nomeados de acordo com os seus grupos alimentares mais significativos. O primeiro cluster foi composto por 31 voluntários e foi nomeado "alimentos doces", pois seus principais grupos alimentares foram os doces e os refrigerantes contendo açúcar. O segundo cluster foi formado por 24 sujeitos e foi denominado "alimentos ricos em amido", pois seus grupos alimentares mais importantes foram as leguminosas e os grãos e feculentos. Já o terceiro cluster foi composto por 10 voluntários e foi chamado de "alimentos frugais", já que seus grupos alimentares mais relevantes foram as frutas, hortaliças e o frango.

A TABELA 11 mostra, para cada cluster de padrão alimentar, as médias e os intervalos de $95 \%$ de confiança da freqüência diária de consumo/1.000 kcal, para cada grupo alimentar analisado. 
TABELA 11 - Freqüências diárias de consumo/1.000 kcal de cada grupo alimentar, obtidas por cada cluster de padrão alimentar - dados apresentados como: média (limite inferior - limite superior do intervalo de 95\% de confiança).

\begin{tabular}{|c|c|c|c|c|}
\hline \multirow[b]{2}{*}{$\begin{array}{c}\text { Grupos alimentares } \\
\text { (freqüência diária } \\
\text { de consumo/1.000 } \\
\text { kcal) }\end{array}$} & \multicolumn{4}{|c|}{ Clusters de padrão alimentar } \\
\hline & $\begin{array}{l}\text { Cluster 1- } \\
\text { “alimentos } \\
\text { doces" } \\
(\mathrm{n}=31)\end{array}$ & $\begin{array}{l}\text { Cluster 2 - } \\
\text { "alimentos ricos } \\
\text { em amido" } \\
(n=24)\end{array}$ & $\begin{array}{l}\text { Cluster } 3 \text { - } \\
\text { “alimentos } \\
\text { frugais" } \\
\text { (n=10) }\end{array}$ & $\begin{array}{c}\text { Valores de } \\
\text { F e p }\end{array}$ \\
\hline Pães & $\begin{array}{c}0,50 \\
(0,37-0,63)\end{array}$ & $\begin{array}{c}0,58 \\
(0,43-0,72)\end{array}$ & $\begin{array}{c}0,50 \\
(0,33-0,67)\end{array}$ & $\begin{array}{l}F=0,40 \\
p=0,69\end{array}$ \\
\hline Grãos e feculentos & $\begin{array}{c}0,68 \\
(0,60-0,76)\end{array}$ & $\begin{array}{c}1,26 \\
(0,99-1,52)\end{array}$ & $\begin{array}{c}0,96 \\
(0,69-1,22)\end{array}$ & $\begin{array}{l}F=11,70 \\
p=0,0001\end{array}$ \\
\hline Leguminosas & $\begin{array}{c}0,27 \\
(0,20-0,34)\end{array}$ & $\begin{array}{c}0,65 \\
(0,46-0,85)\end{array}$ & $\begin{array}{c}0,25 \\
(0,10-0,41)\end{array}$ & $\begin{array}{l}F=10,70 \\
p=0,0001\end{array}$ \\
\hline Frutas & $\begin{array}{c}1,09 \\
(0,84-1,34)\end{array}$ & $\begin{array}{c}1,28 \\
(1,00-1,56)\end{array}$ & $\begin{array}{c}2,68 \\
(1,89-3,50)\end{array}$ & $\begin{array}{l}F=17,10 \\
p=0,0001\end{array}$ \\
\hline Hortaliças & $\begin{array}{c}1,10 \\
(0,89-1,30)\end{array}$ & $\begin{array}{c}1,34 \\
(1,14-1,54)\end{array}$ & $\begin{array}{c}3,03 \\
(2,17-3,89)\end{array}$ & $\begin{array}{l}F=33,00 \\
p=0,0001\end{array}$ \\
\hline Ovos & $\begin{array}{c}0,09 \\
(0,05-0,12)\end{array}$ & $\begin{array}{c}0,10 \\
(0,06-0,13)\end{array}$ & $\begin{array}{c}0,09 \\
(0,02-0,17)\end{array}$ & $\begin{array}{l}F=0,10 \\
p=0,91\end{array}$ \\
\hline $\begin{array}{l}\text { Laticínios sem } \\
\text { redução do teor de } \\
\text { gordura }\end{array}$ & $\begin{array}{c}0,37 \\
(0,24-0,49)\end{array}$ & $\begin{array}{c}0,26 \\
(0,15-0,36)\end{array}$ & $\begin{array}{c}0,27 \\
(0,10-0,44)\end{array}$ & $\begin{array}{l}F=1,00 \\
p=0,36\end{array}$ \\
\hline $\begin{array}{l}\text { Laticínios com } \\
\text { redução do teor de } \\
\text { gordura }\end{array}$ & $\begin{array}{c}0,35 \\
(0,24-0,46)\end{array}$ & $\begin{array}{c}0,39 \\
(0,26-0,86)\end{array}$ & $\begin{array}{c}0,56 \\
(0,09-0,69)\end{array}$ & $\begin{array}{l}F=0,60 \\
p=0,54\end{array}$ \\
\hline Carne bovina & $\begin{array}{c}0,30 \\
(0,24-0,36)\end{array}$ & $\begin{array}{c}0,35 \\
(0,15-0,36)\end{array}$ & $\begin{array}{c}0,25 \\
(0,22-0,48)\end{array}$ & $\begin{array}{l}F=0,70 \\
p=0,52\end{array}$ \\
\hline
\end{tabular}


Clusters de padrão alimentar

\begin{tabular}{|c|c|c|c|c|}
\hline $\begin{array}{c}\text { Grupos alimentares } \\
\text { (freqüência diária } \\
\text { de consumo/1.000 } \\
\text { kcal) }\end{array}$ & $\begin{array}{l}\text { Cluster 1- } \\
\text { "alimentos } \\
\text { doces" } \\
(n=31)\end{array}$ & $\begin{array}{c}\text { Cluster 2- } \\
\text { "alimentos ricos } \\
\text { em amido" } \\
\text { (n=24) }\end{array}$ & $\begin{array}{l}\text { Cluster 3- } \\
\text { "alimentos } \\
\text { frugais" } \\
(n=10)\end{array}$ & $\begin{array}{l}\text { Valores de } \\
\text { F e p }\end{array}$ \\
\hline Carne suína & $\begin{array}{c}0,11 \\
(0,08-0,14)\end{array}$ & $\begin{array}{c}0,14 \\
(0,10-0,18)\end{array}$ & $\begin{array}{c}0,16 \\
(0,04-0,27)\end{array}$ & $\begin{array}{l}F=1,00 \\
p=0,38\end{array}$ \\
\hline Frango & $\begin{array}{c}0,17 \\
(0,13-0,21)\end{array}$ & $\begin{array}{c}0,16 \\
(0,09-0,22)\end{array}$ & $\begin{array}{c}0,31 \\
(0,09-0,52)\end{array}$ & $\begin{array}{l}F=3,10 \\
p=0,05\end{array}$ \\
\hline Peixes & $\begin{array}{c}0,06 \\
(0,04-0,09)\end{array}$ & $\begin{array}{c}0,11 \\
(0,04-0,21)\end{array}$ & $\begin{array}{c}0,12 \\
(0,05-0,17)\end{array}$ & $\begin{array}{l}F=2,10 \\
p=0,14\end{array}$ \\
\hline Biscoitos & $\begin{array}{c}0,26 \\
(0,15-0,37)\end{array}$ & $\begin{array}{c}0,26 \\
(0,14-0,40)\end{array}$ & $\begin{array}{c}0,22 \\
(0,13-0,31)\end{array}$ & $\begin{array}{l}F=0,10 \\
p=0,91\end{array}$ \\
\hline Doces & $\begin{array}{c}1,33 \\
(1,06-1,60)\end{array}$ & $\begin{array}{c}0,43 \\
(0,30-0,57)\end{array}$ & $\begin{array}{c}0,59 \\
(0,32-0,85)\end{array}$ & $\begin{array}{l}F=18,70 \\
p=0,0001\end{array}$ \\
\hline Açúcares & $\begin{array}{c}0,51 \\
(0,33-0,69)\end{array}$ & $\begin{array}{c}0,36 \\
(0,01-0,50)\end{array}$ & $\begin{array}{c}0,24 \\
(0,19-0,52)\end{array}$ & $\begin{array}{l}F=1,70 \\
p=0,19\end{array}$ \\
\hline $\begin{array}{l}\text { Refrigerantes } \\
\text { contendo açúcar }\end{array}$ & $\begin{array}{c}0,20 \\
(0,07-0,32)\end{array}$ & $\begin{array}{c}0,04 \\
(0,05-0,08)\end{array}$ & $\begin{array}{c}0,09 \\
(0,01-0,20)\end{array}$ & $\begin{array}{l}F=2,60 \\
p=0,07\end{array}$ \\
\hline $\begin{array}{l}\text { Refrigerantes } \\
\text { contendo adoçantes } \\
\text { artificiais }\end{array}$ & $\begin{array}{c}0,14 \\
(0,04-0,24)\end{array}$ & $\begin{array}{c}0,07 \\
(0,001-0,14)\end{array}$ & $\begin{array}{c}0,05 \\
(0,006- \\
0,10)\end{array}$ & $\begin{array}{l}F=1,10 \\
p=0,34\end{array}$ \\
\hline $\begin{array}{l}\text { Manteiga/margarina/ } \\
\text { maionese }\end{array}$ & $\begin{array}{c}0,38 \\
(0,23-0,52)\end{array}$ & $\begin{array}{c}0,52 \\
(0,27-0,78)\end{array}$ & $\begin{array}{c}0,41 \\
(0,13-0,70)\end{array}$ & $\begin{array}{l}F=0,60 \\
p=0,54\end{array}$ \\
\hline $\begin{array}{l}\text { Margarina com } \\
\text { redução do teor de } \\
\text { gordura }\end{array}$ & $\begin{array}{c}0,03 \\
(0,006- \\
0,06)\end{array}$ & $\begin{array}{c}0,01 \\
(0,005-0,03)\end{array}$ & $\begin{array}{c}0,07 \\
(0,02-0,17)\end{array}$ & $\begin{array}{l}F=1,90 \\
p=0,17\end{array}$ \\
\hline
\end{tabular}


Clusters de padrão alimentar

\begin{tabular}{lcccc}
\hline $\begin{array}{c}\text { Grupos alimentares } \\
\text { (freqüência diária } \\
\text { de consumo/1.000 } \\
\text { kcal) }\end{array}$ & $\begin{array}{c}\text { Cluster } \mathbf{1 -} \\
\text { "alimentos } \\
\text { doces" } \\
(\mathbf{n}=\mathbf{3 1})\end{array}$ & $\begin{array}{c}\text { Cluster 2 } \\
\text { "alimentos ricos } \\
\text { em amido" } \\
(\mathbf{n}=\mathbf{2 4})\end{array}$ & $\begin{array}{c}\text { Cluster } \mathbf{3}- \\
\text { "alimentos } \\
\text { frugais" } \\
\mathbf{( n = 1 0 )}\end{array}$ & $\begin{array}{c}\text { Valores } \\
\text { de F e p }\end{array}$ \\
\hline Frituras & 0,12 & 0,10 & 0,09 & $\mathrm{~F}=0,29 ;$ \\
Pizza & $(0,08-0,16)$ & $(0,03-0,16)$ & $(0,04-0,14)$ & $\mathrm{p}=0,75$ \\
& 0,06 & 0,06 & 0,08 & $\mathrm{~F}=0,40 ;$ \\
Hambúrguer & $(0,08-0,16)$ & $(0,03-0,16)$ & $(0,04-0,14)$ & $\mathrm{p}=0,7$ \\
& 0,05 & 0,03 & 0,08 & $\mathrm{~F}=2,50 ;$ \\
& $(0,03-0,06)$ & $(0,02-0,05)$ & $(0,01-0,16)$ & $\mathrm{p}=0,09$ \\
\hline
\end{tabular}

A FIGURA 15 mostra a distribuição dos indivíduos sub-relatores por cluster de padrão alimentar. Para o cluster "alimentos doces" foi encontrado um intervalo de $95 \%$ de confiança para proporção de 35,5 a $55,0 \%$. Já para o cluster "alimentos ricos em amido", este foi de 48,6 a $68,0 \%$ e, para o cluster "alimentos frugais" este foi de 61,0 a $79,0 \%$. 


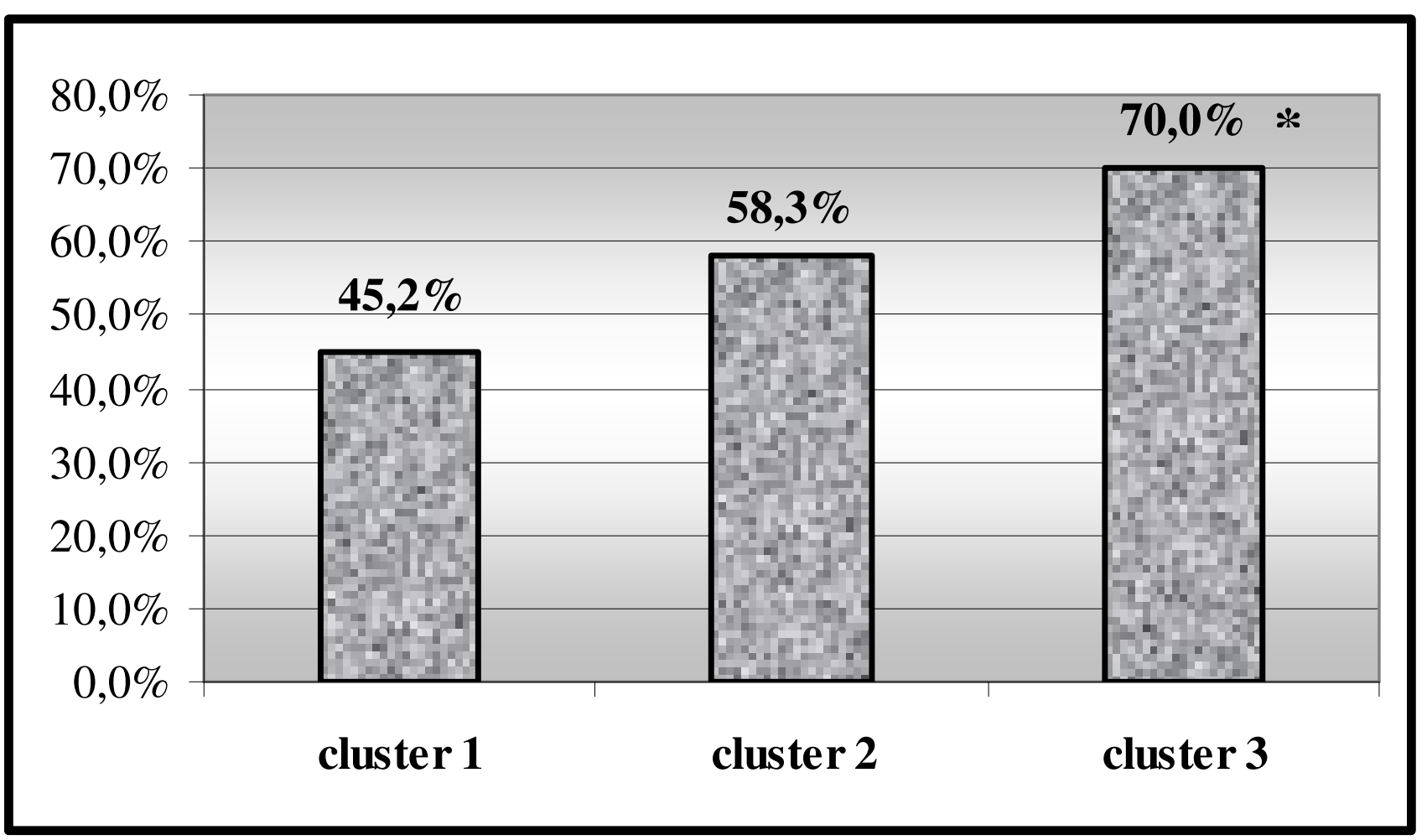

${ }^{*}: x^{2}(2)=2,2 ; p=0,34$

Cluster 1 = "alimentos doces"; cluster 2 = "alimentos ricos em amido"; cluster 3 = "alimentos frugais".

FIGURA 15 - Proporção de sub-relatores em cada cluster de padrão alimentar.

A TABELA 12 apresenta os valores de IE, IE/GET e IG obtidos por cada cluster de padrão alimentar, bem como os resultados das análises de variância que compararam tais variáveis entre os clusters. Já a TABELA 13 compara idade, IMC e ingestão de macronutrientes entre os agrupamentos. 
TABELA 12 - Valores de IE, IE/GET e IG obtidos por cada cluster de padrão alimentar (dados apresentados como: média \pm desvio-padrão [mediana; mínimo - máximo]) ${ }^{*}$.

\begin{tabular}{|c|c|c|c|c|}
\hline Clusters & $\begin{array}{l}\text { Cluster 1- } \\
\text { "alimentos } \\
\text { doces" } \\
(n=31)\end{array}$ & $\begin{array}{c}\text { Cluster 2- } \\
\text { "alimentos ricos } \\
\text { em amido" } \\
(n=24)\end{array}$ & $\begin{array}{l}\text { Cluster 3- } \\
\text { "alimentos } \\
\text { frugais" } \\
(n=10)\end{array}$ & $\begin{array}{c}\text { Valores de } \\
\text { F e p }\end{array}$ \\
\hline $\begin{array}{l}\text { IE (em } \\
\text { kcal/dia) a }\end{array}$ & $\begin{array}{c}2.133 \pm 816 \\
{[1.861} \\
1.088-4.505]\end{array}$ & $\begin{array}{c}1.955 \pm 835 \\
{[1.730 ;} \\
796-3.802]\end{array}$ & $\begin{array}{c}1.591 \pm 818 \\
{[1.259} \\
803-3.351]\end{array}$ & $\begin{array}{c}F=2,50 \\
p=0,08\end{array}$ \\
\hline IE/GET ${ }^{a}$ & $\begin{array}{c}0,86 \pm 0,30 \\
{[0,76} \\
0,45-1,50]\end{array}$ & $\begin{array}{c}0,71 \pm 0,28 \\
{[0,60} \\
0,42-1,44]\end{array}$ & $\begin{array}{c}0,58 \pm 0,31 \\
{[0,48} \\
0,30-1,36]\end{array}$ & $\begin{array}{l}F=6,50 \\
p=0,003\end{array}$ \\
\hline $\begin{array}{l}\text { IG (em } \\
\text { kcal/dia) }\end{array}$ & $\begin{array}{c}-356 \pm 742 \\
{[-521} \\
-1.598-1.508]\end{array}$ & $\begin{array}{c}-764 \pm 749 \\
{[-913} \\
-1.922-1.164]\end{array}$ & $\begin{array}{c}-1.213 \pm 875 \\
{[-1.497} \\
-2.043-888]\end{array}$ & $\begin{array}{l}F=5,30 \\
p=0,008\end{array}$ \\
\hline
\end{tabular}

*: IE = ingestão energética; IE/GET = ingestão energética/gasto energético total; IG = ingestão energética - gasto energético total.

a: para realização da ANOVA, a variável foi transformada em log de base 10. 
TABELA 13 - Valores de idade, índice de massa corporal (IMC) e ingestão de macronutrientes obtidos por cada cluster de padrão alimentar dados apresentados como: média \pm desvio-padrão (mediana; mínimo - máximo).

\begin{tabular}{|c|c|c|c|}
\hline Clusters & $\begin{array}{l}\text { Cluster 1- } \\
\text { “alimentos } \\
\text { doces" } \\
(n=31)\end{array}$ & $\begin{array}{c}\text { Cluster 2 - } \\
\text { “alimentos ricos } \\
\text { em amido" } \\
\text { (n=24) }\end{array}$ & $\begin{array}{l}\text { Cluster } 3 \text { - } \\
\text { "alimentos } \\
\text { frugais" } \\
(n=10)\end{array}$ \\
\hline Idade (anos) & $\begin{array}{c}31 \pm 10 \\
(27 ; 18-55)\end{array}$ & $\begin{array}{c}40 \pm 8 \\
(42 ; 24-53)\end{array}$ & $\begin{array}{c}34 \pm 12 \\
(34 ; 18-57)\end{array}$ \\
\hline IMC $\left(\mathrm{kg} / \mathrm{m}^{2}\right)$ & $\begin{array}{c}25,8 \pm 6,1 \\
(24,2 ; \\
18,5-39,9)\end{array}$ & $\begin{array}{c}31,1 \pm 6,7 \\
(32,9 \\
20,7-39,1)\end{array}$ & $\begin{array}{c}29,3 \pm 6,7 \\
(31,0 \\
18,9-39,2)\end{array}$ \\
\hline $\begin{array}{l}\text { Densidade protéica } \\
\text { (gramas de }\end{array}$ & $\begin{array}{c}39,2 \pm 6,1 \\
\quad(39,4\end{array}$ & $\begin{array}{c}41,1 \pm 6,3 \\
\quad(40,0\end{array}$ & $\begin{array}{c}41,9 \pm 8,0 \\
(40,8\end{array}$ \\
\hline proteínas/1.000 kcal) & $23,1-50,0)$ & $32,0-55,1)$ & $28,2-57,0)$ \\
\hline $\begin{array}{l}\text { Densidade glicídica } \\
\text { (gramas de }\end{array}$ & $\begin{array}{c}128,8 \pm 18,7 \\
(132,1\end{array}$ & $\begin{array}{c}135,8 \pm 20,3 \\
(137,5\end{array}$ & $\begin{array}{c}134,2 \pm 26,0 \\
(137,7\end{array}$ \\
\hline carboidratos/1.000 kcal) & $88,3-170,3)$ & $91,9-166,6)$ & $83,3-180,6)$ \\
\hline $\begin{array}{l}\text { Densidade lipídica } \\
\text { (gramas de }\end{array}$ & $\begin{array}{c}36,5 \pm 6,1 \\
(37,0\end{array}$ & $\begin{array}{c}34,0 \pm 6,3 \\
(34,2\end{array}$ & $\begin{array}{c}34,7 \pm 7,7 \\
(33,4\end{array}$ \\
\hline lipídeos/1.000 kcal) & $19,0-49,0)$ & $26,2-46,9)$ & $20,7-49,5)$ \\
\hline
\end{tabular}


Esse trabalho tinha como objetivo determinar a magnitude do sub-relato da ingestão energética em três métodos de avaliação do consumo alimentar, comparando assim a validade de tais estimativas obtidas pelos mesmos. A água duplamente marcada foi escolhida como o marcador da validade das estimativas de ingestão energética, permitindo identificar os indivíduos sub-relatores com acurácia. Com tal identificação, foi possível explorar diversas facetas do sub-relato, como os fatores correlacionados à acurácia do relato e a presença do sub-relato na análise de padrões alimentares.

A amostra utilizada não foi probabilística e sim de conveniência. Entretanto, foram realizados cálculos para determinar o $n$ amostral necessário e esse foi obtido pelo estudo. De acordo com CADE et al. (2002), os estudos de validação de questionários de frequência alimentar empregam amostras que variam de 6 a 3.750 sujeitos, com mediana de 110. Porém, de acordo com os mesmos autores, apenas 19\% desses estudos validaram tal questionário contra um marcador biológico. Sabe-se que estudos que comparam dois métodos de avaliação do consumo alimentar são mais baratos e simples de serem conduzidos, portanto, nesses, é possível empregar amostras maiores. No entanto, acredita-se que o $\mathrm{n}$ amostral empregado neste estudo foi adequado, pois cumpriu aquilo que foi exigido pelos métodos utilizados. Por exemplo, CADE et al. (2002) afirmam que, para utilizar o gráfico de Bland e Altman com precisão, são necessários pelo menos cinqüenta sujeitos, o que foi atingido pelo presente estudo. Devido ao alto custo da água duplamente marcada, a maior parte dos estudos que a utilizam emprega amostras modestas. O estudo OPEN foi o maior estudo com água duplamente marcada conduzido até então, com 484 sujeitos. Recentemente, KIMM, GLYNN, OBARZANEK, ASTON e DANIELS (2006) conduziram um estudo com a segunda maior amostra em uma pesquisa com água duplamente marcada $(n=120)$.

Pode-se argumentar que uma parte da amostra estudada tem um alto nível sócio-econômico, considerando-se os valores máximos de renda per capita e escolaridade (TABELA 1) e a alta proporção de voluntários que moram em residências de três e quatro dormitórios (QUADRO 4). Porém não se pode argumentar que esta amostra foi constituída exclusivamente por pessoas com alto 
nível sócio-econômico. Percebe-se que os valores mínimos de renda per capita e escolaridade foram bem baixos, e que a variação da renda foi bastante grande. Dessa forma, pode-se afirmar que a amostra tem um perfil sócio-econômico variado, condizente até com a situação de desigualdade social e concentração de renda do país. O estudo poderia ter focado em uma amostra mais homogênea, como, por exemplo, um grupo de mulheres de baixa renda. Contudo, como esse é o primeiro estudo com água duplamente marcada no país, considerou-se que seria mais informativo analisar pessoas de diferentes condições sociais, até para que se pudesse analisar como os fatores sócio-econômicos interferem no sub-relato. Ademais, os dados sócio-econômicos dessa amostra são condizentes com um estudo brasileiro de comparação entre métodos de avaliação do consumo alimentar, no qual a escolaridade variou entre 3,9 e 14,9 anos de estudo e a renda entre 0,1 e 17,5 salários mínimos por mês (CRISPIM, RIBEIRO, SILVA, ROSADO \& ROSADO, 2006).

O presente estudo também não teve interesse em selecionar sujeitos de apenas uma categoria de índice de massa corporal. Poder-se-ia supor, de antemão, que o sub-relato seria maior nas pessoas de índice de massa corporal elevado, a exemplo do que acontece em países desenvolvidos. Sabe-se também que, em mulheres brasileiras, a obesidade é mais freqüente naquelas com baixa renda (MENDEZ, MONTEIRO \& POPKIN, 2005; MONTEIRO, CONDE \& DE CASTRO, 2003). Assim, considera-se que estas constituem uma população de risco e, portanto, de grande interesse para a saúde pública. Dessa forma, torna-se urgente estudar quais fatores dietéticos levam tais mulheres ao excesso de peso. Porém, sem saber o erro associado aos métodos de inquérito alimentar que seriam utilizados em tais pesquisas, quaisquer inferências baseadas nos mesmos tornam-se de difícil interpretação. Com tais colocações, conclui-se que é imprescindível determinar o erro associado ao relato do consumo alimentar nessa população. Todavia, se o presente estudo abordasse apenas mulheres obesas de baixa renda, saberíamos o erro associado ao relato gerado pelas mesmas, mas não saberíamos se tal erro difere daquele gerado por mulheres eutróficas e/ou de alta renda. Por tais motivos, optou-se por incluir na amostra mulheres de variados índices de massa corporal e diversas faixas de renda. 
O uso da água duplamente marcada traz um grande avanço para os estudos de validação, já que ela é, de fato, uma medida de referência. Obviamente, esse método também possui limitações, porém ele é o melhor critério para validação dos métodos de inquérito alimentar porque seu erro, além de pequeno, não é o mesmo e não se correlaciona com os erros dos métodos de avaliação do consumo alimentar (KAAKS \& FERRARI, 2006). Para efeito de comparação, citar-se-á o estudo de CRISPIM et al. (2006), que, em uma amostra de adultos de Minas Gerais, comparou um questionário de freqüência alimentar a quatro recordatórios alimentares de 24 horas, tomando esses últimos como método de referência. Para o grupo de adultos com menor nível sócio-econômico, o questionário de freqüência obteve estimativas maiores do que os recordatórios, para quase todos os nutrientes. Porém, como não se sabia o erro associado ao recordatório e não havia um marcador da ingestão (como o GET medido pela água duplamente marcada), não era possível afirmar se tal discrepância entre os métodos era "boa" (resultante de menor sub-relato no questionário) ou "ruim" (resultante de maior superestimativa com o questionário). CADE et al. (2002) afirmam que esse tipo de desenho de estudo compara as medidas de um questionário freqüência alimentar a um outro método, não necessariamente mais acurado. Essa comparação só mostra se os dois métodos fornecem respostas relacionadas. Se existe desacordo entre os métodos, não é possível identificar qual obtém uma mensuração mais correta. Sabe-se que tais tipos de estudo são mais baratos e simples, porém dada a limitada resposta obtida pelos mesmos, questiona-se sua utilidade. A disponibilidade de um marcador da ingestão real no presente estudo mostrou que os três métodos aqui analisados subestimam seriamente a ingestão de energia. Esse fato pode ser constatado na TABELA 4, que mostra que a diferença entre o GET e a IE, independentemente do método de inquérito alimentar utilizado, é sempre negativa e de grande magnitude. Também se pode observar, nesta mesma tabela, que os valores mínimos de IE/GET são extremamente baixos e este fato é ainda mais alarmante quando se lembra que a amostra, de maneira geral, não perdeu peso durante o período do estudo. Portanto, razões IE/GET tão baixas são, provavelmente, muito mais decorrentes do sub-relato do que de uma real diminuição do consumo alimentar, pois esta levaria à perda de peso. 
Também é notável que os valores mínimos de ingestão energética foram sempre inferiores ao valor mínimo de gasto energético (TABELAS 3 e 4). Essa diferença foi ainda maior para o questionário de freqüência alimentar. Por outro lado, esse mesmo método foi o único que obteve um valor máximo de IE superior ao valor máximo de GET. Os outros dois métodos apresentaram valores máximos de IE ainda inferiores ao valor máximo de GET.

Por meio da análise de variância para medidas repetidas, constatou-se que a IE, obtida pelos três métodos de avaliação do consumo alimentar, era significantemente diferente do GET. Esse dado é condizente com a literatura (BELLISLE, 2001; HILL \& DAVIES, 2001; LIVINGSTONE \& BLACK, 2003). BLANTON, MOSHFEGH, BAER e KRETSCH (2006) também encontraram diferenças significantes entre o GET (medido pela água duplamente marcada) e as ingestões energéticas obtidas por um questionário de freqüência alimentar, uma história alimentar e um diário alimentar de quatorze dias. O único método que produziu valores de IE que não diferiam do GET foi o recordatório alimentar (coletado em dois dias). Essa possível diferença em relação aos resultados do presente estudo pode ter sido causada pelo diferente número de dias de recordatório ou por diferenças na amostra. No estudo de BLANTON et al. (2006), os sujeitos foram extremamente selecionados e só foram avaliados vinte voluntários que estavam muito motivados e interessados no estudo. Isso pode ser um viés, pois, provavelmente, uma amostra comunitária ou epidemiológica não terá tanta motivação e poderá responder ao instrumento de forma diferente e desconhecida. Por outro lado, o estudo de BLANTON et al. (2006) conduziu os recordatórios sem que os sujeitos soubessem que essa avaliação seria feita naquele dia. Essa estratégia não pôde ser adotada no presente estudo; os sujeitos sabiam em que dias teriam que relatar o consumo do dia anterior. Isso pode ter feito com que eles mudassem suas dietas, para causar uma melhor impressão e sentir menos constrangimento durante 0 relato, embora os entrevistadores tenham esclarecido diversas vezes que não tinham interesse em julgar e criticar a ingestão dos sujeitos.

A análise de variância para medidas repetidas também revelou que, embora a IE obtida pelos três métodos de inquérito alimentar fossem diferentes do GET, elas não apresentavam diferença entre si. Assim, se a IE obtida pelo diário ou pelo recordatório fosse considerada um critério de referência para validação, não 
teria sido possível perceber o grande viés gerado pelo questionário. Isso reforça a necessidade de se usar um marcador externo, com erros não correlacionados aos erros dos métodos de avaliação do consumo alimentar, como a água duplamente marcada.

Os diagramas de dispersão (FIGURAS 2 a 4) são úteis para visualizar a relação entre o GET e cada IE. Eles mostram os dados aos pares das duas variáveis, para checar se existe uma real relação entre elas. Constataram-se nos diagramas apresentados dados extremamente dispersos e que não formam um padrão de correlação.

Segundo a Primeira Lei da Termodinâmica, a energia é conservada, isto é, ela não pode ser criada ou destruída. A energia colocada em um sistema é então igual à energia usada e/ou armazenada por este sistema. Em termos de metabolismo humano, a ingestão de energia possível de ser metabolizada é igual ao gasto energético mais qualquer mudança nas reservas energéticas. Assim, em indivíduos com peso e estado fisiológico estáveis, que não estejam em estado ativo de crescimento (como a infância e a gravidez), o gasto energético é igual à ingestão habitual de energia (TRABULSI \& SCHOELLER, 2001). Considerando que os sujeitos desse estudo alegaram não ter tido flutuações de peso maiores do que $5 \mathrm{~kg}$ no último ano e que a maioria deles não perdeu peso durante o estudo, para estar de acordo com a Primeira Lei da Termodinâmica, os gráficos de dispersão deveriam mostrar uma correlação positiva entre a IE e o GET, apresentando uma linha ascendente que iria do canto inferior esquerdo ao canto superior direito do gráfico. Os diagramas de dispersão apresentados mostram situações biologicamente implausíveis, em franco desacordo com a lei supracitada, pois, além de não haver relação entre a IE e o GET, nos três gráficos pode-se observar que alguns indivíduos que têm maior GET ao mesmo tempo apresentam menor IE.

SCAGLIUSI, FERRIOLLI e LANCHA JR (2006b) revisaram recentemente todos os estudos acerca do sub-relato em países em desenvolvimento publicados até aquela data. Como nenhum estudo havia usado a água duplamente marcada, nenhuma conclusão definitiva pode ser obtida. Porém, tais pesquisas podem ser comparadas aos resultados da presente investigação, na tentativa de situar 0 fenômeno do sub-relato no Brasil, em relação aos outros países. 
WINKVIST, PERSSON e HARTINI (2002) analisaram o sub-relato da IE em gestantes da Indonésia, provenientes de uma coorte de gestantes participantes de um estudo epidemiológico. Seis recordatórios alimentares de 24 horas foram conduzidos em cada trimestre, totalizando 18 dias de relato. Infelizmente, o número de dados faltosos foi muito grande; de 490 gestantes recrutadas, apenas 123 forneceram dados dos 18 dias. A TMB foi estimada por equações e pontos de corte para o sub-relato, específicos por trimestre e nível de atividade física, foram estabelecidos. Obtiveram-se as seguintes razões IE/TMB: 1,33 $\pm 0,48$ (primeiro trimestre); 1,53 $\pm 0,43$ (segundo trimestre) e 1,52 $\pm 0,40$ (terceiro trimestre). Em cada trimestre, a porcentagem de sub-relatores foi igual a $29,7 \% ; 16,2 \%$ e $17,6 \%$. Ao contrário do que os dados parecem indicar, a baixa razão IE/TMB do primeiro trimestre não foi proveniente do sub-relato. As gestantes com estes valores foram entrevistadas e foi constatado que elas estavam com muitos enjôos e dificuldades para se alimentarem, o que, inclusive, resultou em um ganho de peso muito pequeno. Embora os autores insistam que as taxas de sub-relato encontradas sejam menores do que aquelas dos países ocidentais, deve-se considerar que a taxa obtida é alta e pode comprometer os levantamentos de consumo alimentar. Este estudo, entretanto, apresenta uma limitação que, nos países em desenvolvimento, não pode ser negligenciada. A subnotificação consiste no relato de IE inferior ao GET, em indivíduos que se encontrem em balanço energético. Indivíduos subnutridos obviamente não estão em balanço energético e, portanto, quando estes indivíduos apresentam IE inferior ao GET, isto não deve ser considerado sub-relato. No estudo de WINKVIST et al. (2002), não houve um critério de seleção com base no IMC. Assim, pode-se supor que algumas gestantes com baixa IE/TMB sejam desnutridas e de fato consumam pouca energia. Já no presente estudo, só foram recrutadas mulheres saudáveis, de peso estável e de IMC de, no mínimo, $18,5 \mathrm{~kg} / \mathrm{m}^{2}$.

SÁNCHEZ-CASTILLO, FRANKLIN, MCNEILL, SOLANO, BONNER, LÓPEZ, DAVIDSON e JAMES (2001) utilizaram a excreção urinária de nitrogênio e a razão IE/TMB para avaliar a validade de um diário alimentar de sete dias, preenchidos por 34 mulheres residentes na Cidade do México e 12 residentes em uma comunidade rural, com idades entre 20 e 45 anos. A TMB foi medida por calorimetria indireta e o ponto de corte para sub-relato foi estabelecido como IE/TMB inferior a 1,4. A prática de atividade física foi registrada em um diário, de tal forma 
que foi possível estimar o GET. Não foram descritos quantos dias de coleta de urina foram obtidos. Foi administrado PABA (ácido paraminobenzóico) aos sujeitos, de tal forma que apenas as coletas completas (cerca de 90\%) foram utilizadas. Apenas razões Nitrogênio urinário/Nitrogênio relatado entre 0,7 e 0,9 foram consideradas válidas. Foram obtidas as seguintes razões IE/TMB: 1,57 $\pm 0,14$ (entre as mulheres rurais) e 1,26 $\pm 0,08$ (entre as mulheres urbanas), enquanto que o GET das mesmas foi estimado como, respectivamente, 1,89*TMB $( \pm 0,05)$ e 1,65*TMB $( \pm 0,03)$. As razões Nitrogênio urinário/Nitrogênio relatado foram iguais a 0,85 $\pm 0,08$ (entre as rurais) e 0,92 $\pm 0,05$ (entre as urbanas). De acordo com o índice IE/TMB, 27,7\% das mulheres sub-relataram e, de acordo com este índice e a razão Nitrogênio urinário/Nitrogênio relatado, 22,2\% das mesmas sub-relataram.

MACINTYRE, VENTER e VORSTER (2000) avaliaram a validade de um questionário de freqüência alimentar desenvolvido para a população sul-africana. Para tanto, o questionário foi comparado com um diário alimentar de sete dias (com pesagem das porções), com a excreção de nitrogênio na urina, e com a TMB estimada por equações. Os autores consideraram muito mais a comparação com o diário do que os dados dos marcadores. O estudo continha uma amostra de 890 sujeitos, dos quais 74 também preencheram o diário e 88 coletaram amostras de urina. O questionário obteve coeficientes de correlação modestos com o diário, variando de 0,14 (ingestão de fibras) a 0,60 (ingestão de vitamina C). Utilizando-se um gráfico de Bland e Altman, verificou-se que, para todos os nutrientes, $90 \%$ dos sujeitos estavam dentro dos limites de concordância. Estes limites, contudo, foram bastante amplos. Apenas $36 \%$ dos sujeitos que fizeram coletas de urina forneceram amostras completas das mesmas, conforme foi constatado pela dosagem de PABA. Os autores não encontraram correlação entre a ingestão de proteínas mensurada pela urina e a ingestão relatada por meio do questionário. Foi afirmado que este resultado era devido à baixa taxa de coleta da urina e talvez ao fato de que um dia apenas de coleta não seria representativo da ingestão habitual. Assim, os pesquisadores resolveram descartar os dados do nitrogênio urinário. Embora tais alegações pareçam razoáveis, acredita-se que seja inadequado desconsiderar estes dados. Os autores deveriam ter examinado com mais atenção se esta falta de correlação não era derivada de um intenso super ou sub-relato da ingestão protéica. A razão IE/TMB foi igual a 1,42 $\pm 0,43$, para o questionário, e a $1,47 \pm 0,43$, para 0 
diário. Embora estes valores sejam parecidos, a taxa de sub-relatores foi de $43 \%$ no questionário e $28 \%$ no diário.

Quando os estudos supracitados e aqueles apresentados na Revisão Bibliográfica são analisados conjuntamente, consegue-se identificar grupos de países subdesenvolvidos em que o sub-relato parece ser menor (como Egito, Indonésia e República dos Camarões) e grupos em que o sub-relato parece ser maior (como o México, África do Sul e Jamaica). O presente estudo, que é o primeiro a utilizar a água duplamente marcada para quantificar o sub-relato em uma nação em desenvolvimento, confirma a hipótese de que a subnotificação é um viés sério nos relatos alimentares, pelo menos nessa amostra de mulheres brasileiras.

A proporção de indivíduos sub-relatores foi muito maior para 0 questionário de freqüência alimentar em relação aos outros dois métodos (que, inclusive, apresentaram proporções semelhantes de sub-relatores). Constatou-se também que, apenas no questionário de freqüência alimentar, a proporção de subrelatores ultrapassou a de não sub-relatores. Alguns outros estudos encontraram resultados similares. Nos Estados Unidos, o maior estudo já realizado com água duplamente marcada encontrou proporções bastante semelhantes às nossas, entre as mulheres analisadas: $49 \%$ de sub-relatores, a partir do questionário de freqüência alimentar, e 22,3\% de sub-relatores, a partir do recordatório alimentar (SUBAR et al., 2003). Esses dados sugerem que o sub-relato pode ser um problema tão presente no Brasil quanto é em nações desenvolvidas como os Estados Unidos. Poder-se-ia especular que a maior proporção de sub-relatores gerada pelo questionário de freqüência alimentar resulta do diferente ponto de corte para o sub-relato obtido por esse método. No recordatório e no diário alimentar, para ser considerado sub-relator, um indivíduo tinha que relatar uma ingestão, respectivamente, pelo menos 31 e $32 \%$ menor do que o GET e não perder peso durante o estudo. Já para o questionário de freqüência alimentar, se o indivíduo não tivesse perdido peso e relatasse ingestão energética pelo menos $18 \%$ inferior ao GET, ele era considerado sub-relator. Porém, essa diferença nos pontos de corte é procedente, já que, dos três métodos, o questionário de freqüência alimentar é o que tem maior capacidade de mensurar a ingestão habitual e, portanto, é o que deveria apresentar maior concordância com o GET. Na pesquisa de SVENDSEN e TONSTAD (2006), para ser considerado subrelator, o sujeito deveria apresentar, pelo menos, ingestão energética $17 \%$ menor do 
que o GET, para o questionário de freqüência alimentar, e pelo menos $31 \%$ menor do que o GET, para o diário alimentar. Tais pontos de corte são extremamente semelhantes aos nossos, pois também derivam das fórmulas indicadas para detecção do sub-relato.

Além da maior proporção de sub-relatores, outros dados indicam que o questionário de freqüência alimentar teve o pior desempenho. Sua razão IE/GET foi a menor e a análise de variância que comparou tal razão entre os três métodos quase atingiu o critério de significância estatística. A mediana e o valor mínimo da variável IE também foram bem menores nesse método (TABELA 4).

Os gráficos de Bland e Altman são úteis para identificar vieses e possíveis "outliers". Caso os métodos de avaliação do consumo alimentar aqui analisados não apresentassem vieses, a diferença média entre a IE e o GET (representada nas FIGURAS 6 a 8 pela linha horizontal sólida) seria igual a zero. Esse, claramente, não foi o caso encontrado no presente estudo. Percebeu-se nos três gráficos que há uma grande dispersão, ou seja, a diferença entre as mensurações variou muito entre os sujeitos. Além disso, foram identificados alguns sujeitos "outliers", cujos valores estavam fora dos limites de concordância. Mais importante ainda, verificou-se nos três casos que os limites de concordância (diferença média mais e menos 1,96 desvio-padrão, representada nas FIGURAS 6 a 8 pelas linhas tracejadas) eram extremamente amplos, revelando a baixa concordância entre a água duplamente marcada e os métodos de inquérito alimentar, sendo que tal amplitude foi ainda maior para o questionário de freqüência alimentar. Considerando esses três aspectos, pode-se afirmar que os três métodos de avaliação do consumo alimentar produziram estimativas enviesadas de ingestão energética e que o erro envolvido em tais métodos não é aleatório e sim sistemático. Porém, diferentemente do que costuma ser encontrado em estudos em nações desenvolvidas (JOHANSSON et al., 1998; MAHABIR, BAER, GIFFEN, SUBAR, CAMPBELL, HARTMAN, CLEVIDENCE, ALBANES \& TAYLOR, 2006; SVENDSEN \& TONSTAD, 2006), notou-se que alguns indivíduos apresentaram diferença média maior do que zero (acima da linha sólida nas FIGURAS 6 a 8) e que alguns inclusive apresentaram essa diferença acima do limite superior (acima da linha tracejada superior nas FIGURAS 6 a 8). Este efeito parece ter sido ligeiramente mais acentuado para o recordatório alimentar e o questionário de freqüência alimentar. Embora o sub-relato tenha sido o erro de maior 
magnitude, é possível, portanto, que ele coexista nessa amostra com a superestimativa.

Notou-se, no presente estudo, que todos os métodos de inquérito alimentar testados apresentaram erros sistemáticos e subestimaram largamente a ingestão energética. Esperava-se que o diário alimentar de três dias apresentasse um desempenho melhor. Os diários alimentares apresentam uma série de vantagens em relação aos outros métodos, como a não dependência da memória e o maior detalhamento. Além disso, ao contrário de um questionário fechado, não é a alimentação do indivíduo que deve se "encaixar nele"; todos os alimentos e preparações podem ser relatados e descritos, independentemente do pesquisador conhecê-los. Sabe-se que os sujeitos consideram os diários cansativos e tediosos (SCAGLIUSI et al., 2003), porém, como o nosso estudo solicitou apenas três dias de registro, esperava-se que essa fadiga não acontecesse tanto. Entretanto, o estudo de REBRO, PATTERSON, KRISTAL e CHENEY (1998) mostrou que mesmo diários de poucos dias podem ser vistos como um fardo para os sujeitos de pesquisa. Esses autores constataram que, ao longo do preenchimento de um diário alimentar de quatro dias, os sujeitos registravam menos alimentos, preparações mistas e lanches. Essa alteração na alimentação em função da mensuração da mesma pode ter contribuído para o sub-relato obtido pelo diário alimentar.

A subnotificação é composta pelo sub-registro e pelo subconsumo. Restringir a alimentação, de várias formas, em função do consumo alimentar estar sendo observado corresponderia ao subconsumo. O subconsumo pode ser praticado de várias maneiras, como, por exemplo, reduzindo o tamanho das porções alimentares, excluindo alimentos da dieta e deixando de realizar algumas refeições (GORIS, WESTERTERP-PLANTENGA \& WESTERTERP, 2000; GORIS \& WESTERTERP, 2000).

Utilizando a água duplamente marcada, GORIS et al. (2000) encontraram sub-relato de $37 \pm 16 \%$ da ingestão energética em homens obesos, sendo que a maior parte deste correspondia ao subconsumo. MACDIARMID e BLUNDELL (1997) analisaram cem indivíduos que preencheram um diário de sete dias com pesagem das porções. Depois do período de registro cada participante foi entrevistado. Quarenta e seis por cento dos voluntários admitiram ter modificado sua ingestão no período de registro. Cerca de $22 \%$ dos indivíduos atribuíram esta mudança ao fato de 
serem mais conscientes sobre sua alimentação e por se sentirem envergonhados ou culpados de relatar alguns alimentos e quantidades, enquanto que $18 \%$ disseram que pesar os alimentos era cansativo e difícil. Na pesquisa anteriormente realizada pelo nosso grupo de pesquisa, os sujeitos admitiram que, quando estavam fazendo o diário alimentar, passaram a perceber diversas falhas da sua alimentação e que, por isso, modificaram seu consumo durante o registro (SCAGLIUSI et al., 2003). É possível que esse efeito também tenha acontecido no presente estudo, justificando as altas taxas de subnotificação obtidas pelo diário alimentar.

Por outro lado, pode-se pensar que a taxa de sub-relato obtida pelo diário alimentar está, na verdade, subestimada, pois ela não incluiu sujeitos que subrelataram apenas por meio do subconsumo. Para medir o subconsumo, os seguintes procedimentos deveriam ser seguidos (GORIS et al., 2000). Um mês antes das avaliações de consumo alimentar, os sujeitos seriam pesados. Após um mês, tal pesagem seria repetida e, assim, seria obtida a taxa mensal de variação normal de peso para cada sujeito. Imediatamente antes e depois do mês de avaliação do consumo alimentar, os sujeitos seriam pesados novamente. Se nesse mês de avaliação o sujeito perdesse mais peso do que sua taxa mensal de variação normal de peso e relatasse uma taxa IE/GET abaixo do ponto de corte para sub-relato, seria constatado que esse indivíduo subconsumiu nesse mesmo período. No presente estudo, essa abordagem não foi utilizada. Todos os sujeitos que apresentaram IE/GET abaixo do ponto de corte para sub-relato e perderam pelo menos $1 \mathrm{~kg}$ de peso corporal não foram considerados sub-relatores. Não se pode negar a hipótese de alguns desses indivíduos eram, na verdade, sub-relatores, pois ingeriram menos energia do que habitual somente no período de investigação, obtendo uma perda de peso que não estava ocorrendo antes do estudo. Contudo, como não foi medida a variação de peso antes da aplicação dos métodos de inquérito alimentar, não foi possível fazer tal discriminação.

O sub-registro de alimentos e/ou refeições, isto é, a omissão de tais eventos do relato, pode ser inconsciente ou consciente. O primeiro caso ocorre devido a lapsos de memória (TOMOYASU et al., 1999) e à incompreensão das perguntas feitas em recordatórios de 24 horas, questionários de freqüência alimentar ou em histórias alimentares (MARGETTS \& NELSON, 1991). A falta de detalhamento sobre um alimento consumido também pode contribuir para a subestimação da 
ingestão, porém isso não deve ter ocorrido na presente pesquisa, já que todos os diários alimentares eram revisados por nutricionistas no momento da entrega e, quando havia algo sem detalhes e/ou clareza, o sujeito era indagado.

A omissão consciente acontece quando o relato de dado alimento é demasiadamente trabalhoso ou quando o indivíduo sente vergonha da sua alimentação devido ao consumo de alimentos geralmente vistos como "nãosaudáveis" (POPPITT, SWANN, BLACK \& PRENTICE, 1998). O sub-registro consciente pode consistir em, por exemplo, relatar deliberadamente quantidades menores do que as de fato consumidas, novamente por constrangimento. É possível que isto tenha ocorrido nos três métodos aqui analisados. De acordo com RUMPLER, KRAMER, RHODES, MOSHFEGH e PAUL (2007), um terço dos erros obtidos em recordatórios alimentares são oriundos da omissão de alimentos e da subestimação das porções alimentares. LARA, SCOTT e LEAN (2004) indagaram a 184 mulheres como elas relatariam seu consumo alimentar se estivessem participando de um levantamento. Cerca de $68 \%$ admitiram que não relatariam de forma acurada, sendo que a maioria conscientemente escolheria sub-relatar.

Já o sub-registro inconsciente de porções alimentares parece ser fruto da dificuldade em quantificá-las (KRESTCH et al., 1999; YOUNG \& NESTLÉ, 1995). Segundo TURCONI, GUARCELLO, BERZOLARI, CAROLEI, BAZZANO e ROGGI (2005), pessoas que consomem grandes porções têm a tendência de subestimar o tamanho das mesmas, e o oposto ocorre em pessoas que consomem pequenas porções, que tendem a superestimar o tamanho das mesmas, diminuindo a acurácia dos relatos. Nessa pesquisa, tentou-se minimizar tal dificuldade com o uso de desenhos e fotografias de porções alimentares e utensílios caseiros, que são recursos comprovadamente eficazes (FROBISHER \& MAXWELL, 2003; PIETINEN, HARTMAN, HAAPA, RASANEN, HAAPAKOSKI, PALMGREN, ALBANES, VIRTAMO \& HUTTUNEN, 1988). É possível, portanto, supor que pesquisas nacionais que utilizem diários e recordatórios alimentares sem tais recursos obtenham taxas de sub-relato superiores às nossas.

Por outro lado, embora todos os métodos de inquérito alimentar tenham apresentado um desempenho ruim, o questionário de freqüência obteve o pior. $O$ questionário de freqüência alimentar é o método mais utilizado em estudos epidemiológicos, devido ao seu baixo custo e facilidade de aplicação. Tais 
vantagens, porém, não devem fazer com que seus defeitos e limitações sejam esquecidos. Em primeiro lugar, ele é muito vago. Para preenchê-lo corretamente, uma pessoa deveria fazer diversos cálculos e abstrações matemáticas (BROWN, 2006). Por exemplo, no Brasil as pessoas têm o hábito de comer freqüentemente arroz e feijão, sendo estes considerados nossos alimentos básicos. Quando o questionário indaga sobre esses alimentos, a pessoa pode pensar "como arroz e feijão todo dia, no almoço e no jantar" e selecionar como opção de freqüência "duas vezes por dia". Entretanto, a pessoa esqueceu-se de descontar as ocasiões em que ingere nas refeições principais alimentos que não são acompanhados por arroz e feijão, como pizza, lanches e massas. O número de alimentos listados no questionário também deve possuir um limite, o que pode fazer com que muitos alimentos não sejam indagados. Contudo, sabe-se que cada vez mais as pessoas consomem alimentos "diferentes", sejam eles industrializados ou preparados fora de casa (ABREU \& TORRES, 2003; AQUINO, 1999). Esses alimentos costumam conter ingredientes calóricos e gordurosos, bem diferentes dos alimentos "básicos" citados no questionário. No presente estudo, alimentos como cereais matinais, alguns embutidos (como presunto e salame) e pratos à base de creme de leite foram muito citados nos diários e recordatórios, mas não constavam no questionário.

O questionário de freqüência também está sujeito a falhas de memória e a dificuldades na interpretação das categorias de freqüência, causadas, especialmente, pelo agrupamento de vários alimentos na mesma questão (SERDULA, BYERS, COATES, MOKDAD, SIMOES \& ELDRIDGE, 1992). Os sujeitos podem ter dificuldade em estimar as porções, principalmente quando os tamanhos fornecidos não estão de acordo com seus referenciais pessoais (SUBAR et al., 1995). Encontrase também que os resultados do questionário podem ser influenciados pela sazonalidade (BINGHAM, 1991).

Além disso, as opções de freqüência alimentar apresentadas pelo questionário também podem ser criticadas. Elas variavam entre "nunca ou quase nunca" e "mais de três vezes por dia", que era computada como quatro vezes por dia. Pode-se supor, entretanto, que alguns alimentos sejam consumidos com freqüência muito maior do que quatro vezes ao dia, como, por exemplo, o açúcar. Essa restrita gama de opções de freqüência pode ter contribuído para o sub-relato generalizado que foi encontrado. 
Devido a tais limitações, alguns autores têm criticado arduamente os questionários de freqüência alimentar. Em um editorial de 2005, KRISTAL, PETERS e POTTER afirmaram que "estamos agora enfrentando uma crise: centenas de milhões de dólares e muitas carreiras de cientistas investiram em estudos que usaram apenas questionários de freqüência alimentar para avaliar dieta, mas é possível que esses estudos não tenham sido e não serão capazes de responder muitas, senão todas, perguntas sobre a relação entre dieta e risco de câncer". Já DANIELLS, em 2006, colocou que "a realidade é que os questionários de freqüência alimentar são uma base frágil para qualquer conclusão, mas mesmo assim eles são o fundamento da maioria dos conselhos sobre alimentação e saúde que as pessoas recebem".

Não se trata de descartar a importância e a utilidade do método. É importante que se investigue porque este instrumento obteve um resultado tão ruim nesse estudo. Seria uma deficiência do método em si ou talvez uma dificuldade da nossa população em respondê-lo, possivelmente relacionada ao menor nível educacional?

Percebe-se, portanto, que o método de avaliação do consumo alimentar interfere diretamente no sub-relato. PRICE et al. (1997) avaliaram o sub-relato em um estudo de coorte, no qual 1.898 indivíduos preencheram diários alimentares de sete dias em 1982 e 1989. Foram considerados como sub-relatores aqueles indivíduos que apresentaram razão IE/TMB inferior a 1,1. Tais autores encontraram que ter sub-relatado sua ingestão no levantamento anterior (de 1982) era o mais forte indicador da subnotificação na próxima avaliação (de 1989). Isto quer dizer que o sub-relato tendeu a ocorrer nos mesmos sujeitos ao longo do tempo, o que mostra que a subnotificação não é um fenômeno randomizado. BLACK e COLE (2001) destacaram em sua revisão que estudos que avaliaram o consumo alimentar diversas vezes pelo mesmo método encontraram que os mesmos indivíduos subrelatavam seu consumo energético em diferentes ocasiões. Desta forma, é coerente tentar identificar características dos indivíduos sub-relatores.

Até hoje, a obesidade foi o fator mais relacionado ao sub-relato. Tal relação já foi inclusive encontrada em amostras bem díspares, como idosos americanos (TOOZE, VITOLINS, SMITH, ARCURY, DAVIS, BELL, DEVELLIS \& QUANDT, 2007) e belgas (BAZELMANS, MATTHYS, DE HENAUW, DRAMAIX, 
KORNITZER, DE BACKER \& LEVÊQUE, 2007), japoneses no início (MURAKAMI, SASAKI, TAKAHASHI, UENISHI, YAMASAKI, HAYABUCHI, GODA, OKA, BABA, OHKI, KOHRI, WATANABE \& SUGIYAMA, 2007) e no final da idade adulta (OKUBO, SASAKI, HIROTA, NOTSU, TODORIKI, MIURA, FUKUI \& DATE, 2006) e diabéticas afro-americanas (SAMUEL-HODGE, FERNANDEZ, HENRÍQUEZ-ROLDÁN, JOHNSTON \& KEYSERLING, 2004), nas quais o IMC explicou $13 \%$ da variação encontrada na razão IE/GET. BUHL, GALLAGHER, HOY, MATTHEWS e HEYMSFIELD (1995) avaliaram dez pacientes obesos com histórico de dificuldade na regulação do peso corporal, com o intuito de identificar se eles apresentavam baixo gasto energético que justificasse tal dificuldade. Todos os pacientes relatavam baixo consumo energético. Eles foram comparados com obesos que não relatavam baixo consumo energético e distúrbios na regulação do peso. Os dez indivíduos apresentaram concentrações séricas normais de hormônios tireoidianos. O GET foi medido pela água duplamente marcada. Oito pacientes apresentavam TMB e GET normais. Um apresentou GET baixo e TMB normal, indicando estilo de vida sedentário. Apenas um paciente obteve o GET e a TMB baixos, indicando de fato a presença de distúrbio. Com estes dados, os autores concluíram que os oito sujeitos que não possuíam baixo GET provavelmente não consumiam pouca energia e sim relatavam consumir pouca energia.

MCGOWAN, HARRINGTON, KIELY, ROBSON, LIVINGSTONE e GIBNEY (2001) avaliaram o sub-relato em um levantamento epidemiológico do consumo alimentar (por meio de diários alimentares de sete dias), conduzido na Irlanda. O ponto de corte para sub-relato foi razão IE/TMB inferior a 1,53, sendo que a TMB foi estimada por equações. Nas pessoas com IMC abaixo de $25 \mathrm{~kg} / \mathrm{m}^{2}$, a razão IE/TMB média foi de 1,52 $\pm 0,40$; nas pessoas com sobrepeso a média foi de 1,37 $\pm 0,40 \mathrm{e}$ nos obesos 1,24 $\pm 0,40$. A menor média foi de $0,96 \pm 0,15$, apresentada por mulheres obesas de 18 a 35 anos. FERRARI et al. (2002) estudaram a validade do instrumento de referência do estudo EPIC (um recordatório alimentar de 24 horas computadorizado), comparando a IE obtida por ele com a TMB estimada por equações. Foi calculada a razão de chance para o sub-relato de acordo com o tercil de IMC. Entre as mulheres, a razão de chance aumentou de 1,58 no primeiro tercil para 4,80 no último tercil de IMC. MENDEZ et al. (2004), ao aplicar um questionário de freqüência alimentar a adultos jamaicanos, constatou que, entre as mulheres, ter 
obesidade acarretava em uma razão de chance para o sub-relato igual a 4,05. Até mesmo na Indonésia, onde as taxas de sub-relato eram mais baixas, o alto IMC esteve correlacionado à subnotificação (WINKVIST et al., 2002).

Todavia, as pesquisas supracitadas não são suficientes para determinar a associação entre sub-relato e IMC, devido ao uso de fórmulas para estimar a TMB e detectar, a partir dela, a subnotificação. Até o momento, poucos estudos aplicaram diversos métodos de avaliação do consumo alimentar em uma mesma amostra e verificaram se a associação entre obesidade e sub-relato é a mesma em cada método, como foi feito no atual estudo. LINDROOS, LISSNER e SJÖSTRÖM (1993), em uma abordagem bastante original, argumentaram que, talvez, o problema não estivesse nos obesos e sim nos métodos de avaliação do consumo alimentar, que, provavelmente, não seriam adequados para esta população. Assim, os autores tentaram desenvolver um instrumento de avaliação do consumo alimentar específico para obesos, de tal forma que os relatos destes sujeitos fossem, pelo menos, tão válidos quanto os relatos de pessoas eutróficas. Foi feita uma adaptação simplificada de uma história alimentar, que possuía 49 questões sobre a ingestão alimentar dos últimos três meses, sendo que as perguntas eram separadas pelo consumo feito entre segunda e quinta-feira, sexta-feira e sábado e, finalmente, domingo. A ênfase das perguntas era nas refeições, e havia fotos de pratos para que se pudessem comparar as porções apresentadas com as consumidas. Por fim, muitas questões indagavam sobre o consumo de sanduíches, que são bastante ingeridos na Suécia. A IE obtida por este método foi comparada com a IE obtida por um diário alimentar de quatro dias e com o GET (calculado por uma equação, que considerava a TMB, medida por calorimetria indireta, e a prática de atividades físicas, estimada por um questionário). Além disso, o consumo de nitrogênio estimado pelos dois métodos de avaliação da ingestão alimentar foi comparado com a excreção de nitrogênio em um dia de coleta de urina. Para as mulheres com IMC entre 19 e $26 \mathrm{~kg} / \mathrm{m}^{2}$, não houve diferença significante entre a IE obtida pelos dois métodos e o GET. A ingestão de nitrogênio relatada no questionário não diferiu daquela excretada na urina, porém 0 mesmo não ocorreu com o diário, que subestimou o consumo de nitrogênio. Entre os sujeitos com IMC acima de $26 \mathrm{~kg} / \mathrm{m}^{2}$, não houve diferença significante entre 0 consumo de energia e nitrogênio obtido pelo questionário e o GET e o nitrogênio excretado, respectivamente. $\mathrm{O}$ diário, por sua vez, subestimou significantemente tais 
parâmetros. Desta forma, os autores concluíram que este novo método era mais apropriado para ser usado em pessoas com excesso de peso. Este estudo, entretanto, apresenta algumas limitações que merecem ser destacadas. A excreção de nitrogênio foi baseada em apenas um dia de coleta, enquanto sabe-se que a história alimentar é uma medida da ingestão habitual e, que, portanto, o marcador que fosse ser comparado a ela também deveria ser representativo da ingestão habitual. BINGHAM (2003), entretanto, apontou que, no mínimo, quatro dias de coleta de urina são necessários para que a excreção de nitrogênio possa ser considerada representativa do consumo habitual. Mais importante ainda, não foi verificado se a coleta de urina foi completa. Finalmente, os autores usaram um questionário para avaliar a prática de atividade física e com isso calcular o GET, quando se sabe que obesos geralmente superestimam a sua prática de atividade física nestes instrumentos (SEIDELL, 1998). Em 1999, LINDROOS, LISSNER e SJÖSTRÖM testaram novamente este novo instrumento de avaliação do consumo alimentar, em 29 sujeitos com IMC entre 25,5 e $43,5 \mathrm{~kg} / \mathrm{m}^{2}$. O GET foi determinado por calorimetria indireta em uma câmara, na qual os sujeitos permanecerem por um dia. Neste mesmo dia, foi feita a coleta de urina para dosagem de nitrogênio. A IE relatada foi apenas $1 \%$ menor do que o GET, em média. Não houve diferenças significantes entre o nitrogênio excretado e o relatado. Este estudo ainda apresenta as mesmas limitações da pesquisa anterior quanto à coleta de urina. Embora o método de determinação do GET usado neste estudo seja mais acurado do que o empregado no estudo de 1993, sabe-se que, em uma câmara de calorimetria indireta, a movimentação é reduzida. Assim, o GET real destes sujeitos é provavelmente maior do que o obtido, o que aumenta a discrepância entre esta medida e a IE.

No presente estudo, diversas análises indicaram que a obesidade estava negativamente associada à acurácia do relato, porém o dado mais interessante foi a constatação de que associação difere entre os métodos de avaliação do consumo alimentar aqui testados.

Nos diagramas de dispersão apresentados (FIGURAS 2 a 4), já é possível ver tal associação. Observando os pontos que representam os indivíduos de maior GET, percebe-se que a IE não aumenta proporcionalmente, como seria esperado para a manutenção do balanço energético. Pelo contrário, em comparação ao alto 
valor de GET, em muitos casos a IE é bastante baixa. Constata-se na TABELA 5 que as obesas apresentaram maior GET, ou seja, provavelmente tais voluntárias são aquelas que, no gráfico de dispersão, apresentam tal discrepância.

$\mathrm{Na}$ TABELA 5 percebe-se que, tanto para o recordatório quanto para 0 diário alimentar, a razão IE/GET e o índice IG diminuem conforme aumenta a categoria de IMC e tais diferenças são significantes. Isso indica que, nesses métodos, as voluntárias obesas subnotificaram mais. Tal constatação também é evidenciada pelas FIGURAS 12 e 13, que mostraram que a proporção de subrelatores é muito maior entre os sujeitos com obesidade, em comparação aos sujeitos com eutrofia ou sobrepeso, quando são considerados os dados do recordatório e do diário alimentar. Entretanto, esses resultados não foram verificados com o questionário de freqüência alimentar. Observa-se na TABELA 5 que, a partir do questionário de freqüência alimentar, as obesas obtiveram as maiores médias de IE, IE/GET e IG, em comparação às médias obtidas pelas mesmas nos outros métodos. Além disso, apenas nesse método tais variáveis não apresentaram diferença estatisticamente significante entre as categorias de IMC. Esses resultados poderiam ser interpretados positivamente, pensando-se que o questionário de freqüência alimentar conseguiu obter estimativas mais válidas de IE entre as obesas. Uma inspeção mais cuidadosa, entretanto, revela que esta interpretação não é correta. A maior média de IE obtida pelo questionário de freqüência alimentar entre as obesas é resultante da maior variação de IE encontrada, pois se percebe que os valores mínimos e máximos são, respectivamente, muito menores e maiores do que aqueles obtidos pelos outros métodos nesse mesmo grupo. Isso se reflete no desviopadrão da IE, que, nesse grupo, foi quase o dobro (916 kcal) daquele obtido pelo recordatório e pelo diário alimentar (respectivamente, 466 e $461 \mathrm{kcal}$ ). Verifica-se também que o maior valor máximo da variável IG foi obtido justamente pelas obesas no questionário de freqüência alimentar $(1.508 \mathrm{kcal})$, indicando que houve nesse grupo, concomitantemente ao sub-relato, superestimativa da IE.

Tais constatações se tornam mais claras quando da observação dos gráficos de Bland e Altman (FIGURAS 9 a 11). Para os três métodos de inquérito alimentar, poucas pessoas encontravam-se perto da diferença entre a IE e o GET igual a zero, isto é, a ausência de viés. Sendo assim, a diferença média entre a IE e o GET (representada pela linha horizontal sólida) é sempre negativa, nos três 
gráficos. Contudo, percebe-se que nas figuras construídas para o recordatório e 0 diário alimentar, as eutróficas são as que se situam mais próximas à diferença média. As obesas, e no caso do recordatório também as mulheres com sobrepeso, se situam geralmente abaixo da linha que representa a diferença média, ou seja, apresentam uma diferença entre as medidas ainda mais negativa e próxima ao limite inferior de concordância. Inclusive, para esses dois métodos, apenas obesas se encontram fora do limite inferior de concordância. Essas figuras também confirmam os achados dos diagramas de dispersão, indicando que quanto maior o GET, maior é a discrepância entre o GET e a IE e que, justamente, quem possui mais tal combinação são as voluntárias obesas. Quando se trata do questionário de freqüência alimentar, os dados se comportam de maneira diferente. Inicialmente, nota-se que não há mais voluntárias abaixo do limite inferior de concordância e sim acima do limite superior. Estas são, inclusive, obesas, confirmando nossa hipótese de que o questionário gerou superestimativas da IE nesse grupo. Muitos sujeitos encontram-se abaixo da diferença média entre as mensurações (representada pela linha sólida), porém estes pertencem às três categorias de IMC.

Na FIGURA 14, verifica-se que proporções semelhantes de sub-relatores foram encontradas nas três classes de IMC, utilizando-se os dados do questionário de freqüência alimentar. Considerando-se conjuntamente os dados apresentados, percebe-se que o questionário de freqüência alimentar obteve estimativas largamente enviesadas para todas as categorias de IMC. Não é verdadeira, portanto, a interpretação de que ele teria gerado menos sub-relato entre as obesas. $O$ que ocorreu foi que ele gerou maiores taxas de sub-relato entre as mulheres com eutrofia e sobrepeso, taxas estas tão grandes que se igualaram àquelas obtidas pelas voluntárias com obesidade. Isso explica porque houve correlação negativa e significante entre o IMC e a IE/GET, obtida pelo recordatório e o diário alimentar (TABELAS 6 e 7), mas não entre o IMC e a razão IE/GET fornecida pelo questionário de freqüência alimentar (TABELA 8).

Alguns outros dados levam à suspeita de que o questionário de freqüência alimentar obteve estimativas inválidas como um todo. A maior parte da amostra subrelatou em apenas um dos métodos de inquérito alimentar. Dentre estas, a maioria sub-relatou apenas no questionário de freqüência alimentar. Isso sugere que esse método induz ao erro, por alguma de suas características. Uma maneira de reforçar 
essa hipótese é verificar se alguma variável está correlacionada com a acurácia obtida por esse método. Caso muitas variáveis estejam correlacionadas, pode-se pensar que nossa hipótese está errada e que são as características dos sujeitos que levam ao erro. Porém este não foi o resultado encontrado. Na TABELA 8, nota-se que apenas uma variável (o desejo de aceitação social) esteve negativa e significantemente correlacionada à razão IE/GET, ao contrário do que ocorreu para os outros métodos, nos quais diversas variáveis apresentaram correlações significantes (TABELAS 6 e 7). É extremamente interessante constatar que nenhum indicador sócio-econômico (renda e escolaridade) correlacionou-se com a IE/GET obtida pelo questionário de freqüência alimentar. Tal correlação parecia ser intuitivamente lógica, dada a complexidade cognitiva do instrumento. Assim, características do questionário, como a lista de alimentos e as opções de freqüência e porções, podem ser responsáveis pelo seu fraco desempenho. Sabe-se que o questionário utilizado nesse estudo já foi reformulado, incorporando alguns itens que foram supracitados como faltosos (como embutidos). Seria relevante comparar a nova versão desse questionário, assim como outro questionário brasileiro de freqüência alimentar, com a água duplamente marcada, para verificar se o problema é este questionário especificamente ou se a utilização de questionários de freqüência alimentar, independentemente de qual seja, é inadequada para amostras brasileiras.

Para cada método de inquérito alimentar aqui testado, foram calculados coeficientes de correlação entre suas respectivas razões IE/GET e diversas variáveis físicas, psicológicas e sociais (TABELAS 6 a 8). De maneira geral, encontrou-se que as mesmas variáveis apresentaram correlações significantes tanto no recordatório quanto no diário alimentar (TABELAS 6 e 7). Isso indica que os mesmos fatores podem influenciar a validade desses dois métodos. Tal constatação é surpreendente, posto que eles apresentam demandas cognitivas muito diferentes. Por exemplo, o recordatório baseia-se na memória e depende de um entrevistador para aplicá-lo, enquanto que o diário é auto-preenchido e depende mais da motivação do sujeito (THOMPSON \& BYERS, 1994). Nesses dois métodos, a renda e a escolaridade apresentaram correlações significantemente positivas com a IE/GET. Por sua vez, as seguintes variáveis apresentaram correlações significantes negativas: restrição dietética, compulsão alimentar, insatisfação corporal, desejo de aceitação social e idade. A correlação entre IE/GET e o desejo de aceitação social foi mais significante 
para o diário alimentar, ao passo que a correlação entre IE/GET e a compulsão alimentar foi mais significante para o recordatório alimentar. Já para o questionário de freqüência alimentar, nenhuma variável apresentou correlação positiva significante, e apenas o desejo de aceitação social correlacionou-se de maneira negativa e significante à razão IE/GET (TABELA 8). Isso reforça a hipótese de que o questionário de freqüência alimentar obteve respostas inválidas para qualquer tipo de sujeito.

Para nenhum dos métodos foi encontrada correlação entre a razão IE/GET e a prática de atividade física (TABELAS 6 a 8). A hipótese de que haveria correlação entre essas variáveis surgiu dos relatos científicos e informais de que algumas atletas do sexo feminino têm IE surpreendentemente baixa, enquanto o GET das mesmas deve ser consideravelmente alto (JONNALAGADDA, BENARDOT \& NELSON, 1998). Como já foi explicitado, para se manter em acordo com as leis da termodinâmica, o balanço energético deve ser mantido em longo prazo, para que 0 peso possa permanecer constante.

EDWARDS, LINDEMAN, MIKESKY e SATGER (1993) aplicaram a água duplamente marcada em nove corredoras do sexo feminino. Durante o mesmo período, elas preencheram um diário alimentar de sete dias, após terem registrado dois dias e relatado um (por meio de um recordatório de 24 horas) como treinamento. Também foi administrado um questionário denominado Escala de Atitudes Alimentares (Food Attitude Scale), que possuía questões sobre imagem corporal, alimentação e nutrição nos domínios emocional, sensorial e social/celebrativo. Não foi encontrada alteração no peso corporal ao longo do estudo, sendo que a IE correspondeu, em média, a 68\% do GET. A diferença entre o GET e a IE variou de 4 a 58\%. O coeficiente de correlação de Pearson entre a IE e o GET foi de $-0,83$. Enquanto o GET apresentava correlação positiva com o peso corporal $(r=0,82)$, a IE apresentava correlação negativa com o mesmo $(r=-0,74)$. Isto acarreta em uma situação biologicamente implausível, semelhante àquela encontrada no presente estudo, na qual indivíduos com maior peso têm maior GET e ao mesmo tempo menor IE. Assim, neste estudo, foi concluído que a menor IE relatada por estas atletas eram frutos da subnotificação e não de menor GET, e que o sub-relato era maior nas atletas com maior peso e IMC, embora a amplitude de variação destes tenha sido pequena. Os autores ainda encontraram correlação negativa entre o peso corporal e 
pior imagem corporal, medida pela Escala de Atitudes Alimentares $(r=-0,78)$. Com base em tais correlações, os pesquisadores compararam as atletas mais pesadas aos sujeitos obesos de outros estudos acerca do sub-relato, afirmando que, apesar das grandes diferenças de adiposidade entre os dois grupos, estas atletas provavelmente estavam menos satisfeitas com seus corpos, e por isso, sentiam mais vergonha sobre sua alimentação, o que teria motivado o sub-relato.

SCHULZ, ALGER, HARPER, WILMORE e RAVUSSIN (1992) também estudaram a IE e o GET de nove corredoras de elite, por meio de um diário alimentar de seis dias e da água duplamente marcada, respectivamente. Além disso, o gasto energético basal e o gasto durante o sono foram mensurados por calorimetria indireta. O GET foi corrigido pela perda de peso ocorrida durante o estudo, gerando, assim, a IE calculada. A diferença entre a IE calculada e a relatada foi de $-221 \pm 550$ $\mathrm{kcal} /$ dia. Não foi encontrada correlação entre a IE calculada e a registrada $(r=0,06)$. JONNAGALADDA, BENARDOT e DILL (2000a) analisaram o sub-relato do consumo energético em diários alimentares de três dias de 28 ginastas de equipes norteamericanas de elite. A TMB foi estimada por equações, com base no peso, idade e gênero, e a partir dos cálculos propostos por GOLDBERG et al. (1991), determinouse que razões IE/TMB inferiores a 1,44 eram indicativas de subnotificação. Dezessete atletas foram classificadas como sub-relatoras, embora o ponto de corte utilizado não permitisse tal classificação, posto que ele foi calculado para um grupo e não para um indivíduo. A razão IE/TMB neste grupo foi igual a $0,99 \pm 0,22$, o que acarreta em um consumo energético médio suficiente apenas para cobrir as necessidades basais. O peso corporal, o IMC e a porcentagem de gordura corporal obtiveram correlações negativas com a IE e a IE/TMB. Estes resultados parecem indicar que há considerável sub-relato da IE neste grupo e que, novamente, este subrelato é proporcional às medidas de adiposidade.

Assim, há evidências que mostram que atletas costumam sub-relatar sua ingestão energética, mesmo considerando o número pequeno de estudos e as amostras pequenas e pouco representativas recrutadas pelos mesmos. Contudo, esses resultados não se traduzem quando se trata de uma amostra de não atletas. Poder-se-ia supor que, em uma amostra de não atletas, aqueles com maior prática de atividade física sub-relatassem mais, porém esse não foi o resultado encontrado no presente estudo. Nossos resultados são semelhantes àqueles encontrados pelo 
estudo de NOVOTNY et al. (2003), no qual o sub-relato foi detectado com base no GET, determinado por água duplamente marcada ou pela IE necessária para manutenção do peso em unidade metabólica. Para quantificar a prática de atividade física, os sujeitos relataram a freqüência e a duração em que eles faziam caminhada, corrida, ciclismo, natação, aeróbica, dança, levantamento de peso, trabalho no campo ou qualquer outra atividade física que eles porventura fizessem e que não correspondesse a estas categorias. Não foi encontrada qualquer correlação entre sub-relato e atividade física. Porém, diferentemente do presente estudo, tais autores não utilizaram um instrumento validado para medir a prática de atividade física.

Foram verificadas significantes correlações negativas entre a restrição dietética e as razões IE/GET obtidas pelo recordatório e pelo diário alimentar (TABELAS 6 e 7), mas não pelo questionário de freqüência alimentar (TABELA 8). Resultados semelhantes foram encontrados por SVENDSEN e TONSTAD (2006): de acordo com os dados do diário alimentar, os sub-relatores apresentavam maiores escores de restrição, o mesmo não era observado quando os dados do questionário eram utilizados. Isso sugere que talvez a restrição esteja mais associada ao subconsumo do que ao sub-registro. É provável que indivíduos com alto escore de restrição passem a comer menos quando seu consumo está sendo avaliado. Assim, é possível supor que, neste trabalho, os sujeitos com alto escore de restrição tenham diminuído seu consumo nos dias de diário alimentar e nos dias precedentes aos recordatórios. Já o questionário de freqüência não é tão afetado pelo subconsumo, pois ele se refere a um passado maior e menos específico.

Autores como RENNIE, SIERVO e JEBB (2006), VANSANT e HULENS (2006), ASBECK et al. (2002) e BATHALON et al. (2000) também notaram correlações negativas entre a restrição e a acurácia do relato. Por sua vez, KRETSCH et al. (1999) e ARD, DESMOND, ALLISON e CONWAY (2006) não verificaram tal correlação. Embora estes autores tenham tentado investigar a influência da restrição no sub-relato, nenhum considerou, com a devida atenção, o significado da prática de restrição dietética. Na literatura que une as áreas de nutrição e psicologia, encontra-se que a restrição dietética não é um construto único, podendo ter diversas facetas e interpretações. Um dos significados de restrição corresponde a estar fazendo dieta no presente, isto é, reduzindo a ingestão de alimentos com sucesso (HEATHERTON et al., 1988; RICCIARDELLI \& WILLIAMS, 
1997). Quando alguns trabalhos utilizaram esta interpretação, foi constatado que a restrição apresentava correlação negativa com o IMC (MASHEB \& GRILO, 2002). Os dois questionários existentes que empregam este conceito de restrição são o Questionário Alimentar de Três Fatores (Three Factor Eating Questionnaire - TFEQ, STUNKARD \& MESSICK, 1985) e o Questionário Holandês de Comportamento Alimentar (Dutch Eating Behavior Questionnaire - DEBQ, VAN STRIEN, FRIJTERS, VAN STAVEREN, DEFARES \& DEURENBERG, 1986), justamente os questionários usados nos estudos supracitados. Desta forma, um sujeito, cuja pontuação em uma dessas escalas indica que ele restringe a alimentação, provavelmente está, de fato, consumindo pouca energia e não sub-relatando. Seria o caso de um indivíduo que estivesse fazendo dieta restritiva, que é justamente o construto medido pelo TFEQ e o DEBQ: a prática de dieta como um estado. Dos três estudos citados, apenas as pesquisas de KRETSCH et al. (1999), ARD et al. (2006) e SVENDSEN e TONSTAD (2006) usaram como critério de exclusão a prática de dietas restritivas. Assim, é provável que as amostras dos trabalhos de ASBECK et al. (2002) e BATHALON et al. (2000) incluíssem sujeitos que estavam, de fato, ingerindo menos energia e não subrelatando o consumo de energia. O estudo de ARD et al. (2006) mostrou que a restrição aguda (como um estado) está correlacionada com menor ingestão energética e não com menor acurácia no relato do consumo energético.

A restrição alimentar também pode ser crônica, de tal forma que ela deixa de ser um estado e passa a ser um traço (RICCIARDELLI \& WILLIAMS, 1997). A pessoa que restringe sua alimentação de forma crônica não consegue manter tal restrição o tempo todo com sucesso. Ela alterna períodos de restrição com episódios de alimentação excessiva (ou lapsos) (HEATHERTON et al., 1988). O único questionário que mede a restrição dentro desta concepção é a Escala de Restrição (Restraint Scale - RS), desenvolvida por HERMAN e MACK (1975). A RS mede, ao mesmo tempo, a preocupação que uma pessoa tem sobre seu corpo e as tentativas crônicas de prática de dieta que ela faz, em função de tal preocupação. Portanto, as três escalas - TFEQ, DEBQ e RS - não são intercambiáveis e devem ser cuidadosamente escolhidas de acordo com o comportamento que se deseja mensurar. A RS foi justamente a escala escolhida para o presente trabalho.

Além da nossa, a única pesquisa que investigou a relação entre a restrição crônica, medida pela RS, e a subnotificação foi conduzida por TAREN, TOBAR, HILL, 
HOWELL, SHISSLAK, BELL e RITENBAUGH (1999). A IE foi estimada por diários alimentares de três dias e o GET pela água duplamente marcada. No modelo de regressão múltipla, a restrição não se mostrou boa preditora do sub-relato. Algumas hipóteses podem ser levantadas a partir destes dados. Se um indivíduo com restrição crônica alterna períodos de maior e menor ingestões, talvez seja importante mensurar em qual destas fases ele se encontra no momento do estudo. Se ele estiver em uma fase de restrição, ele provavelmente estará consumindo pouca IE, o que leva a uma situação semelhante àquela descrita para os indivíduos que estão fazendo dieta e que obtém alta pontuação no TFEQ e no DEBQ. Caso o sujeito esteja na fase de consumo excessivo, ele provavelmente consumirá bastante energia. Como a RS também mede a preocupação que um indivíduo tem sobre seu peso, este sujeito com alta pontuação, no momento de ingestão alimentar excessiva, provavelmente sente culpa e vergonha em relação ao seu consumo. Tais sentimentos de culpa e vergonha podem, por sua vez, contribuir para o sub-relato. Embora o estudo de MUHLHEIM, ALLISON, HESHKA e HEYMSFIELD (1998) não tenha aplicado a RS e possua uma série de limitações metodológicas, seus resultados corroboraram esta hipótese. Foi mostrado que indivíduos que faziam inúmeras dietas, mas nunca conseguiam reduzir seu peso e mantê-lo, apresentavam intenso sub-relato, que não diminuía muito quando os sujeitos eram informados que, por meio da água duplamente marcada, era possível determinar a real ingestão. Esta interface entre a restrição e o consumo excessivo explica porque a compulsão alimentar também esteve, na atual investigação, correlacionada negativa e significantemente à razão IE/GET, tanto no diário quanto no recordatório alimentar. $\mathrm{O}$ sujeito com alto escore de restrição crônica provavelmente também tem um elevado escore de compulsão, pois já foi comprovado que a primeira é fator causal dessa última (POLIVY, 1996). Se esse voluntário sente culpa e preocupação em relação ao seu peso e sua alimentação, ele pode não querer registrar seus episódios de consumo compulsivo, por vergonha. Porém, à medida que tais episódios possuem alto valor energético (ALVARENGA, PHILIPPI \& NEGRÃO, 2003), se o sujeitos os omite do relato, isso certamente causará uma grande taxa de sub-relato.

Um outro fator que deve ser considerado é a influência que a restrição tem sobre o próprio GET. O estudo de GONZÁLES-PACHECO, BUSS, KOEHLER, WOODSIDE e ALPERT (1993) mostrou redução significante da TMB em ratos 
consumindo $60 \%$ menos energia do que o necessário. POEHLMAN, MELBY e GORAN (1991) constataram, em sua revisão, que a perda de peso ocasionada por restrição alimentar diminui a TMB, sendo que, inclusive, nem sempre este declínio é evitado pela prática de atividade física. Desta forma, para que se possa estudar a relação entre restrição e o sub-relato, deve-se determinar o gasto energético, e seus principais componentes com precisão e acurácia, como por meio da água duplamente marcada. Não seria apropriado, por exemplo, determinar o GET de pessoas que restringem sua alimentação da forma que ASBECK et al. (2002) fizeram: multiplicando o gasto no repouso por uma constante, que não é capaz de captar variações biológicas entre os indivíduos, como aquelas geradas pela própria restrição.

Não se notou qualquer relação entre a razão IE/GET e o conhecimento nutricional, em todos os métodos de inquérito alimentar (TABELAS 6 a 8). A hipótese de que existiria tal correlação surgiu a partir dos estudos que constataram que as pessoas tendem a sub-relatar mais aqueles alimentos que julgam não-saudáveis. Segundo HEITMANN et al. (2000), o sub-relato seletivo pode ser conseqüência da maior consciência sobre alimentação, resultante por sua vez das campanhas de saúde pública que visam reduzir o consumo de lipídeos. De acordo com BLUNDELL (2000), quanto mais é dito para a população reduzir a ingestão de gorduras maior é o sub-relato deste nutriente. No estudo de RASMUSSEN, MATTHIESSEN, BILTOFTJENSEN e TETENS (2007), os sub-relatores se preocupavam mais com seus pesos e declararam que estavam tentando se alimentar de forma saudável. Assim, pensouse que os sub-relatores poderiam ter mais conhecimento sobre nutrição, o que não foi comprovado. LARA et al. (2004) afirmaram que é extremamente difícil avaliar o consumo alimentar de pessoas obesas que buscam tratamento, pois estas apresentam crenças muito fortes sobre como deveriam se alimentar. Ao questionar tais pessoas sobre seu consumo habitual, por exemplo, é comum receber respostas como 'comi tudo que não deveria', 'só comi coisas de gordo', por exemplo. Porém nenhuma dessas afirmações de auto-condenação traz informações sobre o que, de fato, a pessoa ingere. Tais crenças sobre como deveriam se alimentar podem leválos ao sub-registro ou ao subconsumo, como foi declarado por uma amostra de mulheres brasileiras, em nosso estudo anterior (SCAGLIUSI et al., 2003). O grande ponto é que tais crenças não correspondem ao conhecimento nutricional e sim, 
muitas vezes, a mitos alimentares (ROZIN, ASHMORE e MARKWITH, 1996). O instrumento utilizado nessa pesquisa media o conhecimento, derivado da ciência, sobre a relação entre alimentação e saúde, porém, provavelmente não é esse tipo de conhecimento que leva ao sub-relato e sim os mitos e crenças distorcidas. Novas pesquisas devem testar essa hipótese utilizando questionários que meçam tais mitos.

RASMUSSEN et al. (2007) afirmaram que o sub-relato é um erro muito sério e que, portanto, sempre deve ser levado em consideração, mas que as características dos sub-relatores não apresentam consistência entre os estudos. É bastante intuitivo supor que tais características dependem tanto da amostra quanto do método de avaliação do consumo alimentar. Tal suposição é claramente comprovada pelos resultados do presente estudo, que mostraram grande diferença entre os fatores correlacionados à subnotificação, dependendo do método de inquérito. No estudo OPEN, a taxa de sub-relatores variou entre, aproximadamente, 13 a $50 \%$ dos sujeitos, dependendo do gênero e do método de avaliação do consumo alimentar utilizado (recordatório alimentar ou questionário de freqüência alimentar). O sub-relato da IE ocorreu simultaneamente nos dois métodos em $14 \%$ dos homens e $13 \%$ das mulheres. Já KÖRTZINGER, BIERWAG, MAST e MULLER (1997) combinaram a calorimetria indireta e um diário de atividades físicas para calcular o GET de 50 adultos. Este GET foi comparado com as estimativas de IE obtidas por um diário alimentar de sete dias e uma história alimentar computadorizada, que possuía diversos recursos multimídia. Embora a proporção de sub-relatores tenha sido a mesma para os métodos (48\%), cerca de $34 \%$ dos sujeitos subnotificaram a ingestão simultaneamente nos dois métodos. Esses resultados estão de acordo com os modelos de mensurações propostos por KAAKS et al. (2002), que postulam que o sub-relato é um viés específico do sujeito, que possui uma porção randômica e uma porção sistemática. $O$ estudo das características dos sub-relatores não encontra resultados totalmente consistentes porque uma parte da distribuição do sub-relato entre os sujeitos é aleatória. Dessa forma, para encontramos resultados consistentes, é mais interessante estudar as características daqueles indivíduos que sempre subnotificam, ou, em outras palavras, naqueles em que, de fato, o sub-relato é sistemático, independentemente dos métodos utilizados para se avaliar o consumo alimentar. 
Para atender a esse objetivo, nossa amostra foi dividida em: a) sujeitos 'nunca sub-relatores' (aqueles que nunca sub-relataram em nenhum dos três métodos de inquérito alimentar); b) sujeitos 'sub-relatores ocasionais' (aqueles que sub-relataram apenas em um método de avaliação do consumo alimentar) e; c) sujeitos 'sub-relatores freqüentes' (aqueles que sub-relataram em dois ou três métodos de avaliação do consumo alimentar). Esses três grupos tiveram suas características físicas, psicológicas e sociais comparadas (TABELA 9). Os subrelatores freqüentes apresentaram menores valores de renda e escolaridade e maiores valores de idade, insatisfação corporal e desejo de aceitação social. Além disso, a proporção de sub-relatores freqüentes foi significantemente maior entre as voluntárias obesas. Portanto, pode-se considerar que essas variáveis são as mais sistematicamente correlacionadas à subnotificação.

Os 'sub-relatores ocasionais' apresentaram estatísticas descritivas muito semelhantes às apresentadas pelos 'nunca sub-relatores' (TABELA 9). Deve-se ter em mente que o método mais presente na categoria 'sub-relatores ocasionais' foi o questionário de freqüência alimentar. Isso, mais uma vez, reforça nossa hipótese de que ele produziu sub-relato randomicamente, independentemente das características dos sujeitos.

A renda e a escolaridade apareceram como alguns dos fatores mais importantes na distinção dos sujeitos que sempre sub-relatavam. Supõe-se que as pessoas com menor renda e escolaridade tenham apresentado mais dificuldade em responder aos inquéritos e talvez até maior constrangimento nessa tarefa. Para responder ao questionário de freqüência alimentar, são necessárias habilidades de cálculo e abstração por parte dos sujeitos, o que pode fazer com que indivíduos com menor escolaridade tenham maior dificuldade em respondê-lo (THOMPSON \& BYERS, 1994; SUBAR et al, 1995). Em um diário alimentar, um sujeito com baixa escolaridade também pode registrar o consumo de forma confusa e vaga, além de se cansar mais facilmente durante o processo de escrita (THOMPSON \& BYERS, 1994). O recordatório alimentar é considerado o melhor método para ser aplicado em indivíduos com pouca escolaridade, porque é o entrevistador quem registra o consumo. Além disso, o entrevistador consegue explicar melhor as perguntas para o entrevistado e obtém mais detalhes sobre a ingestão (THOMPSON \& BYERS, 1994). Mesmo assim, o baixo nível sócio-econômico pode prejudicar a aplicação do 
recordatório, pois o sujeito pode não compreender totalmente as perguntas feitas. No presente estudo, a quantificação das porções alimentares durante o recordatório foi auxiliada pelo uso de fotografias e desenhos. Notou-se que os sujeitos de maior grau sócio-econômico utilizavam tais recursos com mais facilidade. Espontaneamente, eles faziam os seguintes tipos de afirmação: 'minha porção foi $30 \%$ maior do que esta' ou 'meu pedaço correspondia à soma desses dois'. Obviamente, a influência do nível sócio-econômico sobre a habilidade de quantificar porções não foi testada nesse estudo, trata-se apenas de uma observação obtida durante o trabalho de campo que pode contribuir para o entendimento do resultado.

STALLONE, BRUNNER, BINGHAM e MARMOT (1997) encontraram que, entre as mulheres de maior renda, a proporção de sub-relatoras foi 19,3\%, enquanto que, entre aquelas de menor renda, esta proporção foi de $49,2 \%$. Quando todos os sujeitos eram incluídos na amostra, aqueles com menor renda apresentavam menor consumo de diversos nutrientes, como fibras, carboidratos e ácidos graxos poliinsaturados. Desta forma, poder-se-ia concluir que o nível sócio-econômico influenciava o consumo nutricional. Entretanto, esta diferença inexistia quando os sub-relatores eram excluídos da análise. Assim, os autores concluíram que, se o subrelato não tivesse sido considerado, uma "falsa" influência da renda sobre a ingestão nutricional teria sido detectada.

Usando diários alimentares, PRICE et al. (1997) obtiveram resultados semelhantes, já KREBS-SMITH et al. (2000), aplicando recordatórios alimentares, e POMERLEAU et al. (1999), utilizando um questionário de freqüência alimentar, obtiveram resultados opostos. È difícil, entretanto, comparar nossos resultados com estes encontrados em países desenvolvidos, pois um nível educacional x (por exemplo, ter completado o ensino médio) pode significar capacidades intelectuais muito diferentes, dependendo da excelência educacional do ensino de cada país. Embora não exista nenhum estudo brasileiro com o mesmo desenho do atual, podese relacioná-lo a estudos que compararam dois métodos de avaliação do consumo alimentar. SICHIERI (1998), utilizando o mesmo questionário de freqüência alimentar aqui testado, também encontrou que indivíduos com baixo nível sócio-econômico relatavam com maior freqüência IE inferior ao GET, sendo que essa pesquisa usou fórmulas para estimar o GET. No nosso estudo anterior, a baixa escolaridade esteve associada ao sub-relato em mulheres eutróficas. Naquelas com excesso de peso, a 
subnotificação era comum, independentemente da educação (SCAGLIUSI et al., 2003). Na Indonésia, que também é um país pobre, a baixa escolaridade correlacionava-se ao sub-relato (WINKVIST et al., 2002). Mesmo considerando o pequeno número de estudos a esse respeito, pode-se concluir que os fatores sócioeconômicos são muito importantes para o sub-relato. A tendência é de que pessoas mais pobres e menos educadas sub-relatem mais. Tal fato é extremamente preocupante, pois essas pessoas geralmente compõem grupos de risco para diversas doenças nutricionais. MONTEIRO, CONDE e POPKIN (2002) afirmaram que mulheres de baixa renda estão, ao mesmo tempo, mais expostas à desnutrição e à obesidade, doenças essas que necessitam da avaliação do consumo alimentar para fins de diagnóstico, tratamento e pesquisa (como para verificação de fatores alimentares etiológicos e para o monitoramento populacional). A constatação de que tal grupo constantemente sub-relata prejudica a correta interpretação dos dados obtidos pelos inquéritos alimentares, aplicados com as finalidades descritas acima.

Também foi encontrado na presente pesquisa que os sub-relatores freqüentes tinham idade mais elevada (TABELA 9). Esse resultado já foi verificado em outros estudos. TOMOYASU et al. (1999) observaram correlação positiva entre a idade e o sub-relato. Em seu estudo de 2001, realizado com 193 sujeitos, JOHANSSON, WIKMAN, AHREN, HALLMANS e JOHANSSON notaram que o subrelato (definido como ingestão relatada menor que $1,2^{\star} \mathrm{TMB}$ - esta calculada por equações) variou de $26 \%$, entre os indivíduos na faixa de 30 anos, a $54 \%$, naqueles na faixa de 60 anos $(p<0,01)$. Uma possível explicação é que pessoas mais velhas possuem menor capacidade de concentração e estão mais sujeitas a lapsos de memória. Entretanto, a diferença de idade encontrada aqui não foi tão grande para que se possa pensar que os sub-relatores freqüentes tiveram menos acurácia por dificuldades cognitivas ligadas ao envelhecimento. Inclusive, percebe-se na TABELA 9 que os valores mínimos e máximos de idade foram semelhantes para todos os grupos. Uma explanação mais provável envolve o ganho de peso que as mulheres acumulam ao longo dos anos. O estudo longitudinal de WILLIAMS, GERMOV e YOUNG (2007) mostrou que mulheres mais próximas do climatério e da menopausa costumam ganhar peso com mais facilidade e se preocupar com isso. Na tentativa de minimizar tal ganho, elas utilizam diversas práticas, como diminuição da quantidade ingerida e adoção de dietas comerciais, porém poucas dessas ações se mostraram 
efetivas. Tais práticas são semelhantes ao conceito de restrição alimentar, cuja correlação com o sub-relato foi verificada para o recordatório e diário alimentar. Se essas mulheres são mais preocupadas com o controle do peso e da alimentação, é possível supor que quando elas ingerem algo não 'condizente com seus regimes alimentares', elas sentem vergonha ou culpa e podem não querer relatar tal consumo.

Tais suposições estão profundamente relacionadas com o conceito de insatisfação corporal, cujos valores também foram mais altos no grupo de subrelatores freqüentes (TABELA 9). Este resultado não é consistente entre os estudos. Como foi citado na Revisão Bibliográfica, os trabalhos de NOVOTNY et al. (2003) e JOHANSSON et al. (1998) encontraram correlação entre alguns aspectos de imagem corporal e a subnotificação, porém a maneira como avaliaram os quesitos de imagem corporal não foi correta. Já as pesquisas de TAREN et al. (1999), TOOZE, SUBAR, THOMPSON, TROIANO, SCHATZKIN e KIPNIS (2004) e KIMM et al. (2006) avaliaram a imagem corporal utilizando instrumentos com bom desempenho psicométrico e também empregaram a água duplamente marcada. KIMM et al. (2006) encontraram que o ímpeto para a magreza só correlacionava-se com o subrelato entre adolescentes negras. Esses autores verificaram também que as adolescentes negras do tercil mais baixo de IMC possuíam os menores escores de insatisfação corporal e ímpeto para a magreza e apresentavam os relatos mais acurados de IE (nestas, a diferença média entre a IE e o GET foi só de 6\%). Assim, os pesquisadores concluíram que quando o sujeito não é afetado por tais valores culturais e psicológicos, é possível obter estimativas energéticas surpreendentemente acuradas a partir dos diários alimentares. TAREN et al. (1999) testaram a influência de diversas variáveis psicológicas, porém só mostraram significância no modelo multivariado de predição da acurácia dois escores de insatisfação corporal, a idade e a porcentagem de gordura corporal. No Estudo OPEN (TOOZE et al., 2004), os sub-relatores, de ambos os sexos, apresentavam maior escore de insatisfação corporal (medida pela escala de STUNKARD et al., 1983, a mesma usada no presente estudo), quando eram analisados os dados do recordatório alimentar de 24 horas. Em relação ao questionário de freqüência alimentar, esta diferença foi significante entre os homens (entre as mulheres o valor de $\mathrm{p}$ se situou entre 0,10 e 0,05$)$. Entretanto, quando foi realizada uma regressão 
logística para se determinar qual era a combinação linear de variáveis que mais contribuía para a subnotificação, os escores de insatisfação corporal não entraram no modelo. Nossos resultados indicam que a insatisfação corporal é uma característica mais acentuada naqueles que sub-relatam freqüentemente. A falta de consistência desse achado na literatura pode ser derivada de vários motivos. Um deles seria a diferença cultural entre as amostras. O outro se refere à dificuldade em conceituar $e$ mensurar os diversos aspectos e componentes da imagem corporal. De acordo com GLEESON e FRITH (2006), a forma como a imagem corporal foi conceituada e mensurada na presente pesquisa e naquelas supracitadas parte de premissas sem articulação ideológica, o que faz com que o construto 'imagem corporal' se torne menos dinâmico e produtivo. Além disso, embora os instrumentos utilizados tenham sido avaliados quanto à validade e precisão, assume-se que os mesmos obterão uma resposta neutra e representativa de uma imagem que já existia na mente dos sujeitos, quando se sabe que isso não é verdadeiro. A escala utilizada na atual pesquisa mostra uma série de figuras que não representam nenhum corpo em particular. Para respondê-la, as pessoas devem se imaginar com aqueles corpos. Obviamente, tal avaliação pode obter resultados muito variados, subjetivos e até aleatórios. Por outro lado, os resultados de pesquisas qualitativas mostram que quando os sujeitos sentem vergonha sobre seu corpo, eles tendem a mudar sua alimentação no período de avaliação da mesma, corroborando nossos achados (VUCKOVIC, RITENBAUGH, TAREN \& TOBAR, 2000; SCAGLIUSI et al., 2003).

O desejo de aceitação social também diferiu significantemente entre os grupos, sendo maior naqueles que sub-relatavam freqüentemente (TABELA 10). De todos os fatores psicológicos já analisados na literatura, este é mais correlacionado ao sub-relato (MAURER, TAREN, TEIXEIRA, THOMSON, LOHMAN, GOING \& HOUTKOOPER, 2006). De fato, essa relação é bastante lógica e intuitiva: se uma pessoa se preocupa em fornecer a resposta mais bem-vista e aceita pela sociedade, ela responderá algo condizente com tal aceitação, independentemente dessa resposta ser verdadeira. Desta forma, essas pessoas sentem-se incitadas a relatar 0 consumo alimentar considerado saudável e não o real (HILL \& DAVIES, 2001). Esse efeito é ainda mais acentuado quando os sujeitos avaliados são participantes de uma intervenção que visa mudar hábitos alimentares. JOHNSON, FRIEDMAN, HARVEYBERINO, GOLD e MCKENZIE (2005) verificaram que a ocorrência de sub-relatores 
aumentou de 39,7\% para 60,3\%, ao cabo de uma intervenção deste tipo. Independentemente de terem feito as mudanças propostas pela intervenção, as pessoas relatavam uma alimentação coerente com tais orientações.

HEBERT et al. (1995) e HEBERT, EBBELING, MATTHEWS, HURLEY, MA, DRUKER e CLEMOW (2002) encontraram tal correlação em seus estudos. No estudo de 1995, foi observada correlação negativa entre o escore desta variável e 0 consumo relatado de energia, especialmente entre as mulheres. Os métodos de inquérito alimentar utilizados foram um recordatório alimentar de 24 horas e um novo método, parecido com sete dias de recordatório alimentar, porém preenchidos pelos próprios sujeitos. No estudo de 2002, além dos dois métodos de avaliação do consumo alimentar citados acima, foi utilizado um questionário de freqüência alimentar. Os pesquisadores testaram diversos modelos de regressão, nos quais o GET (medido pela água duplamente marcada) era mantido constante, para fazer predições sobre a IE, com base nos escores de desejo de aceitação social e escolaridade. $O$ efeito do desejo de aceitação social foi maior nas estimativas de IE derivadas do questionário de freqüência alimentar, nas mulheres com curso superior (ou mais). Nestes sujeitos, cada ponto do escore de desejo de aceitação social acarretava em relato de menos $42,24 \mathrm{kcal} /$ dia. O desejo de aceitação social explicou cerca de $25 \%$ da variação da IE neste grupo. Segundo os autores, o questionário de freqüência se baseia na memória genérica, ao contrário dos recordatórios, que se baseiam na lembrança de eventos específicos. Desta forma, ao preencher um questionário de freqüência, a lembrança é mais vaga e, por isso, mais sujeita a influências emocionais e sociais. Ao mesmo tempo, os autores especularam que as mulheres com maior escolaridade estejam mais expostas ao padrão magro de beleza, de tal forma que os seus conceitos sobre o que é uma dieta ideal convergem para a dieta que mantém o corpo magro, isto é, com menor conteúdo energético. Assim, essas mulheres, ao relatarem suas ingestões em um método que se baseia na memória mais ampla e vaga, são afetadas pelo desejo de aceitação social e relatam a ingestão idealizada. Como o estudo não incluiu nenhuma medida de imagem corporal que apontasse o padrão de beleza destes sujeitos, não era possível afirmar se isto de fato ocorria. Já TOOZE et al. (2004) encontraram correlação negativa entre o desejo de aceitação social e a acurácia do relato quando os dados de IE eram provenientes de recordatórios alimentares, mas não quando o 
questionário de freqüência alimentar era utilizado. Os autores alegaram que a presença de um entrevistador, como existe no recordatório, constrange as pessoas e amplifica o desejo de aceitação social. Entretanto, nosso estudo anterior utilizou diários alimentares, nos quais não há entrevistador, e mesmo assim essa correlação negativa foi encontrada (SCAGLIUSI et al., 2003). O presente estudo contribui para essa discussão mostrando que, nessa amostra, o desejo de aceitação social apresentou correlação negativa com a razão IE/GET obtida por dois métodos diferentes e que foi uma característica marcante daqueles que sub-relatam de forma constante e independente do método de inquérito alimentar.

De forma geral, os fatores correlacionados à acurácia do relato nessa amostra parecem se dividir em duas frentes: a primeira se refere à dificuldade em expressar o consumo, pelo baixo nível sócio-econômico, e a segunda se refere à dificuldade em "confessar" o consumo. A pressão social exercida sobre as mulheres para que estas possuam a imagem corporal "ideal" parece ser uma razão subjacente aos problemas relacionados ao relato da ingestão alimentar, pois torna o consumo alimentar algo digno de vergonha, transformando um simples relato em uma "confissão". Em concordância com esta hipótese, tem-se o fato de que os homens (que sofrem menor pressão social em relação à sua imagem corporal) apresentam menores índices de sub-relato e de desejo de aceitação social (HEBERT, PETTERSON, HURLEY, STODDARD, COHEN, FIELD \& SORENSEN, 2001). ROZIN, BAUER e CATANESE (2003) mostraram que aproximadamente $14 \%$ de sua amostra de universitárias americanas se sentiam envergonhadas em simplesmente comprar uma barra de chocolate em uma loja. Possivelmente, tais pessoas também se sentem envergonhadas em relatar seu consumo, optando então por modificá-lo durante a avaliação ou por alterar o relato.

Percebe-se, portanto, que as dificuldades envolvidas na avaliação do consumo alimentar são grandes e as fontes de erro são múltiplas e, ao mesmo tempo, sistemáticas. Estudos como o de OLAFSDOTTIR, THORSDOTTIR, GUNNARSDOTTIR, THORGEIRSDOTTIR e STEINGRIMSDOTTIR (2006) têm mostrado que quando a taxa de sub-relato é alta, a correlação entre a ingestão nutricional e os marcadores biológicos de concentração diminui.

Deve-se considerar que a alimentação é algo muito mais amplo do que a nutrição. $\mathrm{O}$ ato de comer é carregado de significados simbólicos que entram em 
choque com a objetividade, neutralidade e precisão exigida pela avaliação do consumo alimentar. As pessoas não somente ingerem alimentos, elas se relacionam com a comida. Segundo FISCHLER (1988), o relacionamento com a comida é ao mesmo tempo banal e fundamental, pois forma nossa identidade nos níveis biológicos, culturais e emocionais. Esse mesmo autor afirmou que "o homem é um onívoro que se alimenta de carne, vegetais e do imaginário: a alimentação conduz à biologia, mas não se reduz a ela; o simbólico, os signos, os mitos, os fantasmas também alimentam e concorrem a regrar nossa alimentação". Em seu cotidiano uma pessoa pensa e enxerga sua alimentação de forma flexível, contraditória e variada, respondendo às instâncias afetivas e sócio-culturais. Porém, a forma pela a qual um inquérito questiona e avalia a alimentação pressupõe atributos contrários a estes, como constância, exatidão e registro de tudo que é consumido (GARCIA, 2004). Entende-se, portanto, porque é tão difícil relatar o consumo alimentar. Ao enquadrar o sujeito numa esfera de regularidade e precisão, são obtidas respostas artificiais e vagas.

Mesmo assim, os instrumentos de avaliação do consumo alimentar continuarão sendo necessários, e até mesmo insubstituíveis, para o monitoramento da ingestão de indivíduos e populações e também para a realização de estudos epidemiológicos acerca da relação entre alimentação e saúde. Porém, para que o grau de acurácia e confiabilidade dessas pesquisas possa ser minimamente suficiente, é condição sine qua non que se conheça o viés do método utilizado, para que ajustes estatísticos possam ser feitos. Esse estudo comprovou que métodos anteriormente considerados "de referência" (como o diário e o recordatório alimentar) estão sujeitos a erros sistemáticos que impedem sua utilização como padrões de referência. Sempre que as validações forem conduzidas comparando-se dois métodos sujeitos a erros correlacionados não se dimensionará corretamente a magnitude do viés e os ajustes estatísticos não serão frutíferos. Assim, preconiza-se que mais estudos com marcadores biológicos de recuperação sejam conduzidos antes que um método de avaliação do consumo alimentar seja utilizado em um estudo.

Pesquisadores têm tentado, então, novas formas de se avaliar o consumo ou de minimizar o sub-relato. YON, JOHNSON, HARVEY-BERINO e GOLD (2006) desenvolveram um diário alimentar na forma de um palm top, que inclusive conta 
com figuras. Já HENDRICSKON e MATTES (2007) ofereceram um incentivo financeiro para os sujeitos cujo relato fosse acurado. Infelizmente, nenhuma dessas abordagens funcionou.

Uma das novas formas de se analisar o consumo é por meio da análise de padrões alimentares. Contudo, é necessário avaliar se essa análise também não é prejudicada pela subnotificação. Tal problema pode proceder quando se considera que a subnotificação pode ser específica para alguns alimentos e, conseqüentemente, nutrientes (PRYER, VRIJHEID, NICHOLS, KIGGINS \& ELLIOT, 1997).

Quando um indivíduo subnotifica seu consumo, espera-se que todos os alimentos sejam igualmente sub-relatados. Dividindo o consumo alimentar deste sujeito pela IE relatada, encontra-se um padrão de consumo de alimentos, que não deveria diferir daquele obtido pelos indivíduos que não sub-relataram. Assim, o baixo consumo relatado de alguns alimentos se deveria ao fato de que a IE relatada é baixa. Se isto fosse verdadeiro, as conseqüências do sub-relato para os estudos de epidemiologia nutricional seriam menores, posto que o ajuste pela IE diminuiria 0 impacto deste erro (BELLACH \& KOHLMEIER, 1998).

Diversos pesquisadores preocuparam-se em verificar, então, se todos os alimentos eram subnotificados com a mesma magnitude. Se isto não ocorresse, isto é, se o sub-relato fosse mais intenso para alguns alimentos, o ajuste pela IE não conseguiria controlar o efeito do viés (BELLACH \& KOHLMEIER, 1998). Três abordagens foram utilizadas para verificar se o sub-relato era seletivo para alguns alimentos e/ou nutrientes: a) uso de marcadores biológicos do consumo de macronutrientes; b) comparação do consumo de alimentos e nutrientes, sem ajuste pela IE, entre sub-relatores e não sub-relatores e; c) a mesma comparação, porém com ajuste pela IE, obtido de várias formas.

Infelizmente, o único marcador que existe para os macronutrientes é a excreção urinária de nitrogênio, utilizada para validar as estimativas de consumo de proteínas. Não existem, atualmente, marcadores para lipídeos e carboidratos. Alguns pesquisadores combinaram o uso de estimativas do GET com a excreção urinária de nitrogênio. O intuito destes estudos era verificar se o sub-relato da IE era proporcional à subnotificação de proteínas, isto é, se a magnitude do sub-relato da IE era igual à magnitude do sub-relato do consumo protéico. Caso isto não fosse 
constatado, poder-se-ia supor que havia maior sub-relato dos outros macronutrientes. HEITMANN e LISSNER (1995) compararam a ingestão de energia e proteína estimada a partir da história alimentar, com a excreção urinária de nitrogênio e o GET, estimado por fórmulas (que consideravam as massas gorda e magra) e pelo fator de atividade física (obtido por um questionário). Cerca de $85 \%$ dos sujeitos sub-relataram o consumo de energia, sendo que, para proteína, a taxa foi de $72 \%$. Utilizando dados ajustados pelo gênero, idade e fumo, a correlação entre a porcentagem de gordura corporal e a ingestão protéica determinada pela urina foi igual a $0,08(p=0,16)$. Já para a ingestão relatada de proteína, a correlação foi igual $a-0,12(p=0,03)$. A razão IE/GET esteve negativamente associada à porcentagem de gordura corporal $(r=-0,37, p=0,0001)$. Os autores concluíram que os indivíduos obesos tenderam a sub-relatar sua IE e superestimar o consumo de proteínas, o que sugere que o sub-relato atinja mais os lipídeos e/ou carboidratos.

HEITMANN et al. (2000) conduziram um estudo para determinar se o subrelato seletivo de lipídeos vem aumentando. Os autores apontaram que os levantamentos de consumo alimentar de diversos países indicam que o consumo de lipídeos tem diminuído nas últimas décadas, enquanto que, paradoxalmente, a prevalência de obesidade tem aumentado muito. Uma das hipóteses que tentam explicar esse fato é o concomitante aumento do sub-relato de lipídeos. A favor desta hipótese estão as estatísticas de produção e compra de alimentos, que não mostram diminuição do consumo dos alimentos ricos nesse nutriente. Estes autores analisaram os dados de consumo alimentar (obtidos por uma história alimentar) de dois levantamentos populacionais dinamarqueses, um datado de 1987-88 e outro de 1993-194. Em cada um, uma sub-amostra de adultos forneceu uma coleta de 24 horas de urina (a partir da qual o consumo protéico foi determinado). O GET foi calculado por fórmulas (que consideravam as massas magra e gorda) e por fatores de atividade física. No primeiro levantamento, os lipídeos contribuíram com 40,4 \pm $6,4 \%$ da IE, enquanto que, em 1993-94, este valor foi igual a 38,2 $\pm 7 \%$. A IE se manteve estável. Em 1987-88, a IE era menor que o GET, assim como a ingestão protéica relatada era menor do que a calculada pela urina. Em 1993-94, só a IE era menor que o GET; a ingestão protéica relatada era igual à calculada pela urina. Embora o consumo protéico (calculado pela urina) tenha diminuído entre os dois levantamentos $(p<0,002)$, o relato de ingestão protéica aumentou $(p<0,05)$. A IE foi 
mais sub-relatada do que as proteínas nos dois momentos, porém em 1987-88 esta diferença foi de 15\% e, em 1993-94 a diferença foi de $29 \%$ ( $p<0,0001$ ). Um outro dado relevante é que, quando os indivíduos foram divididos em octis de acordo com a porcentagem de gordura corporal, esta diferença, em 1987-88, foi de $18 \%$ no octil de maior gordura e $8 \%$ no octil de menor gordura. Já em 1993-94, estes valores foram, respectivamente, iguais a $39 \%$ e $22 \%$. Assim, estes resultados indicaram que, se o sub-relato de proteínas diminuiu, mas a subnotificação de energia permaneceu a mesma, os outros nutrientes fornecedores de energia (carboidratos e lipídeos) certamente passaram a ser mais sub-relatados. Embora a não existência de marcadores de carboidratos e lipídeos impossibilite uma conclusão, os autores sugeriram que este sub-relato era maior para os lipídeos do que para os carboidratos, pois no país estudado (Dinamarca) foram feitas, no mesmo período, muitas campanhas de saúde pública sobre os riscos de uma alimentação com excesso de lipídeos, e outros estudos já mostraram que de fato a população tomou conhecimento destes conceitos. Em todo o caso, este estudo possui falhas metodológicas que já foram bem discutidas nesta revisão, como o uso de apenas um dia de coleta de urina (sendo que o método de avaliação do consumo alimentar empregado obtém estimativas da ingestão habitual), a aplicação de fórmulas para cálculo da TMB e a utilização de instrumentos não validados para estimar a prática de atividade física.

KREBS-SMITH et al. (2000) utilizaram os dados de recordatórios alimentares de 24 horas de um inquérito populacional norte-americano para comparar a freqüência de consumo e o tamanho das porções de diversos grupos alimentares, entre não sub-relatores e sub-relatores. Enquanto $30 \%$ dos não subrelatores alegavam ter consumido bolos e tortas pelo menos uma vez nos dois dias de recordatórios, o mesmo ocorreu com apenas 10\% dos sub-relatores. Outros alimentos que tiveram diferença de pelos menos 15 pontos percentuais foram: pipocas/pretzels, batatas, queijo, carne, peixe, frango, ovos, refrigerantes, condimentos e gorduras de adição que são espalhadas nos alimentos (spreads). Em relação ao tamanho das porções alimentares, os sub-relatores descreveram porções 40-20\% menores de cerveja, salgadinhos, panquecas, arroz, cereais, biscoitos, bolos, tortas, pizza, condimentos e leite. Por outro lado, eles tenderam a relatar consumo de maiores porções de pães, batatas e vegetais sem adição de gordura, 
adoçantes artificiais e refrigerantes diets. Os autores concluíram que os sub-relatores subestimavam suas porções alimentares de forma geral, porém a omissão de alimentos parecia atingir mais os alimentos vistos como "não-saudáveis" ou "engordativos". Analisando diários alimentares de três dias de adultos franceses, LAFAY, MENNEN, BASDEVANT, CHARLES, BORYS, ESCHWEGE e ROMON (2000) observaram que a subnotificação é seletiva para os alimentos considerados "ruins", como açúcar, produtos de pastelaria, bebidas doces e batatas fritas. KANT (2002) constatou que os sub-relatores apresentavam menor número de ocasiões alimentares e de alimentos consumidos, além de menor quantidade relatada de alimentos (em gramas). Contudo, deve-se considerar que estes três estudos compararam a ingestão absoluta de alimentos, sem ajustá-la pela IE. Embora não haja consenso na literatura sobre os benefícios de tal ajuste (BELLACH \& KOHLMEIER, 1998), esta técnica é recomendada quando os dados de consumo alimentar são usados para fazer inferências sobre a relação entre dieta e saúde (WILLETT, 2003). Em relação aos estudos citados acima, poder-se-ia especular que, como os alimentos com maior diferença entre sub-relatores e relatores acurados possuem alto valor energético, esta diferença ocorre em função do baixo relato de IE por parte dos sub-relatores, e não do sub-relato específico.

Para testar esta hipótese, outros estudos fizeram comparações semelhantes, porém empregando o ajuste pela IE, que pode ser feito transformando as ingestões absolutas em medidas de densidade (por exemplo, consumo de batatas - em gramas $/ 1.000 \mathrm{kcal}$, ou porcentagem de energia proveniente de lipídeos) ou por resíduos de análises de regressão (JAIME, LATORRE, FORNÉS \& ZERBINI, 2003).

POMERLEAU et al. (1999) aplicaram um questionário de freqüência alimentar a 30.248 adultos e definiram como sub-relatores aqueles com IE/TMB menor que 1,2, sendo que, novamente, a TMB foi estimada por fórmulas. Os subrelatores apresentaram maior consumo de frutas, hortaliças e laticínios e menor de doces e sobremesas, quando os grupos alimentares foram expressos como número de porções/MJ. PRYER et al. (1997) aplicaram o mesmo ponto de corte para o subrelato em uma outra amostra de adultos, na qual o consumo alimentar foi estimado por um diário alimentar de sete dias, com pesagem das porções. Entre os subrelatores, os seguintes grupos alimentares apresentaram menor participação percentual no conteúdo energético da dieta: biscoitos, tortas, manteiga, açúcares, 
doces e bebidas alcoólicas. Além disso, estes indivíduos tiveram menor densidade energética de carboidratos, sacarose, álcool, gordura saturada, ácidos graxos trans e maior densidade energética de proteínas, amido, fibras, colesterol e ácidos graxos mono e poliinsaturados.

De forma geral, os estudos disponíveis parecem apontar para a existência de especificidade de alimentos e nutrientes dentro do sub-relato. Especula-se que há uma tendência de maior subnotificação de alimentos vistos como "não saudáveis" e "engordativos". Em pesquisa realizada por MELA e AARON (1997) os voluntários foram questionados sobre suas tendências de consumo caso tivessem que relatar sua ingestão. Cerca de 18,6\% afirmaram que reduziriam o consumo de alimentos gordurosos, 30,8\% diminuiriam o consumo de doces e 42,9\% aumentariam 0 consumo de frutas e hortaliças durante o período de avaliação.

Se as constatações supracitadas são verdadeiras, é possível que a análise de padrões alimentares, por derivar desses mesmos dados, apresente resultados enviesados. Entretanto, até hoje, poucos estudos procuraram analisar a presença e as conseqüências do sub-relato para essa análise.

BAILEY, MITCHELL, MILLER e SMICIKLAS-WRIGHT

(2007) determinaram, por meio da análise de agrupamento, os padrões de alimentares de uma amostra de 179 idosos. Os dados de consumo alimentar foram inicialmente obtidos por cinco recordatórios alimentares de 24 horas. Foram obtidos dois agrupamentos de padrões alimentares: o primeiro correspondia a um padrão inadequado, composto principalmente por gorduras de adição, ovos, doces, carne vermelha e snacks, enquanto que o segundo era mais equilibrado nutricionalmente, sendo mais composto por cereais, massas, frutas, hortaliças e leite. Após terem obtido essa solução, os autores identificaram os sujeitos sub-relatores, definidos como aqueles com, pelo menos, IE 55\% inferior ao GET (esse último foi estimado por fórmulas). Tais indivíduos foram excluídos da amostra e a análise de agrupamento foi repetida. Os mesmos padrões alimentares foram obtidos, porém a proporção de sujeitos apresentando o padrão alimentar adequado diminuiu de 40,2 a $33,8 \%$, enquanto que a proporção de voluntários com padrão alimentar inadequado aumentou de 59,8 para $66,2 \%$. Embora os padrões alimentares tenham se mantido relativamente estáveis, algumas diferenças nos grupos alimentares foram ocasionadas pela exclusão dos sub-relatores. Apenas quando a amostra completa 
era analisada, o primeiro padrão (de consumo inadequado) era caracterizado por menor ingestão de algumas hortaliças, leite, frango, peixe e leguminosas. Quando os sub-relatores eram excluídos da amostra, tais diferenças inexistiam. Ao mesmo tempo, apenas quando os sub-relatores eram retirados da amostra, os sujeitos do primeiro padrão apresentavam maior ingestão de tubérculos e oleaginosas. Percebeu-se, portanto, que embora a mesma solução de análise tenha sido obtida com a presença dos sub-relatores, essa afetava os resultados obtidos, pois produzia diferenças que não procediam, ao mesmo tempo em que mascarava diferenças verdadeiras. Além disso, a presença de sub-relatores fazia com que muitos sujeitos fossem alocados no padrão errado. Pode-se imaginar como essa incorreta classificação pode prejudicar os estudos acerca da relação entre alimentação e saúde. Por exemplo, um padrão alimentar composto por alimentos mais ricos em fibras, vitaminas, carboidratos complexos e mais pobres em lipídeos pode proteger contra doenças cardiovasculares. Porém, se em um grupo de pessoas com tal alimentação existem sujeitos que não se alimentam dessa forma e sim relatam se alimentar dessa forma, a correlação entre a exposição e o efeito certamente pode ser prejudicada.

O estudo supracitado foi bastante pioneiro em integrar o sub-relato à análise de padrões alimentares. Contudo, ele possui algumas limitações, como: a) não ter usado a água duplamente marcada, b) ter empregado uma amostra muito específica, não podendo generalizar seus resultados para outras amostras e; c) não ter quantificado a subnotificação nos agrupamentos de padrões alimentares. Assim, o presente estudo tentou abordar tais pontos.

Foi obtida uma solução de três clusters com características bem diferenciadas (TABELA 11). O primeiro e maior cluster, com $47,7 \%$ da amostra, caracterizou-se pela presença de alimentos doces e refrigerantes contendo açúcar. $O$ segundo agrupamento, com $36,9 \%$ da amostra, era mais representado pelo consumo de grãos, feculentos e leguminosas. Já o terceiro cluster, com 15,4\% da amostra, era caracterizado por maior ingestão de frango, frutas e hortaliças. Nota-se que 0 primeiro cluster é menos condizente com as orientações de uma alimentação saudável, de acordo com as recomendações da Pirâmide Alimentar (PHILIPPI, LATTERZA, CRUZ \& RIBEIRO, 1999), ao contrário dos outros clusters. O cluster 'alimentos frugais' segue algumas recomendações deste guia alimentar e é mais 
coerente com o que a população leiga costuma identificar como alimentos saudáveis (ROZIN et al., 1996; OAKES \& SLOTTERBACK, 2002).

A solução encontrada não é muito diferente daquelas apresentadas na literatura, o que sugere que nossa análise foi adequada (BAILEY, GUTSCHALL, MITCHELL, MILLER, LAWRENCE \& SMICIKLAS-WRIGHT, 2006; KHANI, YE, TERRY \& WOLK, 2004; NEWBY \& TUCKER, 2004). Nosso principal achado foi que o sub-relato da IE existe em todos os clusters de padrão alimentar, mas que ele é crescente na seguinte direção: menor no cluster 'alimentos doces', intermediário no cluster 'alimentos ricos em amido' e maior no cluster 'alimentos frugais'. Na TABELA 12 , verifica-se que não só a média, mas também a mediana e os valores mínimos e máximos da razão IE/GET diminuem ao longo dos clusters. $O$ mesmo comportamento é observado para o índice IG. Enquanto o valor mínimo dessa variável é de -1.508 kcal no cluster 'alimentos doces', no cluster 'alimentos frugais', o valor mínimo é de $-2.043 \mathrm{kcal}$. Percebe-se que mesmo no primeiro cluster existe uma grande discrepância negativa entre a IE e o GET, mas essa diferença se acentua nos demais agrupamentos, especialmente no último. O teste do quiquadrado não obteve diferença significante quanto à distribuição percentual dos subrelatores entre os clusters, porém quando os intervalos de $95 \%$ de confiança para a as proporções de sub-relatores em cada cluster são analisados, percebe-se que há diferença significante entre as proporções apresentadas pelos clusters "alimentos doces" e "alimentos frugais" (FIGURA 15). Alguns dados da literatura corroboram nossos achados. WIRFALT, MATTISSON, GULLBERG e BERGLUNG (2000) observou que sujeitos que relatavam razões IE/TMB $\leq 1,35$ tinham maiores chances de pertencerem a agrupamentos de padrões alimentares mais saudáveis, compostos por alimentos ricos em fibras e pobres em lipídeos. Todavia, esse estudo não pôde afirmar que os sujeitos com IE/TMB $\leq 1,35$ eram sub-relatores, pois não foram utilizados métodos que permitissem identificar os indivíduos sub-relatores. Estudando sujeitos obesos, SVENDSEN \& TONSTAD (2006) encontraram que relatar 0 consumo de doces estava positivamente correlacionado com a acurácia do relato.

Portanto, nossos dados indicam que o sub-relato não se distribui de forma uniforme entre os clusters de padrão alimentar. Pelo nosso conhecimento, este dado é inédito. Contudo, nosso achado é condizente com os diversos estudos supracitados que apontavam, mesmo sem analisar padrões alimentares, que o sub- 
relato é seletivo para alimentos. É importante ressaltar que, na presente pesquisa, as freqüências de consumo foram ajustadas pelo consumo energético, de tal forma que as diferenças encontradas não podem ser atribuídas ao baixo relato per se e sim à subnotificação seletiva.

O dado aqui levantado deve servir como ponto de partida para pesquisas futuras. Não foi possível repetir a análise de padrões alimentares retirando-se os subrelatores porque o número desses foi tão alto, que sua retirada tornaria a amostra demasiadamente pequena para realizar a análise de cluster. Porém, tal análise é de suma importância, já que apenas um estudo realizou tal procedimento até então e seus resultados são inconclusivos (BAILEY et al., 2007). Mais relevante ainda seria analisar, em estudos de coorte, se os padrões alimentares obtidos com e sem subrelatores se correlacionam diferentemente com os efeitos de saúde. Tal pesquisa mostraria se, de fato, os sub-relatores prejudicam as inferências sobre a relação entre dieta e saúde, feitas pela Epidemiologia Nutricional, com base na análise de padrões alimentares.

Embora a análise de padrões alimentares seja um campo promissor para a Nutrição, diversas lacunas existem em relação à mesma. Uma delas é a interferência da subnotificação, mas existem outras. NEWBY e TUCKER (2004) questionam, por exemplo, se há diferenças significantes entre os padrões alimentares obtidos pela análise de cluster e pela análise fatorial. Sabe-se que os resultados da análise de cluster são de manejo e interpretação mais fáceis, porém não se sabe o efeito que essa escolha tem sobre a validade da análise. Não se sabe também qual é a melhor forma de descrever e tratar as variáveis que serão submetidas à análise. As variáveis devem ser expressas como freqüências, porções ou contribuições para a ingestão energética (BAILEY et al., 2006)? Também é desconhecido o efeito que procedimentos de transformação das variáveis (como padronização e transformação em log) podem ter (NEWBY \& TUCKER, 2004).

NEWBY e TUCKER (2004) também afirmaram que poucos estudos, até hoje, verificaram a validade da análise de padrões alimentares e, mais importante ainda, não se sabe exatamente como tal validação deve ser feita. Deve-se considerar que a comparação entre os padrões alimentares obtidos por um método com a ingestão nutricional obtida por outro recai no mesmo dilema enfrentado na validação isolada de um método de inquérito alimentar: não existem métodos de referência, 
com erros independentes da ingestão real e não correlacionados com os erros de outros métodos. Associar os padrões alimentares com fatores de risco e marcadores de doenças, como feito por NETTLETON, STEFFEN, MAYER-DAVIS, JENNY, JIANG, HERRINGTON e JACOBS JR (2006), pode ser mais frutífero, porém algumas questões também surgem. A maioria dos estudos desse tipo é de desenho transversal, que não é o mais adequado, já que se sabe que a exposição e o efeito não ocorrem simultaneamente (NEWBY \& TUCKER, 2004; LANGSETH, 1996). Além disso, em muitos estudos, existe uma premissa estabelecida a priori, como: 'sabe-se que a ingestão do nutriente $\mathrm{x}$ protege contra a doença $\mathrm{y}$, portanto o padrão alimentar com maior consumo de $x$ deve ter menor chance de desenvolver $y$ '. Apesar de lógico e intuitivo, tal raciocínio ignora o fato de que não conhecemos todas as relações entre dieta e saúde e que muitas das relações conhecidas podem ser frutos de vieses. Assim, se o pesquisador não encontra aquilo estabelecido na premissa, é possível tanto que a análise de padrões alimentar não seja válida quanto que a premissa (ou hipótese) não seja verdadeira. Dessa forma, a análise de padrões alimentares deve ser mais estudada, especialmente antes que sejam feitas recomendações alimentares com base nas mesmas.

Finalmente, deve-se considerar que o presente estudo apresenta algumas limitações. O n amostral é uma delas. Sabe-se que seria desejável possuir uma amostra maior, porém, dentro das possibilidades financeiras do trabalho, foi conseguida uma amostra de tamanho razoável, tanto em relação aos demais estudos com água duplamente marcada, quanto em relação às exigências dos métodos estatísticos utilizados.

Além disso, deve-se lembrar que este estudo analisou uma amostra composta apenas por mulheres e que, portanto, as conclusões obtidas não podem ser generalizadas para homens e nem mesmo para mulheres de outras faixas etárias.

Também se sabe que parte da diferença entre a IE e o GET pode não ser oriunda de problemas no relato e sim dos dados de composição dos alimentos. Entretanto, nosso estudo tentou controlar ao máximo essa limitação, por meio das seguintes medidas: a) escolha de tabelas brasileiras de composição de alimentos, que medem de fato o conteúdo nutricional dos nossos alimentos, e que apresentam análises confiáveis; b) escolha de apenas um pesquisador experiente para tabular os 
inquéritos e; c) preparação de regras para a tabulação. Ademais, há de considerar que o erro das tabelas de composição de alimentos era o mesmo para todos os sujeitos, não explicando a grande diferença de acurácia inter-indivíduos.

Também podem ser citadas limitações da própria água duplamente marcada. A mais importante é que essa técnica é apenas um marcador do relato da IE e não dos outros nutrientes. Assim, os resultados encontrados podem não proceder para o relato dos outros nutrientes. Além da água duplamente marcada, só existem marcadores de recuperação para proteína, sódio e potássio. O desenvolvimento de novos marcadores seria de grande valia. Uma outra limitação citada na literatura se refere à qualidade da dosagem das amostras utilizadas na técnica da água duplamente marcada, que, segundo SCHOELLER et al. (1995), pode variar muito entre laboratórios. Porém a qualidade e validade das análises realizadas pelo nosso laboratório foram analisadas e certificadas pela International Agency of Atomic Energy (SCHOELLER, 2007), o que garante a fidedignidade das análises. WILLETT (2003) também criticou o estudo OPEN, alegando que os inquéritos alimentares se referiam ao período de um ano e tiveram seus coeficientes de variação intra-individual medidos nesse período, enquanto que o mesmo não ocorreu para a água duplamente marcada. No presente estudo, todas as mensurações se referiram ao período de um mês e o teste-reteste da água duplamente marcada foi também feito com intervalo de um mês. Dessa forma, as principais limitações do estudo foram controladas. 
Os resultados do presente estudo mostraram que os métodos de avaliação do consumo alimentar analisados subestimam intensamente o consumo energético, quando aplicados em mulheres brasileiras adultas. Além disso, foi observado que indivíduos que sub-relatam freqüentemente, em diversos métodos de avaliação do consumo alimentar, tendem a ter menor renda e escolaridade e maior insatisfação corporal, desejo de aceitação social, IMC e idade mais elevada. O questionário de freqüência alimentar obteve graves erros para a maior parte dos sujeitos, e este efeito foi independente de todas as características individuais analisadas, com exceção do desejo de aceitação social. Também foi verificado que o sub-relato não possui distribuição uniforme entre os agrupamentos de padrão alimentar, sendo este fenômeno mais presente nos clusters compostos por alimentos que a população leiga identifica como saudáveis e menos associados ao ganho de peso.

Deve-se lembrar que esse é apenas o primeiro estudo a avaliar métodos de inquérito alimentar contra a água duplamente marcada no Brasil e nos países em desenvolvimento. Também se recomenda que grupos mais diversos, e na medida do possível maiores, sejam estudados. 


\section{REFERÊNCIAS BIBLIOGRÁFICAS}

ABREU, E. S.; TORRES, E. A. F. S. Restaurante "por quilo": vale o quanto pesa? Uma avaliação do padrão alimentar em restaurantes em São Paulo, SP. Nutrire, São Paulo, v. 25, n. 1, p. 7-22, 2003.

AKIN, J. S.; GUILKEY, D. K.; POPKIN, B. M.; FANELLI, M. T. Cluster analysis of food consumption patterns of older Americans. Journal of the American Dietetic Association, Chicago, v. 86, n. 5, p. 616-624, May 1986.

ALLISON, D. B.; KALINSKY, L. B.; GORMAN, B. S. A comparison of the psychometric properties of three measures of dietary restraint. Psychological Assessment, Arlington, v. 4, n. 3, p. 391-398, Sep 1992.

ALVARENGA, M. S.; PHILIPPI, S. T.; NEGRÃO, A. B. Nutritional aspects of eating episodes followed by vomiting in Brazilian patients with bulimia nervosa. Eating and Weight Disorders, Milano, v. 8, n. 2, p. 150-156, Jun 2003.

AMBLER, C.; ELIAKIM, A.; BRASEL, J. A.; LEE, W. N. P.; BURKE, G.; COOPER, D. $M$. Fitness and the effect of exercise training on the dietary intake of healthy adolescents. International Journal of Obesity and Related Metabolic Disorders, Hampshire, v. 22, n. 4, p. 354-362, Apr 1998.

ANDERSEN, L. F.; TOMTEN, H.; HAGGARTY, P.; LOVO, A.; HUSTVEDT, B. E. Validation of energy intake estimated from a food frequency questionnaire: a doubly labelled water study. European Journal of Clinical Nutrition, London, v. 57, n. 2, p. 279-284, Feb 2003.

ANJOS, L. A. Índice de massa corporal (massa corporal.estatura ${ }^{-2}$ ) como indicador do estado nutricional de adultos: revisão da literatura. Revista de Saúde Pública, São Paulo, v. 26, n. 6, p. 431-436, Dec 1992.

APA - American Psychiatric Association. Diagnostic and Statistical Manual of Mental Disorders. 4. ed. Washington, 1994.

AQUINO, R. C. Alimentos industrializados na dieta de crianças do município de São Paulo. 1999. Dissertação (Mestrado) - Faculdade de Saúde Pública, Universidade de São Paulo, São Paulo. 
ARD, J. D.; DESMOND, R. A.; ALLISON, D. B.; CONWAY, J. M. Dietary restraint and disinhibition do not affect accuracy of 24-hour recall in a multiethnic population. Journal of the American Dietetic Association, Chicago, v. 106, n. 3, p. 434-437, Mar 2006.

ASBECK, I.; MAST, M.; BIERWAG, A.; WESTENHÖFER, J.; ACHESON, K. J.; MÜLLER, M. J. Severe underreporting of energy intake in normal weight subjects: use of an appropriate standard and relation to restrained eating. Public Health Nutrition, Wallingford, v. 5, n. 5, p. 683-690, Oct 2002.

BAECKE, J. A.; BUREMA, J.; FRIJTERS, J. E. A short questionnaire for the measurement of habitual physical activity in epidemiological studies. The American Journal of Clinical Nutrition, Bethesda, v. 36, n. 5, p. 936-942, Nov 1982.

BAILEY, R. L.; GUTSCHALL, M. D.; MITCHELL, D. C.; MILLER, C. K.; LAWRENCE, F. R.; SMICIKLAS-WRIGHT, H. Comparative strategies for using cluster analysis to assess dietary patterns. Journal of the American Dietetic Association, Chicago, v. 106, n. 8, p. 1194-1200, Aug 2006.

BAILEY, R. L.; MITCHELL, D. C.; MILLER, C.; SMICIKLAS-WRIGHT, H. Assessing the effect of underreporting energy intake on dietary patterns and weight status. Journal of the American Dietetic Association, Chicago, v. 107, n. 1, p. 64-71, Jan 2007.

BALLARD, B.; CRINO, M. D.; RUBENFELD, S. Social desirability response bias and the Marlowe-Crowne Social Desirability Scale. Psychological Reports, Louisville, v. 63, n. 1, p. 227-237, Aug 1988.

BALLARD, R. Short forms of the Marlowe-Crowne Social Desirability Scale. Psychological Reports, Louisville, v. 71, n. 3 Pt 2, p. 1155-1160, Dec 1992.

BALLARD-BARBASH, R.; GRAUBARD, I.; KREBS-SMITH, S. M.; SCHATZKIN, A.; THOMPSON, F. E. Contribution of dieting to the inverse association between energy intake and body mass index. European Journal of Clinical Nutrition, London, v. 50, n. 2, p. 98-106, Feb 1996. 
BARTRINA, J. A.; MAJEM, L. I. S. Historia dietética. In: MAJEM, L. I. S.; BARTRINA, J. A.; VERDÚ, J. M. Nutrición y salud pública: métodos, bases científicas e aplicaciones. Barcelona: Masson, 1995. p. 126-131.

BARTRINA, J. A.; RODRIGO, C. P. Diario o registro dietetico. Métodos de doble pesada. In: MAJEM, L. I. S.; BARTRINA, J. A.; VERDÚ, J. M. Nutrición y salud pública: métodos, bases científicas e aplicaciones. Barcelona: Masson, 1995. p. 107-112.

BATHALON, G. P.; TUCKER, K. L.; HAYS, N. P.; VINKEN, A. G.; GREENBERG, A. S.; MCCRORY, M. A.; ROBERTS, S. B. Psychological measures of eating behavior and the accuracy of 3 common dietary assessments in healthy postmenopausal women. The American Journal of Clinical Nutrition, Bethesda, v. 71, n. 3, p. 739745, May 2000.

BAZELMANS, C.; MATTHYS, C.; DE HENAUW, S.; DRAMAIX, M.; KORNITZER, M.; DE BACKER, G.; LEVÊQUE, A. Predictors of misreporting in an elderly population: the 'Quality of life after 65' study. Public Health Nutrition,_Wallingford, v. 10, n. 2, p. 185-191, Feb 2007.

BELLACH, B.; KOHLMEIER, L. Energy adjustment does not control for differential recall bias in nutritional epidemiology. Journal of Clinical Epidemiology, Oxford, v. 51, n. 5, p. 393-398, May 1998.

BELLISLE, F. The doubly- labeled water method and food intake surveys: a confrontation. Revista de Nutrição, Campinas, v. 14, n. 2, p. 125-133, May/Aug 2001.

BINGHAM, S. A. Limitations of the various methods for collecting dietary intake data. Annals of Nutrition \& Metabolism, Basel, v. 35, n. 3, p. 117-127, 1991.

Urine nitrogen as a biomarker for the validation of dietary protein intake. The Journal of Nutrition, Philadelphia, v. 133, n. 3, p. 921S-924S, Mar 2003. Supplement.

BINGHAM, S. A.; CASSIDY, A.; COLE, T. J.; WELCH, A.; RUNSWICK, S. A.; BLACK, A. E.; THURNHAM, D.; BATES, C.; KHAW, K. T.; KEY, T. J. A.; DAY, N. E. Validation of weighed records and other methods of dietary assessment using the 24 
$\mathrm{h}$ urine nitrogen technique and other biological markers. The British Journal of Nutrition, Cambridge, v. 73, n. 4, p. 531-550, Apr 1995.

BLACK, A. E. The sensitivity and specificity of the Goldberg cut-off for El:BMR for identifying diet reports of poor validity. European Journal of Clinical Nutrition, London, v. 54, n. 5, p. 395-404, May 2000.

BLACK, A. E.; COLE, T. J. Biased over- or under-reporting is characteristic of individuals whether over time or by different assessment methods. Journal of the American Dietetic Association, Chicago, v. 101, n. 1, p. 70-80, Jan 2001.

. Within- and between-subject variation in energy expenditure measured by the doubly-labelled water technique: implications for validating reported dietary energy intake. European Journal of Clinical Nutrition, London, v. 54, n. 5, p. 386394, May 2000.

BLACK, A. E.; GOLDBERG, G. R.; JEBB, A. S.; LIVINGSTONE, B. E. M.; COLE, T. J.; PRENTICE, A. M. Critical evaluation of energy intake data using fundamental principles of energy intake physiology: 2 . Evaluating the results of published surveys. European Journal of Clinical Nutrition, London, v. 45, n. 12, p. 583-599, Dec 1991.

BLACK, A. E.; PRENTICE, A. M.; COWARD, W. A. Use of food quotients to predict respiratory quotients for the doubly-labelled water method of measuring energy expenditure. Human Nutrition. Clinical Nutrition, London, v. 40, n. 5, p. 381-391, Sep 1986.

BLACK, A. E.; PRENTICE, A. M.; GOLDBERG, G. R.; JEBB, A. S.; BINGHAM, S. A.; LIVINGSTONE, B. E. M.; COWARD, A. Measurements of total energy expenditure provides insights into validity of dietary measurements of energy intake. Journal of the American Dietetic Association, Chicago, v. 93, n. 5, p. 872-579, May 1993.

BLACK, A. E.; WELCH, A. A.; BINGHAM, S. A. Validation of dietary intakes measured by diet history against $24 \mathrm{~h}$ urinary nitrogen excretion and energy expenditure measured by the doubly-labelled water method in middle-aged women. The British Journal of Nutrition, Cambridge, v. 83, n. 4, p. 341-354, Apr 2000.

BLAND, J. M.; ALTMAN, D. G. Statistical methods for assessing agreement between two methods of clinical measurement. The Lancet, London, v. 1, n. 8476, p. 307-310, Feb 1986. 
BLANTON, C. A.; MOSHFEGH, A. J.; BAER, D. J.; KRETSCH, M. J. The USDA Automated Multiple-Pass Method accurately estimates group total energy and nutrient intake. The Journal of Nutrition, Philadelphia, v. 136, n. 10, p. 594-599, Oct 2006.

BLUNDELL, J. E. What foods do people habitually eat? A dilemma for nutrition, an enigma for psychology. The American Journal of Clinical Nutrition, Bethesda, v. 71, n. 1, p. 3-5, Jan 2000.

BRAAM, L. A.; OCKÉ, M. C.; BUENO-DE-MESQUITA, B.; SEIDELL, J. C. Determinants of obesity-related underreporting of energy intake. American Journal of Epidemiology, Baltimore, v. 147, n. 11, p. 1081-1086, Jun 1998.

BROWN, D. Do food frequency questionnaires have too many limitations? Journal of the American Dietetic Association, Chicago, v. 106, n. 10, p. 1541-1542, Oct 2006.

BUHL, K. M.; GALLAGHER, D.; HOY, K.; MATTHEWS, D. E.; HEYMSFIELD, S. B. Unexplained disturbance in body weight regulation: diagnostic outcome assessed by doubly labeled water and body composition analyses in obese patients reporting low energy intakes. Journal of the American Dietetic Association, Chicago, v. 95, n. 12, p. 1393-1400, Dec 1995.

CADE, J.; THOMPSON, R.; BURLEY, V.; WARM, D. Development, validation and utilisation of food-frequency questionnaires - a review. Public Health Nutrition, Wallingford, v. 5, n. 4, p. 567-587, Aug 2002.

CARDOSO, M. A.; KIDA, A. A.; TOMITA, L. Y.; STOCCO, P. R. Reproducibility and validity of a food frequency questionnaire among women of Japanese ancestry living in Brazil. Nutrition Research, New York, v. 21, n. 5. p. 725-733, May 2001.

CHAMPAGNE, C. M.; BAKER, N. B.; DELANY, J. P.; HARSHA, D. W.; BRAY, G. A. Assessment of energy intake underreporting by doubly labeled water and observations on reported nutrient intakes in children. Journal of the American Dietetic Association, Chicago, v. 98, n. 4, p. 426-433, Apr 1998.

COLUCCI, A. C. A. Desenvolvimento de um questionário de freqüência alimentar para avaliação do consumo alimentar de crianças de 2 a 5 anos de idade. 2002. Dissertação (Mestrado) - Faculdade de Saúde Pública, Universidade de São Paulo, São Paulo. 
CONWAY, J. M.; INGWERSEN, L. A.; MOSHFEGH, A. J. Accuracy of dietary recall using the USDA five-step multiple-pass method in men: an observational validation study. Journal of the American Dietetic Association, Chicago, v. 104, n. 4, p. 595603, Apr 2004.

CONWAY, J. M.; INGWERSEN, L. A.; VINYARD, B. T.; MOSHFEGH, A. J. Effectiveness of the US Department of Agriculture 5-step multiple-pass method in assessing food intake in obese and nonobese women. The American Journal of Clinical Nutrition, Bethesda, v. 77, n. 5, p. 1171-1178, May 2003.

COWARD, W. A. Contributions of the doubly labeled water method to studies of energy balance in the Third World. The American Journal of Clinical Nutrition, Bethesda, v. 68, n. 4, p. 962S-969S, Oct 1998. Supplement.

CRISPIM, S. P.; RIBEIRO, R. C.; SILVA, M. M.; ROSADO, L. E.; ROSADO, G. P. The influence of education in the validation process of a food frequency questionnaire for adults in Viçosa, Minas Gerais, Brazil. European Journal of Clinical Nutrition, London, v. 60, n. 11, p. 1311-1316, Nov 2006.

CROWNE, P. D.; MARLOWE, D. A new scale of social desirability independent of psychopathology. Journal of Consulting and Clinical Psychology, Washington, v. 24, p.349-354, Aug 1960.

DANIELLS, S. Time to ditch the FFQ. Food Navigator, Jan 2006. Disponível em: <http://www.foodnavigator.com/news/ng.asp?id=65448>. Acesso em: 12 nov. 2006.

DEAN, A. G.; SULLIVAN, K. M.; SOE, M. M. OpenEpi: Open Source Epidemiologic Statistics for Public Health, Version 2. Updated 2007-06-07. Disponível em: <http://www.openepi.com>. Acesso em: 06 jul. 2007.

EDWARDS, J. E.; LINDEMAN, A. K.; MIKESKY, A. E.; STAGER, J. M. Energy balance in highly trained female endurance runners. Medicine and Science in Sports and Exercise, Madison, v. 25, n. 12, p. 1398-1404, Dec 1993.

FERRARI, P.; SLIMANI, N.; CIAMPI, A.; TRICHOPOULOU, A.; NASKA, A.; LAURIA, C.; VEGLIA, F.; BUENO-DE-MESQUITA, H. B.; OCKÉ, M.; BRUSTAD, M.; BRAATEN, T.; TORMO, M. J.; AMIANO, P.; MATTISON, I.; JOHANSSON, G.; WELCH, A.; DAVEY, G.; OVERVAD, K.; TJONNELAND, A.; CLAVEL-CHAPELON, F.; THIEBAUT, A.; LINSEISEN, J.; BOEING, H.; HEMON, B.; RIBOLI, E. Evaluation 
of under-and overreporting of energy intake in the 24-hour diet recalls in the European Prospective Investigation into Cancer and Nutrition (EPIC). Public Health Nutrition, Wallingford, v. 5, n. 6B, p. 1329-1345, Dec 2002.

FISBERG, R. M.; VILLAR, B. S. Manual de receitas e medidas caseiras para cálculo de inquéritos alimentares. São Paulo: Signus, 2002.

FISCHLER, C. Food, self and identity. Social Science Information, Borough Green, v. 27, n. 2, p. 275-292, Jun 1988.

FISHER, D. G.; FICK, C. Measuring social desirability: short forms of the MarloweCrowne Social Desirability Scale. Educational and Psychological Measurement, Washington, v. 53, n. 2, p. 417-424, Summer 1993.

FLORINDO, A. A.; LATORRE, M. R. D. O. Validation and reliability of the Baecke questionnaire for the evaluation of habitual physical activity in adult men. Revista Brasileira de Medicina do Esporte, Niterói, v. 9, n. 3, p. 121-128, May/Jun 2003.

FREITAS, S. R.; LOPES, C. S.; APPOLINÁRIO, J. C.; COUTINHO, W. The assessment of binge eating disorder in obese women: a comparison of the binge eating scale with the structured clinical interview for the DSM-IV. Eating Behaviors, New York, v. 7, n. 3, p. 282-289, Aug 2006.

FREITAS, S.; LOPES, C. S.; COUTINHO, W.; APPOLINARIO, J. C. Tradução e adaptação para o português da Escala de Compulsão Alimentar Periódica. Revista Brasileira de Psiquiatria, São Paulo, v. 23, n. 4, p. 215-220, Dec 2001.

FRISANCHO, A. R. Anthropometric standards for the assessment of growth and nutritional status. Michigan: University of Michigan Press, 1999.

FROBISHER, C.; MAXWELL, S. M. The estimation of food portion sizes: a comparison between using descriptions of portion sizes and a photographic food atlas by children and adults. Journal of Human Nutrition and Dietetics, Oxford, v. 16, n. 3, p. 181-188, Jun 2003.

GARCIA, R. W. D. Representações sobre consumo alimentar e suas implicações em inquéritos alimentares: estudo qualitativo em sujeitos submetidos à prescrição dietética. Revista de Nutrição, Campinas, v. 17, n. 1, p. 15-28, Jan/Mar 2004. 
GIBSON, R. S. Principles of nutritional assessment. Nova York: Oxford University Press, 1990.

GLADIS, M. M.; WADDEN, T. A.; FOSTER, G. D.; VOGT, R. A.; WINGATE, B. L. A comparison of two approaches to the assessment of binge eating in obesity. The International Journal of Eating Disorders, New York, v. 23, n. 1, p. 17-26, Jan 1998.

GLEESON, K.; FRITH, H. (De)constructing body image. Journal of Health Psychology, London, v. 11, n. 1, p. 79-90, Jan 2006.

GOLDBERG, G. R.; BLACK, A. E.; JEBB, A. S.; COLE, T. J.; MURGATROYD, P. R.; COWARD, W. A.; PRENTICE, A. M. Critical evaluation of energy intake data using fundamental principles of energy intake physiology: 1. Derivation of cut-off limits to identify under-recording. European Journal of Clinical Nutrition, London, v. 45, n. 12, p. 569-581, Dec 1991.

GONZALES-PACHECO, D. M.; BUSS, W. C.; KOEHLER, K. M.; WOODSIDE, W. F.; ALPERT, S. S. Energy restriction reduces metabolic rate in adult male Fisher-344 rats. The Journal of Nutrition, Philadelphia, v. 123, n. 1, p. 90-97, Jan 1993.

GORIS, A. H.; WESTERTERP, K. R. Improved reporting of habitual food intake after confrontation with earlier results on food reporting. The British Journal of Nutrition, Cambridge, v. 83, n. 4, p. 363-369, Apr 2000.

GORIS, A. H.; WESTERTERP-PLANTENGA, M. S.; WESTERTERP, K. R. Undereating and underrecording of habitual food intake in obese men: selective underreporting of fat intake. The American Journal of Clinical Nutrition, Bethesda, v. 71, n. 1, p. $130-134$, Jan 2000.

GORMALLY, J.; BLACK, S.; DASTON, S.; RARDIN, D. The assessment of binge eating severity among obese persons. Addictive Behaviors, Oxford, v. 7, n. 1, p. 47$55,1982$.

GREENO, C. G.; MARCUS, M. D.; WING, R. R. Diagnosis of binge eating disorder: discrepancies between a questionnaire and clinical interview. The International Journal of Eating Disorders, New York, v. 17, n. 2, p. 153-160, Mar 1995. 
GUEDES, D. P. Composição corporal: princípios, técnicas e aplicações. 2. ed. Londrina: APEF, 1994.

HARNACK, L.; BLOCK, G.; SUBAR, A.; LANE, S.; BRAND, R. Association of cancer prevention-related nutrition knowledge, beliefs and attitudes to cancer prevention dietary behavior. Journal of the American Dietetic Association, Chicago, v. 97, n. 9, p. 957-965, Sep 1997.

HARRISON, G. G.; GALAL, O. M.; IBRAHIM, N.; KHORSHID, A.; STORMER, A.; LESLIE, J.; SALEH, N. T. Underreporting of food intake by dietary recall is not universal: a comparison of data from Egyptian and American women. The Journal of Nutrition, Philadelphia, v. 130, n. 8, p. 2049-2054, Aug 2000.

HASKELL, W. L.; KIERNAN, M. Methodological issues in measuring physical activity and physical fitness when evaluating the role of dietary supplements for physically active people. The American Journal of Clinical Nutrition, Bethesda, v. 72, n. 2, p. 541S-550S, Aug 2000. Supplement.

HEATHERTON, T. F.; HERMAN, C. P.; POLIVY, J.; KING, G. A.; MCGREE, S. T. The (mis)measurement of restraint: an analysis of conceptual and psychometric issues. Journal of Abnormal Psychology, Washington, v. 97, n. 1, p. 19-28, Feb 1988.

HEBERT, J. R.; CLEMOW, L.; PBERT, L.; OCKENE, I. S.; OCKENE, J. K. Social desirability bias in dietary self-report may compromise the validity of dietary intake measures. International Journal of Epidemiology, London, v. 24, n. 2, p. 389-398, Apr 1995.

HEBERT, J. R.; EBBELING, C. B.; MATTHEWS, C. E.; HURLEY, T. G.; MA, Y.; DRUKER, S.; CLEMOW, L. Systematic errors in middle-aged women's estimates of energy intake: comparing three self-report measures to total energy expenditure from doubly labeled water. Annals of Epidemiology, New York, v. 12, n. 8, p. 577-586, Nov 2002.

HEBERT, J. R.; PETTERSON, K. E.; HURLEY, T. G.; STODDARD, A. M.; COHEN, N.; FIELD, A.; SORENSEN, G. The effect of social desirability trait on self-reported dietary measures among multi-ethnic female health center employees. Annals of Epidemiology, New York, v. 11, n. 6, p. 417-427, Aug 2001. 
HEITMANN, B. L. The influence of fatness, weight change, slimming history, and other lifestyle variables on diet reporting in Danish men and women aged 35-65 years. International Journal of Obesity and Related Metabolic Disorders, Hampshire, v. 17, n. 6, p. 329-336, Jun 1993.

HEITMANN, B. L.; LISSNER, L. Dietary underreporting by obese individuals: is it specific or non-specific? British Medical Journal, London, v. 311, n. 7011, p. 986989, Oct 1995.

HEITMANN, B. L.; LISSNER, L.; OSLER, M. Do we eat less fat or just report so? International Journal of Obesity and Related Metabolic Disorders, Hampshire, v. 24, n. 4, p. 435-442, Apr 2000.

HENDRICKSON, S.; MATTES, R. Financial incentive for diet recall accuracy does not affect reported energy intake or number of underreporters in a sample of overweight females. Journal of the American Dietetic Association, Chicago, v. 107, n. 1, p. 118-121, Jan 2007.

HERMAN, C. P.; MACK, D. Restrained and unrestrained eating. Journal of Personality, Durham, v. 43, n. 4, p. 647-660, Dec 1975.

HESS, M. A. Portion photos of popular foods. Washington: American Dietetic Association, 1997.

HILL, R. J.; DAVIES, P. S. W. The validity of self-reported energy intake as determined using doubly labelled water technique. The British Journal of Nutrition, Cambridge, v. 85, n. 4, p. 415-430. Apr 2001.

HIRVONEN, T.; MÄNNISTÖ, S.; ROOS, E.; PIETINEN, P. Increasing prevalence of underreporting does not necessarily distort dietary surveys. European Journal of Clinical Nutrition, London, v. 51, n. 5, p. 297-301, May 1997.

HISE, M. E.; SULLIVAN, D. K.; JACOBSEN, D. J.; JOHNSON, S. L.; DONNELLY, J. E. Validation of energy intake measurements determined from observer-recorded food records and recall methods compared with the doubly labeled water method in overweight and obese individuals. The American Journal of Clinical Nutrition, Bethesda, v. 75, n. 2, p. 263-267, Feb 2002. 
HORNER, N. K.; PATTERSON, R. E.; NEUHOUSER, M. L.; LAMPE, J. W.; BERESFORD, S. A.; PRENTICE, R. L. Participant characteristics associated with errors in self-reported energy intake from the Women's Health Initiative foodfrequency questionnaire. The American Journal of Clinical Nutrition, Bethesda, v. 76, n. 4, p. 766-773, Oct 2002.

HU, F. B. Dietary patterns analysis: a new direction in nutritional epidemiology. Current Opinion in Lipidology, Cambridge, v. 13, n. 1, p. 3-9, Feb 2002.

JAIME, P. C.; LATORRE, M. R. D. O.; FORNÉS, N. S.; ZERBINI, C. A. F. Estudo comparativo entre dois métodos de ajuste energético do consumo de nutrientes. Nutrire, São Paulo, v. 26, n. 2, p. 11-18, Jun 2003.

JOHANSSON, G.; WIKMAN, A.; AHREN, A. M.; HALLMANS, G.; JOHANSSON, I. Underreporting of energy intake in repeated 24-hour recalls related to gender, age, weight status, day of interview, educational level, reported food intake, smoky habits and area of living. Public Health Nutrition, Wallingford, v. 4, n. 4, p. 919-927, Aug 2001.

JOHANSSON, L.; SOLVOLL, K.; BJORNEBOE, G. E. A.; DREVON, C. A. Under- and overreporting of energy intake related to weight status and lifestyle in a nationwide sample. The American Journal of Clinical Nutrition, Bethesda, v. 68, n. 2, p. 266274, Aug 1998.

JOHNSON, R. K.; DRISCOLI, P.; GORAN, M. I. Comparison of multiple-pass 24-hour recall estimates of energy intake with total energy expenditure determined by the doubly labeled water method in young children. Journal of the American Dietetic Association, Chicago, v. 96, n. 11, p. 1140-1144, Nov 1996.

JOHNSON, R. K.; FRIEDMAN, A. B.; HARVEY-BERINO, J.; GOLD, B. C.; MCKENZIE, D. Participation in a behavioral weight-loss program worsens the prevalence and severity of underreporting among obese and overweight women. Journal of the American Dietetic Association, Chicago, v. 105, n. 12, p. 19481951, Dec 2005.

JOHNSON, R. K.; RUSS, J.; GORAN, M. I. Physical activity related energy expenditure in children by doubly labeled water as compared with the Caltrac accelerometer. International Journal of Obesity and Related Metabolic Disorders, Hampshire, v. 22, n. 11, p. 1046-1052, Nov 1998. 
JONNALAGADDA, S. S.; BENARDOT, D.; DILL, M. N. Assessment of underreporting of energy intake by elite female gymnast. International Journal of Sport Nutrition and Exercise Metabolism, Champaign, v. 10, n. 3, p. 315-325, Sep 2000a.

JONNALAGADDA, S. S.; BENARDOT, D.; NELSON, M. Energy and nutrient intakes of the United States National Women's Artistic Gymnastics Team. International Journal of Sport Nutrition, Champaign, v. 8, n. 4, p. 331-344, Dec 1998.

JONNALAGADDA, S. S.; MITCHELL, D. C.; SMICIKLAS-WRIGHT, H.; MEAKER, K. B.; VAN HEEL, N.; KARMALLY, W.; ERSHOW, A. G.; KRIS-ETHERTON, P. M. Accuracy of energy intake data estimated by a multiple-pass, 24-hour dietary recall technique. Journal of the American Dietetic Association, Chicago, v. 100, n. 3, p. 303-308, Mar 2000b.

JUNQUEIRA-FRANCO, M. V. M.; VANNUCCHI, H.; FERRIOLI, E.; PADOVAN, G. J.; MARCHINI, J. S. Aplicações clínicas de isótopos estáveis: utilização da técnica de espectrometria de massa. Cadernos de Nutrição, São Paulo, v. 18, n. 4, p. 35-54, 1999.

KAAKS, R.; FERRARI, P. Dietary intake assessments in epidemiology: can we know what we are measuring? Annals of Epidemiology, New York, v. 16, n. 5, p. 377-380, May 2006.

KAAKS, R.; FERRARI, P.; CIAMPI, A.; PLUMMER, M.; RIBOLI, E. Uses and limitations of statistical accounting for random error correlations, in the validation of dietary questionnaire assessments. Public Health Nutrition, Wallingford, v. 5, n. 6A, p. 969-976, Dec 2002.

KANT, A. K. Nature of dietary reporting by adults in the third National Health and Nutrition Examination Survey, 1988-1994. Journal of the American College of Nutrition, New York, v. 21, n. 4, p. 315-327, Aug 2002.

KARKECK, J. M. Improving the use of dietary survey methodology. Journal of the American Dietetic Association, Chicago, v. 87, n. 7, p. 869-871, Jul 1987.

KHANI, B. R.; YE, W.; TERRY, P.; WOLK, A. Reproducibility and validity of major dietary patterns among Swedish women assessed with a food-frequency questionnaire. The Journal of Nutrition, Philadelphia, v. 134, n. 6, p. 1541-1545, Jun 2004. 
KIMM, S. Y. S.; GLYNN, N. W.; OBARZANEK, E.; ASTON, C. E.; DANIELS, S. R. Racial differences in correlates of misreporting of energy intake in adolescent females. Obesity, Silver Spring, v. 14, n. 1, p. 156-164, Jan 2006.

KIPNIS, V.; SUBAR, A. F.; MIDTHUNE, D.; FREEDMAN, L. S.; BALLARDBARBASH, R.; TROIANO, R. P.; BINGHAM, S.; SCHOELLER, D. A.; SCHATZKIN, A.; CARROLL, R. J. Structure of dietary measurement error: results of the OPEN biomarker study. American Journal of Epidemiology, Baltimore, v. 158, n. 1, p. 1421, Jul 2003.

KÖRTZINGER, I.; BIERWAG, A.; MAST, M.; MULLER, M. J. Dietary underreporting: validity of dietary measurements of energy intake using a 7-day dietary record and a diet history in non-obese subjects. Annals of Nutrition \& Metabolism, Basel, v. 41, n. 1, p. 37-44, 1997.

KREBS-SMITH, S. M.; GRAUBARD, B. I.; KAHLE, L. L.; SUBAR, A. F.; CLEVELAND, L. E.; BALLARD-BARBASH, R. Low energy reporters vs. others: a comparison of reported food intakes. European Journal of Clinical Nutrition, London, v. 54, n. 4, p. 281-287, Apr 2000.

KRETSCH, M. J. K.; FONG, A. K. H.; GREEN, M. W. Behavioral and body sizes correlates of energy intake underreporting by obese and normal-weight women. Journal of the American Dietetic Association, Chicago, v. 99, n. 3, p. 300-306, Mar 1999.

KRISTAL, A. R.; PETERS, U.; POTTER, J. D. Is it time to abandon the food frequency questionnaire? Cancer Epidemiology, Biomarkers \& Prevention: a publication of the American Association for Cancer Research, cosponsored by the American Society of Preventive Oncology, Philadelphia, v. 14, n. 12, p. 28262828, Dec 2005.

KROKE, A.; KLIPSTEIN-GROBUSCH, K.; VOSS, S.; MÖSENEDER, J.; THIELECKE, F.; NOACK, R.; BOEING, $H$. Validation of a self-administered food-frequency questionnaire administered in the European Prospective Investigation into Cancer and Nutrition (EPIC) Study: comparison of energy, protein, and macronutrient intakes estimated with the doubly labeled water, urinary nitrogen, and repeated 24-h recall methods. The American Journal of Clinical Nutrition, Bethesda, v. 70, n. 4, p. 439447, Oct 1999. 
LAESSLE, R. G.; TUSCCHL, R. J.; KOTTHAUS, B. C.; PIRKE, K. M. A comparison of the validity of three scales for the assessment of dietary restraint. Journal of Abnormal Psychology, Washington, v. 98, n. 4, p. 504-507, Nov 1989.

LAFAY, L.; MENNEN, L.; BASDEVANT, A.; CHARLES, M. A.; BORYS, J. M.; ESCHWEGE, E.; ROMON, M. Does energy intake underreporting involve all kinds of food or only specific food items? Results from the Fleurbaix Laventie Ville Santé (FLVS) study. International Journal of Obesity and Related Metabolic Disorders, Hampshire, v. 24, n. 11, p. 1500-1506, Nov 2000.

LAJOLO, F. M.; MENEZES, E. W. Tabela Brasileira de Composição de Alimentos. 1997. Disponível em: <http://www.fcf.usp.br/tabela>. Acesso em: 03 jul. 2002.

LANDIS, J. R.; KOCH, G. G. The measurements of observer agreement for categorical data. Biometrics, Washington, v. 33, n. 1, p. 159-174, Mar 1977.

LANGSETH, L. Nutritional epidemiology: possibilities and limitations. Bruxelas: ILSI Europe, 1996.

LARA, J. J.; SCOTT, J. A.; LEAN, M. E. J. Intentional mis-reporting of food consumption and its relationship with body mass index and psychological scores in women. Journal of Human Nutrition and Dietetics, Oxford, v. 17, n. 3, p. 209-218, Jun 2004.

LEAL, M. C.; BITTENCOURT, S. A. Informações nutricionais: o que se tem no país? Cadernos de Saúde Pública, Rio de Janeiro, v. 13, n. 3, p. 551-555, Jul/Sep 1997.

LENNERNÄS, M. Dietary assessment and validity: to measure what is meant to measure. Scandinavian Journal of Nutrition, Lund, v. 42, p. 63-65, 1998.

LINDQUIST, C. H.; CUMMINGS, T.; GORAN, M. I. Use of tape-recorded food records in assessing children's dietary intake. Obesity Research, Baton Rouge, v. 8, n. 1, p. 2-11, Jan 2000.

LINDROOS, A. K.; LISSNER, L.; SJÖSTRÖM, L. Does degree of obesity influence the validity of reported energy and protein intake? Results from the SOS Dietary Questionnaire. Swedish Obese Subjects. European Journal of Clinical Nutrition, London, v. 53, n. 5, p. 375-378, May 1999. 
Validity and reproducibility of a self-administered dietary questionnaire in obese and non-obese subjects. European Journal of Clinical Nutrition, London, v. 47, n. 7, p. 461-481, Jul 1993.

LISSNER, L.; HABICHT, J. P.; STRUPP, B. J.; LEVITSKY, D. A.; HAAS, J. D.; ROE, D. A. Body composition and energy intake: do overweight women overeat and underreport? The American Journal of Clinical Nutrition, Bethesda, v. 49, n. 2, p. 320-325, Feb 1989.

LISSNER, L.; HEITMANN, B. L.; LINDROOS, A. K. Measuring intake in free-living human subjects: a question of bias. The Proceedings of the Nutrition Society, London, v. 57, n. 2, p. 333-339, May 1998.

LIVINGSTONE, M. B. E.; BLACK, A. E. Markers of the validity of reported energy intake. The Journal of Nutrition, Philadelphia, v. 133, n. 3, p. 895S-920S, Mar 2003. Supplement.

LIVINGSTONE, M. B.; PRENTICE, A. M.; STRAIN, J. J.; COWARD, W. A.; BLACK, A. E.; BARKER, M. E.; MCKENNA, P. G.; WHITEHEAD, R. G. Accuracy of weighed dietary records in study of diet and health. British Medical Journal, London, v. 300, n. 6726, p. 708-712, Mar 1990.

LOO, R.; THORPE, K. Confirmatory factor analyses of the full and short versions of the Marlowe-Crowne Social Desirability Scale. The Journal of Social Psychology, Provincetown, v. 140, n. 5, p. 628-635, Oct 2000.

LÓPEZ, J. V. Validez de la evaluación de la ingesta dietética In: MAJEM, L. I. S.; BARTRINA, J. A.; VERDÚ, J. M. Nutrición y salud pública: métodos, bases científicas e aplicaciones. Barcelona: Masson, 1995. p. 132-136.

LOVELADY, C. A.; MEREDITH, C. N.; MCCRORY, M. A.; NOMMSEN, L. A.; JOSEPH, I.; DEWEY, K. G. Energy expenditure in lactating women: a comparison of doubly labeled water and heart rate monitoring methods. The American Journal of Clinical Nutrition, Bethesda, v. 57, n. 4, p. 512-518, Apr 1993.

MACDIARMID, J. I.; BLUNDELL, J. E. Dietary under-reporting: what people say about recording their food intake. European Journal of Clinical Nutrition, London, v. 21, n. 3, p. 199-200, Mar 1997. 
MACINTYRE, U. E.; VENTER, C. S.; VORSTER, H. H. A culture-sensitive quantitative food frequency questionnaire used in an African population: 1. Development and reproducibility. Public Health Nutrition, Wallingford, v. 4, n. 1, p. 53-62, Feb 2001.

MAHABIR, S.; BAER, D. J.; GIFFEN, C.; SUBAR, A.; CAMPBELL, W.; HARTMAN, T. J.; CLEVIDENCE, B.; ALBANES, D.; TAYLOR, P. R. Calorie intake misreporting by diet record and food frequency questionnaire compared to doubly labeled water among postmenopausal women. European Journal of Clinical Nutrition, London, v. 60, n. 4, p. 561-565, Apr 2006.

MAISEY, S.; LOUGHRIDGE, J.; SOUTHON, S.; FULCHER, R. Variation in food group and nutrient intake with day of the week in an elderly population. The British Journal of Nutrition, Cambridge, v. 73, n. 3, p. 359-373, Mar 1995.

MAJEM, L. I. S.; BARBA, L. R. Recordatorio de 24 horas. In: MAJEM, L. I. S.; BARTRINA, J. A.; VERDÚ, J. M. Nutrición y salud pública: métodos, bases científicas e aplicaciones. Barcelona: Masson, 1995. p. 113-119.

MARGETTS, B. M.; NELSON, M. (Eds.). Design concepts in nutritional epidemiology. New York: Oxford University Press, 1991.

MASHEB, R. M.; GRILO, C. M. On the relation of flexible and rigid control of eating to body mass index and overeating in patients with binge eating disorder. The International Journal of Eating Disorders, New York, v. 31, n. 1, p. 82-91, Jan 2002.

MAURER, J.; TAREN, D. L.; TEIXEIRA, P. J.; THOMSON, C. A.; LOHMAN, T. G.; GOING, S. B.; HOUTKOOPER, L. B. The psychosocial and behavioral characteristics related to energy misreporting. Nutrition Reviews, Baltimore, v. 64, n. 2 Pt 1, p. 5366, Feb 2006.

MCGOWAN, M. J.; HARRINGTON, K. E.; KIELY, M.; ROBSON, P. J.; LIVINGSTONE, M. B. E.; GIBNEY, M. J. An evaluation of energy intakes and the ratio of energy intake to estimated basal metabolic rate (El/BMRest) in the North/South Ireland Food Consumption Survey. Public Health Nutrition, Wallingford, v. 4, n. 5A, p. 1043-1050, Oct 2001. 
MCKEOWN, N. M.; DAY, N. E.; WELCH, A. A.; RUNSWICK, S. A.; LUBEN, R. N.; MULLIGAN, R. N.; MCTAGGART, A.; BINGHAM, S. A. Use of biological markers to validate self-reported dietary intake in a random sample of the European Prospective Investigation into Cancer United Kingdom Norfolk cohort. The American Journal of Clinical Nutrition, Bethesda, v. 74, n. 2, p. 188-196, Aug 2001.

MELA, D. J.; AARON, J. I. Honest but invalid: what subjects say about recording their food intake. Journal of the American Dietetic Association, Chicago, v. 97, n. 7, p. 791-793, Jul 1997.

MENDEZ, M. A.; MONTEIRO, C. A.; POPKIN, B. M. Overweight exceeds underweight among women in most developing countries. The American Journal of Clinical Nutrition, Bethesda, v. 81, n. 3, p. 714-721, Mar 2005.

MENDEZ, M. A.; WYNTER, S.; WILKS, R.; FORRESTER, T. Under- and overreporting of energy is related to obesity, lifestyle factors and food group intakes in Jamaican adults. Public Health Nutrition, Wallingford, v. 7, n. 1, p. 9-19, Feb 2004.

MENNEN, L. I.; JACKSON, M.; CADE, J.; MBANYA, J. C.; LAFAY, L.; SHARMA, S.; WALKER, S.; CHUNGONG, S.; WILKS, R.; BLAKAU, B.; FORRESTER, T.; CRUICKSSHANK, J. K. Underreporting of energy intake in four populations of African origin. International Journal of Obesity and Related Metabolic Disorders, Hampshire, v. 24, n. 7, p. 882-887, Jul 2000.

MERTZ, W. Food intake measurements: is there a "gold standard"? Journal of the American Dietetic Association, Chicago, v. 92, n. 12, p. 1463-1465, Dec 1992.

MILLEN, B. E.; QUATROMONI, P. A.; COPENHAFER, D. L.; DEMISSIE, S.; O'HORO, C. E.; D'AGOSTINO, R. B. Validation of a dietary pattern approach for evaluating nutrition risk: the Framingham Nutrition Studies. Journal of the American Dietetic Association, Chicago, v. 101, n. 2, p. 187-194, Feb 2001.

MONTEIRO, C. A.; CONDE, W. L.; DE CASTRO, I. R. The changing relationship between education and risk of obesity in Brazil (1975-1997). Cadernos de Saúde Pública, Rio de Janeiro, v. 19, p. S67-75, 2003. Supplement 1.

MONTEIRO, C. A.; CONDE, W. L.; POPKIN, B. M. Is obesity replacing or adding to under-nutrition? Evidence from different social classes in Brazil. Public Health Nutrition, Wallingford, v. 5, n. 1A, p. 105-112, Feb 2002. 
MUHLHEIM, L. S.; ALLISON, D. B.; HESHKA, S.; HEYMSFIELD, S. B. Do unsuccessful dieters intentionally underreport food intake? The International Journal of Eating Disorders, New York, v. 24, n. 3, p. 259-266, Nov 1998.

MURAKAMI, K.; SASAKI, S.; TAKAHASHI, Y.; UENISHI, K.; YAMASAKI, M.; HAYABUCHI, H.; GODA, T.; OKA, J.; BABA, K.; OHKI, K.; KOHRI, T.; WATANABE, R.; SUGIYAMA, Y. Misreporting of dietary energy, protein, potassium and sodium in relation to body mass index in young Japanese women. European Journal of Clinical Nutrition, London, 14 Feb 2007.

NAGY, K. A. Introduction. In: PRENTICE, A. M. (Ed.). The doubly labelled water method for measuring energy expenditure: technical recommendations for use in humans. Viena: International Dietary Energy Consultancy Group/International Atomic Energy Agency, 1990. p. 1-16.

NEPA - Núcleo de Estudos e Pesquisas em Alimentação. TACO - Tabela brasileira de composição de alimentos. Campinas: NEPA-UNICAMP, 2004.

NETTLETON, J. A.; STEFFEN, L. M.; MAYER-DAVIS, E. J.; JENNY, N. S.; JIANG, R.; HERRINGTON, D. M.; JACOBS JR, D. R. Dietary patterns are associated with biochemical markers of inflammation and endothelial activation in the Multi-Ethnic Study of Atherosclerosis (MESA). The American Journal of Clinical Nutrition, Bethesda, v. 83, n. 6, p. 1369-1379, Jan 2006.

NEWBY, P. K.; TUCKER, K. L. Empirically derived eating patterns using factor or cluster analysis: a review. Nutrition Reviews, Baltimore, v. 62, n. 5, p. 177-203, May 2004.

NOVOTNY, J. A.; RUMPLER, W. V.; RIDDICK, H.; HEBERT, J. R.; RHODES, D.; JUDD, J. T.; BAER, D. J.; MCDOWELL, M.; BRIEFEL, R. Personality characteristics as predictors of underreporting of energy intake on 24-hour dietary recall interviews. Journal of the American Dietetic Association, Chicago, v. 103, n. 9, p. 1146-1151, Sep 2003.

NUTRITION COORDINATING CENTER. NHANES-III Dietary Interviewer's Manual. Rockville, 1992.

OAKES, M. E.; SLOTTERBACK, C. S. The good, the bad, and the ugly: characteristics used by young, middle-aged, and older men and women, dieters and 
non-dieters to judge healthfulness of foods. Appetite, London, v. 38, n. 2, p. 91-97, Apr 2002.

OKUBO, H.; SASAKI, S.; HIROTA, N.; NOTSU, A.; TODORIKI, H.; MIURA, A.; FUKUI, M.; DATE, C. The influence of age and body mass index on relative accuracy of energy intake among Japanese adults. Public Health Nutrition, Wallingford, v. 9, n. 5, p. 651-657, Aug 2006.

OLAFSDOTTIR, A. S.; THORSDOTTIR, I.; GUNNARSDOTTIR, I.; THORGEIRSDOTTIR, H.; STEINGRIMSDOTTIR, L. Comparison of women's diet assessed by FFQs and 24-hour recalls with and without underreporters: associations with biomarkers. Annals of Nutrition \& Metabolism, Basel, v. 50, n. 5, p. 450-460, 2006.

PENNINGTON, J. A. T. Methods for obtaining food consumption information. In: MACDONALD, I. (Ed.). Monitoring dietary intakes. London: Springer-Verlag, 1991. p. 3-7.

PEREIRA, R. A.; KOIFMAN, S. Uso do questionário de freqüência alimentar na avaliação do consumo alimentar pregresso. Revista de Saúde Pública, São Paulo, v. 33, n. 6, p. 610-621, Dec 1999.

PHILIPPAERTS, R. M.; WESTERTERP, K. R.; LEFEVRE, J. Doubly labelled water validation of three physical activity questionnaires. International Journal of Sports Medicine, Stuttgart, v. 20, n. 5, p. 284-289, Jul 1999.

PHILIPPI, S. T. Manual de utilização do Rec 24h. São Paulo: Centro de Atendimento Nutricional - CLINUT/Centro de Saúde Geraldo Paula Souza/FSP/USP, 2004.

PHILIPPI, S. T.; LATTERZA, A. R.; CRUZ, A. T. R.; RIBEIRO, L. C. Pirâmide alimentar adaptada: guia para escolha dos alimentos. Revista de Nutrição, Campinas, v. 12, n. 1, p. 65-80, Jan/Apr 1999.

PHILIPPI, S. T.; SZARFARC, S. C.; LATTERZA, A. R. Virtual Nutri. Versão 1.0 para Windows: Faculdade de Saúde Pública/USP, 1996. 1 CD-ROM. 
PIETINEN P., HARTMAN, A. M.; HAAPA, E.; RASANEN, L.; HAAPAKOSKI, J.; PALMGREN, J.; ALBANES, D.; VIRTAMO, J.; HUTTUNEN, J. K. Reproducibility and validity of dietary assessment instruments. I. A self-administrated food use questionnaire with a portion size picture booklet. American Journal of Epidemiology, Baltimore, v. 128, n. 3, p. 655-666, Sep 1988.

PINHEIRO, A. B. V.; LACERDA, E. M. A.; BENZECRY, E. H.; GOMES, M. C. S.; COSTA, V. M. Tabela para avaliação de consumo alimentar em medidas caseiras. 2. ed. Rio de Janeiro: Grupo de Nutrição Materno-Infantil, 1994.

POEHLMAN, E. T.; MELBY, C. L.; GORAN M. I. The impact of exercise and diet restriction on daily energy expenditure. Sports Medicine, Auckland, v. 11, n. 2, p. 78101, Feb 1991.

POLACOW, V. O.; CUNHA, C. S. F.; SCAGLIUSI, F. B.; ARTIOLI, G. G.; BENATTI, F. B.; LANCHA JR, A. H. Avaliação quali e quantitativa de um instrumento de auxílio à quantificação de porções alimentares. Revista de Nutrição, Campinas, 2007 (submetido).

POLIVY, J. Psychological consequences of food restriction. Journal of the American Dietetic Association, Chicago, v. 96, n. 6, p. 589-592, Jun 1996.

POMERLEAU, J.; OSTBYE, T.; BRIGHT-SEE, E. Potential underreporting of energy intake in the Ontario Health Survey and its relationship with nutrient and food intakes. European Journal of Epidemiology, Rome, v. 15, n. 6, p. 553-557, Jul 1999.

POPPITT, S. D.; SWANN, D.; BLACK, A. E.; PRENTICE, A. M. Assessment of selective under-reporting of food intake by both obese and non-obese women in a metabolic facility. International Journal of Obesity and Related Metabolic Disorders, Hampshire, v. 22, n. 4, p. 303-311, Apr 1998.

PRENTICE, A. M.; BLACK, A. E.; COWARD, W. A.; COLE, T. J. Energy expenditure in overweight and obese adults in affluent societies: an analysis of 319 doubly labelled water measurements. European Journal of Clinical Nutrition, London, v. 50, n. 2, p. 93-97, Feb 1996.

PRENTICE, A. M.; BLACK, A. E.; COWARD, W. A.; DAVIES, H. L.; GOLDBERG, G. R.; MURGATROYD, P. R.; ASHFORD, J.; SAWYER, M.; WHITEHEAD, R. G. High 
levels of energy expenditure in obese women. British Medical Journal, London, v. 292, n. 6526, p. 983-987, Apr 1986.

PRENTICE, A.; COWARD, A.; COLE, T.; SCHOELLER, D.; HAGGARTY, P. Practical recommendations and worked examples. In: PRENTICE, A. M. (Ed.). The doubly labelled water method for measuring energy expenditure: technical recommendations for use in humans. Viena: International Dietary Energy Consultancy Group/International Atomic Energy Agency, 1990. p. 212-247.

PRICE, G. M.; PAUL, A. A.; COLE, T. J.; WADSWORTH, E. J. Characteristics of the low-energy reporters in a longitudinal national dietary survey. The British Journal of Nutrition, Cambridge, v. 77, n. 6, p. 833-851, Jun 1997.

PRYER, J. A.; VRIJHEID, M.; NICHOLS, R.; KIGGINS, M.; ELLIOT, P. Who are the "low energy reporters" in the dietary and nutritional survey of British adults? International Journal of Epidemiology, London, v. 26, n. 1, p. 146-153, Feb 1997.

QUATROMONI, P. A.; COPENHAFER, D. L.; DEMISSIE, S.; D'AGOSTINO, R. B.; O'HORO, C. E.; NAM, B. H.; MILLEN, B. E. The internal validity of a dietary pattern analysis: the Framingham Nutrition Studies. Journal of Epidemiology and Community Health, London, v. 56, n. 5, p. 381-388, May 2002.

RACETTE, S. B.; SCHOELLER, D. A.; LUKE, A. H.; SHAY, K.; HNILICKA, J.; KUSHNER, R. F. Relative dilution spaces of $2 \mathrm{H}$ and $18 \mathrm{O}$-labeled water in humans. The American Journal of Physiology, Washington, v. 267, n. 4 Pt 1, p. E585-590, Oct 1994.

RASMUSSEN, L. B.; MATTHIESSEN, J.; BILTOFT-JENSEN, A.; TETENS, I. Characteristics of misreporters of dietary intake and physical activity. Public Health Nutrition, Wallingford, v. 10, n. 3, p. 230-237, Mar 2007.

REBRO, S. M.; PATTERSON, R. E.; KRISTAL, A. R.; CHENEY, C. L. The effect of keeping food records on eating patterns. Journal of the American Dietetic Association, Chicago, v. 98, n. 10, p. 1163-1165, Oct 1998.

RENNIE, K. L.; SIERVO, M.; JEBB, S. A. Can self-reported dieting and dietary restraint identify underreporters of energy intake in dietary surveys? Journal of the American Dietetic Association, Chicago, v. 106, n. 10, p. 1667-1672, Oct 2006. 
REYNOLDS, W. M. Development of reliable and valid short forms of the MarloweCrowne Social Desirability Scale. Journal of Clinical Psychology, Brandon, v. 38, n. 1, p. 119-125, Jan 1982.

RICCA, V.; MANNUCCI, E.; MORETTI, S.; DI BERNARDO, M.; ZUCCHI, T.; CABRAS, P. L.; ROTELLA, C. M. Screening for binge eating disorder in obese outpatients. Comprehensive Psychiatry, New York, v. 41, n. 2, p. 111-115, Mar/Apr 2000.

RICCIARDELLI, L. A.; WILLIAMS, R. J. A two-factor model of dietary restraint. Journal of Clinical Psychology, Brandon, v. 53, n. 2, p. 123-131, Feb 1997.

ROBERTS, S. Use of the doubly labeled water method for measurement of energy expenditure, total body water, water intake, and metabolizable energy intake in humans and small animals. Canadian Journal of Physiology and Pharmacology, Ottawa, v. 67, n. 10, p. 1190-1198, Oct 1989.

ROZIN, P.; ASHMORE, M.; MARKWITH, M. Lay American conceptions of nutrition: dose insensitivity, categorical thinking, contagion, and the monotonic mind. Health Psychology: Official Journal of the Division of Health Psychology, American Psychological Association, Hillsdale, v. 15, n. 6, p. 438-447, Nov 1996.

ROZIN, P.; BAUER, R.; CATANESE, D. Food and life, pleasure and worry, among American college students: gender differences and regional similarities. Journal of Personality and Social Psychology, Washington, n. 85, n. 1, p. 132-141, Jul 2003.

RUMPLER, W. V.; KRAMER, M.; RHODES, D. G.; MOSHFEGH, A. J.; PAUL, D. R. Identifying sources of reporting error using measured food intake. European Journal of Clinical Nutrition, London, 11 Apr 2007.

SALVO, V. L. M. A.; GIMENO, S. G. A. Reprodutibilidade e validade do questionário de freqüência de alimentos. Revista de Saúde Pública, São Paulo, v. 36, n. 4, p. 505-512, Aug 2002.

SAMUEL-HODGE, C. D.; FERNANDEZ, L. M.; HENRÍQUEZ-ROLDÁN, C. F.; JOHNSTON, L. F.; KEYSERLING, T. C. A comparison of self-reported energy intake with total energy expenditure estimated by accelerometer and basal metabolic rate in African-American women with type 2 diabetes. Diabetes Care, New York, v. 27, n. 3, p. 663-669, Mar 2004. 
SÁNCHEZ-CASTILLO, C. P.; FRANKLIN, M.; MCNEILL, G.; SOLANO, M. L.; BONNER, S.; LÓPEZ, N.; DAVIDSON, L.; JAMES, P. T. Are the proposed limits of energy intake:basal metabolic rate and dietary nitrogen:urinary nitrogen ratios suitable for validation of food intake? The British Journal of Nutrition, Cambridge, v. 85, n. 6, p. 725-731, Jun 2001.

SAWAYA, A. L.; TUCKER, K.; TSAY, R.; WILLETT, W.; SALTZMAN, E.; DALLAL, G. E.; ROBERTS, S. Evaluation of four methods for determining energy intake in young and older women: comparison with doubly labeled water measurements of total energy expenditure. The American Journal of Clinical Nutrition, Bethesda, v. 63, n. 4, p. 491-499, Apr 1996.

SCAGLIUSI, F. B.; ALVARENGA, M.; POLACOW, V. O.; CORDÁS, T. A.; DE OLIVEIRA QUEIROZ, G. K.; COELHO, D.; PHILIPPI, S. T.; LANCHA JR, A. H. Concurrent and discriminant validity of the Stunkard's figure rating scale adapted into Portuguese. Appetite, London, v. 47, n. 1, p. 77-82, Jul 2006a.

SCAGLIUSI, F. B.; CORDÁS, T. A.; POLACOW, V. O.; COELHO, D.; ALVARENGA, M.; PHILIPPI, S. T.; LANCHA JR, A. H. Tradução da escala de desejo de aceitação social de Marlowe \& Crowne para a língua portuguesa. Revista de Psiquiatria Clínica, São Paulo, v. 31, n. 6, p. 272-278, 2004.

SCAGLIUSI, F. B.; FERRIOLLI, E.; LANCHA JR, A. H. Underreporting of energy intake in developing nations. Nutrition Reviews, Baltimore, v. 64, n. 7 Pt 1, p. 319330, Jul 2006b.

SCAGLIUSI, F. B.; FRANCISCHI, R. P.; PEREIRA, P. M.; POLACOW, V. O.; OLIVEIRA, P. V.; FREITAS, C. S.; BUENO, M. K.; VIEIRA, P.; KLOPFER, M.; PEREIRA, L. O.; LANCHA JR, A. H. Underreporting of energy intake among physically active and non-active Brazilian women. Canadian Journal of Applied Physiology, Champaign, v. 26b, n. S, p. 267, Aug 2001.

SCAGLIUSI, F. B.; POLACOW, V. O.; ARTIOLI, G. G.; BENATTI, F. B.; LANCHA JR, A. H. Selective underreporting of energy intake in women: magnitude, determinants, and effect of training. Journal of the American Dietetic Association, Chicago, v. 103, n. 10, p. 1306-1313, Oct 2003.

SCAGLIUSI, F. B.; POLACOW, V. O.; CORDÁS, T. A.; COELHO, D.; ALVARENGA, M.; PHILIPPI, S. T.; LANCHA JUNIOR, A. H. Test-retest reliability and discriminant 
validity of the Restraint Scale translated into Portuguese. Eating Behaviors, New York, v. 6, n. 1, p. 85-93, Jan 2005.

SCAGLIUSI, F. B.; POLACOW, V. O.; CORDÁS, T. A.; COELHO, D.; ALVARENGA, M.; PHILIPPI, S. T.; LANCHA JUNIOR, A. H. Tradução, adaptação e avaliação psicométrica da escala de Conhecimento Nutricional do National Health Interview Survey Cancer Epidemiology. Revista de Nutrição, Campinas, v. 19, n. 4, p. 425436, Jul/Aug 2006c.

SCHOELLER, D. A. Hidrometry. In: ROCHE, A. F.; HEYMSFIELD, S. B.; LOHMAN, T. G. Human Body Composition. Champaign: Human Kinetics, 1996. p. 25-43.

Measurement of energy expenditure in free-living humans by using doubly labeled water. The Journal of Nutrition, Philadelphia, v. 118, n. 11, p. 1278-1289, Nov 1988.

. Stable isotope analyses performance report: analysis of ${ }^{2} \mathrm{H}$ and ${ }^{18} \mathrm{O}$ for total body water and energy expenditure. Madison: University of WisconsinMadison, 2007.

. Validation of habitual energy intake. Public Health Nutrition, Wallingford, v. 5, n. 6A, p. 883-888, Dec 2002.

SCHOELLER, D. A.; BANDINI, L. G.; DIETZ, W. H. Inaccuracies in self-reported intake identified by comparison with the doubly labelled water method. Canadian Journal of Physiology and Pharmacology, Ottawa, v. 68, n. 7, p. 941-949, Jul 1990.

SCHOELLER, D. A.; TAYLOR, P. B.; SHAY, K. Analytic requirements for the doubly labeled water method. Obesity Research, Baton Rouge, v. 3, n. 1, p. 15-20, Mar 1995. Supplement.

SCHULZ, L. O.; ALGER, S.; HARPER, I.; WILMORE, J. H.; RAVUSSIN, E. Energy expenditure of elite female runners measured by respiratory chamber and doubly labeled water. Journal of Applied Physiology, Bethesda, v. 72, n. 1, p. 23-28, Jan 1992. 
SCRIMGEOUR, C. M.; ROLLO, M. M.; MUDAMBO, S. M. K. T.; HANDLEY, L. L.; PROSSER, S. J. A simplified method for deuterium/hydrogen isotope ratio measurements in water samples of biological origin. Biological Mass Spectrometry, Chichester, v. 22, n. 7, p. 383-387, Jul 1993.

SEIDELL, J. C. Dietary fat and obesity: an epidemiologic perspective. The American Journal of Clinical Nutrition, Bethesda, v. 67, n. 3, p. 546S-550S, Mar 1998. Supplement.

SERDULA, M.; BYERS, T.; COATES, R.; MOKDAD, A.; SIMOES, E. J.; ELDRIDGE, $L$. Assessing consumption of high-fat foods: the effect of grouping foods into single questions. Epidemiology, Cambridge, v. 3, n. 6, p. 503-508, Nov 1992.

SICHIERI, R. Epidemiologia da obesidade. Rio de Janeiro: EdUERJ, 1998.

SICHIERI, R.; EVERHART, J. E. Validity of a Brazilian food frequency questionnaire against dietary recalls and estimated energy intake. Nutrition Research, New York, v. 18, n. 10, p. 1649-1659, Oct 1998.

SIRI, W. E. Analysis of methods and techniques for measuring body composition. In: Body composition from fluid spaces and density. Washington (DC):

National Academy of Sciences, National Research Council, 1961. p. 223-244.

SLATER, B.; PHILIPPI, S. T.; FISBERG, R. M.; LATORRE, M. R. Validation of a semi-quantitative adolescent food frequency questionnaire applied at a public school in São Paulo, Brazil. European Journal of Clinical Nutrition, London, v. 57, n. 5, p. 629-635, May 2003.

SLIMANI, N.; FERRARI, P.; OCKÉ, M.; WELCH, A.; BOEING, H.; VAN LIERE, M.; PALA, V.; AMIANO, P.; LAGIOU, A.; MATTISON, I.; STRIPP, C.; ENGESET, D.; CHARRONDIĖRE, R.; BUZZARD, M.; VAN STAVEREN, W.; RIBOLI, E. Standardization of the 24-hour recall calibration method used in the European Prospective Investigation into Cancer and Nutrition (EPIC): general concepts and preliminary results. European Journal of Clinical Nutrition, London, v. 54, n. 12, p. 900-917, Dec 2000.

SMITH, A. F. Cognitive psychological issues of relevance to the validity of dietary reports. European Journal of Clinical Nutrition, London, v. 47, n. 2, p. S6-S18, Oct 1993. Supplement. 
SPEAKMAN, J. R. The history and theory of the doubly labeled water technique. The American Journal of Clinical Nutrition, Bethesda, v. 68, n. 4, p. 932S-938S, Oct 1998. Supplement.

STALLONE, D. D.; BRUNNER, E. J.; BINGHAM, S. A.; MARMOT, M. G. Dietary assessment in Whitehall II: the influence of reporting bias on apparent socioeconomic variation in nutrient intakes. European Journal of Clinical Nutrition, London, v. 51, n. 12, p. 815-825, Dec 1997.

STUNKARD, A. J.; MESSICK, S. The three-factor eating questionnaire to measure dietary restraint, disinhibition and hunger. Journal of Psychosomatic Research, London, v. 29, n. 1, p. 71-83, 1985.

STUNKARD, A.; SORENSEN, T.; SCHLUSINGER, F. Use of Danish adoption register for the study of obesity and thinness. In: KETY, S.; ROWLAND, L. P.; SIDMAN, R. L.; MATTHYSSE, S. W. The genetics of neurological and psychiatric disorders. New York: Raven, 1983. p. 115-120.

SUBAR, A. F.; KIPNIS, V.; TROIANO, R. P.; MIDTHUNE, D.; SCHOELLER, D. A.; BINGHAM, S.; SHARBAUGH, C. O.; TRABULSI, J.; RUNSWICK, S.; BALLARDBARBASH, R.; SUNSHINE, J.; SCHATZKIN, A. Using intake biomarkers to evaluate the extent of dietary misreporting in a large sample of adults: the OPEN study. American Journal of Epidemiology, Baltimore, v. 158, n. 1, p. 1-13, Jul 2003.

SUBAR, A. F.; THOMPSON, F. E.; SMITH, A. F.; JOBE, J. B.; ZIEGLER, R. G.; POTISCHMAN, N.; SCHATZKIN, A.; HARTMAN, A.; SWANSON, C.; KRUSE, L.; HAYES, R. B.; LEWIS, D. R.; HARLAN, L. C. Improving food frequency questionnaires: a qualitative approach using cognitive interviewing. Journal of the American Dietetic Association, Chicago, v. 95, n. 7, p. 781-788, Jul 1995.

SVENDSEN, M.; TONSTAD, S. Accuracy of food intake reporting in obese subjects with metabolic risk factors. The British Journal of Nutrition, Cambridge, v. 95, n. 3, p. 640-649, Mar 2006.

TAPSELL, L. C.; BRENNINGER, V.; BARNARD, J. Applying conversation analysis to foster accurate reporting in the diet history interview. Journal of the American Dietetic Association, Chicago, v. 100, n. 7, p. 818-824, Jul 2000. 
TAREN, D. L.; TOBAR, M.; HILL, A.; HOWELL, W.; SHISSLAK, C.; BELL, I.; RITENBAUGH, C. The association of energy intake bias with psychological scores of women. European Journal of Clinical Nutrition, London, v. 53, n. 7, p. 570-578, Jul 1999.

THOMPSON, F. E.; BYERS, T. Dietary assessment resource manual. The Journal of Nutrition, Philadelphia, v. 124, n. 11, p. 2245S-2317S, Nov 1994. Supplement.

TOMITA, L. Y.; CARDOSO, M. A. Relação de medidas caseiras, composição química e receitas de alimentos nipo-brasileiros. 2. ed. São Paulo: Metha, 2002.

TOMOYASU, N. J.; TOTH, M. J.; POEHLMAN, E. T. Misreporting of total energy intake in older men and women. Journal of the American Geriatrics Society, New York, v. 47, n. 6, p. 710-715, Jun 1999.

TOOZE, J. A.; SUBAR, A. F.; THOMPSON, F. E.; TROIANO, R.; SCHATZKIN, A.; KIPNIS, V. Psychosocial predictors of energy underreporting in a large doubly labeled water study. The American Journal of Clinical Nutrition, Bethesda, v. 79, n. 5, p. 795-804, May 2004.

TOOZE, J. A.; VITOLINS, M. Z.; SMITH, S. L.; ARCURY, T. A.; DAVIS, C. C.; BELL, R. A.; DEVELLIS, R. F.; QUANDT, S. A. High levels of low energy reporting on 24hour recalls and three questionnaires in an elderly low-socioeconomic status population. The Journal of Nutrition, Philadelphia, v. 137, n. 5, p. 1286-1293, May 2007.

TRABULSI, J.; SCHOELLER, D. A. Evaluation of dietary assessment instruments against doubly labeled water, a biomarker of habitual energy intake. American Journal of Physiology. Endocrinology and Metabolism, Bethesda, v. 281, n. 5, p. E891-899, Nov 2001.

TRAN, K. M.; JOHNSON, R. K.; SOULTANAKIS, R. P.; MATTHEWS, D. E. In-person vs. telephone-administered multiple-pass 24-hour recall in women: validation with doubly labeled water. Journal of the American Dietetic Association, Chicago, v. 100, n. 7, p. 777-783, Jul 2000.

TRIGO, M. Estudo da metodologia de inquérito dietético: validade do método recordatório 24 horas. 1993. Tese (Doutorado) - Faculdade de Saúde Pública, Universidade de São Paulo, São Paulo. 
TURCONI, G.; GUARCELLO, M.; BERZOLARI, F. G.; CAROLEI, A.; BAZZANO, R.; ROGGI, C. An evaluation of a colour food photography atlas as a tool for a quantifying food portion size in epidemiological dietary surveys. European Journal of Clinical Nutrition, London, v. 59, n. 8, p. 923-931, Aug 2005.

USDA - United States Department of Agriculture. National Nutrient Database for Standard Reference. 2004. Disponível em: <http://www.nal.usda.gov/fnic/cgibin/ nut_search.pl>. Acesso em: 11 nov. 2003.

1997.

What we eat in America: Food Instruction Booklet. Rockville: Westat,

VAN STRIEN, T.; FRIJTERS, J. E.; VAN STAVEREN, W. A.; DEFARES, P. B.; DEURENBERG, P. The predictive validity of the Dutch Restrained Eating Scale. The International Journal of Eating Disorders, New York, v. 5, n. 4, p. 747-755, May 1986.

VANSANT, G.; HULENS, M. The assessment of dietary habits in obese women: influence of eating behavior patterns. Eating Disorders, New York, v. 14, n. 2, p. 121-129, Mar/Apr 2006.

VUCKOVIC, N.; RITENBAUGH, C.; TAREN D. L.; TOBAR, M. A qualitative study of participants' experiences with dietary assessment. Journal of the American Dietetic Association, Chicago, v. 100, n. 9, p. 1023-1028, Sep 2000.

WALCZYK, T.; COWARD, A.; SCHOELLER, D. A.; PRESTON, T.; DAINTY, J.; TURNLUND, J. R.; IYENGAR, V. Stable isotope techniques in human nutrition research: concerted action is needed. Food and Nutrition Bulletin, Tokyo, v. 23, n. 3, p. 69-75, Sep 2002. Supplement.

WEIR, J. B. New methods for calculating metabolic rate with special reference to protein metabolism. Journal of Physiology, London, v. 109, n. 1-2, p. 1-9, Aug 1949.

WHO - World Health Organization. Obesity: preventing and managing the global epidemic. Geneva, 1997.

WILLETT, W. C. Dietary assessment methods. The British Journal of Nutrition, Cambridge, v. 74, n. 1, p. 141-143, Jul 1995. 
. Invited commentary: OPEN questions. American Journal of Epidemiology, Baltimore, v. 158, n. 1, p. 22-24, Jul 2003.

Nutritional epidemiology. 2. ed. New York: Oxford University Press, 1998.

WILLIAMS, L.; GERMOV, J.; YOUNG, A. Preventing weight gain: a population cohort study of the nature and effectiveness of mid-age women's weight control practices. International Journal of Obesity, London, v. 31, n. 6, p. 978-986, Jun 2007.

WINKVIST, A.; PERSSON, V.; HARTINI, T. N. Underreporting of energy intake is less common among pregnant women in Indonesia. Public Health Nutrition, Wallingford, v. 5, n. 4, p. 523-529, Aug 2002.

WIRFÄLT, A. K.; JEFFERY, R. W. Using cluster analysis to examine dietary patterns: nutrient intakes, gender, and weight status differ across food pattern clusters. Journal of the American Dietetic Association, Chicago, v. 97, n. 3, p. 272-279, Mar 1997.

WIRFÄLT, E.; MATTISSON, I.; GULLBERG, B.; BERGLUND, G. Food patterns defined by cluster analysis and their utility as dietary exposure variables: a report from the Malmö Diet and Cancer Study. Public Health Nutrition, Wallingford, v. 3, n. 2, p. 159-173, Jun 2000.

WONG, W. W.; LEE, L. S.; KLEIN, P. D. Deuterium and oxygen-18 measurements on microliter samples of urine, plasma, saliva and human milk. The American Journal of Clinical Nutrition, Bethesda, v. 45, n. 5, p. 905-913, May 1987.

WONG, W.; SCHOELLER, D. Mass spectrometric analysis. In: PRENTICE, A. M. (Ed.). The doubly labelled water method for measuring energy expenditure: technical recommendations for use in humans. Viena: International Dietary Energy Consultancy Group/International Atomic Energy Agency, 1990. p. 20-47.

YON, B. A.; JOHNSON, R. K.; HARVEY-BERINO, J.; GOLD, B. C. The use of a personal digital assistant for dietary self-monitoring does not improve the validity of self-reports of energy intake. Journal of the American Dietetic Association, Chicago, v. 106, n. 8, p. 1256-1259, Aug 2006. 
YOUNG, L. R.; NESTLE, M. Portion sizes in dietary assessment: issues and policy implications. Nutrition Reviews, Baltimore, v. 53, n. 6, p. 149-158, Jun 1995. 


\title{
TERMO DE CONSENTIMENTO LIVRE E ESCLARECIDO
}

\author{
I) Dados de identificação do sujeito da pesquisa \\ Nome: \\ Documento de identidade $\mathrm{n}^{0 .}$ : \\ Sexo: \\ Data de nascimento: / / \\ Endereço: \\ Bairro: \\ Cidade: \\ Estado: \\ CEP: \\ Telefone: ( ) \\ Sexo: \\ E-mail:
}

\section{II) Dados sobre a pesquisa científica}

Você está sendo convidado a participar do projeto de pesquisa "Influência da Atividade Física, da Adiposidade e de Fatores Psicossociais Sobre a Validade de Três Métodos de Avaliação do Consumo Alimentar, Segundo Marcadores Biológicos". O pesquisador responsável por ele é o Prof. Dr. Antonio Herbert Lancha Junior, professor titular da Escola de Educação Física e Esporte. Sua participação na pesquisa durará três semanas e o risco envolvido em tal participação é considerado baixo. O documento abaixo contém todas as informações necessárias sobre a pesquisa que estamos fazendo. Sua colaboração neste estudo será de muita importância para nós, mas se desistir a qualquer momento, isso não causará nenhum prejuízo a você.

\section{III) Explicações sobre a pesquisa}

O objetivo desta pesquisa é verificar como a atividade física e os fatores psicossociais podem interferir na validade de três métodos de avaliação do consumo alimentar. Nesta investigação, você realizará os seguintes procedimentos:

A) Ingestão de água duplamente marcada, que consiste em um marcador biológico do gasto energético, não-radioativo, seguro, nas quantidades de $0,12 \mathrm{~g}$ de ${ }^{2} \mathrm{H}_{2} \mathrm{O}$ $\left(99,8 \%\right.$ de excesso de átomos)/kg de água corporal e $2 \mathrm{~g} \mathrm{de}_{2}{ }^{18} \mathrm{O}$ (10\% de excesso de átomos) normalizada/kg de água corporal.

B) Fornecimento de nove amostras de urina, de cerca de $80 \mathrm{~mL}$ cada.

C) Avaliação da composição corporal, por meio de dobras cutâneas.

D) Avaliação da alimentação por meio de três instrumentos (diário alimentar de três dias, recordatório de 24 horas e questionário semi-quantitativo de freqüência alimentar). Nos dias correspondentes ao diário alimentar, deve-se anotar todos os alimentos e bebidas consumidos.

E) Preenchimento de questionários sobre características sociais, comportamentais e psicológicas.

F) Coleta de $10 \mathrm{~mL}$ de sangue.

G) Comparecimento ao Laboratório de Metabolismo do Exercício e Nutrição (LABMEN) no Centro de Práticas Esportivas da Universidade de São Paulo (CEPE USP) uma vez por semana, durante três semanas, em horários previamente agendados, para realização dos procedimentos supracitados.

A pesquisa não Ihe trará desconfortos e riscos, a não ser os explicitados acima, como coleta de nove amostras de urina, coleta de sangue e preenchimento do diário alimentar. 
Como benefício, você receberá um relatório com dados da sua composição corporal, gasto energético e consumo alimentar e orientações por escrito sobre como ter uma alimentação saudável.

\section{IV) Garantias do sujeito da pesquisa}

Você pode questionar o pesquisador responsável a qualquer momento, para solucionar eventuais dúvidas quanto à pesquisa. Você tem a liberdade de desistir ou interromper a colaboração neste estudo no momento em que desejar, sem necessidade de qualquer explicação. A desistência não causará nenhum prejuízo à sua saúde ou bem estar físico.

Os resultados obtidos durante o ensaio serão mantidos em sigilo, e serão divulgados em publicações científicas, sem a menção dos seus dados pessoais.

Caso você desejar, poderá pessoalmente tomar conhecimento dos resultados, ao final desta pesquisa.

Se a pesquisa causar algum mal-estar ou desconforto em relação à sua saúde, você terá tratamento médico no Hospital Universitário ou Hospital das Clínicas, da Faculdade de Medicina da USP.

\section{V) Informações sobre o pesquisador responsável}

O pesquisador responsável, Prof. Dr. Antonio Herbert Lancha Junior, pode ser encontrado no telefone (11) 3091-3096, ou no Laboratório de Nutrição e Metabolismo Aplicados à Atividade Motora, Escola de Educação Física e Esporte, Av. Prof. Mello Moraes, 65, CEP 05508-900, Cidade Universitária, São Paulo/SP.

\section{VI) Consentimento pós-esclarecido}

Declaro que, após convenientemente esclarecido pelo pesquisador e ter entendido o que me foi explicado, consinto em participar do presente Projeto de Pesquisa.

São Paulo, de de 20 . 